Una paciente en manos impropias:

Un estudio del Sistema General de Seguridad Social en Salud

José Vicente Casas Díaz

Trabajo de grado para optar al título de

Magister en Derecho Público

Milena Pacheco

Tutora

Universidad Santo Tomás

Universidad de Konstanz

Maestría en derecho público

Bogotá, D.C., mayo de 2017 
En mi ser múltiples almas danzan alrededor de mi existencia, a ellas debo mis mejores alegrías, mis más vivificantes experiencias y la cumbre de mis más caros propósitos. A todas ellas mis eternos agradecimientos por su incondicional amor y su infinita perseverancia por mi plena realización.

A José Vicente, María Odalinda, Gloria Stella, Laura Patricia, Diego Alejandro, Juan Luis, Clemencia, Fernando, Edgar Alfonso, Libardo, Luz, Freddy Fernando, Martha Luz, Nancy, Marleni, Esperanza, Uriel y a quienes, sin que les mencione, han dejado en mi una huella imperecedera...

¡Velad, será para bien!

José Vicente 


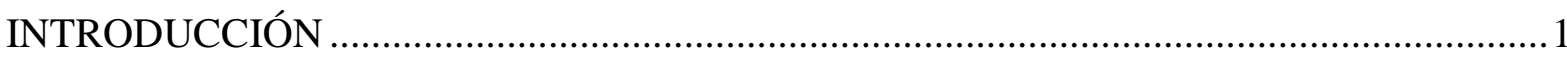

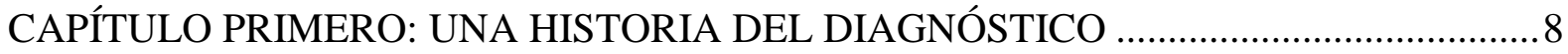

1.1 Situación epidemiológica a nivel global y nacional. ....................................................

1.2 El sistema de salud colombiano anterior a la Constitución Política de 1991. .................... 14

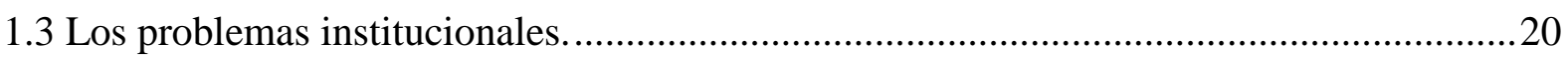

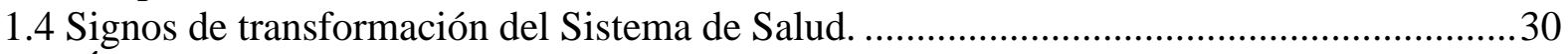

CAPÍTULO SEGUNDO: PLURALISMO ESTRUCTURADO: EL CENTRO ENTRE LA INTERVENCIÓN ABSOLUTA Y LA LIBERTAD A ULTRANZA DEL MERCADO. .....45

2.1 Los supuestos constitucionales y los elementos fundamentales del nuevo sistema de

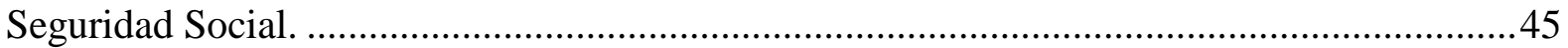

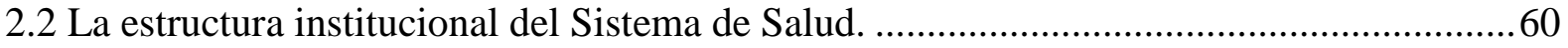

2.3 Ley 100 de 1993. El Sistema General de Seguridad Social en Salud................................70

2.3.1 Estado: Rol en la garantía del derecho a la salud........................................................... 74

2.3.2 Principios rectores: Fines orientadores en la garantía del derecho................................ 76

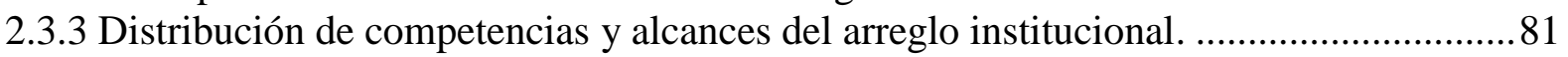

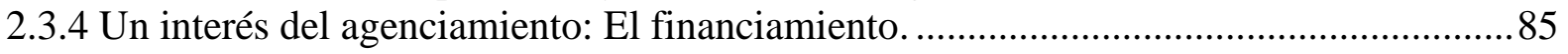

2.3.5 Agentes responsables de la gestión, administración y control de los recursos..............88

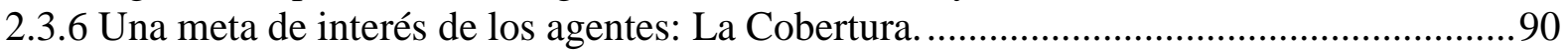

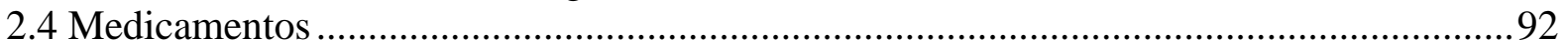

2.5 La perspectiva de la concertación y la participación .......................................................94

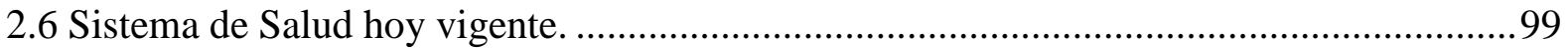

CAPÍTULO TERCERO: COMPORTAMIENTO Y RESULTADOS DEL SISTEMA GENERAL DE SEGURIDAD SOCIAL EN SALUD ….................................................. 105

3.1 Funcionamiento del Sistema General de Seguridad Social en Salud y sus efectos sobre el cumplimiento del derecho fundamental a la salud.............................................................. 105

3.1.1 El principio de universalidad: Cobertura y garantía de los derechos. Protagonismo de la

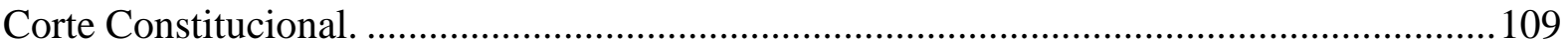

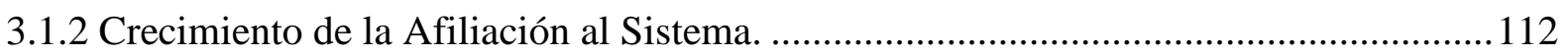

3.1.3 Salud, Solidaridad y acciones sanitarias: Contradicciones en permanencia..................118

3.2. El pluralismo estructurado: Nuevas tendencias del Sistema....................................... 122

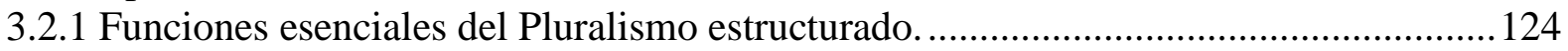

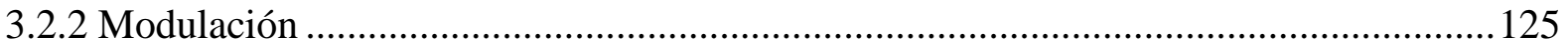

3.2.3 Limitaciones que se han presentado a la Modulación. Las falencias de las instancias de

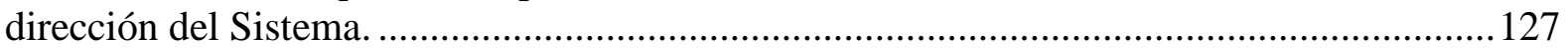

3.2.4 Desviación del Financiamiento del Sistema. Incumplimiento y desvío del rol de las

E.P.S. Desarticulación entre el financiamiento y la prestación de los servicios..................... 134

CAPITULO CUARTO: FACTORES ASOCIADOS A LA GESTIÓN DEL SISTEMA

GENERAL DE SEGURIDAD SOCIAL EN SALUD. .................................................... 140

4.1 Regulación, políticas, inspección, vigilancia y control y, otros factores asociados al cumplimiento de las competencias del Sistema General de Seguridad Social en Salud....... 140

Falencias de la función reguladora del Estado, en materia de salud...................................... 141

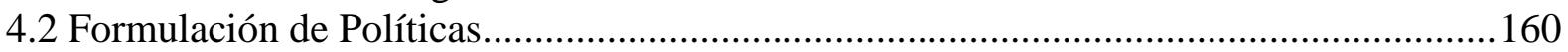

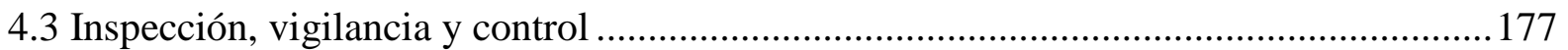

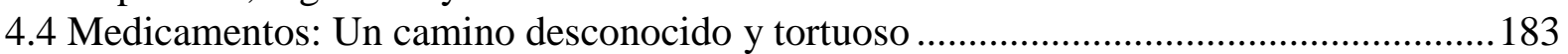

4.5 Estabilidad, eficiencia y eficacia afectadas por destinación diferente de los recursos de

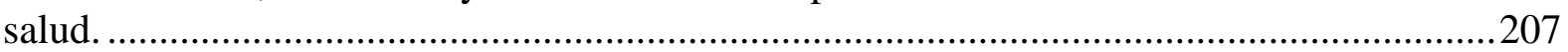

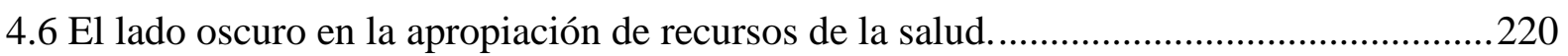

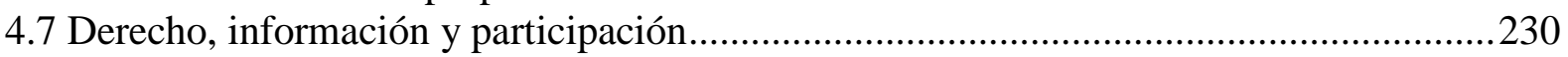

4.8 Alternativas recientes y continuidad de mitos ..............................................................234

4.9 Esfuerzos en la caracterización y búsqueda de alternativas de mejoramiento..................237 
4.9.1 Límites impuestos oficialmente a los determinantes de la Salud.

239

4.9.2 Impotencia en un mundo "informado".

4.9.3 Desconocimiento de factores asociados a las patologías y a la carga de la enfermedad.

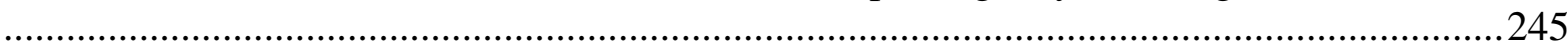

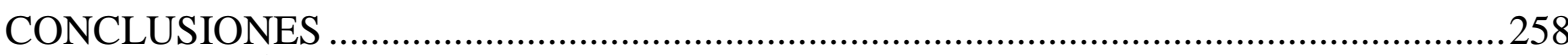

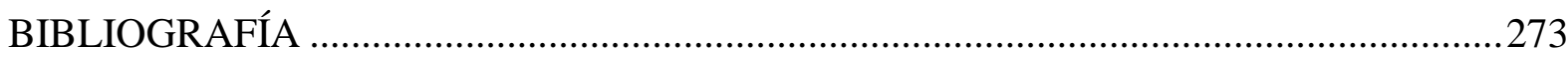




\section{Lista de tablas}

Tabla 1. Recobros de pagos 1997-2014............................... 184 


\section{Lista de figuras}

Figura 1. Afiliación al sistema general de seguridad social en salud............ 130 


\section{Introducción}

La salud es una situación de la persona, la familia y la comunidad y, constituye uno de los factores claves de la existencia humana, ya que la misma es fundamental para el ejercicio de una vida plena, libre de limitaciones e impedimentos orgánicos, físicos y psicológicos. El estado de salud de las personas refleja el nivel de progreso alcanzado por una sociedad, en tanto muestra un conjunto de elementos interrelacionados que condicionan, inciden, dan carácter y contenido al bienestar y al proyecto de vida que, en ejercicio de sus derechos, elige un Ser Humano.

Las sociedades del Siglo XXI y sus aparatos institucionales dan cuenta, ya desde los albores del Siglo XX, de la polémica en torno a la definición y contenido de la salud, así se puede apreciar en las aseveraciones de Dossey, Dossey, Larry., Carlson, Richard, Shield, Benjamin, (1994):

El gran error consiste en suponer que la sanación implica una mejoría física. Se cree que parte del cuerpo es sanado y parte no, y que conocemos la diferencia. Sostenemos definiciones ridículas y arbitrarias de la enfermedad porque la juzgamos como no deseada y antinatural, y hasta como señal de un esfuerzo espiritual inadecuado. En consecuencia, buscamos evitar todo tipo de síntoma de enfermedad en nosotros. (p.26).

La dificultad es mayor si se trata específicamente del derecho fundamental a la salud, así como de las características de la Institución y el Sistema que se deben implementar para lograr los objetivos relacionados con la promoción, prevención y cuidado de la salubridad pública e individual, y el diagnóstico, tratamiento y superación de las patologías que puede sufrir una persona.

La historia de la salud en la sociedad colombiana refleja los pormenores de las contradicciones del significado, contenidos, alcances, financiación y prestaciones, bien como beneficencia o como derecho fundamental (estatus que alcanzó en Colombia a partir de la 
Constitución Política de 1991 y, objetivamente, por las decisiones de la Corte Constitucional), en un ámbito donde diversos intereses, públicos y privados, individuales y colectivos, colisionan y buscan obtener, para sí, el rédito de los beneficios. Tales contradicciones se exacerban por la existencia de agentes al margen de la ley, cuyos provechos se obtienen con el ejercicio violento, abierto o soterrado, de su poder, la violación de las disposiciones jurídicas, la indebida apropiación de los recursos públicos, la imposición sobre las personas, familias y comunidades de la obediencia ciega de sus órdenes so pena de maltratos y, la consolidación de redes ilícitas que han reconfigurado las instituciones. (Garay \& Salcedo A., 2012).

Los habitantes del país asistieron, en la última década del Siglo XX, a la promulgación de la Constitución Política de Colombia, la descentralización de los servicios de salud (Ley 10 de 1990) y la adopción del Sistema General de Seguridad Social en Salud (Ley 100 de 1993).

Las mencionadas disposiciones crearon una gran expectativa en torno a la posibilidad de solucionar los problemas de universalidad (insuficiente ingreso a los sistemas de seguridad social, cobertura familiar baja, protección parcial en el acceso y prestación de servicios, deficiente acceso de los beneficiarios familiares de las personas pertenecientes a un régimen de seguridad social y, afiliación y atención centrada en los trabajadores asalariados); solidaridad (insuficiencia de recursos para garantizar el acceso de amplias capas de la población, diferencias en la asignación de recursos entre subsistemas atomizados que tenían beneficios distintos y ninguna conexión entre ellos y, múltiples ineficiencias y grandes desigualdades en los niveles de protección en detrimento de las personas más pobres) y, eficiencia (desorganización institucional, contradicciones en los criterios de asignación, gestión y utilización de los recursos e incoherencia en la prestación de los servicios que incrementaban el gasto público, sin mejoras en la cobertura y la atención); así como para 
atender las demandas creadas por la transición epidemiológica (disminución progresiva de morbilidad y mortalidad asociadas a enfermedades transmisibles contra incremento de patologías asociadas a enfermedades crónicas y degenerativas y, el aumento de muertes producidas por accidentes y homicidios).

El Sistema General de Seguridad Social en Salud instituyó mecanismos destinados a adoptar y consolidar los principios de universalidad, por medio de la afiliación obligatoria de todos las personas habitantes del país; solidaridad, a través del acceso a un plan de protección integral de la salud que tendría cobertura universal en el año 2001 y, eficiencia, con el diseño y funcionamiento de un arreglo institucional especializado que separaba las funciones de regulación, dirección y control, de las de financiamiento, prevención y disminución de los riesgos, así como las de acceso efectivo a la prestación de los servicios.

El Sistema adoptó, como principio complementario, la competencia entre agentes públicos y privados en la organización y prestación de los servicios, con el fin de empoderar y dar capacidad de negociación a las personas afiliadas y sus beneficiarios, fomentar la prestación de servicios por diferentes organizaciones y, asegurar la calidad de la prestación con base en criterios de eficacia, uso y aplicación del conocimiento científico, incorporación de tecnologías y atención integral a los usuarios en las etapas de promoción y prevención, además de las acciones de diagnóstico, tratamiento, superación y rehabilitación de las patologías que aquejen a los pacientes.

Los resultados del Sistema General de Seguridad Social en Salud son diversos y han concitado la controversia entre defensores y detractores. Sin embargo, en las versiones de las noticias y en la voz común ha adquirido carta de ciudadanía el denominado “paseo de la muerte” (El Espectador. Redacción Política, 2016) y la tendencia que aparentemente domina el diario vivir es un llamado, en algunos sectores de la opinión pública, a acabar con el Sistema General de Seguridad Social en Salud (Oficina de Prensa del Senador Gustavo Petro, 
2010). Sin embargo, las sucesivas reformas a la Ley 100 de 1993 buscan, al contrario de intentar su derogación, consolidar y cualificar el Sistema.

Las afectaciones recurrentes en el Sistema General de Seguridad Social en Salud están asociadas a las barreras de acceso y atención, la negación de la prestación de los servicios, incluso los contemplados en el Plan Obligatorio de Salud, la falta de toma de decisiones por parte de los organismos reguladores para garantizar a las personas su derecho fundamental, el incremento de la justiciabilidad como mecanismo en la obtención efectiva de la prestación de servicios $y$, en general, la incertidumbre de quienes enferman frente al acceso oportuno, pertinente y de calidad al diagnóstico, tratamiento y superación de la enfermedad. Todas esas circunstancias que muestran la presencia de dificultades en la prestación efectiva de los servicios de salud merecen ser explicadas, por ello la pregunta principal de este trabajo es:

¿Las afectaciones al ejercicio del derecho a la salud son atribuibles al Sistema General de Seguridad Social en Salud, tal como fue concebido en la Ley 100 de 1993 ?

La hipótesis que se plantea para responder a la pregunta propuesta expresa que el Sistema General de Seguridad Social en Salud está diseñado para atender y satisfacer las exigencias del derecho fundamental y el servicio público de salud. Por consiguiente, los problemas recurrentes que sufren las personas para acceder oportuna y plenamente a las prestaciones que requieren para la promoción, protección y cuidado de la salud y, la superación de la enfermedad, no pueden, ni deben, ser atribuidos a su diseño.

El objetivo general del trabajo es determinar las características diferenciales del Sistema General de Seguridad Social en Salud y su incidencia en el cumplimiento del derecho fundamental a la salud, el cual se despliega en los siguientes objetivos específicos:

Identificar los elementos históricos de la salud y su incidencia en la creación del Sistema General de Seguridad Social en Salud. 
Determinar los componentes y atributos específicos del Sistema General de Seguridad Social en Salud.

Caracterizar el comportamiento de los diferentes componentes del Sistema General de Seguridad Social en Salud y sus efectos sobre el cumplimiento del derecho fundamental a la salud.

Examinar los factores asociados a la gestión del Sistema General de Seguridad Social en Salud y sus efectos sobre el derecho y la prestación de los servicios de salud.

La metodología utilizada para la presentación de los resultados de la investigación consistió en organizar cuatro capítulos temáticos dirigidos a exponer, en una estructura lógica, los contenidos que permiten alcanzar una comprensión de cada uno de los elementos que integran la relación entre la pregunta, la hipótesis y los conocimientos obtenidos para definir, en las conclusiones, la validez o invalidez de la respuesta dada, prima facie, al interrogante que motivó el diseño y ejecución del proyecto de investigación.

El primer capítulo está dedicado a la historia de la salud en términos de las orientaciones e incidencia de los organismos internacionales en la organización, gestión y prestación de los servicios de salud, así como las características de las decisiones estatales en torno al diseño institucional, la adopción planes y la ejecución de las políticas, acciones y prestaciones que buscaron dar respuesta a la situación de la salud en Colombia, con el fin de determinar los elementos históricos y sus potenciales efectos sobre la creación del Sistema General de Seguridad Social en Salud.

El segundo capítulo describe los supuestos, elementos, principios y contenidos del Sistema General de Seguridad Social en Salud, así como los alcances del arreglo institucional y las competencias de los diferentes agentes en la garantía del derecho fundamental a la 
salud. Por consiguiente, el resultado del tratamiento temático permite señalar los componentes y atributos del Sistema General de Seguridad Social en Salud.

El tercer capítulo está orientado a caracterizar el comportamiento y resultados de diferentes componentes del Sistema General de Seguridad Social en Salud, considerados sustanciales en el objeto de este trabajo, y sus efectos sobre el cumplimiento del derecho fundamental a la salud para identificar argumentos y razones que dan cuenta de la problemática planteada y sustentan la validez o negación de la hipótesis suscrita.

El cuarto capítulo se refiere a los factores asociados a la regulación, las políticas, las funciones de inspección, vigilancia y control, los recursos y la participación de las personas en el Sistema y, sus efectos sobre el derecho y los servicios de salud. Estos elementos complementan la argumentación y se suman al conjunto de explicaciones que contribuyen a despejar el interrogante que se planteó y determinar la validez de la hipótesis formulada.

Las conclusiones describen los resultados de la investigación y señalan, grosso modo, los argumentos esenciales que se dan al interrogante a fin de establecer la validez de la hipótesis formulada $\mathrm{y}$, recomendar temas de investigación que pueden contribuir a profundizar la temática planteada, cuya comprensión exige el desarrollo de múltiples líneas de investigación, en diferentes áreas del conocimiento, asociadas al estado de salud de las personas.

El documento muestra, como resultado de la investigación, el incumplimiento de los fines, funciones y objetivos a cargo de los agentes del Sistema General de Seguridad Social en Salud; así mismo, la tendencia de actores privados a capturar rentas en detrimento de sus obligaciones, especialmente las referidas a promover la afiliación, fomentar la orientación e información a los afiliados y beneficiarios con el fin de contribuir en la superación de las asimetrías de información y mejorar su capacidad de selección. También la imposición de barreras de acceso a servicios, medicamentos y tratamientos, aunque estén contemplados en 
los planes obligatorios de salud, así como las condiciones onerosas impuestas por empresas farmacéuticas sobre la oferta y venta de medicamentos. Se evidencia la intervención negativa de agentes al margen de la ley, especialmente en los niveles territoriales, quienes se han apropiado y han desviado los recursos de salud.

La metodología del trabajo se desarrolló con base en la compilación, estudio y análisis de las normas constitucionales y legales para determinar los componentes articulados e interdependientes del Sistema General de Seguridad Social en Salud; indagó la historia colombiana sobre los sistemas de salud y las respuestas gubernamentales a las necesidades de atención en materia de salud; consultó los pactos y normas internacionales suscritos por el Estado Colombiano en torno al derecho fundamental a la salud; examinó jurisprudencia constitucional sobre la garantía del derecho y sus efectos sobre las instituciones responsables de la regulación, dirección, control, administración, afiliación, información y prestación de los servicios; consultó literatura sobre las alternativas relacionadas con los enfoques de salud y, revisó estudios, oficiales y no oficiales, sobre el cumplimiento de las competencias y logros del sistema vigente. 


\section{Capítulo primero: Una historia del diagnóstico}

Este capítulo identifica los elementos históricos de la salud, como derecho y servicio público, y su incidencia en el diseño y adopción del Sistema General de Seguridad Social en Salud.

\subsection{Situación epidemiológica a nivel global y nacional.}

La situación de la salud es la característica de mayor relevancia en el diagnóstico de las necesidades de prestación y permea las políticas y acciones de promoción, prevención y cuidado de la salud, así como el tratamiento y superación de la enfermedad y, en consecuencia, las condiciones en las cuales se gesta el cumplimiento de las obligaciones estatales relacionadas con la salud pública, familiar e individual.

La mayor expresión de las necesidades de salud que enfrentó el mundo, al final del siglo pasado, están relacionadas con problemas de mortalidad en niñas y niños causadas esencialmente por enfermedades diarreicas, respiratorias y malnutrición, todas asociadas, en general, a la pobreza, la violencia intrafamiliar - especialmente la agresión de género contra la mujer, los menores y los jóvenes - el abandono y, la explotación laboral de los menores de edad.

Las enfermedades evitables tenían, en este contexto, una fuerte incidencia en la mortalidad de adultos, entre ellas la tuberculosis y las asociadas al embarazo y el parto en las mujeres, sobre todo en los denominados países en desarrollo, las cuales registraron tasas de mortalidad 30 veces superiores a las de los llamados países desarrollados (Banco Mundial, 1993a).

La morbilidad reflejó, simultáneamente, las condiciones de miseria de vastos sectores de población, los cuales tuvieron que soportar la discapacidad y la disfuncionalidad causada por enfermedades prevenibles, la carencia de agua potable y saneamiento básico, la desnutrición y las deficientes condiciones laborales que 
afectaban la salud y el bienestar de quienes accedían a empleos informales, mal remunerados y en condiciones nocivas de salubridad, con implicaciones negativas en los años de vida saludables y en la capacidad laboral de las personas.

Los países del Orbe convivieron con situaciones que afectaron la salud de sus poblaciones, muchas de las cuales se expandieron conforme se consolidaban las políticas de apertura y el intercambio en el mercado mundial, entre ellas, las enfermedades asociadas a los virus, el síndrome de inmunodeficiencia adquirida, la resistencia del parásito del paludismo, el cáncer, las enfermedades cardiovasculares, la diabetes, la obesidad y el envejecimiento de las personas ${ }^{1}$, así como las enfermedades "asociadas" al desarrollo, cuyos costos, para las finanzas de las personas y los Estados, hicieron pasar al primer lugar las enfermedades no transmisibles de los adultos y los ancianos (Banco Mundial, 2003).

Los avances de los sistemas de salud, en la época acotada, mostraton importantes resultados de las medidas de salud pública, entre las cuales es preciso destacar las inmunizaciones y el mejoramiento de la oportunidad de las acciones de salubridad en los limitados lugares que contaban con instancias de prestación de servicios y de atención médica de pacientes con enfermedades infecciosas y traumatismos.

Los Estados, entre ellos Colombia, tuvieron que enfrentar, en esa época, un panorama diverso en relación con el derecho a la salud especialmente en la fase prestacional, que se encaminó a resolver los problemas de mortalidad, morbilidad y discapacidad, cuya incidencia en la pérdida de años saludables fue importante. Entre los retos que enfrentaron se cuentan los temas asociados a deficiencias en la asignación y utilización de recursos, el limitado acceso de las poblaciones pobres a servicios y la

1 Uno de los paradigmas cuestionables de la visión de la salud es la creencia, convertida en dogma, de que la vejez es sinónimo de enfermedad. 
mala calidad en los pocos casos en que los atendían, el despilfarro de recursos públicos en la compra de medicamentos de marca, en contravía a la adquisición de genéricos, así como el incremento de los costos administrativos sin un control eficaz.

En general, es posible señalar que las enfermedades que determinaron la demanda de servicios de salud, durante el siglo XX en Colombia, fueron de origen infeccioso y las causadas por desnutrición, “al igual que en otros países en desarrollo, en Colombia la desnutrición proteico-energética de los menores de edad era un grave problema de salud pública a mediados del siglo XX” (Idrovo, Eslava, Ruiz-Rodríguez, \& Rodríguez, 2008, p. 486); entre las de mayor importancia estaban la viruela, el paludismo, la fiebre amarilla, el tifo y la tuberculosis, con una distribución por zonas geográficas, en las que predominaban las "enfermedades tropicales" en la zona rural y, la tuberculosis, los problemas intestinales, las disenterías bacilares y las enfermedades venéreas, en los centros urbanos.

Los trabajos sobre el bocio endémico, el cáncer gástrico, el cáncer de cuello uterino y los efectos de la desnutrición infantil y los suplementos, sin duda alguna constituyen los hitos más importantes en la historia de la epidemiología de los factores de riesgo en Colombia, junto a las grandes encuestas de salud que permitieron identificar los cambios en los patrones epidemiológicos nacionales. (Idrovo et al., 2008, p. 487).

Otros factores que se destacan en el condicionamiento del derecho y el acceso a los servicios de salud están asociados a procesos decisorios totalmente centralizados, fluctuaciones sin coherencia en las asignaciones presupuestales, desmotivación de los responsables y del personal de las entidades prestadoras de servicios de salud, deficiencias en la adopción y ejecución de políticas encaminadas a la protección del ambiente, la seguridad y la salubridad laboral, y la ausencia de acciones de impacto que 
motivaran el cambio de los comportamientos de las personas en relación con los consumos nocivos para su salud, entre ellos el tabaco y el alcohol.

Las políticas internacionales crearon un ambiente de priorización en torno a las acciones de salud y, particularmente, con las decisiones plasmadas en el objetivo de Salud para todos y la estrategia del Servicio denominada la atención primaria, se forjaron metas, desde finales de la década de los setenta del siglo pasado, en torno a lo que debería ser y hacer el sistema de salud, entre ellas los objetivos propuestos para finales del siglo XX "Salud para todos en el año 2000”, mediante los cuales se decidió:

La meta social más importante de los Estados Miembros y de la OMS en el sector salud es conseguir que en el año 2000 todos los ciudadanos del mundo hayan alcanzado un nivel de salud que les permita llevar una vida social y económicamente productiva (Organización Mundial de la Salud, 2002, p. 197).

A través de la estrategia de atención primaria en salud2 se buscaba consolidar la prestación de los servicios a partir de comunidades base atendidas directa y preferencialmente en sus zonas de residencia.

Las políticas internacionales en este contexto concentraron, desde mediados de los años 70 del siglo anterior, sus orientaciones en la asistencia primaria como respuesta a la crisis de los sistemas de salud, y propusieron que los Estados planificaran y ejecutaran acciones con preferencia en los servicios asistenciales, a partir de las experiencias de varios países, con la intención de crear mecanismos de entrada a los servicios y, simultáneamente, servir de barrera de contención de costos, los cuales sumados al saneamiento básico, el acceso a la vivienda, la nutrición, la educación y otras prestaciones, debían genenerar una nueva visión para mejorar la calidad de vida y la salud de los más pobres (Organización Panamericana de la Salud, 2002).

2 La Atención Primaria en Salud es una estrategia, aún vigente, que se adopta durante la Conferencia Internacional realizada en Alma-Ata en 1978, como reacción al enfoque predominantemente curativo de los servicios de salud. 
Esas políticas se empeñaron en mostrar la relación entre las condiciones de vida, la cultura, el ambiente, la economía y la salud. En tal sentido, incluir los factores prestacionales, atrás mencionados, suponía que los Estados y los organismos internacionales debían considerar como clave la relación entre el estado de salud de la sociedad, la comunidad y las personas con las condiciones materiales y psicosociales en las que se encontraban.

Las autoridades internacionales al poner en evidencia la necesaria atención sobre los factores sociales, económicos y culturales que influyen en las condiciones de salubridad y bienestar señalaban, de manera explícita, la importancia estratégica de atender las necesidades sanitarias básicas, como condición para disminuir los riesgos que afectaban y limitaban la salud. Esta visión incluía el tema ambiental, por ello, se recomendaba la adopción y aplicación de medidas que, de manera preventiva, incidían sobre el control o supresión de factores coincidentes con el estado de salud, específicamente, aquellos que podían gestar enfermedades.

Es importante señalar la coincidencia y confluencia de varios organismos internacionales en la nueva visión, especialmente en lo relacionado con las medidas que se proponían para mejorar la calidad de vida y el énfasis que ellos hacían sobre la priorización de las acciones en las poblaciones pobres, las cuales tenían, a su juicio, un impacto mayor sobre el desarrollo. Según el Banco Mundial (1978):

Los pobres soportan no solo ingresos bajos, sino también un acceso insuficiente a los servicios públicos esenciales para su salud y productividad. Dado que muchos de estos servicios, como el de saneamiento y abastecimiento de agua, no pueden adquirirse privadamente, un programa público ampliado para su distribución más generalizada debe constituir un elemento importante de las estrategias destinadas a mitigar la pobreza (p.29). 
Las recomendaciones del Banco Mundial, el Fondo Monetario Internacional, la Organización Mundial de la Salud y la Organización Panamericana de la Salud, estaban orientadas a promover la creación de mecanismos institucionales y de entrada, en los cuales las personas de menores recursos, a través de flujos programados, deberían contar con las facilidades para acceder a las prestaciones médicas, previa su participación en las actividades de atención básica en salud. Por ejemplo, la Declaración de Alma-Ata definió las características de la Atención Primaria en Salud. Dicha declaración en su primer punto señalaba:

La Conferencia reitera firmemente que la salud, estado de completo bienestar físico, mental y social, y no solamente la ausencia de afecciones o enfermedades, es un derecho humano fundamental y que el logro del grado más alto posible de salud es un objetivo social sumamente importante en todo el mundo, cuya realización exige la intervención de muchos otros sectores sociales y económicos, además del de la salud (OMS. Conferencia Internacional sobre Atención Primaria de Salud, 1978, p. 2)

En la mencionada Conferencia se sentaron las bases que, a juicio de los expertos, influyeron la organización y gestión de los sistemas de salud, en el largo plazo, al establecer que la prestación de servicios esenciales está basada en métodos y tecnologías científicamente desarrollados y socialmente aceptados, los cuales se ponen a disposición de las familias y personas de una comunidad, en todas las etapas de su vida, bajo los principios de responsabilidad y autocuidado $\mathrm{y}$, por consiguiente, esta forma de prestación, como núcleo central, debía incidir en el desarrollo económico y social y conformar la puerta de entrada a los servicios de salud especializados, bajo el supuesto de que la salud, en sus diferentes facetas, debería ser puesta al servicio de la persona en el lugar de residencia o trabajo (Conferencia Internacional sobre Atención Primaria de Salud, 1978) 
Esa estrategia constituyó, en consecuencia, un viraje en la atención al partir de la necesidad de considerar los múltiples factores que inciden en la salud y poner en el orden del día las acciones de prevención de la enfermedad, así como las destinadas a proteger el buen estado de salud para, finalmente, actuar sobre las enfermedades (Organización Panamericana de la Salud, 2002).

\subsection{El sistema de salud colombiano anterior a la Constitución Política de 1991.}

\section{Enfoque del sistema de salud: la atención de la enfermedad y la estrategia}

de la prestación de los servicios. La historia reciente de la salud en Colombia tiene, antes de la expedición de la Constitución Política, una huella signada por una visión enfocada en la atención de la enfermedad y, particularmente, en la estrategia de prestación de los servicios a través de agentes de diferente naturaleza, entre ellos, el denominado sector oficial, las entidades de la seguridad social - cobertura específica a los trabajadores y empleados del sector formal de la economía afiliados a dichas instituciones - y, el sector privado, conformado por fundaciones, clínicas y profesionales de la salud, dedicados, preferencialmente, a las personas con capacidad de pago, sin que existiera una clara política en la organización y administración de los servicios de salud, situación que se presentaba en otros países, tal como es reconocido en la III Reunión de Ministros de Salud de las Américas (Organización Panamericana de la Salud, 2002).

En este contexto, un análisis de los planes de desarrollo de los gobiernos comprendidos entre 1970 y 1990 (DNP https://www.dnp.gov.co/Plan-Nacional-deDesarrollo/Paginas/Planes-de-Desarrollo-anteriores.aspx) permite verificar varios de los problemas recurrentes con incidencia e impacto en la calidad de vida y, particularmente, en las afectaciones y el estado de la salud de las personas, entre ellos: 
a) Las deficiencias en la disposición de los servicios de acueducto y alcantarillado, especialmente en lo relacionado con sistemas de agua potable suficientes y adecuados. Esta situación tenía un mayor impacto negativo en las áreas rurales.

b) La alta mortalidad infantil, la deserción escolar, la baja calidad de la educación y el subempleo, la desprotección de las niñas y niños por el acceso de la mujer al mercado laboral, el aumento de los accidentes en los grandes centros urbanos y la falta de atención a la población de la tercera edad y, por efectos del desarrollo, la desprotección de los menores de edad y el crecimiento de la informalidad en el mercado laboral urbano.

c) La desprotección de los y las menores de edad quedó reflejada en las principales causas de muerte que, en este grupo poblacional, eran fácilmente prevenibles, mientras que la informalidad laboral estaba acompañada de la falta de acceso a algún tipo de seguridad social y, en consecuencia, el gasto de bolsillo, que las personas dedicaban a los servicios de salud, se convertía en una carga gravosa en detrimento de los ingresos de las personas menos favorecidas.

d) Los cambios acaecidos, a partir de 1980, en la morbimortalidad, entre otras razones por el incremento de muertes atribuibles a homicidios, ligados a la violencia producida por el narcotráfico, generan que "La tasa global de muertes causadas por homicidios para Colombia en el período estudiado estuvo entre 18 a 80 por 100.000 (1991 fue el año más violento) y el período más violento el comprendido entre 1987 y 1996 (últimos datos disponibles)” (Gómez Restrepo, 2003)

e) El predominio de las enfermedades infecciosas, respiratorias agudas, prevenibles por vacunación y la desnutrición.

f) Las enfermedades tropicales que continuaban afectando la población en las zonas endémicas y, como fenómeno particular, la zoonosis se convirtieron en uno de los 
factores que incidió en la morbilidad por la falta de vacunación y el bajo acceso a servicios médicos.

g) El reconocimiento formal de la relación íntima entre la situación socioeconómica y el estado de salud de la población, expresado en la aceptación de que las desigualdades conducen a incrementar los riesgos de morbimortalidad en personas más pobres. Es decir que las condiciones habitacionales, el acceso a servicios públicos básicos y las oportunidades de consumo de productos básicos determinan los riesgos a enfermar; por ello, el control de plagas, la prevención de enfermedades respiratorias, la tasa de prevalencia de patologías infecciosas intestinales y, en general, la aseveración según la cual la protección de la salud y el aumento de la calidad de vida tiene mejores probabilidades para aquellas familias cuyos ingresos dan acceso al conocimiento, sana alimentación, agua potable, sistema de disposición de residuos sólidos y líquidos, y atención médica.

h) El reconocimiento, desde la época de los ochenta del siglo pasado, a nivel internacional de los efectos del mal uso de los antibióticos, tal como lo señala la declaración de Santo Domingo:

Actualmente vivimos frente a un problema de salud pública a nivel mundial, debido en gran parte al empleo indiscriminado de antibióticos. por lo siguiente: a) la venta de antibióticos sin prescripción médica: b) el empleo de antibióticos útiles en medicina humana como promotores del crecimiento en alimentación animal y en agricultura; c) la prescripción de antibióticos para enfermedades en las cuales son inefectivos; d) el engaño al consumidor al anunciar antibióticos como "drogas mágicas", especialmente en áreas en los que la venta no está legislada; e) el uso de distintos nombres y propaganda para la venta del mismo producto en diferentes partes del mundo 
(Asistentes a la Conferencia sobre biología molecular. Patogenicidad y ecología de plásmidos, 1981).

i) La morbimortalidad por accidentes, enfermedades respiratorias agudas, órganos de los sentidos y afecciones orales.

j) La adopción formal de estrategias de promoción, prevención, atención y rehabilitación de las enfermedades, sin que se lograra la consolidación de las mismas.

k) El desarrollo de programas especiales adoptados para áreas afectadas por lo que se denominó la "subversión”.

1) El reconocimiento de los efectos de la urbanización sobre la calidad de vida y la salud de las familias, en especial los relativos a la migración campesina y la mayor participación del sexo femenino en el mercado laboral.

m) Los objetivos de mejoramiento de las condiciones de empleo, ingresos y seguridad social de las familias, la ampliación de la cultura de utilización eficiente de servicios, el incremento en la educación y capacitación de la pareja, la prevención de la desintegración familiar y el abandono de los menores y, el fomento formal a la coordinación de las entidades públicas en todos las áreas relacionadas con la calidad de vida y la salud.

\section{Acciones centrales: La unificación de la diversidad institucional y la}

universalidad de la atención. Una de las acciones centrales de las políticas de salud, según los resultados de los planes de desarrollo, se expresó en el Sistema Nacional de Salud como el intento de superar la dispersión institucional y lograr la universalidad en la atención, por cuanto existían un sinnúmero de entidades, desarticuladas, entre sí, descoordinadas y carentes de un propósito sectorial unificado.

Además, de lo antes mencionado, las autoridades de Salud tenían el imperativo de enfrentar los problemas asociados al financiamiento, por la inequidad derivada de la 
dispersión de aportes y tarifas, el bajo acceso de las personas sin capacidad de pago a las entidades de salud financiadas por el Estado, las cuales operaban bajo el principio de subsidios a la oferta, y de ejecutar acciones tendientes a superar la ineficiencia en la prestación de los servicios; los limitados niveles de cobertura, así como la carga que recaía en las personas con menor capacidad de pago, y el consecuente incremento del gasto de bolsillo para acceder a atención médica, tratamientos y medicamentos necesarios para superar sus enfermedades, dada la carencia de acciones de promoción y protección de la salud (Organización Panamericana de la Salud, 2002).

Acciones prioritarias. Los diferentes gobiernos se propusieron, a través de sus planes de desarrollo, acciones que reflejan una continuidad en la concepción y estrategia de acción sobre la prestación de los servicios de salud:

a) La reducción de la morbimortalidad generada por accidentes, traumatismos, enfermedades diarreicas, desnutrición y afecciones orales, con base en el incremento de la cobertura de la atención médica, y las actividades para prevenir, tratar y rehabilitar las enfermedades producidas por parásitos, así como acciones específicas contra la fiebre reumática, la caries y la desnutrición.

b) La disminución de la mortalidad por accidentes, traumas, lesiones personales, infecciones respiratorias, tuberculosis y aborto, y el control de la morbilidad causada por trastornos mentales, enfermedades venéreas y periodontopatías, a través de acciones educativas, de prevención de accidentes, tratamiento de enfermedades venéreas, acciones de control sobre contaminación ambiental y salud ocupacional, incremento de la cobertura de actividades odontológicas e, investigación de las características en la situación de salud mental.

c) La superación de los niveles de desnutrición en la población materno infantil

d) La disminución del impacto de accidentes y traumatismos. 
e) El mejoramiento de las condiciones ambientales y promoción de la atención básica a las personas (abastecimiento de agua, disposición de desechos, vigilancia de zoonosis, mejoramiento de la vivienda y control de la calidad de los alimentos; atención a las personas con énfasis en la población materno-infantil, vacunación, prevención de accidentes y salud oral y, alimentación y nutrición con prelación en la complementación alimentaria, educación nutricional y, producción y conservación de alimentos).

f) La priorización de atención al grupo materno infantil y la lucha contra las enfermedades endémico prevalentes (paludismo, dengue, fiebre amarilla).

g) El incremento de la atención médica ambulatoria.

h) La ampliación de la atención preescolar.

i) El incremento de los niveles de inmunización y la extensión de las coberturas de alimentación y nutrición.

j) La detección precoz, el control de las patologías y la ampliación de los servicios, especialmente en geriatría, urgencias y rehabilitación.

k) El aumento de la prevención, control y tratamiento del paludismo, dengue y fiebre amarilla, con la estrategia de motivar la participación de las personas, el aumento de la vigilancia, la atención de salud, acciones de carácter focal e investigaciones encaminadas al diseño y ejecución de estrategias que tuvieran impacto en la disminución de la morbimortalidad.

1) Otras acciones, de carácter estratégico, fueron reducir la mortalidad por causas atribuibles a los riesgos de embarazo, parto y puerperio, aborto y cáncer de cérvix, con base en el incremento de la atención institucional del parto, el control prenatal y la planificación familiar. Un elemento de prevención, incluido en estas acciones, fue el desarrollo de programas de educación nutricional para las madres. 


\subsection{Los problemas institucionales.}

El Sistema Nacional de Salud - creado por el Decreto Ley 056 de 1975- reflejó especificamente la institucionalidad relacionada con las reglas de juego, la organización, la administración y la gestión de la salud, el cual integró las entidades de asistencia pública, de derecho público y privado, como los pilares de la atención y prestación de servicios de salud y estableció los denominados subsistemas nacionales de inversión, información, planeación, suministros, personal e investigaciones.

La Fragmentación y polarización. Una de las deficiencias que antecedieron a la creación del Sistema General de Seguridad Social en Salud estaba relacionada con la constante fragmentación y polarización de los sistemas de salud, los bajos niveles de cobertura, la concentración de la atención en las personas de mayor capacidad de pago, quienes eran las que accedían preferencialmente a las instituciones hospitalarias financiadas con recursos públicos, los múltiples regímenes de prestaciones en salud y, la culturalmente aceptada selección adversa, la cual afectaba negativamente a las poblaciones marginadas, especialmente las rurales, además de los problemas asociados a la carencia de servicios públicos, especialmente agua potable y saneamiento básico, todo lo cual conduce al incremento de paros cívicos, con los cuales las poblaciones demandan, del Estado, la atención de las necesidades básicas insatisfechas (Castro, 1984).

Las competencias y responsabilidades del Sistema Nacional de Salud: Niveles nacional, seccional y local.

La institucionalidad regulada durante el segundo quinquenio, de la década de los setenta del siglo pasado, contempló responsabilidades a los niveles nacionales, seccionales y locales y, señaló, entre sus competencias, las de construir, conservar y mantener los hospitales, centros y puestos de salud, acueductos y alcantarillados, así 
como la adquisición de bienes inmuebles para el desarrollo de los programas de salud, la formación, capacitación y adiestramiento del personal de la salud y, la investigación y el desarrollo administrativo.

La preeminencia del órgano rector: el Ministerio de Salud. Una de las características básicas de los sistemas de salud, independientemente de su configuración, es la preeminencia del Ministerio de Salud, como órgano rector del diseño, adopción y control de las políticas, planes y objetivos, así como del manejo de los recursos. Tal característica lo convertía en una entidad, por excelencia, responsable de todo el proceso administrativo (rectoría, regulación, planeación, administración, ejecución, supervisión, vigilancia, control y evaluación).

La operación del Sistema de Salud a través de tres subsistemas territoriales: el nacional, el seccional y el local. Cada una de las instancias territoriales era responsable de conocer objetivamente la situación; orientar la ejecución de la política y utilizar adecuadamente los recursos, en concordancia con la política de salud y el Plan General de Desarrollo del país; expedir la regulación de la inversión, así como reglas relacionadas con la programación, control y evaluación de la misma; determinar las necesidades y demandas de la población en materia de salud; establecer la cantidad y características de las actividades técnicas y administrativas a cargo de las entidades de salud; determinar la cantidad y calidad de personal que requería el sistema, con formación y actualización del personal; realizar la selección, recepción, adaptación y ubicación del personal, así como la utilización adecuada de las capacidades de trabajo; expedir normas y mecanismos para la adquisición y control de calidad de suministros, nacionales y extranjeros, elaborar y actualizar el catálogo de suministros del Sistema Nacional de Salud; elaborar y actualizar el manual de procedimientos para el Subsistema Nacional de suministros; dar concepto favorable previo para la importación 
de suministros y adquirir directamente suministros nacionales o extranjeros para el sistema, cuando la conveniencia lo exigía; determinar las prioridades de investigación, el estudio y aprobación de proyectos de investigación, la participación de entidades, grupos o personas en investigaciones de salud; realizar las investigaciones en salud, así como divulgar sus resultados $\mathrm{y}$, analizar el efecto de los programas en la salud de la población.

Estas instancias se han mantenido, con diferente modulación y especialización, como parte de la institucionalidad a través de las cuales fluyen responsabilidades estatales en el cumplimiento del derecho y de los servicios de salud.

Incremento de los servicios de salud. El aumento de los servicios de salud como estrategia de atención acompaña la exposición de motivos de los diferentes arreglos institucionales, especialmente para resolver las necesidades en las áreas rurales y las poblaciones marginales pobres con escasa posibilidad de acceder a un servicio, dados los reiterados bajos niveles de cobertura existentes a lo largo de la geografía nacional.

Aumento de cobertura. Una de las preocupaciones históricas está relacionada con las limitaciones de acceso a los servicios y los mecanismos de solución están atados a lograr desarrollar y consolidar un único sistema de salud, unificar las distintas y variadas entidades, aumentar el gasto público, crear nuevas instituciones de salud y mejorar la atención.

Límites en el cumplimiento de la política pública de Salud. El cumplimiento de las obligaciones estatales en materia de salud, especialmente en la fase prestacional, está relacionado con varios factores que limitan la eficiencia, eficacia y efectividad del aparato público en torno al derecho y a los servicios, entre ellos se pueden mencionar, por su reincidencia histórica, los siguientes: 


\section{La diferenciación entre personas atendidas bajo el crierio de beneficencia y} aquellas asociadas a la Seguridad Social. Uno de los factores que incidió en el cumplimiento de las políticas y acciones de salud es la diferenciación cultural, social y política entre la denominada asistencia pública (beneficencia) y la Seguridad Social, así como el acceso a servicios médicos privados. La primera orientada como un conjunto de organizaciones y servicios de ayuda a las personas necesitadas, a quienes no se reconocía objetivamente su dignidad humana y, las segundas orientadas a las personas asalariadas o a quienes tenían capacidad de pago. Este tratamiento, personas con capacidad de pago contra personas en condición de pobreza - muchas veces absoluta- es uno de los elementos que impide adoptar, desarrollar y consolidar la salud como un derecho fundamental.

La atención preferente y cualificada de las personas con capacidad de pago, los trabajadores privados y los servidores públicos. Las entidades con mayor capacidad de gestión -recursos, tecnología, personal especializado, disponibilidad de medicamentos, hotelería, entre otros- concentraron su gestión en la atención de las personas pertenecientes a los sistemas de seguridad social o con capacidad de pago. Tales condiciones favorecían, igualmente, a los servidores del Estado, quienes en virtud de su relación legal y reglamentaria o de contrato de trabajo, en el caso los trabajadores oficiales, contaban con instituciones de previsión social con diferentes regímenes que les garantizaban el acceso a la atención en salud y demás prestaciones, las cuales estaban negadas a un importante grupo de la población colombiana.

El perfil epidemiológico. La situación epidemiológica muestra variaciones importantes que condicionan la planeación, gestión y operaciones de los servicios de salud, al igual que la garantía del derecho, que va desde la existencia de enfermedades infecciosas, como uno de los determinantes de la salud pública, a temas de 
morbimortalidad asociados a la enteritis, las neumonías, la avitaminosis y los efectos sobre la salud derivados de la desnutrición, la carencia de sistemas de acueducto, alcantarillado y la disposición de desechos de diversa procedencia:

...persisten problemas importantes de acceso y calidad, en especial en el nivel urbano, que crean situaciones de riesgo, como las mostradas recientemente por epidemias de cólera y leptospirosis y por el incremento de la morbilidad por enfermedades de transmisión hídrica (Organización Panamericana de la Salud, 1998, p. 12)

Simultáneamente otras patologías, asociadas a la mortalidad, comienzan a destacar, entre ellas el trauma, los accidentes, las enfermedades cardiovasculares, las derivadas de la violencia y las que posteriormente tendrán una fuerte incidencia en los servicios de salud, conocidas como enfermedades crónicas no transmisibles o afectaciones de la salud, asociadas al "desarrollo", tales como el cáncer, la diabetes, las afecciones coronarias, las enfermedades auto inmunes, entre otras. Así se asevera en el documento "Estilo de vida saludable y enfermedades no transmisibles":

El perfil de morbilidad y mortalidad se caracteriza por un predominio de las Enfermedades Crónicas No Transmisibles que son desde hace ya varios años las principales causas de morbilidad y mortalidad: los cánceres, las enfermedades cardiovasculares, las enfermedades metabólicas y las enfermedades neurodegenerativas aparecen en los primeros lugares a nivel nacional en los estudios de carga de la enfermedad en 1995 y 2005 (Ministerio de Salud y Protección Social \& Organización Panamericana de la Salud, 2010, p. 14)

Las políticas públicas. Las políticas públicas se encaminaron a disminuir la morbilidad producida por las enfermedades infectocontagiosas, aumentar los servicios de salud en áreas rurales, incrementar y cualificar la prestación de servicios materno 
infantiles, promover la formación de profesionales de la salud, elevar la disponibilidad hospitalaria, y mejorar la utilización de los recursos en las instituciones.

Retos problemáticos. El cumplimiento de las responsabilidades del Estado en materia de prestación de servicios de salud enfrentaba varios retos:

a) Las prebendas de las que gozaban los servidores vinculados a las instituciones de seguridad social y las entidades hospitalarias, algunos de los cuales disfrutaban de doble contratación ${ }^{3}$ en entidades públicas.

b) La oposición del Instituto Colombiano de los Seguros Sociales al funcionamiento de un sistema único, lo cual impedía integrar las diferentes instituciones, los recursos y las prestaciones para el mejoramiento de la cobertura y la cualificación de la atención.

c) Los requerimientos financieros de las instituciones de la Red Pública, sin respuesta fiscal, generaron un creciente déficit fiscal y condujeron a la crisis económica estrucutural de las entidades hospitalarias.

d) La inveterada y fuerte influencia de los políticos territoriales sobre la planeación, programación y ejecución de la inversión pública, especialmente en la construcción y dotación de hospitales contradecía la política de planificación de la inversión pública y diezmaba la capacidad del Estado sobre el incremento cuantitativo y cualitativo de instituciones en la atención de la demanda de servicios de salud (Organización Panamericana de la Salud, 2002).

e) Los fenómenos de corrupción que tenían una incidencia alta sobre el destino del patrimonio asignado a las entidades que hacian parte del sistema de salud vigente.

f) La incoherencia entre la política, la planeación y las acciones desarticuladas de las instituciones responsables de los servicios de salud.

3 Los profesionales de la salud, especialmente los médicos especialistas, tenían vinculaciones laborales que, en muchos casos, sumaban cerca de 16 horas diarias de jornada laboral. 
g) La inestabilidad institucional de las entidades hospitalarias.

h) La incompatibilidad jurídica entre los diversos regímenes de la seguridad social y, de los responsables de la prestación de los servicios de salud.

i) Las deficiencias estructurales del sistema de organización y gestión.

j) La captura de instituciones oficiales por intereses particulares (políticos, sindicatos, profesionales, entre otros) y

k) La dispersión de un sistema de financiamiento que no respondía a las lógicas elementales de la planificación, programación, ejecución y control de recursos en armonía con los objetivos de salud y bienestar.

La crítica situación en los temas de prestación de servicios y garantía del derecho de salud se hacía más gravosa por la crisis económica internacional y el creciente déficit fiscal nacional, tal como lo plantea Ocampo:

La década de los ochenta ha sido caracterizada, con razón, por la Comisión Económica para América Latina, como la "década perdida". La crisis de la deuda, generada por el sobre-endeudamiento de muchos países latinoamericanos en los años setenta y la radical interrupción de dichos flujos en 1981-1982, generó en la región una fuerte crisis de desarrollo, que se reflejó en caídas del Producto Interno Bruto por habitante en la mayoría de los países de la región, el debilitamiento general de sus estructuras productivas y estatales, la desigualdad creciente en la distribución del ingreso y el incremento en los niveles de pobreza (Ocampo, 1987).

Los efectos de esta crisis generaron ajustes estructurales que cobraron fuerza a partir de 1982 y, signaron los programas gubernamentales con la impronta de la disminución del aparato público, a través de dos mecanismos preferenciales: decaimiento de la inversión pública y supresión de empleos públicos, además de las decisiones de disminución real del salario y el impacto de las políticas monetarias que 
acompañaban el ajuste. Las consecuencias se hicieron evidentes en la reducción del gasto social, tal como lo señala Perry en su artículo del diario El Tiempo:

...el gasto público social por habitante (en educación, salud, seguridad social y vivienda) se redujo entre 1981 y 1988, en términos reales, y perdió participación en relación con el gasto público total y el PIB, a pesar de un aumento significativo hasta 1984 (Perry, 1990)

De igual forma en el tema de salud se dio un incumplimiento en el logro de los objetivos de cobertura universal y acceso a servicios de mayor complejidad, los cuales quedaron excluidos de la agenda gubernamental por efectos de la incapacidad fiscal del Estado para garantizar su financiamiento (Organización Panamericana de la Salud, 2002).

La situación de los factores incidentes en el estado de salud reflejaba, en aquella época, a su vez, el impacto de las deficiencias de otros sectores sobre la calidad de vida y el estado de salud de las personas. De hecho, la cobertura de acueducto, entre los años 1985-1986, era de 60\%; la de alcantarillado del 44\%, mientras que de la población que tenía algún acceso al servicio de acueducto, únicamente el $60 \%$ consumía agua con algún tipo de tratamiento para su potabilización. Las aguas servidas tenían muy pocas opciones de procesamiento, situación que estaba planteada con el fin de evitar su impacto negativo sobre fuentes hídricas. De las basuras se recogía tan solo el $60 \%$ (Turbay, 1996, p. 87). La cobertura en el año 2003 alcanzó el 75\% en acueducto; el 60\% en alcantarillado; y, el tratamiento de aguas servidas llegó tan solo al 12\%, con el agravante de la contaminación de los flujos hídricos por las descargas que sobre las quebradas, ríos y demás fuentes se realizaba, especialmente de residuos urbanos (Santamaría \& Villa, 2004, p. 75). 
El Banco Mundial señaló que una manera de fomentar el crecimiento en los países en desarrollo estaba ligada a la combinación de políticas de estabilización y de ajuste estructural. Sobre estas últimas hizo mención a las reformas a incentivos a instituciones gubernamentales y a las disposiciones relativas a los derechos de propiedad, responsabilidad e información, por su efecto sobre la producción, comercio y distribución y, a las consecuencias en el mejoramiento de la competitividad, la mayor eficiencia de las entidades estatales y la reducción del déficit fiscal (Banco Mundial, 1986).

Con respecto a la situación de la deuda externa colombiana, Rubio (Rubio, Ojeda, \& Montes, 2011) expone que:

La década de los ochenta fue en general un período de ajuste de las finanzas públicas $^{5} \mathrm{y}$ del sector externo, con una fuerte reducción del gasto público y medidas tributarias cuyo resultado fue un ajuste en la cuenta corriente y un aumento en el nivel de reservas internacionales. Asimismo, marcó el inicio de un proceso de flexibilización de las restricciones a la entrada de capitales externos (p.7).

Unido a este fenómeno, la crisis internacional y su incidencia en las políticas nacionales, así como el creciente déficit fiscal, que bien esboza el entonces ministro de hacienda Junguito “(...) la política económica futura tendría como énfasis equilibrar el sector externo de la economía, reducir el déficit fiscal y el impacto negativo de su financiamiento a través de la emisión monetaria, y recuperar la dinámica del sector privado..." (citado por Garay S. \& Carrasquilla, 1987, p. 24), cuyo impacto en las condiciones económicas y sociales tenía su mayor expresión en las deficientes coberturas y baja calidad de los servicios públicos domiciliarios, los cuales a su vez incidían en la calidad de vida y la salud de los habitantes del país, unido a las condiciones y recomendaciones de los organismos multilaterales de crédito, generaron, 
motivados por algunos países desarrollados (Inglaterra, Estados Unidos, etc.) cambios en las políticas económicas, las cuales tendían a priorizar los mercados y la iniciativa privada como mecanismo para afrontar la crisis. Tal perspectiva, llevó a adoptar desregulaciones, flexibilización de controles, privatizaciones, ajustes sobre el gasto público con incidencia sobre el gasto social y el empleo.

Aunque modesto, el crecimiento económico de Colombia durante los años ochenta le permitió al gobierno mantener el aumento per cápita en gastos sociales. El gasto público en educación como porcentaje del PNB subió de $1.7 \%$ en 1960 a $2.8 \%$ en 1980, y el correspondiente a salud, de $0.4 \%$ al $0.8 \%$ del PNB. Sin embargo, el programa de ajuste adoptado en 1984 redujo el gasto público, incluido el destinado a sectores sociales. Con todo el gasto social sigue representando cerca de la tercera parte del gasto público total... Sin embargo, todo parece indicar que las políticas de ajuste económico tan sólo han disminuido el ritmo del progreso humano, sin haber llegado a invertirlo (Programa de las Naciones Unidas para el Desarrollo, 1991, pp. 124-125).

En síntesis, los análisis realizados en torno a la crisis de los diversos aspectos de la vida socio-económica que se presentó en aquella época, permitieron a los expertos señalar que ésta tenía un fuerte impacto en el sector salud (Almeida, 2002). Como causas de ellas se reconocieron: las deficiencias institucionales del Estado, la fragmentación en los procesos de diagnóstico y tratamiento de la enfermedad, el papel del personal de la salud, especialmente de los médicos, la incidencia sobre los costos que tenían los medicamentos, el crecimiento de la demanda de servicios de salud, los efectos negativos de la falta de atención sobre los condicionantes sociales y económicos que afectan el estado de salud, y los cambios epidemiológicos propios de una población en permanente transición. 


\subsection{Signos de transformación del Sistema de Salud.}

El Estado colombiano enfrentó, en los inicios de la década de los 90, varios de los problemas reseñados por el Banco Mundial, entre ellos: las deficiencias de la institucionalidad vigente en el sector salud, la dispersión de entidades y regímenes de seguridad social y atención de salud, los temas asociados a la asignación de recursos, la inequidad en el acceso a los servicios, en detrimento de las personas más pobres, la desigualdad en los tratamientos, la ineficiencia del gasto público, el incremento injustificado de los costos de acceso y atención, el bajo nivel de información y participación de las personas $\mathrm{y}$, particularmente, el desorden institucional de las instancias responsables de la prestación de servicios, el déficit de recursos para la atención de una población reducida, la centralización en el proceso de toma decisiones, especialmente en el modelo de atención, la prestación de servicios concentrada en niveles especializados, la poca adaptación a los cambios estructurales motivados por la descentralización, la baja participación de las comunidades, grupos y personas, las limitaciones del Ministerio de Salud en el ejercicio de funciones de planificación, dirección y evaluación de la política, y los problemas de gestión de los recursos humanos (González S., 1997).

El ordenamiento institucional de la prestación de servicios de salud en los diversos Estados ha enfrentado disímiles problemas, Colombia no ha sido ni es excepción, especialmente en temas relacionados con el gasto público asociados al crónico déficit fiscal de fines del siglo XX y, las políticas impulsadas por las agencias internacionales con énfasis en decisiones de financiamiento y estabilidad fiscal.

Aunque el número relativo de proyectos no haya aumentado mucho durante los años ochenta, el monto de los recursos de préstamo al sector salud no paró de crecer a lo 
largo del tiempo. En los años noventa, se presentó un fuerte crecimiento del número de préstamos de salud aprobados por el Banco (Medici \& Solari, 2002, p. 8)

Las discusiones, decisiones y acciones que se han gestado han sido notorias, en el contexto señalado, desde finales de la década del setenta del siglo pasado entre las teorías neoliberal, que han centrado su atención en la flexibilidad y eficiencia de los mercados y, el intervencionismo de Estado que ha pretendido el mayor control del mercado por la presión y crisis fiscal originada en la deuda externa. Entre estos extremos, Colombia enfrentó sus crisis y dio particular importancia a las recomendaciones de los organismos multilaterales, cuyas recomendaciones apuntalaban políticas encaminadas a superar la pobreza por los efectos potenciales que la misma generaba en el estado de la salud pública:

La lucha contra las enfermedades transmisibles es otro caso en el que todos los ciudadanos se benefician de los programas orientados a los pobres, ya que es casi imposible que un grupo evite esas enfermedades a menos que se erradiquen las fuentes de contagio. Los pobres, que están mal nutridos y viven en medios más expuestos a la enfermedad, son especialmente vulnerables a la infección. Tienen también menos probabilidades de recibir los servicios de salud preventivos y curativos adecuados. Por tanto, suelen formar focos de contagio a partir de las cuales las enfermedades pueden difundirse a otros grupos (Banco Mundial, 2000, p. 109).

Esta perspectiva promovió la atención de necesidades básicas insatisfechas para las poblaciones más deprimidas, ya que según el organismo multilateral:

Aunque el estado de derecho beneficie a los pobres de muchas maneras, las leyes y los estatutos no están necesariamente concebidos para proteger sus intereses. Los sistemas jurídicos, que son producto de las relaciones de poder entre diferentes grupos de la sociedad, suelen concentrarse en la protección de los intereses de quienes 
tienen poder político, y están representados en ese nivel. Para que las leyes y su interpretación sean más acordes con las necesidades de los desfavorecidos hay que crear coaliciones con ese fin. Este es, por ejemplo, el propósito de las iniciativas emprendidas para conseguir unas leyes más equitativas en sustrato de las mujeres y las minorías (Banco Mundial, 2000, p. 103)

La preocupación también encaminó las políticas públicas hacia el capital humano, cuestión que también es resaltada ya que "Los datos disponibles parecen indicar que el capital humano de los pobres, sobre todo de los niños pobres, se puede deteriorar" (Banco Mundial, 2000, p. 162)

Una tema estratégico adicional se manifiestó en relación con los derechos sociales:

En casi todos los países, los pobres son quienes obtienen los peores resultados de salud. La mala salud los sume cada vez más en la pobreza. Y regularmente quedan excluidos de las redes de apoyo que refuerzan los beneficios sociales y económicos de la buena salud (Niño Torres, 2003, p. 135).

Existía, igualmente, la preocupación sobre la visión de la importancia de las libertades para una vida mejor (Londoño, 2001).

En consecuencia, los gobiernos de los países del tercer mundo, especialmente los latinoamericanos, entre ellos Colombia, ante los efectos nocivos de la deuda pública externa en sus finanzas públicas fueron obligados a realizar fuertes ajustes fiscales en las últimas décadas del siglo pasado, a tal punto que desde principios de la década de los ochenta, del Siglo XX, se pregonó como política multilateral que:

A la mayor parte de los países en desarrollo les espera una década difícil de ajuste a tales condiciones. Deben reducir su actual déficit de balanza de pagos a niveles sostenibles. En último término, el ajuste requiere orientación del comercio, de la 
producción interna y del consumo; la obtención de préstamos es un instrumento necesario para efectuar inversiones que aceleren el crecimiento y para ganar tiempo a fin de que el ajuste se efectúe, pero a los países que han obtenido préstamos... pronto les llega la hora enfrentarse a una deuda excesiva y a una contracción macroeconómica forzada (Banco Mundial, 1981, p. 133).

El déficit se dio entre otras razones por la reacción en cadena, durante los años ochenta, contra el paradigma de la intervención del Estado en la organización y prestación directa de los servicios sociales, dados los problemas asociados a inequidad en el acceso, baja calidad, limitada cobertura, subsidios ligados a la oferta que favorecían a personas de mayor capacidad de pago y crecientes deudas hospitalarias, todo lo cual, condujo a la aplicación de políticas de liberalización, a través de la descentralización de los servicios y su asignación como responsabilidad de los municipios, la reducción del sector público como mecanismo preferido del ajuste fiscal, la promoción de instrumentos laborales que apuntaban a la disminución de los costos de la mano de obra y, la oferta de paquetes mínimos de salud destinado a las poblaciones pobres y vulnerables (Rey y otros, 2012). Es, en consecuencia, materialmente obvio que las políticas de los organismos internacionales influyeron, de manera directa, en las decisiones que forjaron el diseño institucional de la salud en Colombia.

El Banco Mundial, por ejemplo, propuso un enfoque que consistió en el desarrollo de un entorno económico que contribuyera a que las familias mejoraran su nivel de salud, con base en la implementación de políticas de crecimiento para mejorar los ingresos de los más pobres y motivar la educación, con énfasis en las niñas; la reorientación del gasto público a programas más eficaces que disminuyeran la prestación de servicios de alta complejidad y permitieran la atención de las personas más pobres para conseguir diversidad en el financiamiento $\mathrm{y}$, una mayor competencia 
en la prestación de los servicios de salud (Banco Mundial, 1993b). Todo lo anterior, sumado a la ola de reformas del Estado, en las décadas de los ochenta y noventa del siglo pasado, motivadas en visiones de eficiencia del gasto y énfasis en la iniciativa privada como mecanismo de crecimiento y desarrollo, cuyos argumentos, especialmente en los servicios de salud, fundamentaron la necesidad de aumentar la equidad en la prestación de servicios, la eficiencia en la utilización de recursos, la efectividad en el logro de resultados y la obtención de un alto nivel de satisfacción de las necesidades de salud, a tal punto que "En algunos países los elementos fundamentales de la reforma sectorial se incluyeron en el marco de debates más globales de reforma de la Constitución..." (Organización Panamericana de la Salud, 1998, p. 348).

La importancia de enfrentar la desigual distribución de los condicionantes de salud (Organización Panamericana de la Salud, 1998, p. 277) y su efecto perverso mayor sobre las poblaciones más pobres, el bajo acceso a la seguridad social, la necesidad de reducir el impacto de las crisis sobre los ingresos de la población pobre, evitar daños irreversibles en capital humano de los pobres generó que "desde mediados de los noventas, la investigación y la política social han puesto más énfasis en la dimensión de riesgo de la vida social” (Londoño, 2001, p. 19), así como el objetivo de hacer políticamente viables los ajustes fiscales, han incido en el diseño de los sistemas de Seguridad Social en los diferentes Estados, en particular en los latinoamericanos, situación para nada ajena a Colombia, tal como lo subrayó el BID en el año 2000.

Un nuevo modelo de intervención: la Ley 10 de 1990. El Sistema Nacional de Salud, con el panorama antes expuesto, ingresa en la última década del Siglo XX y es sometido, a través de la Ley 10 de 1990, a un “nuevo” modelo de intervención pública.

La Ley 10 de 1990 introdujo y definió el concepto de servicio público de salud, bajo la responsabilidad de la Nación, con la dirección a cargo del Ministerio de Salud 
quien debía dictar todas las normas científico - administrativas. Ella estableció la gratuidad, en los niveles básicos de la salud, para todos los habitantes. Además, declaró que ese servicio público sería administrado por la Nación, en asocio con las entidades territoriales, sus entidades descentralizadas, y con las personas, naturales o jurídicas, autorizadas para su prestación.

El texto normativo estableció que el Estado interviene para definir la prestación de asistencia pública en salud, establecer los servicios básicos gratuitos, fijar los niveles integrales de atención compleja, organizar la participación comunitaria en la prestación de los servicios, determinar los derechos y deberes de las personas, señalar el sistema de registro y control de quienes prestan servicios de salud, expedir el régimen tarifario, fijar las normas de calidad para controlar y vigilar su cumplimiento, regular los procedimientos para autorizar la prestación de servicios de salud al sector privado, dictar normas sobre organización y funcionamiento de la medicina prepagada, señalar las disposiciones técnicas para la construcción, remodelación, ampliación y dotación de la infraestructura de salud y, organizar y establecer el régimen de referencia y contrareferencia de pacientes. Desde la expedición de esta norma, bajo el concepto de asistencia pública en salud, se estableció que la atención inicial de urgencias es obligatoria para todas las instituciones o entidades que presten servicios de salud, sin que puedan discriminar a persona alguna.

La reforma incluyó los principios de universalidad, participación ciudadana, participación comunitaria, subsidiariedad (apoyo de entidades de niveles especializados superiores en la atención de pacientes a entidades de niveles inferiores de prestación), complementariedad e integración funcional (concurrencia armónica de funciones, acciones y recursos); determinó la organización y administración del servicio público de salud, el cual comprendía los procesos de fomento, prevención, tratamiento y 
rehabilitación, teniendo en cuenta los diversos factores que inciden, entre ellos, los biológicos, ambientales, comportamentales, y las acciones de prestación de servicios y, planteaba, de manera explícita, que estaba conformado por el conjunto de instituciones públicas y privadas del Sector Salud y, por las entidades de otros sectores que, por su naturaleza y acciones, incidían en los riesgos sobre el estado de salud de una persona, familia o comunidad.

La organización del Sistema de Salud planteaba dos sectores, el primero denominado Subsector Oficial, al cual pertenecían todas las entidades públicas que dirigían o prestaban servicios de salud y, el Subsector Privado, compuesto por las entidades o instituciones privadas encargadas de la prestación de servicios de salud, independientemente de su denominación, las cuales tenían la obligación de cumplir con las condiciones de calidad científico - tecnológica, patrimoniales y de capacidad técnico - administrativa para la atención de los servicios de salud. Tales exigencias pretendían depurar y garantizar la capacidad y calidad de la prestación, además de obligar a las entidades, que recibían recursos públicos, a suscribir un contrato a través del cual se obligaban a diseñar y ejecutar un programa o proyecto al que destinarían los recursos y, participar y consolidar los mecanismos de articulación con los planes o programas del sector oficial.

La Ley reguló, en aquella época, temas laborales al definir el Estatuto de Personal, en el cual fijó la clasificación de los empleos de la Nación, las entidades territoriales y las entidades descentralizadas, en cargos de libre nombramiento y remoción y de Carrera, mientras que legó la categoría de trabajadores oficiales a aquellos puestos dedicados al mantenimiento de la planta física hospitalaria y a los servicios generales; además estableció para los empleos de Carrera dos tipos de concursos: abiertos y cerrados y, definió el régimen disciplinario a aplicar. 
La norma fijó disposiciones orientadas a reordenar la aplicación de las fuentes de financiamiento, en particular señaló la prioridad de los recursos del situado fiscal en orden a atender los servicios básicos de salud, asistencia pública, funcionamiento de la infraestructura del primer nivel de atención, pago de prestaciones adeudadas, gastos de funcionamiento de la infraestructura utilizada en la prestación de servicios del segundo nivel y gastos de funcionamiento en infraestructura del tercer nivel; instituyó los requisitos y trámites para la transferencia de recursos; prohibió a las entidades del sector asumir directamente las prestaciones asistenciales y económicas que estaban cubiertas por fondos de cesantías o entidades de previsión y seguridad social; determinó las obligaciones de los sujetos pasivos responsables de impuestos destinados a la prestación de servicios de salud y, señaló las sanciones que podía imponer la autoridad responsable de las funciones de inspección y vigilancia.

El Sistema Nacional de Salud, en esa década, inició un proceso de transformación motivado, además de su específica crisis, por la aplicación de las políticas de ajuste económico; en particular, por la adopción de mecanismos de mercado abierto que tuvieron por objeto aumentar la competitividad, a partir de la redefinición del rol del Estado y de la privatización de algunos servicios, así como del papel que se otorgó a los agentes privados en la organización, administración y operación de la producción y comercialización de servicios, con base en el supuesto de que la iniciativa privada produce mayor riqueza, desarrollo y estabilidad económica, tal como se muestra en el Informe Sobre el Desarrollo Mundial del año 2000:

La inversión y la innovación tecnológica son los principales motores del crecimiento del empleo y los ingresos derivados del trabajo. Para fomentar la inversión privada hay que reducir el riesgo para los inversionistas privados, con una política fiscal y monetaria firme, regímenes estables de inversión, sistemas financieros sólidos y un 
entorno económico claro y transparente. Pero supone también garantizar el imperio de la ley y adoptar medidas para acabar con la corrupción: combatir aquellas situaciones en que la vida de las empresas está basada en comisiones clandestinas, subvenciones para los grandes inversionistas, acuerdos especiales y monopolios favorecidos (Banco Mundial, 2000. P 8).

El análisis del sector salud, cuya problemática hizo parte en aquella época de los debates sobre las responsabilidades del Estado, en torno al financiamiento incentivó ese proceso de transformación, el cual se impulsó con mayor fuerza por los compromisos internacionales que Colombia suscribió en torno al respeto de los derechos humanos, los objetivos y metas acordados con los demás países para el cuidado de la salud y la superación de las afecciones de mayor impacto, el pago de la deuda externa, así como los pactos con incidencia en la educación, el trabajo y la calidad de vida.

La situación y el punto de partida. El inicio de la década de los noventa del siglo pasado dio origen al diseño, adopción y operación del Sistema General de Seguridad Social en Salud, algunos de cuyos componentes territoriales tuvieron una primera expresión en la Ley 10 de 1990. Los elementos que acompañaron el diagnóstico que sustentó la institucionalidad de la organización y gestión de la garantía del derecho a la salud y la prestación de los servicios señalaban que:

a) El acceso a los servicios de salud no cobijaba a la mayoría de la población colombiana, especialmente por las deficiencias y carencias de las instituciones responsables de la atención en salud.

b) La situación en salud estaba ligada a las acciones de diferentes sectores que incidían sobre la calidad de vida, el bienestar y la capacidad que tenían las personas para ejercer sus potencialidades. 
c) Existían regiones donde la mortalidad continuaba en niveles muy altos, entre ellas la Costa Pacífica y los denominados Territorios Nacionales, especialmente por factores asociados a la desnutrición, la cual afectaba a los sectores más pobres, especialmente aquellos que vivían lejos de los centros urbanos y dispersos en las áreas rurales, situación cuyo efecto negativo era multiplicado por el nivel de analfabetismo. Sobre el particular afirmaba el Departamento Nacional de Planeación:

La población de escolares presenta también un estado nutricional deficitario que incide directamente en las altas tasa de deserción escolar y el bajo rendimiento educativo. Según el Estudio Nacional de Salud (1980), el 20.8\% de los escolares sufría de anemia originada en el inadecuado consumo de nutrientes como el hierro, presentándose con frecuencia mayor en los niños de 5 a 14 años y en la población rural dispersa que vivía en concentraciones menores de 2.500 habitantes (Colombia. Departamento Nacional de Planeación. DNP, 1991).

d) La caracterización de los temas relacionados con la situación en salud llevaron a considerar los efectos de los cambios en el estilo de vida, específicamente las consecuencias sobre la salud de la vida sedentaria, el aumento de bebidas alcohólicas, el acceso a drogas psicotrópicas, el alto consumo de grasas y carbohidratos y, los efectos del deterioro ambiental que conducían a nuevos riesgos patológicos, cuyos tratamientos pasaban por la educación, el acceso a información y la adquisición de conciencia sobre los efectos que los comportamientos y acciones, de las personas y comunidades, tenían sobre su bienestar y salud.

e) La baja cobertura de los servicios de salud en el nivel primario y la duplicidad de las prestaciones, concentrada en un mismo grupo de personas, era la expresión de la situación institucional, entre otras razones porque las entidades de la Seguridad Social cubrían, en servicios de salud, al 18\% del total de la población, el sector oficial llegaba 
al 39\%, los seguros médicos privados abrigaban al 17\% y, el Instituto de Seguros Sociales alcanzaba el 13\%, mientras que las cajas de compensación duplicaban la atención al prestar servicios a personas que tenían cubrimiento por otras entidades. En este contexto, el porcentaje de servicios de consulta médica externa alcanzaba al $30.2 \%$ de la población asignada al denominado Sector Oficial, cifra que permite señalar la reducida cobertura en la atención y muestra que los servicios eran un privilegio, al cual no accedía un importante número de personas, ni siquiera al nivel básico.

f) El crecimiento de los profesionales, técnicos y demás agentes requeridos en la prestación de servicios alcanzaban, en aquella época, los promedios internacionales de la relación personas / personal de la salud, aunque la ubicación de los mismos estaba en contravía de las necesidades de los habitantes de las áreas territoriales; situación que generó significativos déficit en las pequeñas poblaciones y las áreas rurales, por lo que puede afirmarse que desde esta época existía conocimiento de la “...discrepancia entre el perfil educacional de los profesionales de la salud y las necesidades de atención, requiriéndose mayor personal para la atención primaria” (González S., 1997), ya que cerca del $61 \%$ del personal médico del sector oficial se ubicaba en las capitales de departamento, las cuales albergaban cerca del $43 \%$ por ciento la población, mientras la atención ambulatoria tenía menos de una enfermera y cerca de cuatro auxiliares por cada 10.000 habitantes, datos que muestran un déficit comparado con los estándares que había establecido la Organización Panamericana de Salud.

g) La infraestructura existente llegaba a 4.000 instituciones, entre centros y puestos de salud, y 947 hospitales con 45.800 camas, de las cuales 29.500 pertenecían a 680 hospitales públicos, sin que existiera una ocupación eficiente de las mismas, dado que el promedio de utilización ascendía al 57\%; mientras que el Instituto de Seguros Sociales poseía 36 unidades de atención con 4512 camas y un porcentaje de utilización 
de 73\%. Resultaba paradójico que el nivel más bajo de utilización se presentaba en los hospitales donde, aparentemente, las necesidades de atención parecían ser más altas, entre ellos, Tolima, Huila, Chocó, Magdalena y Caquetá, ya que la ocupación era inferior al 30\%. Mientras que los problemas asociados a necesidades de infraestructura nada tenían que ver con la falta de instalaciones, sino que eran el resultado de la manera como se administraban, manejaban, utilizaban y cuidaban los bienes muebles e inmuebles que poseían las entidades para prestar los servicios de salud.

h) Los déficit en medicamentos estaban relacionados con la estructura oligopolística de la producción y mercadeo de los mismos, aunada a las deficiencias en la prescripción, programación, adquisición y entrega de fármacos para los tratamientos ordenados por el personal médico.

El mercado de medicamentos se encuentra caracterizado por la proliferación de productos... muchos de los cuales son repeticiones costosas de los ya existentes, o son combinaciones que no reportan mayor beneficio - costo. Un análisis efectuado por el Ministerio de Salud sobre las ventas de 8 productos esenciales comparados con su demanda potencial, estimada con base en las estadísticas enfermedad y muerte, mostró que uno de ellos no existía el mercado, en contraste con otros cuyas ventas son superiores al consumo esperado (Colombia. Departamento Nacional de Planeación. DNP., 1991).

i) Las deficiencias en la gestión administrativa incidieron en las bajas coberturas, los limitados niveles de calidad de los servicios y los injustificados costos de operación.

j) La centralización del proceso administrativo en su totalidad, unido a la baja capacidad ejecutora del Ministerio de Salud y, a la falta de compromiso de las entidades territoriales. Estas falencias contribuyeron a impulsar la crisis al generar mayor inequidad en el acceso a la prestación de servicios. 
k) Las fallas en la capacidad de dirección, planificación, orientación y control del Ministerio de Salud, circunstancia que aumentó las deficiencias de las entidades del sector, las cuales se incrementaron por la falta de sistemas de información administrativo, financiero y de servicios que permitieran obtener datos para la toma de decisiones, conocer el cumplimiento de las acciones y servir de soporte al control y a la evaluación.

1) Las demoras en el estudio de los problemas de gestión y toma decisiones, unidas a la tardanza en su comunicación e implementación, circunstancias que afectaron la capacidad de respuesta y acción de los entes territoriales, los cuales, a su vez, carecían de instrumentos de gestión para la ejecución de las tareas a su cargo, tales como la administración de suministros, el mantenimiento, la generación de información, y el manejo administrativo y financiero.

m) Las deficiencias en la administración y operación institucional y en la coordinación entre las entidades sectoriales, todo lo cual estaba limitado por los efectos de un enfoque eminentemente asistencial, con múltiples barreras ante la imposibilidad de asegurar una planeación social integral, carente de claridad normativa ante la indefinición jurídica de la naturaleza de los hospitales y los múltiples regímenes de vinculación laboral con diversidad patronal, desprovisto de una política y programas de mantenimiento de las instituciones oficiales prestadoras de servicios, costoso por la falta de repuestos para la variedad de marcas de los equipos, y desproporcionado por su alto grado de centralismo y excesiva asignación de funciones.

n) La persistencia de enfermedades que podían ser prevenidas, controladas o tratadas con base en la estrategia de atención primaria en salud. El cuadro epidemiológico de la época permitía aseverar que esas enfermedades aún subsistían por 
deficiencias en materia de promoción, protección de la salud y, prevención de las patologías.

ñ) La desarticulación de los diferentes sectores, a pesar de ser mencionada como estrategia de gestión en las políticas de gobiernos precedentes.

o) La reducida cobertura en la prestación de los servicios, lánguida en el nivel de atención primaria, pues existía una predilección hacia las acciones de alta complejidad para el tratamiento de las enfermedades.

p) La descentralización y participación de las comunidades, predicada y normada desde los primeros años de la década de los ochenta, eran muy débiles, limitadas y ausentes en el conciero de la organización, gestión y operación de los servicios de salud.

La década de los noventa inició con viejas, reiteradas y bien conocidas barreras para el ejercicio del derecho de salud y el acceso a la prestación de los servicios, las cuales exigían un cambio estructural ya que, a pesar de las políticas públicas, los planes de desarrollo, los objetivos planteados y las constantes reformas institucionales, continuaban en boga (Colombia. Ministerio de Salud, 1994) y sin una real solución:

La baja universalidad reflejada en la protección limitada del sistema de seguridad social, la mínima cobertura a los integrantes de la familia de un afiliado, la falta de afiliación de la población con capacidad de pago, la dependencia de la población sin opción de acceder a las prestaciones de los servicios de salud públicos y, la imposibilidad de acceso oportuno a los servicios por parte de personas que lo requerían.

La falta de solidaridad expresada en las diferencias de las asignaciones de los recursos entre subsistemas, así como al interior de cada uno de ellos y el déficit recurrente que impedía la ampliación de la financiación para el acceso. 
La ineficiencia de los subsistemas y entidades expresada en los múltiples regímenes de seguridad social, las dicotomías atribuibles a la organización institucional vigente que impedía una adecuada asignación, administración y disposición de los recursos y, la expansión del gasto privado en detrimento de las personas pobres y en situación de miseria. 


\section{Capítulo segundo: Pluralismo Estructurado: el centro entre la intervención} absoluta y la libertad a ultranza del mercado.

Este capítulo está dirigido a determinar los atributos y componentes específicos del Sistema General de Seguridad Social en Salud.

El inicio del presente siglo muestra en materia de salud, como ya se afirmó anteriormente, la preocupación del Banco Mundial en torno a los servicios de salud para los más pobres como elemento que permite la catarsis de los sistemas de atención, al recomendar la prestación de servicios clínicos con mayor empoderamiento de las personas y una fuerte participación e incidencia, de las mismas, en las decisiones, la extensión de servicios estandarizados que generen efectos en la salud pública y, servicios comunitarios orientados a la familia que apoyen el auto cuidado (Niño Torres, 2003).

El arreglo institucional asigna al Estado la intervención, en el servicio público de Salud, para garantizar la observancia de los principios, asegurar su carácter obligatorio, desarrollar las responsabilidades de dirección, coordinación, vigilancia y control, lograr la ampliación progresiva de la cobertura, establecer la atención básica en salud, organizar los servicios de salud en forma descentralizada, evitar que los recursos se destinen a fines diferentes y, garantizar la asignación prioritaria del gasto público como parte fundamental del gasto público social.

\subsection{Los supuestos constitucionales y los elementos fundamentales del nuevo sistema} de Seguridad Social.

La constitución de 1991, determinó en los artículos 48 y 49 los fundamentos de los servicios públicos de la seguridad social y la atención en salud y el saneamiento ambiental que permitieron configurar el actual Sistema General de Seguridad Social en Salud, así: 


\section{La Seguridad social es un servicio obligatorio con miras a la realización de la}

dignidad humana y la solidaridad. La Constitución política de 1991 signa los derechos a la seguridad social y a la salud como parte de la realización de la dignidad humana, con base en la declaración de servicios públicos de carácter obligatorio determinados por los principios de eficiencia, universalidad y solidaridad propios del Estado social de derecho que inspira la Carta, cuya prestación se encuentra, bajo la responsabilidad del Estado, quien define su organización, dirección y reglamentación.

La responsabilidad del Estado, se acompaña con la definición de las competencias de la Nación, de las entidades territoriales y de los particulares en la prestación de los servicios de salud, las obligaciones sobre los aportes para el financiamiento, y el ejercicio de las funciones de inspección, vigilancia y control.

Sobre el particular, algunos autores señalan que la Carta Política expresa una tendencia a la privatización de la prestación de los servicios:

...a partir de la Constitución de 1991 el régimen de la seguridad social en salud se sitúa en medio de dos tendencias. Por una parte, la realización el Estado social de derecho fundado, entre otros principios, en la dignidad humana y la solidaridad social.... la segunda tendencia, se refiere a la liberalización y privatización de la prestación del servicio público de la salud, lo cual supone un nuevo acuerdo político y social de cooperación entre el sector público y el privado, para alcanzar las metas fijadas por el propio constituyente (Cepeda Espinosa, 2007, p. 89).

Sin embargo, es preciso aseverar que la atención en salud es desde sus inicios, en Colombia y en otros países, una combinación de acción pública con participación de los particulares en especial en la atención médico - odontológica. Así lo señala la Sentencia de la Corte Constitucional "No obstante, en términos generales, a principios 
del siglo XX la atención en salud siguió siendo un asunto de dominio privado, entre otras razones, por ser este sector el propietario de los hospitales, dispensarios, hospicios, casas de refugio y asilos" (Corte Constitucional de Colombia, 2007). Incluso, muchas de las acciones de beneficencia social, como la atención y el cuidado de personas enfermas, están indisolublemente ligadas a las actividades de organizaciones fundadas y administradas, preferencialmente, por comunidades religiosas (Organización Mundial de la Salud, 2002).

Elementos del Modelo del Sistema de Seguridad Social en Salud. El texto constitucional introduce tres elementos que condicionan cualquier modelo institucional de la prestación de servicios de salud: El primero es su organización, la cual debe ser descentralizada, por niveles de atención y con la participación de las personas y las comunidades; el segundo, es la exigencia de establecer las condiciones bajo las cuales se presta la atención básica gratuita y obligatoria para todas las personas y, el tercero, tiene que ver con la obligación que toda persona tiene con el cuidado integral de su salud y el de la comunidad a la que pertenece.

\section{Expresión de los contenidos de la Salud, en el nuevo sistema de seguridad}

social. Los contenidos de la salud como derecho y bajo la concepción de servicio público, según dictado de los artículos 48 y 49 de la Constitución Política, se expresan en la garantía de acceso a los servicios de promoción, protección y recuperación de la salud, de la cual se desprende, ente otros aspectos: la responsabilidad del Estado en la regulación, dirección, orientación, inspección, vigilancia y control del diseño, gestión y prestaciones de los servicios de salud y, la posibilidad de que los particulares participen en la organización, operación y prestación de los servicios de salud, en cuyo caso adquieren el deber de afiliar, atender y garantizar las prestaciones que se establecen en favor de quienes son atendidos en las instancias prestadoras de servicios, de 
conformidad con sus riesgos, necesidades y patologías, en lo que se conoce en la literatura económica como libertad regulada (Azuero Z., 2012).

Tal caracterización como un modelo de mercado en el que la asignación de los servicios se realiza siguiendo ciertas reglas de competencia, en su carácter de sistema se subraya el concepto de pluralismo estructurado que determina una serie de funciones, especialización y actuaciones exigidas a cada uno de los agentes en el marco de un esquema no monopólico. Para sus principales impulsores, el esquema por medio del cual se garantiza la prestación del servicio de salud, con la participación de entidades privadas de acuerdo con unas normas que lo modulen, se denominó 'pluralismo estructurado', el cual:

... intenta expresar la búsqueda de un punto medio entre los arreglos polares que tanto han dañado el funcionamiento de los sistemas de salud. 'Pluralismo' evita los extremos del monopolio en el sector público y la atomización del sector privado. 'Estructurado' evita los extremos de los procedimientos autoritarios del gobierno y la ausencia anárquica de reglas de juego transparentes para evitar o compensar las fallas del mercado (Londoño, 1997, p. 16). ${ }^{4}$

La Noción del concepto de Salud, en la Constitución del 91. La Salud como derecho, y la salud como servicio público. La Corte Constitucional sostiene que existen, al menos, dos nociones interdependientes del concepto salud: de un lado, aquella que se refiere al derecho y, de otro, el servicio público, nociones que constituyen dos facetas de una misma expresión: una se decanta en las condiciones de vida, bienestar y realización de algunos derechos asociados e interdependientes y la demanda de servicios como acción concreta del derecho y, la otra, se particulariza, en la oferta a través de la

4 Resaltado fuera del texto. 
prestación de los servicios (Corte Constitucional. Sentencia C-313 de 2014); sin embargo, el mismo Tribunal Constitucional:

Resalta que el núcleo esencial de todo derecho fundamental es el mínimo de contenido que el legislador debe respetar y que le otorga un grado de inmunidad respecto de la intervención de las autoridades públicas, generándole una protección efectiva, evitando su nulidad; así como también se tiene como aquella parte del derecho fundamental que no admite restricción, dado que en caso de hacerlo resulta impracticable o se desnaturaliza. Sin embargo, al reducirlo a su connotación prestacional, se lo anula y desnaturaliza (Corte Constitucional. Sentencia C-313 de 2014)

Las normas internacionales expresan que el derecho a la salud tiene contenidos que están más allá de las prestaciones médicas, odontológicas o, en general, de aquellas relacionadas con el tratamiento de enfermedades o la superación de estados patológicos de las personas, para trascender a las dimensiones sociales, ambientales, políticas y económicas. Por ello, el Sistema de Seguridad Social en Salud adquiere varias dimensiones: las atinentes a las condiciones objetivas y materiales y a su interacción con la demanda de servicios relacionados con otros derechos que tienen impacto sobre la calidad de vida, las relativas a los ambientes en los que se desenvuelven y gestan las relaciones en la sociedad que demandan políticas y acciones de salud pública, y, la situación de salud personal que motiva la prestación de servicios de atención médica, así como las circunstancias concretas en las que se expresan las interacciones de los individuos, los grupos y la sociedad y, su estado de bienestar objetivo.

Muchas y variadas son las expresiones relacionadas con el espectro de temas y condiciones que suponen un estado de salud 'perfecto': de un lado están los cofactores que inciden en el estado de bienestar de una persona, "como ha sido profusamente 
demostrado en el campo de las ciencias sociales, las ideas y experiencias en torno al proceso de enfermedad implican una serie de factores que superan ampliamente la mera consideración de las causas de índole biológica" (Saizar, 2008, p. 42); la elección de una vida libre y digna que contribuye a estar bien física, mental, social y espiritualmente (Corte Constitucional. Sentencia T-745 de 2013c); el disfrute efectivo de los derechos económicos, sociales y culturales (Asamblea General de las Naciones Unidas, 1966), que coadyuvan a elegir y seguir el camino de la realización de su $\operatorname{ser}^{5}$; la defensa de sus derechos que debe acompañarla como un acto de la conservación de sí misma (Ihering, 2011); la conciencia plena con la que asume sus actos y acciones, las cuales le afectan y tienen incidencia sobre el estado de salud de sus congéneres: "Sólo cuando es productivamente activa, puede una persona encontrar un sentido a su vida y, aunque así goza de la vida, no está aferrándose a ella codiciosamente" (Fromm, 1962, p. 40); el papel activo que juegan las instituciones estatales, privadas y la sociedad, en las condiciones que recrean el ambiente, así como las formas e interacciones en las que asume su rol como individuo y como persona que hace parte de la sociedad.

En consecuencia, el acceso a la salud conformado, entre otros, por un conjunto de servicios y prestaciones, tiene una primera expresión fáctica en el ejercicio de las funciones públicas que ejecutan agentes del Estado encargados del diseño, regulación, inspección, vigilancia y control y, de particulares autorizados a prestar los servicios de salud, en términos de acciones de promoción, prevención y, de ser necesario, atención diagnóstica y tratamiento de los pacientes, en el sistema que se diseña para tal fin.

5 Sobre el particular "El hombre necesitado, cargado de preocupaciones, no puede apreciar siquiera el espectáculo más hermoso" (Fromm, 1962, p. 142). 
La Salud como Derecho, y Derecho Fundamental. Criterios que permiten la fundamentación del Derecho a la Salud. La Corte Constitucional ha expuesto criterios que sirven de elementos marco de orientación en la determinación de la fundamentabilidad de un derecho:

Los derechos todos son fundamentales pues se conectan de manera directa con los valores que las y los Constituyentes quisieron elevar democráticamente a la categoría de bienes especialmente protegidos por la Constitución. Estos valores consignados en normas jurídicas con efectos vinculantes marcan las fronteras materiales más allá de las cuales no puede ir la acción estatal sin incurrir en una actuación arbitraria (Corte Constitucional. Sentencia T-016 de 2007)

Entre los elementos de fundamentabilidad se encuentran:

a) La dignidad humana.

b) La situación de indefensión de una persona frente a un presunto agresor.

c) La libertad de elección de un plan de vida.

d) La posibilidad real y efectiva de gozar de algunos bienes y servicios para desarrollar la vida personal y socialmente.

e) La necesidad de compensar los desequilibrios que condicionan el inicio y desarrollo de la vida de una persona.

Los criterios en mención, al ser examinados, dan lugar a un derecho de carácter subjetivo, el cual, como en el caso del derecho a la salud, según la extensa jurisprudencia en sede de tutela, puede considerarse fundamental cuando comprometa la vida digna o la integridad de una persona o cuando se trata de los niños, las personas de la tercera edad o sujetos de especial protección constitucional. En consecuencia, la Corte asevera que el derecho a la salud es fundamental per se, cuando expresa un valor subjetivo, derivado de la Constitución Política, el Bloque de Constitucionalidad o las 
leyes, que puede ser exigido por la persona por cuanto su carencia afecta su naturaleza o dignidad humana:

Como lo ha señalado la propia Corte Constitucional, su postura respecto a qué es un derecho fundamental “(...) ha oscilado entre la idea de que se trata de derechos subjetivos de aplicación inmediata y la esencialidad e inalienabilidad del derecho para la persona ...no existe en su jurisprudencia un consenso respecto a qué se ha de entender por derecho fundamental... será fundamental todo derecho constitucional que funcionalmente esté dirigido a lograr la dignidad humana y sea traducible en un derecho subjetivo... (Corte Constitucional. Sentencia T-760 de 2008c)

No obstante, de manera previa al citado pronunciamiento, el alto Tribunal al efectuar el examen de constitucionalidad de prestaciones de salud no previstas en el plan de beneficios, afirma que el derecho a la salud hoy es en sí mismo fundamental no solo por su conexidad con otros derechos fundamentales, dado que su fundamentabilidad deriva del principio de universalidad que informa el artículo 48 Superior, en su doble significación: respecto del sujeto en tanto comprende a todas las personas del territorio nacional, y respecto del objeto en tanto implica todos los servicios de salud en sus fases de promoción, prevención, tratamiento, recuperación y rehabilitación.

La jurisprudencia de la Corte Constitucional refleja la caracterización del derecho a la salud a través de sus fallos de constitucionalidad y las sentencias de tutela relativas al acceso a las prestaciones de los servicios. El máximo tribunal comienza por considerar tal derecho como fundamental a través de tres criterios: conexidad, subjetividad y materialidad: 
...se requiere para aceptar el carácter fundamental del derecho... que exista una conexión entre el derecho... y otros derechos fundamentales... el criterio subjetivo puede ser de orden iuspositivo explícito... o de orden interpretativo... respecto al criterio material... la prestación de salud ya reconocida por la ley o plan obligatorio de salud, adquiere el carácter de derecho fundamental autónomo (Cepeda Espinosa, 2007, pp. 95-96).

Igualmente, el Tribunal Constitucional, al considerar las limitaciones de la capacidad financiera del Estado y el Bloque de Constitucionalidad, señala que el mencionado derecho comprende el máximo nivel posible, en un proceso ascendente, que permite un acercamiento constante al ideal de su pleno ejercicio.

Los sucesivos fallos de la Corte Constitucional transitan de los tres criterios referenciados a la determinación de derecho fundamental per-se por su importancia intrínseca. La Institución señala, a título de ejemplo en la sentencia de Tutela T-573 de 2005 ((Corte Constitucional de Colombia, 2005c), que en la historia de sus decisiones sostuvo, inicialmente, que el derecho a la salud no era por sí mismo un derecho fundamental y que sería protegido mediante la acción de tutela cuando se demostrara su estrecha relación con el derecho a la vida, para ir ampliando el espectro y acabar en una decisión de cierre, la cual caracteriza el derecho a la salud como fundamental, bajo los argumentos de que sin salud es imposible una vida digna y de calidad y, por la característica que le imprime el principio de universalidad. Así se manifiesta en la Sentencia C-463 de 2008:

Del principio de universalidad en materia de salud se deriva primordialmente el entendimiento de esta Corte del derecho a la salud como un derecho fundamental, en cuanto el rasgo primordial de la fundamentabilidad de un derecho es su exigencia de universalidad, esto es, el ser un derecho predicable y 
reconocido para todas las personas sin excepción, en su calidad de seres humanos con dignidad. En virtud del entendimiento del derecho a la salud como un derecho constitucional con vocación de universalidad y por tanto de fundamentabilidad, esta Corte en su jurisprudencia, ha resaltado la importancia que adquiere la protección del derecho fundamental a la salud en el marco del estado social de derecho, en cuanto afecta directamente la calidad de vida. También, la Corte Constitucional ha sostenido que el derecho a la salud eventualmente puede adquirir el estatus de derecho fundamental autónomo, tal es el caso del derecho a la salud de los niños, de las personas de la tercera edad, o sujetos de especial protección constitucional por lo que no hay necesidad de relacionarlo con ninguno otro para que adquiera tal status, al igual que por conexidad con otros derechos fundamentales. De forma progresiva, la jurisprudencia constitucional ha reconocido del derecho a la salud su carácter de derecho fundamental considerado en sí mismo (Corte Constitucional. Sentencia C-463 de 2008a).

A partir de esta consideración la Corte señala que:

...el Estado tiene la obligación jurídica de implementar todas las medidas legislativas, administrativas, políticas y financieras para hacer efectivo en forma material y pronta el derecho a la salud de todos los habitantes del territorio nacional y respecto de la totalidad de los servicios de salud requeridos para garantizar la prevención, promoción, protección y curación de la salud, precisamente por el carácter fundamental de este derecho.” y por ello, la libertad configurativa del legislador “... está limitada y restringida por el respeto de los valores, principios y derechos de orden superior constitucional, no pudiendo traspasar dicho límites jurídicos que constituyen el presupuesto analítico - 
normativo del Estado constitucional y social de derecho.”, en especial, los principios de universalidad, y los derechos fundamentales a la salud y a la igualdad (Corte Constitucional. Sentencia C-463 de 2008a).

\section{La distinción entre el "núcleo esencial", y la "periferia" de un derecho}

fundamental. La doctrina y la jurisprudencia de los derechos discuten la necesidad de distinguir entre el "núcleo esencial" de todo derecho y su "periferia". Toda atención de un derecho debe satisfacer plenamente su núcleo esencial. La insatisfacción de todo ese núcleo constituye una violación del derecho, la que se juzga injustificada. Todo cuanto supere la atención esencial representa ganancia y optimización de la satisfacción del derecho. Su falta de atención si bien no se juzgaría como injustificada, en sí misma, representaría un quebranto de la optimización del principio, tal como el mandato exige.

La Salud como servicio público. La Salud como 'prestación'. La salud tiene, según algunos autores y la jurisprudencia, un carácter prestacional y expresa la obligación del Estado de garantizar el diagnóstico y tratamiento de las enfermedades y patologías y es la que más referencias tiene en el conjunto de estudios, análisis, políticas y jurisprudencia de la historia de la salud, al punto que se afirma que las preocupaciones por el Sistema General de Seguridad Social en Salud están directamente ligadas a la concepción de lo que es la prestación, más que al derecho mismo, y sus diferentes aristas en la efectiva materialización de su goce:

El problema de la salud en Colombia es un problema de varias facetas, pero esencialmente es un problema de la organización de la salud en este país, actualmente la cobertura de los servicios de salud es de aproximadamente un $70 \%$, cifra significativamente igual a la cobertura que tenían los servicios de salud hace 20 o 30 años (Asamblea Nacional Constituyente. Sesión Comisión Quinta. 14 de mayo de1991, p. 43) 
Sin embargo, la parte prestacional y progresiva del derecho a la salud, al constituir uno de los componentes de su disfrute, no afecta la naturaleza esencial del mismo (Corte Constitucional. Sentencia C-463 de 2008a) y, en consecuencia, obliga al Estado, y a quienes actúan en nombre de éste, a garantizar, en la mayor medida posible, los demás componentes del mismo (Asamblea General de las Naciones Unidas, 1966).

El Derecho a la salud supone garantizar, a todas las personas residentes en el país, el acceso a los denominados servicios de promoción, protección y recuperación de la salud, por lo cual el arreglo institucional que decidan las ramas del poder público competentes estará encaminado a la organización, dirección y reglamentación de su prestación efectiva a todas las personas, independientemente de su ubicación geográfica, condición económica, características personales o cualquier otro tipo de particularidad asociada al ser humano. Un conjunto de principios, reiterados por el máximo Tribunal Constitucional, acompaña la confirmación de la esencialidad del derecho:

El derecho a la salud es un derecho constitucional fundamental. La Corte lo ha protegido por tres vías. La primera ha sido estableciendo su relación de conexidad con el derecho a la vida, el derecho a la integridad personal y el derecho a la dignidad humana... la segunda ha sido reconociendo su naturaleza fundamental en contextos donde el tutelante es un sujeto de especial protección... la tercera, es afirmando en general la fundamentalidad del derecho a la salud en lo que respecta a un ámbito básico, el cual coincide con los servicios contemplados por la Constitución, el bloque de constitucionalidad, la ley y los planes obligatorios de salud, con las extensiones necesarias para proteger una vida digna (Corte Constitucional. Sentencia T-760 de 2008c). 
Los Principios que orientan el Servicio Público de Salud. La jurisprudencia se muestra de acuerdo con que la salud es un estado variable que incide sobre la vida y los años de vida saludables de las personas, la cual puede enfrentar variadas situaciones que causan afectaciones de diversa índole sobre las capacidades de los seres humanos:

La 'salud', por tanto, no es una condición de la persona que se tiene o no se tiene. Se trata de una cuestión de grado, que ha de ser valorada específicamente en cada caso. Así pues, la salud no sólo consiste en la 'ausencia de afecciones y enfermedades' en una persona... la jurisprudencia constitucional ha señalado que la salud es 'un estado completo de bienestar físico, mental y social' dentro del nivel posible de salud para una persona (Corte Constitucional. Sentencia T760 de 2008c).

La Corte Constitucional asumió la definición de la Organización Mundial de la Salud, la cual señala que la salud es un estado completo de bienestar físico, mental y social; sin embargo, también aclaró que es imposible tener una definición definitiva y pétrea, por las características de los habitantes del país, las condiciones sociales, económicas, culturales y ambientales y, los demás factores asociados que inciden sobre el estado de salud y bienestar de la persona, así como en la financiación de la garantía del derecho y la prestación de los servicios:

... todos los derechos constitucionales fundamentales - con independencia de si son civiles, políticos, económicos, sociales, culturales, de medio ambienteposeen un matiz prestacional, y por ello su implementación práctica siempre dependerá de una mayor o menor erogación presupuestaria (Corte Constitucional. Sentencia T-160 de 2011). 
En la Constitución Política del 91, y esto constituye una gran innovación, se formulan algunos principios que permiten la estructuración y el funcionamiento del sistema. Esos principios son: solidaridad, eficiencia, universalidad e irrenunciabilidad.

La Solidaridad como principio rector del Servicio Público de Salud. El principio de solidaridad, cuya esencia expresa la interacción entre las personas de diferente capacidad de pago, bien por el mecanismo del aporte obligatorio que es girado a la subcuenta de solidaridad para la afiliación al régimen subsidiado, bien porque los afiliados de mayores ingresos con su aporte absorben el costo de la atención de los afiliados de menores ingresos en el régimen contributivo, o bien por ser usuarios de las acciones de promoción, prevención o estar asignadas a programas específicos que las considera "vinculadas". En consecuencia, la solidaridad orienta, de manera particular, la ayuda económica entre las personas para garantizar la afiliación y pago de los aportes exigidos en el aseguramiento y la atención de los riesgos.

La solidaridad tiende a ser caracterizada de manera exclusiva como ayuda económica, a tal punto que las normas y la jurisprudencia han hecho referencia a la obligación que les asiste a las personas de mayores recursos de participar en el financiamiento de la atención de aquellas personas con baja capacidad de pago.

El principio de eficiencia. Otro principio reiterado es el de eficiencia, el cual hace referencia a la mejor utilización y racionalización de los recursos económicos disponibles para el financiamiento del Sistema General de Seguridad Social en Salud y, obviamente, a la obligación estatal de utilizar las cuantías disponibles para garantizar la afiliación y prestación de los servicios de salud a todos los habitantes del territorio nacional.

El principio de Universalidad. Conforme al principio de universalidad se garantiza a todas las personas, sin discriminación alguna, el acceso a los servicios de 
promoción, protección y recuperación de la salud, y así mismo se impone el deber al Estado, con participación de los particulares, de ampliar de forma progresiva su cobertura.

El principio de Irrenunciabilidad. El carácter irrenunciable del derecho a la Salud hace imprescindible que el Estado garantice los mecanismos de acceso que definen, dan contenido, carácter y esencia al derecho, entre ellos las entidades, los bienes y los servicios disponibles para que una persona pueda usarlos:

...la Corte ha sintetizado este criterio afirmando que el carácter prestacional y progresivo del derecho a la salud conlleva tres obligaciones por parte del Estado: en primer lugar, el deber del Estado de tomar todas las medidas -económicas, jurídicas y políticas- para su realización plena; en segundo lugar, el deber del Estado de garantizar unos contenidos mínimos y esenciales de prestación de servicios a una cobertura universal de los mismos y la obligación de maximizarlos en cuanto sea posible; y en tercer lugar, el nivel de protección alcanzado no se puede afectar o disminuir (Corte Constitucional. Sentencia C463 de 2008a)

Sin que esas opciones reales, como oferta concreta, se opongan a la voluntad y autonomía de la persona sobre las decisiones que tome frente a su utilización y disfrute: "la titularidad de los derechos fundamentales es irrenunciable, pero, el ejercicio de los mismos por parte del titular es expresión de su autonomía" (Corte Constitucional. Sentencia C-313 de 2014). En este sentido, la característica de irrenunciabilidad plantea una obligación: la afiliación inexcusable al Sistema General de Seguridad Social en Salud y, el pago de los aportes de conformidad con la capacidad financiera del afiliado («Ley 100 de 1993») 


\subsection{La estructura institucional del Sistema de Salud.}

El Estatuto de Salud, ya mencionado, tiene por objeto regular y establecer los mecanismos de protección para garantizar el derecho fundamental a la salud, el cual se define como autónomo e irrenunciable, cuyo contenido comprende la prestación a todas las personas de los servicios destinados a preservar, mejorar y promocionar la salud, con base en la igualdad de trato y oportunidades de acceso a las actividades de promoción, prevención, diagnóstico, tratamiento, rehabilitación y paliación de la enfermedad y, con la dirección, supervisión, organización, regulación, coordinación y control del Estado sobre el denominado servicio público esencial obligatorio de salud («Ley 1751 de $2015 »)$

\section{La Noción de "Sistema de Salud".}

La salud en el marco del Sistema de Seguridad Social se define como el conjunto de instituciones, normas y procedimientos, de que disponen la persona y la comunidad para gozar de una calidad de vida, mediante el cumplimiento progresivo de los planes y programas que el Estado y la sociedad desarrollen para proporcionar la cobertura integral de las contingencias que menoscaban la salud ${ }^{6}$; la Ley Estatutaria de Salud define el concepto de Sistema de Salud como un "conjunto articulado y armónico de principios y normas; políticas públicas; instituciones; competencias y procedimientos; facultades, obligaciones, derechos y deberes; financiamiento; controles; información y evaluación, que el Estado disponga para la garantía y materialización del derecho fundamental de la salud." (Artículo 4, Ley 1751 de 2015). Por su parte la OMS señala que:

Un sistema de salud comprende todas las organizaciones, instituciones, recursos y personas cuya finalidad primordial es mejorar la salud. Fortalecer los sistemas

6 Véase el Preámbulo de la Ley 100 de 1993. 
de salud significa abordar las limitaciones principales relacionadas con la dotación de personal y la infraestructura sanitaria, los productos de salud (como equipo y medicamentos), y la logística, el seguimiento de los progresos y la financiación eficaz del sector. Es la suma de todas las organizaciones, instituciones y recursos cuya finalidad primordial es mejorar la salud (Organización Mundial de la Salud, s. f.).

En síntesis, el sistema de salud es un conjunto relacionado y sistémico de principios y normas, políticas públicas, instituciones; competencias y procedimientos, facultades, obligaciones, derechos y deberes, financiamiento, controles, información y evaluación:

Por regla general, se reconoce cada vez más que para mantener y mejorar el grado de salud de la población del mundo, los gobiernos deben diseñar sistemas de salud sólidos y eficientes, que presten buenos servicios preventivos y curativos a las mujeres, los hombres y los niños, sin distinción alguna. La OMS ha contraído el compromiso de prestar asistencia a sus Estados Miembros en esa tarea (Organización Mundial de la Salud, s. f.)

El Sistema de Salud se expresa en el conjunto de variables, normas, relaciones e interacciones sobre las cuales se diseñan, adoptan y ejecutan los procesos, las actividades y las acciones de planeación, organización, financiamiento, administración, operación, manejo, participación, seguimiento, evaluación y control de la prestación de los servicios de salud que concretan los factores prestacionales, así como los demás componentes, que hacen efectivo el hoy derecho fundamental.

Cada una de las mencionadas competencias está asignada a una o más entidades, las cuales concretan el mundo institucional (C. Rodríguez, 2012) de la acción estatal y privada, bajo las siguientes premisas («Ley 100 de 1993»): 
1.- La dirección, orientación, regulación, control y vigilancia está a cargo del Gobierno Nacional.

2.- La afiliación al sistema es obligatoria, independientemente de la capacidad de pago, y es responsabilidad de las Entidades Promotoras de Salud, quienes, a su vez, tienen funciones de recaudo y, esencialmente, administran la prestación de los servicios. («Ley 100 de 1993», Artículo 178)

3.- Todos los afiliados y su núcleo familiar pueden acceder a los servicios y prestaciones del plan de beneficios, denominado Plan Obligatorio de Salud -POS: “Todos los afiliados al Sistema General de Seguridad Social en Salud recibirán un Plan Integral de protección de la salud, con atención preventiva, médico-quirúrgica y medicamentos esenciales...”, («Ley 100 de 1993», Artículo 156, literal c), hoy denominado Plan de Beneficios en Salud con cargo a la UPC del Sistema General de Seguridad Social en Salud (Ministerio de Salud y Protección Social, 2015b).

4.- La prestación de los servicios de salud está a cargo de particulares, a través de las Instituciones Prestadoras de Servicios de Salud («Ley 100 de 1993», Artículo 185), y del Estado, por medio de las empresas sociales del Estado («Ley 100 de 1993», Artículo 194).

5.- La administración de las cotizaciones está asignada al Fondo de Solidaridad y Garantía ${ }^{7}$, el cual debe garantizar la compensación entre personas de distintos ingresos y riesgos, asumir las acciones tendientes a lograr la plena solidaridad, cubrir riesgos catastróficos y accidentes de tránsito.

6.- La garantía de la prestación de servicios a quienes no estén amparados por el sistema es responsabilidad de las entidades territoriales, así como las competencias relacionadas con la planificación y prestación de los servicios en el respectivo territorio.

7 Sus competencias serán asumidas, una vez sea suprimido el FOSYGA, por la Entidad Administradora de los Recursos del Sistema General de Seguridad Social en Salud, creada por la Ley 1753 de 2015. 
7.- El desarrollo y gestión del conocimiento científico en salud y biomedicina, la investigación científica básica y aplicada en salud y biomedicina, la promoción de la investigación científica, la innovación y la formulación de estudios de salud pública y, la producción de insumos biológicos están a cargo del Instituto Nacional de Salud («Decreto 4109 de 2001» Departamento Administrativo de la Función Pública).

8.- Los temas asociados a la vigilancia sanitaria y al control de la calidad de los medicamentos, productos biológicos, alimentos, dispositivos y elementos médico quirúrgicos, productos naturales, de biotecnología y los que tengan impacto sobre la salud son responsabilidad del Instituto de Vigilancia de Medicamentos y Alimentos.

9.- La inspección, vigilancia y control está en cabeza de la Superintendencia de Salud, de manera desconcentrada, quien puede delegar funciones en las entidades del nivel departamental o distrital, específicamente en las dependencias responsables de salud que estén acreditadas («Ley 100 de 1993», título IV. «Ley 1438 de $2011 »$, Título VII).

El componente institucional del Sistema de Salud que estamos analizando se dirige a la conformación, desarrollo y consolidación de entidades que garanticen la afiliación, atención y prestación de servicios preventivos, de promoción y rehabilitación, en forma oportuna, pertinente, eficiente y eficaz. De esta manera, se pretende consolidar una gestión que incorpore flexible y dinámicamente los avances en el conocimiento científico y su desarrollo tecnológico, además de todos los desarrollos en materia de planeación, dirección, control y participación social.

La regla de cercanía. Un elemento particular de la estructura del Sistema de Salud, relacionada con la existencia de las entidades es la regla de cercanía, de tal manera que las personas puedan acceder fácil y oportunamente a los diagnósticos, tratamientos y cuidados que requieren; la adopción de mecanismos de coordinación 
interinstitucional; el diseño, operación, seguimiento y control de sistemas y tecnologías de la información y la comunicación y, el fortalecimiento de la autonomía territorial en la prestación de servicios públicos, con incidencia en la situación de salud de la población, así como el desarrollo y consolidación de la capacidad resolutiva de las instituciones estatales relacionadas directamente con los servicios de salud.

Otras características de la estructura institucional. La institucionalidad del Sistema General de Seguridad Social en Salud plasma el carácter y las alternativas que buscan dar respuesta a las inquietudes, necesidades y demandas en materia de salud, esencialmente motivada por tres circunstancias:

a.- El énfasis en los derechos humanos que impulsan instituciones nacionales, como la Corte Constitucional, e internacionales.

b.- Las recomendaciones de las agencias multinacionales preocupadas por el desarrollo económico y, esencialmente, por la solución de la pobreza, el desarrollo y el crecimiento, los cuales llevan a considerar a organismos multilaterales que:

La política sanitaria oficial es satisfactoria si conduce a un aumento del bienestar como consecuencia de mejores resultados en materia de salud, mayor equidad, mayor satisfacción del consumidor o menor costo total que en ausencia de medidas públicas. Por supuesto, la búsqueda de uno o más de estos objetivos no justifica por sí sola la intervención del gobierno.... Hay tres razones de carácter general por las que ello puede ser cierto: una tiene que ver con la pobreza y la distribución equitativa de la atención de salud, y las otras dos se refieren a deficiencias del mercado (Banco Mundial, 1993b, pp. 55-56).

c.- Las experiencias nacionales en la consecución de la atención de las necesidades básicas insatisfechas, así como en la búsqueda de estabilidad y aumento de los activos de los pobres (Londoño, 2001). 
Descentralización. La descentralización de las responsabilidades, en cabeza de los municipios, con un claro inicio en la década de los ochenta del siglo pasado ${ }^{8}$, tiene una expresión concreta, en el caso de salud, en las leyes 10 de 1990 y, fiscalmente, en la Ley 60 de 1993, derogada por la Ley 715 de 2001 que institucionaliza normas orgánicas en materia de recursos y competencias para las entidades territoriales y el reparto de competencias entre los municipios, los distritos, los departamento y la Nación en materia de salud.

La Ley 715 de 2001 asigna competencias a las entidades territoriales, de conformidad con las siguientes responsabilidades:

Responsabilidades de los Departamentos. Los departamentos deben dirigir, coordinar y vigilar el sector salud y el Sistema General de Seguridad Social en Salud en el territorio de su jurisdicción, de acuerdo con las normas y directrices emanadas de la autoridad nacional, por ello les compete la dirección del sector salud en el ámbito departamental; la formulación de planes, programas y proyectos para el desarrollo del sector salud y del Sistema General de Seguridad Social en Salud; la adopción, difusión, implantación, ejecución y evaluación de las normas, políticas, estrategias, planes, programas y proyectos del sector salud y del Sistema General de Seguridad Social en Salud; la prestación de asistencia técnica y asesoría a los municipios e instituciones públicas que prestan servicios de salud; la supervisión y control del recaudo, la aplicación de los recursos propios y los cedidos, específicamente para salud; la vigilancia y control del cumplimiento de las políticas y normas técnicas, científicas y administrativas expedidas por el Ministerio de Salud y Protección Social; la adopción, implementación, administración y coordinación de la operación del sistema integral de información en salud; la promoción de la participación social y la promoción del 
ejercicio pleno de los deberes y derechos de los ciudadanos en materia de salud y de seguridad social en salud; financiar los tribunales seccionales de ética médica y odontológica y vigilar la correcta utilización de los recursos; la promoción de planes, programas, estrategias y proyectos en salud para su inclusión en los planes y programas nacionales; la ejecución de las acciones inherentes a la atención en salud de las personas declaradas por vía judicial como inimputables por trastorno mental o inmadurez psicológica; la gestión de la prestación de los servicios de salud a la población pobre en lo no cubierto con subsidios a la demanda; la adopción, difusión, implantación, ejecución y evaluación de la Política de Prestación de Servicios de Salud, formulada por la Nación; la organización, dirección, coordinación y administración de la red de las Entidades del Estado; la participación en la financiación de las inversiones para la organización funcional y administrativa de la red de las entidades sociales del Estado a su cargo; el registro, vigilancia y control de los prestadores públicos y privados de servicios de salud; la preparación del plan bienal de inversiones públicas en salud; la vigilancia del cumplimiento de las normas técnicas dictadas por la Nación para la construcción de obras civiles, dotaciones básicas y mantenimiento integral de las entidades prestadoras de servicios de salud y de los centros de bienestar de anciano; la adopción, difusión, implantación y ejecución de la política de salud pública formulada por la Nación; el deber de garantizar la financiación y la prestación de los servicios de laboratorio de salud pública directamente o por contratación; la caracterización de la situación de salud en el departamento; la formulación y ejecución del Plan de Atención Básica Departamental; el monitoreo y evaluación de la ejecución de los planes y acciones en salud pública de los municipios de su jurisdicción; la dirección y control del Sistema de Vigilancia en Salud Pública; la vigilancia y control de la producción, expendio, comercialización y distribución de medicamentos; la ejecución de las 
acciones de inspección, vigilancia y control de los factores de riesgo del ambiente que afectan la salud humana, y de control de vectores y zoonosis de competencia del sector salud, y, la coordinación, supervisión y control de las acciones de salud pública que realicen las Entidades Promotoras de Salud.

Responsabilidades de los municipios. Los municipios son responsables, en el ámbito de su jurisdicción, de dirigir y coordinar el sector salud y el Sistema General de Seguridad Social en Salud, para tal efecto deben formular, ejecutar y evaluar planes, programas y proyectos en salud; gestionar el recaudo, flujo y ejecución de los recursos con destinación específica; gestionar y supervisar el acceso a la prestación de los servicios de salud de la población; impulsar mecanismos para la adecuada participación social y el ejercicio pleno de los deberes y derechos de los ciudadanos; adoptar, administrar e implementar el sistema integral de información en salud; promover planes, programas, estrategias y proyectos en salud y seguridad social en salud para su inclusión en los planes y programas departamentales y nacionales; financiar y cofinanciar la afiliación la población pobre y vulnerable y ejecutar eficientemente los recursos destinados a tal fin; identificar a la población pobre y vulnerable en su jurisdicción y seleccionar a los beneficiarios; promover en su jurisdicción la afiliación al Sistema General de Seguridad Social en Salud; adoptar, implementar y adaptar las políticas y planes en salud pública de conformidad con las disposiciones del orden nacional y departamental, así como formular, ejecutar y evaluar el Plan de Atención Básica Municipal; caracterizar la situación de salud en el municipio y propender por el mejoramiento de las condiciones determinantes; promover la coordinación, cooperación e integración funcional de los diferentes sectores para la formulación y ejecución de los planes, programas y proyectos en salud pública en su ámbito territorial; vigilar y controlar la calidad, producción, comercialización y distribución de alimentos para 
consumo humano; vigilar las condiciones ambientales que afectan la salud y el bienestar de la población generadas por ruido, tenencia de animales domésticos, basuras y olores, entre otros; vigilar en su jurisdicción, la calidad del agua para consumo humano, la recolección, transporte y disposición final de residuos sólidos, el manejo y disposición final de radiaciones ionizantes, excretas, residuos líquidos y aguas servidas y, la calidad del aire; formular y ejecutar las acciones de promoción, prevención, vigilancia y control de vectores y zoonosis; ejercer vigilancia y control sanitario sobre los factores de riesgo para la salud, y, cumplir y hacer cumplir las normas de orden sanitario.

A los Distritos les corresponde ejercer las competencias otorgadas tanto para los departamentos como para los municipios, salvo las de intermediación entre los municipios y la Nación.

La relación de las responsabilidades en salud, a cargo de las entidades territoriales, refleja muchos de los problemas institucionales vigentes, especialmente los de organización, planeación, financiamiento, infraestructura, servicios, tecnología, disponibilidad de personal del área de la salud y medicamentos que permitan garantizar la prestación de los servicios con cobertura, eficiencia, eficacia y efectividad. Esta situación es más grave en algunos territorios, y especialmente crítica en zonas marginadas, por lo que es necesario garantizar el cumplimiento de acciones estatales tendientes a diseñar e implementar la política de articulación intersectorial que, en principio, priorice la acción integrada y coordinada entre las entidades estatales que tienen presencia en las zonas marginadas, a partir de un análisis de rentabilidad social que contribuya a finar los proyectos y actividades que garanticen el ejercicio del derecho a la salud y, particularmente, como lo plantea la Ley Estatutaria, la disponibilidad de servicios de salud en los términos y condiciones del plan de beneficios. Una condición sine qua non es diagnosticar cuáles son los determinantes 
sociales de mayor incidencia en la salud y el bienestar y, decidir los proyectos que, con base en los recursos fiscales disponibles, deben ser ejecutados inmediatamente para impactar positivamente el estado de salud.

La asunción de las competencias en salud se da bajo un esquema institucional en el que brilla por su ausencia el estudio, análisis de modelos o alternativas institucionales que permitan considerar formas específicas territoriales de organización, planificación, operación, ejecución y control de las funciones a cargo de los entes territoriales y, desde el centro del Poder Político, casi siempre se definen la estructura interna, los procesos, las funciones e incluso, por vía reglamentaria, la forma de organización e intervención de las comunidades en ejercicio de su derecho a la participación comunitaria, de acuerdo con la Ley .

Componentes del Sistema de Salud, según las normas y jurisprudencia de las

\section{últimas décadas.}

La determinación de los componentes esenciales del actual Sistema General de Seguridad Social en Salud exige explicitar que el concepto de salud tiene múltiples elementos que interactúan, inciden y son consustanciales a la situación de salud de una persona, comunidad o sociedad.

El estado de salud está asociado al bienestar de la persona, al nivel de vida, la nutrición, el cobijo, el trabajo y las condiciones laborales en las que se ejerce, el vestido, el respeto de su existencia como Ser Humano, además, como bien lo expresa Giraldo (2002) de variados factores de naturaleza psicológica: “...la ansiedad, la depresión y el pánico son agentes estresantes que contaminan ahora a toda la especie humana.” (p. 7); química: "drogas psicoactivas, fármacos, alcohol, afrodisíacos, polución química” (p. 24); física: Radiaciones no ionizantes, radiaciones de frecuencia baja, vibración, calor, altura" (p. 26); biológica: "mal nutrición, malas condiciones sanitarias, infecciones, 
semen humano" (p. 27), ambiental, económica, social y política, por lo que la prestación de servicios de salud constituye apenas uno de los ámbitos en los que se puede expresar el derecho (Corte Constitucional. Sentencia C-313 de 2014); esas son las razones, entre otras, que obligan al Estado a garantizar condiciones, bienes y servicios que contribuyen a lograr lo que, en desarrollo del PIDESC, se denomina el más alto nivel posible de salud.

Del Sistema General de Seguridad Social en Salud, “en lo que guarda relación con la prestación de este servicio público esencial obligatorio, cuya ejecución debe hacerse bajo la indelegable dirección, supervisión, organización, regulación, coordinación y control del Estado" (Corte Constitucional. Sentencia C-313 de 2014), hacen parte disposiciones normativas orientadas a garantizar el pleno ejercicio del derecho y su efectivo disfrute, así como a impedir que otras personas interfieran en la realización del mismo; facilitar el acceso a todos los servicios, bienes y medicamentos $\mathrm{y}$, promover, proteger y restablecer la salud de las personas que se vean afectadas por la enfermedad (Asamblea General de las Naciones Unidas, 1966). Igualmente, las personas son responsables de su auto cuidado, así como de participar en la protección de la salud de su familia, grupo y comunidad, de las cuales hacen parte integral («Ley Estatutaria 1751 de 2015»).

\subsection{Ley 100 de 1993. EI Sistema General de Seguridad Social en Salud.}

La primera norma general relacionada con los temas prestacionales de los derechos a la seguridad social que intenta plasmar las decisiones de la Asamblea Nacional Constituyente, particularmente los mandatos de los artículos 48 y 49 de la Constitución Política, es la Ley 100 de 1993 que crea el Sistema de Seguridad Social Integral, el cual pretende garantizar los derechos irrenunciables a través de la protección de las contingencias que puedan afectar la calidad de vida y la dignidad humana de las 
personas, con base en los principios de universalidad y solidaridad, los cuales, a su vez, hacen parte del soporte argumental en el trámite, aprobación y expedición del Sistema General de Seguridad Social en Salud, por el que se definen los fundamentos, dirección, organización, funcionamiento, administración, financiamiento y obligaciones de los partícipes responsables de crear las condiciones de acceso y garantizar la prestación de los servicios de salud. La exposición de motivos de uno de los proyectos señala: “...el nuevo Sistema se fundamenta en los principios de eficiencia, universalidad y solidaridad, principios que deben informar cualquier sistema de seguridad social que se pretenda implementar" (Ramírez, 1992)

Los componentes esenciales del Sistema General de Seguridad Social en Salud están contenidos, esencialmente, en las normas constitucionales y legales, así como en la jurisprudencia que, como atrás se referencia, interpreta el contenido y alcances de las máximas normas y sus efectos sobre el cumplimiento de los fines del Estado y la garantía de los derechos humanos.

El tratamiento del tema de Salud exige, como antes se señaló, considerar su doble connotación: de un lado su calificación, en la Constitución Política, como servicio público, en conjunto con el saneamiento ambiental, el cual obliga a garantizar a todas las personas el acceso a las acciones de promoción, protección y recuperación de la salud y, de otro, por su consideración en los precedentes jurisprudenciales y la decisión del legislador («Ley estatutaria 1751 de 2015») como derecho fundamental, sin que pueda desconocerse que tal categoría le fue reconocida, en el ámbito internacional, de tiempo atrás, por cuanto:

El derecho a la salud es una garantía ampliamente reconocida en el derecho internacional de los derechos humanos, así como también, en los sistemas regionales de protección. La fundamentalidad e importancia del derecho a la 
salud dentro de los derechos humanos ha sido reconocida expresamente por el órgano competente para interpretarlo (Corte Constitucional de Colombia, Sentencia T-760 de 2008c).

La inflación normativa es, en el caso del servicio y del derecho fundamental a la salud, uno de los factores que han incidido, y aún incide, en la interpretación de los componentes del Sistema. Entre las normas expedidas, a partir de la Constitución Política de 1991, sin mencionar las relacionadas con temas fiscales (financiamiento, participaciones, etc.) es preciso destacar las siguientes:

a) Ley 972 de 2005, que adoptó medidas destinadas a mejorar la atención de la población que padece enfermedades ruinosas o catastróficas, especialmente el VIH/Sida.

b) Ley 1122 de 2007, que introdujo modificaciones al Sistema General de Seguridad Social en Salud.

c) Ley 1164 de 2007, que estableció disposiciones relacionadas con los procesos de planeación, formación, vigilancia y control del ejercicio, desempeño y ética del Talento Humano del área de la salud

d) Ley 1346 de 2009, que aprobó la "convención sobre los derechos de las personas con discapacidad".

e) Ley 1384 de 2010, establece las acciones para la atención integral del cáncer;

f) Ley 1392 de 2010, reconoce las enfermedades huérfanas como de especial interés y protección por parte del Estado.

g) Ley 1438 de 2011, que reformó el Sistema General de Seguridad Social en Salud.

h) Ley 1562 de 2012, modifica el Sistema de Riesgos Laborales.

i) Ley 1566 de 2012, expide regulaciones sobre atención integral de personas que consumen sustancias psicoactivas. 
j) Ley 1616 de 2013, que reguló temas de salud mental.

k) Ley 1626 de 2013, que garantiza la vacunación gratuita y obligatoria a la población colombiana objeto de la misma y adopta medidas integrales para la prevención del cáncer cérvico-uterino.

1) Ley Estatutaria (1751 de 2015) que reguló el derecho fundamental a la salud, y la Ley 1753 de $2015^{9}$, mediante la cual se expidió el Plan Nacional de Desarrollo 2014-2018.

De esta normativa destaca el Plan Nacional de Salud Pública ordenado por la Ley 1438 de 2011, el cual constituye un verdadero decálogo de obligaciones que impacta al Sistema General de Seguridad Salud Social en Salud y, particularmente a las entidades públicas ${ }^{10}$ y a los particulares que desempeñan funciones públicas asociadas a las dimensiones del referido plan.

La revisión de las normas, la jurisprudencia y los trabajos relacionados con el ejercicio del derecho y la prestación de servicios de salud permite aseverar que existe un marcado énfasis en la prestación de servicios, como elemento sustantivo del derecho, sobre los costos de los mismos y, esencialmente, sobre su financiamiento.

En este contexto, una vista de las normas internacionales, la Constitución Política de Colombia y la jurisprudencia, permiten señalar que existen, al menos, los siguientes componentes base en el diseño, adopción, alcances y responsabilidades del Sistema de Salud:

9 Crea una entidad y define la administración, manejo y disposición de los recursos de salud.

10 El Plan Decenal de Salud Pública 2012-2021 contempla como dimensiones prioritarias: Salud Ambiental; Vida Saludable y Condiciones no Transmisibles; Convivencia Social y Salud Mental, Seguridad Alimentaria y Nutricional; Sexualidad, Derechos Sexuales y Reproductivos; Vida Saludable y Enfermedades Transmisibles; Salud Pública en Emergencias y Desastres; Salud y Ámbito Laboral; Gestión Diferencial de Poblaciones Vulnerables y, Fortalecimiento de la Autoridad Sanitaria para la Gestión en Salud. 


\subsubsection{Estado: Rol en la garantía del derecho a la salud}

El componente primigenio de un Sistema de Salud está asociado a las obligaciones del Estado respecto de las condiciones objetivas y materiales que permiten garantizar el derecho fundamental a la salud, el cual tiene, entre sus factores constitutivos, los servicios de atención de salud y saneamiento ambiental, tal como se puede apreciar en la aseveración de la Corte Constitucional:

El crecimiento y el desarrollo del país, son fines del Estado para servir a la comunidad, creando empleo, infraestructura, fuentes de ingreso y mayores recursos que generen prosperidad y riqueza, obviamente dentro de los límites de la Constitución Ecológica y bajo la planeación y las previsiones necesarias que garanticen el empleo racional de los recursos y el respeto y la protección del medio ambiente, del paisaje, de las cuencas hídricas, de los recursos naturales y de la salud...

El énfasis de la Constitución de 1991 se materializa en un cúmulo de disposiciones que, entendidas sistemáticamente, denotan la importancia que tiene en nuestro ordenamiento jurídico el ambiente, ya sea como principio fundamental, derecho constitucional y deber constitucional (Corte Constitucional. Sentencia C-123, 2014)

Tales obligaciones nacen de las características del Estado Social de Derecho, de la potestad estatal en el ejercicio del Poder Público, de los fines que acompañan la existencia del Aparato Público y de las garantías a los derechos humanos que subyacen en la estabilidad política, el desarrollo económico integral y, por sobre todo, del respeto a la dignidad humana y al perfeccionamiento del proyecto de vida que cada persona emprende. 
El desarrollo del Sistema de Salud tiene por objeto la adopción de las políticas e instrumentos que permitan la dirección, supervisión, organización, regulación, coordinación y control de los programas, actividades y acciones de promoción, prevención, diagnóstico, tratamiento, rehabilitación y paliación de las enfermedades, a través de redes integrales de servicios que integren, cohesionen, coordinen y articulen la acción de diferentes organismos, públicos y privados, en la planeación, ejecución y atención de servicios de salud, de conformidad con los riesgos potenciales y las contingencias que sufran las personas en su bienestar, y, las tecnologías, instrumentos, infraestructura, personal disponible y capacidad de resolución de las diferentes instancias que participan en la red integral de servicios de salud («Ley Estatutaria 1751 de 2015»)

Las obligaciones del Estado tenidas en cuenta en el diseño, operación y gestión del Sistema General de Seguridad Social en Salud son: a.- El reconocimiento para que toda persona disfrute el derecho a la salud y, en consecuencia, la obligación de realizar acciones tendientes a garantizar el acceso y la prestación de servicios; b.- La prohibición de causar daño, deterioro, menoscabo o perjuicio al estado de salud de las personas. c.El diseño y la adopción de políticas y la ejecución de acciones de promoción de la salud, prevención, atención y superación de la enfermedad, en condiciones de acceso iguales y sin ningún tipo de discriminación negativa. d.- El deber de velar porque sean atendidos todos los factores, directos e indirectos, que afecten la salud humana y el bienestar de quienes ejercen el derecho. e.- La disposición de procesos e instrumentos para impedir violaciones al derecho fundamental a la salud. f.- El estudio y diagnóstico de las condiciones y factores que determinan o condicionan el estado de salud de las personas. g.- La adopción de las medidas y acciones requeridas para garantizar el financiamiento y estabilidad del Sistema, con el fin de garantizar el máximo nivel 
posible de salud. h.- La realización sistemática de evaluaciones a la gestión y a los resultados del goce del derecho, en especial a los factores que determinan el estado de salud y el acceso a los servicios. i.- El deber de velar por el acceso oportuno, pertinente y de calidad a los medicamentos, así como a las tecnologías e insumos requeridos en la prestación de los servicios y evitar que, por su carencia, se pueda afectar la salud de los pacientes. j.- El deber de ejercer las competencias de regulación, inspección, vigilancia y control de los agentes del sistema, en la perspectiva de garantizar la eficiencia, eficacia y efectividad del sistema.

\subsubsection{Principios rectores: Fines orientadores en la garantía del derecho.}

El avance en la concepción del derecho a la salud, como fundamental, se refleja en la comprensión de lo que se denomina salud y en la adopción de principios sobre las condiciones y características complejas que determinan el estado de bienestar, respeto por la dignidad humana y desarrollo del proyecto de vida de las personas. Se refleja, también, en las políticas, programas, acciones y acceso a los servicios de promoción, protección, cuidado y recuperación de la salud y, en las responsabilidades que tiene el Ser Humano consigo mismo, en términos de su autocuidado, autoprotección y autorrealización, así como frente al efecto, positivo o negativo, que sus acciones tienen con respecto a la salud, estabilidad y bienestar de su núcleo familiar, la comunidad y la sociedad.

Son principios rectores del Sistema General de Seguridad Social en Salud («Ley 100 de 1993», Artículo 153) y («Ley 1438 de 2011» Artículo 3):

a.- Universalidad, cuya razón está encaminada a que todas las personas pertenezcan al sistema y los servicios se presten a todos los habitantes del país. 
b.- Solidaridad, a través del cual se expresa la ayuda mutua en el financiamiento del sistema para lograr el acceso de todos, independientemente de su capacidad de pago.

c.- Igualdad, que se expresa en la obligación de afiliar y atender a todas las personas sin ningún tipo de discriminación.

d.- Obligatoriedad, principio que supone que todas las personas deben afiliarse al Sistema.

e.- Prevalencia de derechos, principio que está referido a la obligación de la familia, la sociedad y el Estado de cuidar, proteger y asistir a las mujeres en estado de embarazo y en edad reproductiva, a los niños, niñas y adolescentes, con el objeto de garantizar su vida, su salud, su integridad física y moral y su desarrollo armónico e integral.

f.- Enfoque diferencial, cuyo propósito es el de identificar poblaciones que requieren intervenciones particulares por razones de edad, género, raza, etnia, situación de discapacidad, así como temas de salud asociados a las víctimas de la violencia.

g.- Equidad, que expresa el acceso al plan de beneficios, de todas las personas, independientemente de la capacidad de pago y, la disminución de los riesgos asociados a la utilización ineficiente de los recursos.

h.- Calidad, principio que impone la obligación de prestar servicios que atiendan la situación de la salud de la persona conforme a la evidencia científica y de manera integral.

i.- Eficiencia, que tiene que ver con la utilización de los recursos existentes, los cuales deben maximizarse en la consecución de los mejores resultados en la prestación de los servicios. 
j.- Participación social, que permite, y exige la intervención de las personas y de las comunidades, a través de formas de asociación autónomas o iniciativa individual, en la organización, control, gestión y fiscalización de las instituciones y del sistema en conjunto.

k.- Progresividad, medida como el aumento gradual en la actualización de las prestaciones de salud incluidas en el plan de beneficios.

l.- Libre escogencia, que consiste en la autonomía para elegir la entidad promotora de salud a la que se quiere afiliar la persona y su grupo familiar, así como la institución prestadora de servicios de salud y los profesionales de la salud que los atenderán, conforme a la disponibilidad de la oferta.

ll.- Sostenibilidad, entendida como el manejo de las prestaciones en un ámbito de responsabilidad fiscal para garantizar la continuidad del Sistema.

m.- Transparencia, garantía de hacer públicas, claras y visibles las condiciones de prestación de los servicios y la relación entre los diferentes agentes del sistema.

n.- Descentralización administrativa, consiste en la asignación de competencias y autonomía a entes territoriales en el Sistema, en forma tal que garantice el principio de colaboración armónica; complementariedad y concurrencia, apoyo y soporte entre los diferentes agentes del Sistema encaminado al logro de los fines.

o.- Corresponsabilidad, que impone a las personas, el deber de velar por su autocuidado, el de su familia y el de la comunidad, en un ambiente sano y con la conciencia de hacer un uso racional de los recursos disponibles.

p.- Irrenunciabilidad, o imposibilidad de apartarse o negarse los derechos que provee el Sistema en materia de prestación de servicios. 
q.- Intersectorialidad, consiste en la coordinación entre los distintos niveles del Estado, entidades y organizaciones cuyas acciones están relacionadas con los determinantes y estado de salud de los habitantes del país.

r.- Prevención, o enfoque de precaución que se aplica a la gestión de riesgo, evaluación de procedimientos y prestación de servicios y, continuidad, entendida como la permanencia de las personas en el Sistema a fin de propender por la calidad de su vida e integridad.

A los citados principios, vale la pena agregar los siguientes, que si bien se formulan para el derecho fundamental a la salud, se enfocan a la salud como prestación de servicios. Son ellos:

s.- Disponibilidad. Se entiende como existencia de entidades, servicios, tecnologías y personal de la salud que brinda la atención requerida por una persona.

t.-Aceptabilidad. Se expresa en el respeto por la dignidad humana, el carácter y la identidad social y cultural de cada persona y su derecho a la confidencialidad, de tal manera que la relación médico - paciente se geste en el mutuo respeto y la atención consensuada de las necesidades de quien accede a los servicios.

u. Accesibilidad. Se refleja en la posibilidad real y efectiva de utilización de los servicios cuando sean necesitados y requeridos por una persona;

v.- Pro homine. Principio que se caracteriza por la interpretación más favorable a las personas en la garantía del derecho fundamental a la salud.

El conjunto de principios referenciados permite notar el reiterado intento de las autoridades estatales de responder con disposiciones legales a todas las inquietudes, necesidades, demandas y problemas asociados a la organización, gestión y operación de los servicios de salud. De esta manera se intenta plasmar, en una lista interminable, diversos temas que, desde el punto de vista de la gestión pública, tienen disposiciones 
legales previas y jurisprudencia, en algunos casos, plenamente consolidada. Por ejemplo los principios de descentralización tienen una amplia regulación que inicia en la Constitución Política, está contenida en normas anteriores y posteriores a 1991. La Corte Constitucional asevera que:

La palabra 'descentralización' se emplea en sentido genérico y en sentido técnico. De acuerdo con el primero, se le da ese nombre a todo proceso que traslada a asuntos de la capital del Estado a las entidades secciónales o locales, cualquiera que sea su índole; así se habla de descentralización fiscal, económica o industrial. En sentido técnico jurídico, la descentralización significa traslado de competencias de carácter administrativo a manos de autoridades regionales o locales (Corte Constitucional. Sentencia C-497, 1994b)

En materia de principios la Ley Estatutaria hace énfasis en aquellos asociados a la prestación de servicios $\mathrm{y}$, respecto de la naturaleza y contenido del derecho fundamental a la salud. Ella señala que comprende el acceso a los servicios de salud de manera oportuna, eficaz y con calidad para la preservación, mejoramiento y promoción de la salud; sin embargo, el Estatuto de Salud que está encaminado a la prestación de los servicios de salud, introduce, un artículo completo para prohibir la negación de los servicios, especialmente los relacionados con la atención de urgencias ${ }^{11}$, disposición que deja entrever la poca efectividad institucional, de los órganos de control del Sistema General de Seguridad Social, en el ejercicio de control y vigilancia y, la superación de problemas administrativos y burocráticos, y su poca eficacia a la hora de motivar o generar estímulos necesarios para que las instituciones prestadoras brinden atención, especialmente cuando se trata de un riesgo vital.

11 La obligación del acceso inmediato a la atención inicial de urgencias es una obligación que data, al menos, desde 1990, ya que el artículo 2 de la Ley 10 de ese año, al refrirse a la asistencia pública en salud, determina que todas las instituciones o entidades que prestan servicios de salud están obligadas a prestar la atención inicial de urgencias, independientemente de la capacidad socioeconómica de los pacientes. 


\subsubsection{Distribución de competencias y alcances del arreglo institucional.}

De dirección, Vigilancia y Control. Las entidades responsables de la dirección, vigilancia y control del Sistema de Seguridad Social en Salud son los Ministerios de Trabajo y, Salud y Protección Social, órgano rector del sistema; la Superintendencia Nacional de Salud y el Consejo Nacional de Seguridad Social en Salud ${ }^{12}$.

De administración y financiación. Las instancias responsables de la administración y financiación son las direcciones seccionales, distritales y locales de salud; las Entidades Promotoras de Salud y el Fondo de Solidaridad y garantía.

De prestación de los Servicios. La prestación de servicios está a cargo de las Instituciones Prestadoras de Servicios de Salud y las empresas sociales del Estado.

Otros agentes del sistema. Además hacen parte del Sistema los empleadores, los trabajadores (dependientes e independientes), los pensionados, los beneficiarios, los Comités de Participación Comunitaria ${ }^{13} \mathrm{y}$, las entidades adscritas a los ministerios de Salud y Protección Social y Trabajo.

Distribución de funciones. La organización del Sistema supone la distribución descentralizada de funciones por niveles de atención, teniendo en cuenta las competencias relacionadas con regulación, formulación y adopción de políticas, planes generales, programas y proyectos, prestación de servicios, inspección, vigilancia y control.

Rectoría del Sistema. La Ley 100 de 1993 creó una institucionalidad cuya base es la especialización y distribución de competencias que tienden a repartir el poder entre varios agentes, públicos y privados, a través de los cuales busca garantizar la afiliación universal de todas las personas habitantes del territorio colombiano, con base en la libre

12 Las competencias del Consejo Nacional de Seguridad Social en Salud fueron modificadas por la Ley 1122 de 2007 como resultado de la creación de la Comisión de Regulación en Salud, la cual, a su vez, fue suprimida por el Decreto 2560 de 2012. En consecuencia las funciones pasaron al Ministerio de Salud.

13 Creados a partir de la Ley 10 de 1990 
elección del asegurador y prestador; financiar la demanda de los servicios de salud, independientemente de la capacidad de pago de las personas, por medio de los principios de equidad, solidaridad y eficiencia; articular y coordinar las acciones de las entidades a través de instancias plurales de decisión en las que están representados todos los actores del Sistema General de Seguridad Social en Salud y, fortalecer los mecanismos de seguimiento, evaluación y control por vía de la Superintendencia Nacional de Salud, la delegación de funciones de vigilancia a las entidades territoriales y el control de los afiliados y beneficiarios sobre la prestación de servicios.

La asignación de la dirección y control a las entidades de la Administración Pública Nacional del nivel central, los ministerios de Salud y Trabajo, el primero como rector del Sector Salud, a quien le compete en el Sistema General de Seguridad Social en Salud formular y adoptar, en coordinación con el Ministerio de Trabajo, las políticas, estrategias, programas y proyectos para el SGSSS, de acuerdo con los planes y programas de desarrollo económico, social y ambiental aprobados por Congreso de la República, muestran que existen las competencias y la instancia estatal clave para ejercer las funciones estratégicas de orientación, dirección y control, en una perspectiva que permite un sistema de participación más abierto, promueve la descentralización, aumenta la competencia y hace más visibles las reglas de juego a través de la interacción de agentes con roles específicos (Londoño, 1997).

El papel del Ministerio de Salud se expresa en las atribuciones específicas que le otorga la disposición referenciada, al ser el responsable de dictar las normas científicas que regulan la calidad de los servicios y el control de los factores de riesgo, de obligatorio cumplimiento para las Entidades Promotoras de Salud, las Instituciones Prestadoras de Servicios de Salud, las direcciones departamentales, distritales y locales de salud y las Empresas Sociales del Estado. 
La responsabilidad de expedir normas administrativas de obligatorio cumplimiento para las citadas entidades, muestran que el Ministerio de Salud tiene la capacidad regulatoria para motivar la eficiente gestión a través de reglas claras, específicas y transparentes que creen modelos, procesos y procedimientos para garantizar el acceso efectivo al derecho a la salud y los elementos básicos de su funcionamiento: prestaciones, tarifas, unidad de pago por capitación, pagos moderadores, requisitos de operación de los actores y, en general, las reglas a través de las cuales se preserva dicha garantía dentro de un modelo no monopólico y de libre escogencia.

Inspección, vigilancia y control del sistema. Estas funciones están a cargo de la Superintendencia Nacional de Salud. La Superintendencia Nacional de Salud es responsable $^{14}$ de autorizar como Entidades Promotoras de Salud a entidades de naturaleza pública, privada o mixta; verificar la conformidad de la prestación del Plan Obligatorio de Salud por cada entidad promotora; verificar que en el régimen contributivo el valor de la unidad de pago por capitación se dé únicamente para aquellos afiliados que hayan pagado íntegra y oportunamente la cotización mensual; imponer sanciones por violación de los empleadores a sus deberes, la discriminación de la atención a los usuarios y la no atención inicial de urgencias a cargo de las Instituciones Prestadoras de Servicios de Salud, incumplimiento de las Entidades Promotoras de Salud a sus responsabilidades, entre ellas la violación de régimen de prohibiciones: “terminar unilateralmente la relación contractual con sus afiliados o negar la afiliación de quien desee ingresar al Sistema General de Seguridad Social en Salud, salvo los casos exceptuados en la disposiciones legales” («Decreto 1485 de 1994»). El retardo o no giro de las cotizaciones que recauden y la carencia de información de costos,

14 La Ley 100 de 1993 le asigna otras competencias en los artículos 162, 164, 180, 205, 208, 220, 225, 226, 230, 233 у 271. 
facturación y publicidad y, la violación a las normas del Sistema Obligatorio de Garantía de Calidad y, ejercer las funciones de inspección, vigilancia y control de las Entidades Promotoras de Salud. Igualmente, debe resolver administrativamente las diferencias que en materia de preexistencias se presenten en el Sector Salud.

\section{La afiliación al sistema, la captación de los aportes y la administración de los} servicios de salud. Estas Funciones se establecieron a cargo de la Entidades Promotoras de Salud. Ellas son las responsables de captar los aportes de los afiliados al Sistema General de Seguridad Social en Salud; de promover la afiliación de grupos de población no cubiertos; de organizar la forma y mecanismos a través de los cuales los afiliados y sus familias pueden acceder a los servicios de salud en todo el territorio nacional; de aceptar a toda persona que solicite afiliación y cumpla con los requisitos de ley; de definir procedimientos para garantizar el libre acceso de los afiliados y sus familias, a las instituciones prestadoras con las cuales haya establecido convenios o contratos en su área de influencia o en cualquier lugar del territorio nacional, en caso de enfermedad del afiliado y su familia; de remitir al fondo de solidaridad y garantía la información relativa a la afiliación del trabajador y su familia, a las novedades laborales, a los recaudos por cotizaciones y a los desembolsos por el pago de la prestación de servicios y, establecer procedimientos para controlar la atención integral, eficiente, oportuna y de calidad en los servicios prestados por las Instituciones Prestadoras de Servicios de Salud.

Prestación de los servicios de salud. La prestación de los servicios de salud fue asignada a dos tipos de entidades, las de carácter público, denominadas Empresas Sociales del Estado y, las privadas, llamadas Instituciones Prestadoras de Servicios de Salud, las cuales están obligadas a garantizar la calidad de la prestación de los diferentes tipos de servicios, lograr niveles de eficiencia competitivos, y tener autonomía 
administrativa, técnica y financiera. Además, estas entidades están obligadas a: propender por la libre concurrencia en sus acciones; proveer información oportuna, suficiente y veraz a los usuarios; evitar el abuso de posición dominante; oponerse a todo tipo de acuerdo o convenio cuyo objetivo sea impedir, restringir o falsear el juego de la libre competencia, así como impedir, restringir o interrumpir la prestación de los servicios de salud; acreditar un sistema contable que permita registrar los costos de los servicios ofrecidos; solicitar la acreditación de los servicios de salud ante la autoridad competente; destinar recursos mínimos a las actividades de mantenimiento de infraestructura y dotación hospitalaria; premiar y dar incentivos a la eficiencia laboral de médicos, profesionales y trabajadores, basándose en el rendimiento individual, grupal o de la institución; e implementar sistemas de contratación por capitación.

\subsubsection{Un interés del agenciamiento: El financiamiento.}

Es el componente que permite a la institucionalidad estatal diseñar, adoptar, dirigir y controlar un sistema que financie el mayor nivel de prestación de servicios con los recursos disponibles, respecto de las prestaciones reconocidas nacional o internacionalmente, así como la extensión de los beneficios a todas las personas y, la operación del sistema en términos de la responsabilidad en la aplicación de los principios de eficiencia y equidad.

Los recursos que financian el Sistema General de Seguridad Social en Salud son de naturaleza fiscal y parafiscal y se encuentran destinados a la prestación de los servicios contenidos en el plan de beneficios incluidas las actividades de promoción de la salud y de prevención de la enfermedad, al cubrimiento de las prestaciones económicas para los afiliados al régimen contributivo, y a la atención en accidentes de tránsito y eventos catastróficos. 
La prestación de los servicios contenidos en el plan de beneficios del régimen contributivo se financia con los recursos que reconoce el Sistema (subcuenta de compensación del FOSYGA) a las entidades promotoras de salud por concepto de la Unidad de Pago por Capitación - UPC - y las cuotas moderadoras y copagos a cargo de los afiliados; recursos de carácter parafiscal, cuyo naturaleza ha sido ampliamente reconocida por la Corte Constitucional (Corte Constitucional Sentencia SU-480, 1997b); (Corte Constitucional. Sentencia C-828, 2001); (Corte Constitucional. Sentencia C-1040, 2003b); (Corte Constitucional. Sentencia C-542, 1998b) y (Corte Constitucional. Sentencia C-710, 2005a).

La prestación de los servicios contenidos en el plan de beneficios en el régimen subsidiado se financia con los recursos del Sistema General de Participaciones en el componente de subsidios a la demanda, los recursos de la subcuenta de solidaridad del Fondo de Solidaridad y Garantía - FOSYGA, y demás recursos de las entidades territoriales (rentas cedidas, provenientes de la explotación de juegos de suerte y azar, regalías y demás recursos propios) que destinen para el pago a las entidades promotoras de salud del régimen subsidiado contratadas, del valor de la Unidad de Pago por Capitación Subsidiada. En las prestaciones no previstas en el plan de beneficios y a cargo de las Entidades Territoriales, se financia con los recursos de la participación de prestación de servicios de salud del Sistema General de Participaciones.

La atención de las víctimas de eventos catastróficos y accidentes de tránsito y las prestaciones económicas que de dichos riesgos pudieran derivarse se financian con los recursos de la subcuenta de seguro de riesgos catastróficos y accidentes de tránsito del FOSYGA proveniente de las primas del SOAT de orden parafiscal.

Como se evidencia, los recursos que financian las prestaciones que reconoce el Sistema General de Seguridad Social en Salud son fiscales y parafiscales, con una 
diversidad de fuentes destinados a sufragarlas y una diversidad de instancias encargadas de su gestión, administración, control y prestación: Fondo de Solidaridad y Garantía, Unidad Adinistrativa Especial de Gestión Pensional y Contribuciones Parafiscales, Departamentos y Municipios, Entidades Promotoras de Salud, Instituciones Prestadoras de Servicios de Salud y usuarios, entre otros.

\section{Recursos para la atención de los factores que determinan la aparición de la}

enfermedad. La Ley Estatutaria define como copartícipes de la situación en salud a aquellos factores que determinan la aparición de la enfermedad y establece que el financiamiento para su prevención, superación o mitigación, se hace con recursos diferentes a los utilizados en servicios y tecnologías de salud. De tales afirmaciones se coligen dos elementos: el primero que la disposición infiere una relación de causalidad para establecer cuáles son los determinantes, lo que, prima facie, obliga a las instituciones estatales a conocer cuáles de las funciones a su cargo están relacionadas con componentes que afectan la salud y, en consecuencia, actuar para evitar la generación de enfermedades y, segundo, el financiamiento de tales acciones corre por fuentes diferentes a las existentes en el Sistema General de Seguridad Social en Salud. Estas disposiciones crean, al nivel decisorio del Sistema de Salud, la obligación de coordinar y articular el estudio y solución de conflictos que surjan por efecto de contradicción entre actores estatales, y cruces incoherentes o intereses contrapuestos, ya que más allá de la separación institucional, se requiere la priorización de políticas, programas, proyectos y acciones que contribuyan a la realización efectiva del derecho fundamental, sin que ello suponga o exija la actuación estatal en todas y cada una de las variables, internas o externas, que condicionan el estado de salud de las personas. En este caso, como en la solución de los conflictos entre derechos, el desarrollo del sistema podrá utilizar principios como el de proporcionalidad que ha institucionalizado el 
máximo Tribunal Constitucional, como mecanismo de estudio, análisis y decisión en torno a los inevitables choques u oposiciones que surgen en las disposiciones legales frente al respeto y realización de los derechos o, recurrir a diferentes instrumentos legales que permiten priorizar el gasto a partir de los planes de desarrollo, las reglas fiscales, los intereses y participación de las comunidades y, de acuerdo con el mayor impacto posible que se espere de una política o acción específica.

\subsubsection{Agentes responsables de la gestión, administración y control de los recursos.}

El Fondo de Solidaridad y Garantía. FOSYGA. La política de especialización del manejo de los recursos del Sistema General de Seguridad Social, se ha separado del manejo directo del Ministerio de Salud a través del Fondo de Solidaridad y Garantía, medida que permite a su vez concentrar la administración, disposición y oportunidad de la planeación, programación, ordenación y giro de varias fuentes de financiamiento.

El Fondo de Salvamento y Garantías para el Sector Salud- FONSAET. Es un fondo cuenta administrado por el Ministerio de Salud y Protección Social, que tiene por objeto asegurar el pago de las obligaciones que no fuere posible cancelar por parte de las Empresas Sociales del Estado - ESE -, intervenidas por la Superintendencia Nacional de Salud o liquidadas, así como aquéllas que se encuentren en riesgo alto o medio según la categorización del mismo o las que adopten programas de saneamiento fiscal y financiero con el acompañamiento de la Nación y que se encuentra financiado con los siguientes recursos: hasta el $10 \%$ de los recursos que se transfieren para oferta del Sistema General de Participaciones para Salud y los excedentes de los recursos destinados para salud de la Ley 1393 de 2010 que sean recaudados por la Nación.

\section{Unidad Administrativa Especial de Gestión Pensional y Contribuciones}

Parafiscales. Es una Unidad Administrativa Especial del orden nacional, con personería jurídica, autonomía administrativa y patrimonio independiente adscrita al Ministerio de 
Hacienda y Crédito Público. Es la entidad responsable de adelantar, de manera preferente, las tareas de seguimiento, control y determinación de la adecuada liquidación y pago de las contribuciones parafiscales de la Protección Social a cargo de los empleadores o de las personas que por su capacidad de pago se encuentran obligadas a cotizar.

Entidad Administradora de recursos del Sistema General de Salud. Es ésta una entidad creada por Ley 1753 de 2015, con una junta directiva presidida por el Ministro de Salud de la cual hacen parte el Ministro de Hacienda y Crédito Público o uno de sus viceministros, el Director del Departamento Nacional de Planeación o uno de los subdirectores generales, un representante de los gobernadores y un representante de los alcaldes de los distritos y municipios, asimilada a empresa industrial y comercial del Estado («Ley 1753 de 2015» Artículo 66) ${ }^{15}$, vinculada al Ministerio de Salud y Protección Social responsable del manejo unificado de los recursos del Sistema General de Seguridad Social en Salud, cuyas condiciones legales son las de poder hacer unidad de caja con todos los recursos, excepción de los que son de propiedad de las entidades territoriales, los cuales mantienen su condición de destinación específica.

La misión de esta entidad es administrar los recursos de las subcuentas que pertenecen al Fondo de Solidaridad y Garantía, los del Fondo de Salvamento y Garantías para el Sector Salud, los destinados a financiar el aseguramiento en salud, los copagos que se paguen por prestaciones no incluidas en el plan de beneficios del Régimen Contributivo, los recursos que se obtengan como resultado de la acción de la Unidad Administrativa Especial de Gestión Pensional y Contribuciones Parafiscales.

El cumplimiento del objeto social de la mencionada empresa se da con base en las funciones de administrar los recursos; reconocer y pagar las Unidades de Pago por

15 La empresa cuenta, obviamente, con personería jurídica, autonomía administrativa y financiera y, patrimonio independiente. 
Capitación y demás obligaciones del aseguramiento en salud; pago de las indemnizaciones por muerte o incapacidad permanente y auxilio funerario a víctimas de eventos terroristas o eventos catastróficos, así como los gastos derivados de la atención psicosocial de las víctimas del conflicto; el pago de los gastos derivados de la atención en salud inicial a las víctimas de eventos terroristas y eventos catastróficos; el pago de los gastos financiados con recursos del impuesto social a las armas y de municiones y explosivos; efectuar pagos y giros directos a los prestadores de servicios y proveedores de tecnologías en salud, y ordenar las transferencias que correspondan a los diferentes agentes del Sistema; realizar las verificaciones necesarias a fin de reconocer y pagar las obligaciones y, promover la eficiencia en la gestión de los recursos; procurar que las instituciones del sector salud tengan medios para otorgar la liquidez necesaria para dar continuidad a la prestación de servicios de salud; servir de instrumento para el fortalecimiento patrimonial de aseguradores y prestadores de servicios de salud y de garantía para el acceso a crédito y otras formas de financiamiento; participar transitoriamente en el capital de los aseguradores y prestadores de servicios de salud; apoyar financieramente los procesos de intervención, liquidación y de reorganización de aseguradores y prestadores de servicios de salud; adelantar la compra de cartera reconocida de Instituciones Prestadoras de Servicios de Salud con Entidades Promotoras de Salud y, recuperar la cartera a través de descuentos de los recursos que a cualquier título gire a las EPS y, administrar la información de sus operaciones.

\subsubsection{Una meta de interés de los agentes: La Cobertura.}

Este componente del Sistema de Salud, supone, el diseño, adopción y control de acciones de prevención y tratamiento de enfermedades endémicas, laborales y de otro tipo; la discriminación positiva para cubrir necesidades, en materia de salud, de los grupos de más alto riesgo o que, por sus condiciones económicas y sociales, son los de 
mayor vulnerabilidad, y, la promoción de medios de vida saludables, entornos propicios, independencia y participación de las personas en todos los aspectos de la sociedad relacionados con su bienestar y proyecto de vida.

El Estatuto de Salud sostiene que el sistema garantiza el derecho fundamental a la salud a través de la prestación de servicios y tecnologías, salvo, entre otros, en los casos que no exista evidencia científica sobre su seguridad, eficacia y efectividad clínica o estén en fase de experimentación. Estas disposiciones generan importantes inquietudes sobre lo que puede considerarse evidencia científica, en el campo de la salud y el bienestar humanos, entre otras razones por la autorización legal («Ley 1164 de 2007»), del ejercicio de medicinas y terapias alternativas complementarias (medicinas Tradicional China, Ayurveda, Naturopática y Homeopática), las discusiones entre investigadores en relación con las causas de las patologías no transmisibles (cáncer, enfermedades cardiovasculares, padecimientos respiratorios y diabetes). Sobre el particular Mukherjee (2011) asevera:

Dos polémicas recientes han puesto bajo una intensa luz esos puntos ciegos de la epidemiología. En 2000, el llamado Estudio del Millón de Mujeres del Reino Unido mostró que el estrógeno y la progesterona, recetados a las mujeres como parte del tratamiento de reemplazo hormonal para aliviar los síntomas de la menopausia, eran importantes factores de riego en la incidencia y el carácter mortal del cáncer de mama estrógeno positivo ${ }^{15}$. Científicamente hablando, esto es perturbador...Un enfoque más integrado de la prevención del cáncer, que incorporara las ideas previas de la biología de esta enfermedad, podría haber previsto esta actividad inductora del cáncer, disipado la necesidad de un estudio de asociación de un millón de personas y salvado potencialmente la vida de miles de mujeres (p. 559). 
Así mismo, los enfrentamientos sobre la validez de la hipótesis de la causalidad única de enfermedades a las cuales se les asigna una exclusiva factura viral (verbigracia, el SIDA):

Hoy en día, los científicos favorecen la teoría de un solo agente en lugar de una vista más amplia de la enfermedad... Además, este método aleja a la ciencia del estudio de las condiciones ambientales y los estilos de vida. En otras palabras, la aleja de las complejidades del mundo (Regush, 2003, pp. 44-46)

En el mismo sentido, las recientes inquietudes de miembros de la Academia Nacional de Medicina de Colombia sobre la efectividad de algunas vacunas y, esencialmente, sobre su inocuidad:

La Comisión de Salud de la Academia Nacional de Medicina -institución médica que estudia los principales problemas de salud del país- envió una carta al ministro de Salud, Alejandro Gaviria, solicitándole un cambio en los actuales protocolos para la aplicación de la vacuna contra el VPH. Las razones de la Comisión se fundamentan, según dicen, en información recopilada sobre la aplicación de la inyección y el agravamiento de diversas enfermedades autoinmunes (Semana, 2016a).

\subsection{Medicamentos}

El campo de la evidencia científica, en el caso de la medicina alopática, está plantado con innumerables interrogantes, controversias y limitaciones que van desde las razones por las que aparece la enfermedad, transita por las obligaciones metodológicas de probar la existencia de una causa, continua por el inhóspito camino de "aislar" el agente, prosigue con la búsqueda de tratamientos y tecnologías que eliminen la causa, se extiende por las pruebas de laboratorio en conejillos de indias, marcha por las aprobaciones de patentes y se encamina a diagnosticar y tratar al paciente con los 
medicamentos y tecnologías "científicos", sin la certeza de la cura, entre otras razones porque los mismos medicamentos, generalmente, tienen efectos que pueden generar mayores desequilibrios en el sistema inmunológico, aumentar las enfermedades y causar la muerte. Una de las mayores ironías de los tratamientos se aloja en las clínicas, cuya asepsia, aunada a la toma indiscriminada de antibióticos, conduce, al parecer, a una de las mayores causas de muerte intrahospitalaria: las bacterias resistentes a los antibióticos:

Como un ejemplo, la tasa de mortalidad para los pacientes con infecciones graves causadas por bacterias comunes tratados en hospitales puede ser aproximadamente el doble de la de los pacientes con infecciones causadas por las mismas bacterias no resistentes. Por ejemplo, las personas con MRSA (resistente a la meticilina Staphylococcusaureus, otra fuente común de infecciones graves en la comunidad y en los hospitales) se estiman en $64 \%$ más de probabilidades de morir que las personas con una forma no resistente de la infección (Organización Mundial de la Salud. Sala de Prensa, 2016).

En un campo tan controversial como el de la salud humana, además de la denominada "transición epidemiológica" del país, pretender que la solución de conflictos, por diagnósticos y alternativas terapéuticas generadas a partir de la atención, se resuelve administrativamente a través de juntas médicas de la red prestadores de servicios de salud plantea una serie de contradicciones, independientemente de los criterios de razonabilidad científica con los que actúe la mencionada instancia, en el modelo de salud. Las disposiciones legales («Decreto 1416 de 1990»); («Ley 100 de 1993»); («Ley 1438 de 2011») y («Ley 1562 de 2012»), plantean de tiempo atrás varios enfoques de atención orientados al conocimiento actualizado de la situación de salud de una persona, su familia y su comunidad, entre ellos la Atención Primaria en Salud, 
Salud Familiar y Comunitaria, Articulación de las Actividades Individuales y Colectivas, Enfoque Poblacional y Diferencial, Análisis de Determinantes Sociales de Salud, Evaluación Tecnológica, Fortalecimiento de la Prevención de Riesgos Laborales, Sistemas de Garantía de Calidad en Salud y Salud Ocupacional y Riesgos Laborales;

\subsection{La perspectiva de la concertación y la participación}

Este componente supone que todos los integrantes de la sociedad (personas, profesionales de las ciencias y tecnologías de la salud, familias, comunidades locales, organizaciones intergubernamentales y no gubernamentales, organizaciones de la sociedad civil y empresa privada) son responsables de la realización del derecho a la salud. Las relaciones de la participación están asociadas, en el campo de la salud, al derecho - deber, individual y colectivo, en los que concurren las personas para conocer los riesgos sobre el estado de su salud, las acciones de cuidado, promoción, protección y preservación de la salud, así como los mecanismos institucionales y procedimentales para diagnosticar y superar las situaciones patológicas a las que se ven abocadas.

Consejo Nacional de Seguridad Social en Salud. La creación de una instancia de concertación de todos los agentes del sistema, cuyas decisiones son de obligatorio cumplimiento, denominada Consejo Nacional de Seguridad Social en Salud ${ }^{16}$, fue uno de los elementos importantes en la interacción, análisis, discusión y toma de decisiones relacionada con temas esenciales al Sistema de Seguridad Social en Salud, en la primera fase de desarrollo y consolidación de los mandatos de la Ley 100 de 1993, entre ellos los relativos a la definición del Plan Obligatorio de Salud, el monto de la cotización de los afiliados, el valor de la unidad de pago por capitación, el costo por beneficiario del

16 Conformado, según el artículo 171 de la Ley 100 de 1993, por el Ministro de Salud, quien lo preside, los Ministros de Trabajo y Hacienda o sus delegados, sendos representantes de las entidades departamentales y municipales de salud, dos representantes de los empleadores, dos representantes de los trabajadores, el representante del extinto Instituto de Seguros Sociales, un representante de las Empresas Promotoras de Salud, un representante de las Instituciones Prestadoras de Servicios de Salud, un representante de los profesionales del área de la salud y un representante de los usuarios de los servicios de salud del sector rural. 
régimen de subsidios en salud, los medicamentos esenciales y genéricos que hacían parte del Plan Obligatorio de Salud, los criterios generales de selección de los beneficiarios del régimen subsidiado de salud por parte de las entidades territoriales, el régimen de pagos compartidos, el régimen que debían aplicar las Entidades Promotoras de Salud en el reconocimiento y pago de incapacidades originadas en enfermedad general y licencias de maternidad, así como las medidas para evitar la selección adversa de usuarios, por parte de las Entidades Promotoras de Salud, y la distribución inequitativa de los costos de atención de los distintos tipos de riesgo.

La intervención de los diferentes agentes en la concertación contemplaba aspectos de política, en los cuales se podía recomendar el régimen y los criterios para establecer las tarifas de los servicios prestados por las entidades hospitalarias en los casos de riesgo catastrófico, accidentes de tránsito y atención inicial de urgencias, así como su atribución de reglamentar los Consejos Territoriales de Seguridad Social en Salud y, ejercer las funciones del Consejo de Administración del Fondo de Solidaridad y Garantía, tales atribuciones son una concreta manifestación de la efectiva interacción de diferentes intereses, gubernamentales, privados y sociales que pueden perfectamente estudiar, analizar y tomar decisiones sobre los aspectos de regulación de mayor incidencia en el cumplimiento del Derecho Fundamental a la Salud, específicamente en su fase prestacional.

La Comisión de Regulación en Salud. El máximo escenario institucional de discusión, estudio y concertación de las decisiones claves del Sistema General de Seguridad Social en Salud pierde, por decisión legal («Ley 1122 de 2007»), sus funciones, obviamente su papel en el Sistema, al ser creada la Comisión de Regulación en Salud, conformada por los Ministros de Protección Social, - creado en el año 2002 («Ley 790 de 2002») («Decreto 205 de 2003») por la fusión de los Ministerios de Salud 
y de Trabajo y Seguridad Social y, escindido en el año 2011 como Ministerio de Salud y Protección Social («Ley 1444 de 2011») y («Decreto 4147 de 2011») - y el Ministerio de Hacienda y Crédito Público y cinco comisionados expertos, con el objeto de resolver problemas de administración, gestión, eficiencia y eficacia del Sistema General de Seguridad Social, entre los que sobresalen la fragmentación institucional, por efectos de incentivos que tomaron fuerza para que algunos agentes del sistema se convirtieran en capturadores de rentas ${ }^{17}$, las restricciones y barreras al flujo de recursos que inciden en la estabilidad financiera de los prestadores de servicios y el personal de la salud, puede generar una crisis sistémica, el incremento de los costos por aumento en la atención de alta complejidad, dadas las bajas acciones en promoción y prevención, la concentración del aseguramiento en el manejo financiero en detrimento de la gestión del riesgo, y los impedimentos y restricciones impuestos por aseguradores y prestadores al acceso a los servicios.

A los problemas señalados se responde con una concentración del estudio, análisis y decisiones sobre los temas clave del sistema, vale decir que los representantes del Estado serán los responsables de fijar los Planes Obligatorios de Salud, determinar el listado de medicamentos esenciales y genéricos, señalar el valor de la Unidad de Pago por Capitación, definir los criterios para establecer los pagos moderadores, precisar el régimen que aplican las Entidades Promotoras de Salud para el reconocimiento y pago de las incapacidades originadas en enfermedad general o licencias de maternidad y, establecer y actualizar un sistema de tarifas y, como corolario, el Decreto 2560 de 2012 termina cualquier pluralidad en el ejercicio de las mencionadas competencias, al

17 Investigación especial merece el papel de congresistas, diputados, concejales y autoridades territoriales en la captura de las Direcciones Territoriales de Salud, las Aseguradores Públicas Territoriales y las Empresas Sociales del Estado como fortines financieros, politiqueros y de control social sobre las personas más pobres pertenecientes al Régimen Subsidiado. Así como el papel del paramilitarismo en el control de las instituciones de salud, preferencialmente territoriales. Este elemento jamás se contempla en los análisis, argumentos y exposiciones de proyectos normativos. 
suprimir la Comisión de Regulación en Salud ${ }^{18}$ y, trasladar las funciones al Ministerio de Salud y Protección Social.

La persona, grupo, comunidad o integrantes de la sociedad colombiana constituyen los sujetos dinámicos del Sistema General de Seguridad Social en Salud y, a ellos, les corresponden unos derechos y unos deberes. Sobre los primeros, todos los derechos establecidos en la Ley Estatutaria están asociados a la relación de la persona con la prestación de los servicios de salud (acceso a servicios y tecnologías, atención de urgencias, comunicación con el profesional de la salud, información para conocer riesgos y tomar decisiones sobre procedimientos, recibir prestaciones y trato digno, confidencialidad y reserva de la historia clínica, asistencia de calidad durante el proceso de enfermedad, provisión y acceso oportuno a tecnologías y medicamentos, recibir servicios en condiciones de higiene, seguridad y respeto a su intimidad, confidencialidad de la información suministrada en el acceso a los servicios, presentar reclamaciones, quejas y sugerencias, solicitar explicaciones de los costos de los tratamientos, decidir sobre la donación de sus órganos, evitar asumir cargas administrativas $\mathrm{y}$, agotar posibilidades de tratamiento que permitan superar la enfermedad). En cuanto a los segundos, hay unos que miran la responsabilidad con el cuidado personal, familiar y comunitario, la obligación de solidaridad en situaciones de peligro de la vida o salud de otras personas y, a reglón seguido, las obligaciones relacionadas con la prestación de servicios, entre ellas, respetar el personal que presta y administra los servicios, cumplir las normas del sistema, actuar de buena fe, suministrar información oportuna y suficiente y, contribuir al financiamiento de los gastos que demande la atención y la seguridad social en salud.

$18 \mathrm{El}$ argumento que aduce el decreto es que un informe de gestión administrativa recomienda la supresión y liquidación de la Unidad Administrativa y, por consiguiente, el traslado de funciones al Ministerio. 
Las normas establecen un trato preferencial a las personas de especial protección, entre ellas las niñas, niños, adolescentes, mujeres en estado de embarazo, desplazados, víctimas de violencia y del conflicto armado, adultos mayores, personas que sufren enfermedades huérfanas y personas en condición de discapacidad.

La participación de las personas es uno de los elementos con más proliferación normativa, a través de las disposiciones se llama a que las personas se organicen y ejerzan su derecho a intervenir en la formulación de políticas, planes, instancias de deliberación, veedurías, seguimiento, decisiones relacionadas con la inclusión o exclusión de servicios y tecnologías, prioridades y evaluación de los resultados de las políticas.

Rendición de Cuentas. Los desarrollos recientes de la gestión estatal, especialmente motivados por las corrientes de la gobernanza y las recomendaciones de organismos multilaterales, motivan que sea de competencia de las entidades estatales responsables de la regulación, dirección, orientación, inspección, vigilancia y control, la obligación de informar y sustentar los resultados sobre el cumplimiento de los principios, deberes y funciones relacionados con el cumplimiento del derecho a la salud En el informe del Banco Mundial (2011) se describe este fenómeno así:

En los países con instituciones sólidas pero consideradas ilegítimas porque pecan de exclusión, abusos o falta de rendición de cuentas (como en algunas transiciones a partir de un gobierno autoritario), las medidas en los frentes de la transparencia, la participación y la justicia pueden ser más importantes para instaurar la confianza en breve tiempo que la prestación de bienes y servicios (Banco Mundial, 2011, p. 22)

La presentación de logros y resultados, de las entidades responsables de la política y la prestación, implica el análisis de los efectos que producen los cambios 
económicos, sociales, culturales sobre la caracterización, contenido y alcance de los servicios de salud y su interacción con otros derechos, en dos sentidos: cuando colisionan y producen un efecto negativo sobre la posibilidad de realización de uno o más de ellos y tienen efectos directos sobre el bienestar de las personas:

Dado que la determinación del contenido normativo de todo enunciado jurídico es un presupuesto lógico de su aplicación, los derechos fundamentales no pueden aplicarse, si su contenido no ha sido previamente determinado, es decir, si no han sido disipadas todas las perplejidades que se presentan a causa del irreductible déficit de precisión y de explicitud semántica de las disposiciones constitucionales que los tipifican (Bernal, 2007, p. 63)

O cuando son complementarios $y$, en consecuencia se refuerzan entre sí al imprimir un verdadero goce por la concurrencia, simultánea o diferida, de las consecuencias positivas.

\subsection{Sistema de Salud hoy vigente.}

Articulación de los principios rectores del sistema. Su agrupación. Un análisis institucional del sistema de salud supone, prima facie, una relación articulada y sinérgica de los principios ya referenciados, con el fin de examinar la manera como ellos interactúan, teniendo en cuenta, entre otras razones, que el Estado Colombiano adopta un modelo de libertad regulada a través del cual busca superar las imperfecciones del mercado (Azuero Z., 2012). Supone, también, atender las decisiones de la Asamblea Nacional Constituyente - los miembros de la Comisión V, entre los cuales se encuentran los representantes del M19, consideraban oportuna la concurrencia de particulares en la prestación de servicios de salud - (Asamblea Nacional Constituyente. 1991); la forma como sus componentes contribuyen a la garantía del derecho a la libertad de empresa, impulsar mecanismos de competencia que afecten 
positivamente la calidad de la prestación, inducir a las personas a superar el concepto de beneficencia en el acceso a cualquier prestación y, desarrollar un sistema multifacético que dé cuenta de las diferentes interrelaciones en las que se gesta la Función Pública, con participación de servidores públicos y agentes privados, en la planeación, administración, gestión y operación de los servicios de salud.

El esquema que a continuación se presenta agrupa esos principios con el propósito de mostrar gráficamente esa articulación, a partir de tres conceptos interrelacionados, teniendo en cuenta la gestión, los resultados y sus impactos.

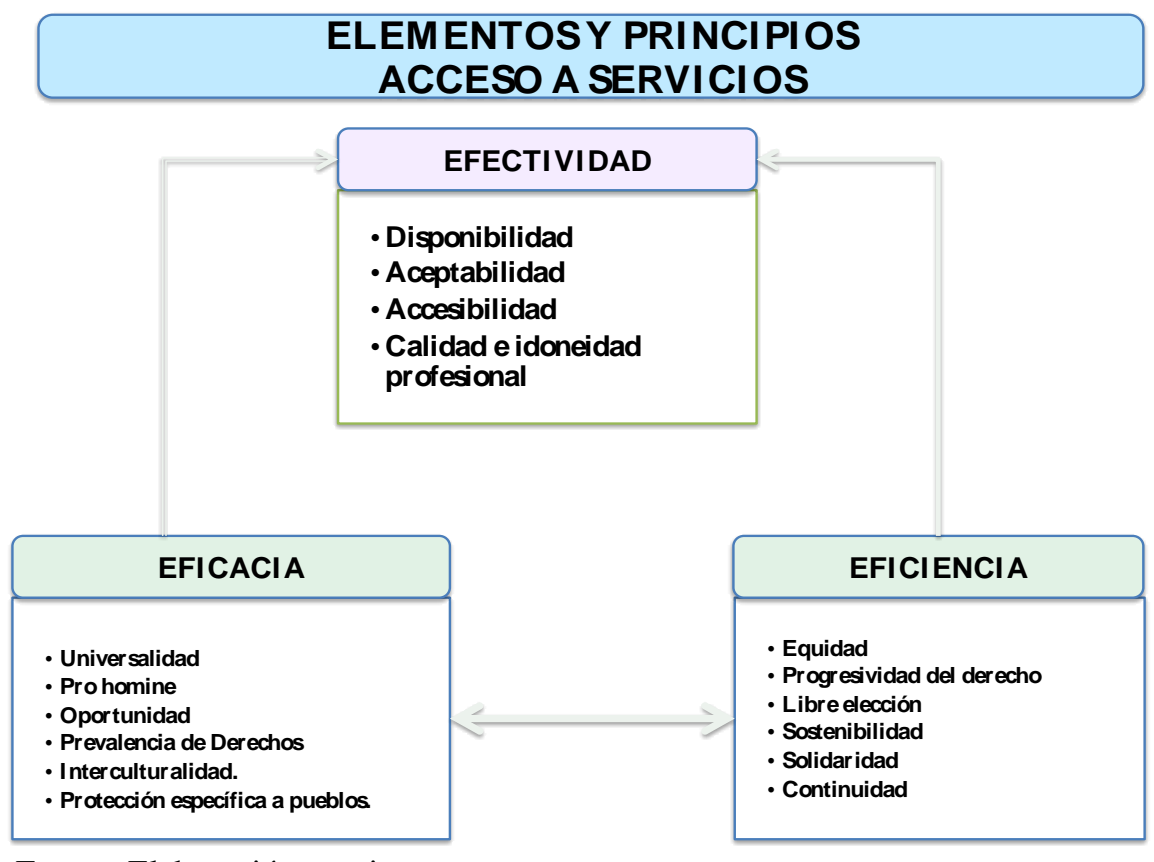

Fuente: Elaboración propia

Tendencia que se observa en las disposiciones legales vigentes. Las disposiciones legales existentes, en especial los principios, reflejan una tendencia a priorizar los temas relacionados con la prestación de servicios de salud, particularmente, los atinentes a responsabilidades («Ley 100 de 1993» Artículos 2 y 153), en la dirección, vigilancia, control, administración, financiación, afiliación, participación social y atención de las demandas de las personas en relación con el diagnóstico, tratamiento y superación de las enfermedades. 
El Plan Decenal de Salud de Salud Pública orienta sus objetivos estratégicos a alcanzar mayor equidad en salud; a mejorar las condiciones de vida y salud de la población, bajo la premisa de cero tolerancia con la morbilidad, la mortalidad y la discapacidad evitables (Ministerio de Salud y Protección Social, 2013b, pp. 73-74).

La Corte Constitucional, al referirse a las facetas positivas y negativas del derecho a la salud, señala que la violación del derecho fundamental de la salud se produce por omisión, la cual asocia a la carencia o falta de prestación de un servicio, y por acción, cuando realiza una conducta que termina en el deterioro de la salud de la persona (Corte Constitucional. Sentencia C-313 de 2014)

Aquí, como en varios apartes de las normas y la jurisprudencia, así como en las situaciones específicas de la práctica cotidiana, se presenta una reducción del derecho al adscribirlo, con preferencia, al tema de prestación de servicios, lo que parece una clara reacción a los problemas administrativos, operativos y de gestión que inciden en la fuerte intervención de la justicia, vía tutela, para asegurar que las personas accedan a las $\operatorname{prestaciones}^{19}$; mientras que, a pesar de estar reglada la obligación de lograr la reducción de las desigualdades de los determinantes sociales de la salud que inciden en el goce efectivo del derecho a la salud, el Ministro de Salud y Protección Social asevera que el plan decenal de la salud se concertó a partir de señalar que los determinantes sociales simplemente son elementos de priorización de la política pública y no hacen parte del núcleo esencial del derecho, para evitar que sean tutelables “... porque de alguna manera estaríamos, vía el derecho fundamental a la salud, entregando toda la priorización del gasto público a los jueces de la República...” (Ministerio de Salud y Protección Social, 2013a), frente a estas aseveraciones basta señalar que los planes de desarrollo, desde la década de los ochenta del anterior siglo, han contemplado y

19 Es diciente que la primera obligación del Estado, en el goce efectivo del derecho fundamental a la salud, sea una abstención. Ver literal a) del artículo 5 de la Ley 1751 de 2015. 
contemplan dichos elementos como esenciales en el logro de los fines del bienestar y la calidad de vida de las personas.

Las Políticas de Salud. En la perspectiva del Ministerio de Salud y Protección Social, las políticas de salud propiamente dichas y las relacionadas con los determinantes sociales deben tener una separación institucional, una de la otra, con el fin de evitar mezclar, como parte de las mismas, las prioridades, en razón a la imposibilidad fiscal y operativa de planear, ejecutar y solucionar simultáneamente todos los asuntos, a los necesarios cambios presentes y futuros en torno a las necesidades esenciales de salud pública y las limitaciones de los recursos financieros (Ministerio de Salud y Protección Social, 2013a).

Las reglas y el conjunto de sus componentes, en las recientes disposiciones, expresan una tendencia a separar las funciones estructurales del Sistema General de Seguridad Social en Salud, con base, además de los problemas relacionados con las deficiencias en la prestación de servicios y el flujo de recursos, en los magros resultados de decisiones sustentadas en políticas de Estado que aparecen, en la literatura del siglo pasado como antagónicas. Esas funciones estructurales que pueden ser reconocidas en el actual sistema de salud son:

a.- El financiamiento y suministro de servicios directamente por el Estado con mecanismos institucionales centralizados e integrados verticalmente. Así lo afirma Londoño (1997), “...cuando el ministerio de salud participa de manera directa en la prestación de servicios, puede desarrollar una renuencia a promover la acreditación de hospitales por temor a que sus propios servicios e instalaciones resulten deficientes" (p.11).

b.- La prestación de servicios por entidades y personal de la salud privados a través del financiamiento de cada persona, bien sea con el desembolso de recursos al 
momento de la demanda de la prestación o el pago previo de pólizas que aseguran determinados riesgos. (Londoño, 1997)

c.- La contratación de servicios por parte del Estado para que instituciones privadas (preferentemente fundaciones "sin ánimo de lucro", organizaciones de personal de la salud, clínicas privadas, entre otros), presten atención a poblaciones tradicionalmente cautivas que reciben los servicios como una caridad, lo cual produce, como consecuencia, baja capacidad de exigencia en cuanto a calidad, oportunidad, pertinencia y cobertura de los servicios y tratamientos médicos.

Los estudios sobre la organización y prestación de los servicios de salud permiten señalar que es imposible un mercado totalmente libre, sin la intervención estatal, ya que la maximización de los beneficios, en favor de las personas que acceden a la prestación de servicios de salud, está condicionada, entre otras razones, por el desequilibrio estructural en el acceso a la información.

El poder dominante de quienes proveen los servicios y la manifiesta debilidad de la contraparte; el bajo interés de los proveedores privados en transacciones o actividades que, a pesar de generar externalidades positivas, no producen ganancias; y el impacto que cualquier efecto nocivo, especialmente en la salud pública, propician la adopción de medidas y la realización de acciones que únicamente tengan como fuente de decisión la relación entre inversión y obtención de ganancias, máxime cuando las actividades de promoción, protección, prevención y cuidado hacen considerar a la salud como un bien de confianza, en el cual el experto (médico, odontólogo, especialista, productor y comercializador de medicamentos, clínicas, etc.) establece cuál es el tratamiento que debe seguir el paciente $\mathrm{y}$, al mismo tiempo, provee los insumos, tecnologías, instrumentos y actividades del mismo (Azuero Z., 2012). 
Ámbito de acción de las políticas. Las políticas tienen como ámbito de acción:

a.- El diseño del marco normativo, financiero y operativo que determina las competencias de la Nación, las entidades territoriales y los particulares.

b.- El diseño, adopción, ejecución y evaluación de la prestación de servicios de salud pública.

c.- El diseño, adopción y verificación de la garantía de calidad en la ejecución de programas, proyectos y actividades que buscan el logro de los más altos niveles de calidad en la prestación.

d.- Los diseños y acciones encaminados a que el personal de la salud participe eficiente y eficazmente en el diagnóstico, protección y mejoramiento de las condiciones de salud de las personas que recurren a las Instituciones Prestadoras de Servicios de Salud y,

e.- Las encaminadas al diseño y ejecución de programas de inmunización contra las enfermedades transmisibles. 


\section{Capítulo tercero: Comportamiento y resultados del Sistema General de Seguridad}

\section{Social en Salud}

\subsection{Funcionamiento del Sistema General de Seguridad Social en Salud y sus efectos sobre el cumplimiento del derecho fundamental a la salud.}

El objetivo de este capítulo está orientado a caracterizar el comportamiento de los diferentes componentes del Sistema General de Seguridad Social en Salud y sus efectos sobre el cumplimiento del derecho fundamental a la salud.

\section{El efecto de los Principios constitucionales y legales del Sistema General de} Seguridad Social en Salud. El Sistema General de Seguridad Social en Salud constituyó una respuesta institucional a los problemas del Sistema de Salud que antecedieron a la Ley 100 de 1993, relacionados con la protección y atención de la mayoría de la población colombiana, en la medida que el anterior sistema concentraba su cobertura en las prestaciones dirigidas a los trabajadores asalariados, de los cuales cerca del $50 \%$ tenían dicha protección, mientras que la población total cubierta por el sistema de Seguridad Social era inferior al 20\%, con una cobertura familiar, especialmente a favor de los afiliados al extinto Instituto de Seguros Sociales, que llegaba al 18\%, mientras otras entidades asumían protecciones parciales, entre ellas servicios de maternidad y pediatría, y, como el caso de las Cajas de Compensación, otros servicios para afiliados de menores ingresos, en consecuencia, la cobertura total de trabajadores y el núcleo familiar frisaba el 42\% (Ministerio de Salud, 1994a).

El $11 \%$ de los habitantes no estaba afiliado a ninguna entidad, a pesar de tener capacidad de pago, mientras que la prestación de servicios, a las personas sin capacidad de pago, era una tarea de los denominados servicios seccionales de salud dirigida al $50 \%$ de la población, cuya financiación corría a cargo del patrimonio público, sin que su cobertura fuera suficiente, la atención era inoportuna y, en algunos casos, inexistente, 
situación que, al final de cuentas, muestra que el $19 \%$ de la población nacional no accedía a ningún servicio, a pesar de su inevitable necesidad (Ministerio de Salud, 1994b).

El primer objetivo del Sistema General de Seguridad Social fue superar el deficiente acceso a los servicios de salud y motivar que todas las personas, independientemente de su estatus o condición económica, contaran con la posibilidad real de acceder a las prestaciones médicas, odontológicas, tratamientos y medicamentos, a partir de la afiliación obligatoria de los trabajadores y los grupos con capacidad de pago al denominado Régimen Contributivo, quienes legalmente deben cotizar al sistema, conforme lo establecen las reglas que sobre el particular adoptó la ley 100 de 1993 y las reformas sucesivas, mientras que a las personas con baja o nula capacidad de pago se les brindó la oportunidad de acceder a subsidios parciales o totales, los cuales hacen parte del mecanismo de financiación de su afiliación y del acceso a los servicios de salud del calificado como Régimen Subsidiado.

Las personas que, se supone, son partícipes de este mecanismo son las más pobres y vulnerables de las áreas rural y urbana, entre ellas, con preferencia, las madres durante el embarazo, parto y postparto, las mujeres cabeza de familia, los niños menores de un año, los menores en situación especial, los mayores de 65 años, las personas en situación de discapacidad, los campesinos, las comunidades indígenas y otras poblaciones sin capacidad de pago (normas del Sistema General de Seguridad Social en Salud; mientras que otro grupo de personas accedería, en calidad temporal de participantes vinculados, vía la oferta de servicios de los hospitales públicos y las instituciones privadas que tenían contratos suscritos con entes estatales.

La visión del sistema contenía la obligación de lograr la totalidad de la afiliación, en cualquiera de los dos regímenes, en el año 2000, así como la unificación 
progresiva de los planes de beneficios en un único Plan Obligatorio de Salud, al cual tendrían derecho la totalidad de los habitantes del país, independientemente de las condiciones de vida económicas, sociales, políticas, geográficas u otras en las que se encontraren las personas.

El Sistema General de Seguridad Social en Salud se expresa, en el contexto referido, como la regulación de un servicio público encaminado al acceso de actividades de promoción, protección y recuperación de la salud y, es sobre dicha connotación que se consolidará y adquirirá carta de ciudadanía la enfermedad como columna vertebral del afán estatal para regular el manejo de los riesgos, reglar el acceso a los servicios de diagnóstico, tratamiento y superación de las patologías, institucionalizar los planes de beneficios y, en general, planificar el gasto de salud, ya que, desde la aplicación del sistema, el énfasis se centró en las relaciones paciente - entidades prestadoras de servicios de salud ${ }^{20} \mathrm{y}$, el Estado como responsable y garante del servicio, a pesar de las iniciales advertencias de la Corte Constitucional, la cual, a su vez, ayudó a consolidar el tema como un factor esencialmente de acceso a prestaciones:

Las relaciones paciente y entidad de salud encargada de la prestación del servicio, como expresión de los derechos sociales y prestacionales a la seguridad social, son objeto de específicas regulaciones, controles y prohibiciones en las que el deber de atención es mayor y son más graves sus responsabilidades que

20 Las formas de intervención de la Corte Constitucional, las deficiencias de las instancias de dirección, inspección, vigilancia y control, así como su baja capacidad para adoptar decisiones oportunas, pertinentes y eficientes, teniendo en cuenta la jurisprudencia constitucional, el bajo conocimiento de las personas de su derecho y de los condicionantes sociales y personales que determinan el estado de salud y, los intereses, por capturar rentas, de los particulares que intervienen en el aseguramiento y la prestación de servicios, a través de las diferentes modalidades, imprimen un sello característico a la justiciabilidad de la salud, desde el inicio del Sistema: la controversia por el acceso a las prestaciones (procedimientos, tratamientos, medicamentos y tecnologías), directamente asociadas a la identificación y "liquidación" de la enfermedad, a pesar de la advertencia de la propia Corte Constitucional sobre la doble connotación del concepto salud. 
las que de ordinario se exige a entidades y personas públicas y privadas encargadas de la atención del servicio público en general (Corte Constitucional. Sentencia T-2081, 1996).

El primer resultado del Sistema es la incorporación de la totalidad de las personas, que componen el núcleo familiar del afiliado, a la Seguridad Social en Salud $\mathrm{y}$, por consiguiente, su derecho a acceder a las prestaciones asistenciales establecidas en cada uno de los planes de beneficios. Sin embargo, el mencionado acceso está signado por la controversia en torno a qué prestaciones cubre el servicio de salud y cuáles son los límites de uno u otro agente del sistema frente a la garantía de las prestaciones. De hecho la Corte Constitucional, en sus primeras sentencias, señaló que las entidades, encargadas de prestar los servicios, están en capacidad de condicionar la atención de patologías al cumplimiento del usuario de un determinado número de semanas cotizadas al Sistema General de Seguridad Social en Salud, reivindicando, de esta manera, el principio de equidad, al manifestar que el paciente debería cancelar, de conformidad con su capacidad económica, aquellos servicios no contemplados en los planes de beneficios. Ha reiterado, la Corte, que ni las entidades responsables de la afiliación, ni aquellas que prestan los servicios, pueden regular aspectos relacionados con las enfermedades o determinar períodos de cotización mínimos para el acceso a los servicios (Corte Constitucional. Sentencia C-112, 1998a), entre otras razones porque el afiliado y sus beneficiarios ingresan al Sistema General de Seguridad Social en Salud y no a una Entidad Promotora de Salud: "la persona se afilia al sistema, no a una de las entidades integrantes del mismo" (Corte Constitucional. Sentencia T-1289, 2005d).

Desde entonces se han producido un conjunto de decisiones jurisprudenciales, esencialmente de la Corte Constitucional, que vía, la justiciabilidad, intentan resolver las deficiencias de la regulación y los fallos, por la falta de acción de los órganos 
responsables de la dirección, orientación, inspección, vigilancia y control, han dispuesto garantizar las prestaciones atinentes al derecho fundamental a la salud, sin tener que buscar la vía de la tutela como única salida a sus demandas (Corte Constitucional. Sentencia T-760, 2008c).

\subsubsection{El principio de universalidad: Cobertura y garantía de los derechos.}

\section{Protagonismo de la Corte Constitucional.}

Una característica que acompañará el desarrollo del Sistema General de Seguridad Social en Salud es que la cobertura, universalidad y garantía de los derechos estará en cabeza de los jueces constitucionales, mientras que las autoridades administrativas estarán rezagadas sin aprovechar oportuna y efectivamente la jurisprudencia, así como los hechos y comportamientos de quienes forman parte del Sistema General de Seguridad Social en Salud para lograr la eficiencia de sus competencias en materia de regulación, dirección y control y, hacer valer la autonomía de las entidades responsables de la Función Administrativa en la corrección de las desviaciones o superación de los incumplimientos de los agentes del Sistemas. Esta actitud y el comportamiento de algunas de las entidades de la Rama Ejecutiva, fortalecerán y consolidarán el papel protagónico de la Corte Constitucional, el cual llevará a que ésta se inmiscuya, incluso, en decisiones de tipo administrativo y señale los procedimientos y acciones correspondientes.

Desde muy temprano la Corte Constitucional ordenó tratamientos en el exterior, sin que las autoridades administrativas, las responsables del aseguramiento y quienes prestan sus servicios de salud lograrán argumentar y demostrar, en una multiplicidad de casos, la posibilidad y pertinencia de los tratamientos realizados en Colombia. A título de ejemplo el Máximo Tribunal señaló: 
El Estado, a través del Ministerio de Salud -o en su caso la EPS conforme lo defina el Consejo Nacional de Seguridad Social-, podrá, una vez efectuada la respectiva evaluación y obtenidos los resultados de los exámenes realizados al paciente y determinada la entidad en el exterior que se debe hacer cargo del procedimiento, y antes de su remisión, exigir a la EPS a la que se encuentre afiliado para que ésta proporcionalmente asuma el pago de lo que costaría un tratamiento similar, si este existiere, que se hubiera podido realizar en Colombia conforme a los contenidos del Plan Obligatorio de Salud para la correspondiente patología... El Ministerio de Salud, previamente a la remisión del paciente al exterior, deberá disponer de los recursos a través del Fosyga con los cuales se cancelarán los gastos de traslado, intervenciones, procedimientos y otros a practicarle al paciente, así como la entidad que en el exterior se deberá hacer cargo del procedimiento; recursos que se adicionarán a los que la EPS proporcionalmente deberá asumir en las condiciones mencionadas en el literal anterior...En el caso de la población vinculada, la responsabilidad y coordinación en cuanto al otorgamiento de prestaciones por fuera del POS, se debe efectuar a través de la red pública de prestadores y sus correspondientes fuentes de financiación (Corte Constitucional. Sentencia SU-819, 1999). ${ }^{21}$

De otra parte, La Corte Constitucional ordena, en el Auto 413 de 2015, la intervención en el Departamento del Chocó sin que ninguna autoridad analice, busque, determine y adopte las decisiones para determinar responsabilidades y las potenciales sanciones sobre quienes han mantenido la situación paupérrima de salud en este y otros territorios del País y, a la vez se obligue a las entidades del Sistema a cumplir con

21 Negrilla fuera del texto. 
eficiencia, eficacia y efectividad las competencias que tienen asignadas. Véanse los resultados de las decisiones y órdenes de la Tutela T-760 de 2008 presentados por las autoridades a la Corte Constitucional. En esta sentencia señala el Órgano Constitucional que las fallas de regulación constatadas representan una violación de las obligaciones constitucionales, a cargo de las entidades responsables de respetar, proteger y garantizar el derecho, sin que las mismas tengan efectos sobre los servidores públicos responsables de tal gestión y de sus 'resultados'.

La jurisprudencia determinó la salud como derecho fundamental, con mucha antelación a su reconocimiento en una Ley Estatutaria, a instancias del Gobierno Nacional y decisión del Congreso de la República. La Ley Estatutaria que regula el derecho fundamental a la salud es de febrero de 2015, mientras que la Corte Constitucional señaló el carácter fundamental, al menos formalmente desde el 2008, al aseverar:

Del principio de universalidad en materia de salud se deriva primordialmente el entendimiento de esta Corte del derecho a la salud como un derecho fundamental, en cuanto el rasgo primordial de la fundamentabilidad de un derecho es su exigencia de universalidad, esto es, el hecho de ser un derecho predicable y reconocido para todas las personas sin excepción, en su calidad de tales, de seres humanos con dignidad. (Corte Constitucional. Sentencia C-463, 2008a)

Así mismo, la Corte determina que: ...el derecho a la salud es un derecho fundamental, así sea considerado usualmente por la doctrina como un derecho social y, además, tenga una importante dimensión prestacional (Corte Constitucional. Sentencia T-760, 2008c). Esta connotación estuvo precedida de múltiples decisiones simultáneas, de la Corte Constitucional, sobre el carácter de la salud, al establecer su doble 
connotación de servicio y derecho fundamental; al reconocer la carencia de recursos suficientes para hacer efectivo a plenitud el acceso a la totalidad de prestaciones de salud y, concomitantemente, señalar que es el Estado quien debe financiar las prestaciones excluidas de los planes de beneficios y garantizar los tratamientos, medicamentos y demás intervenciones que permitieran la superación de la enfermedad (Corte Constitucional. Sentencia SU-819, 1999), la revisión de los planes obligatorios de salud y su fusión en un único plan de beneficios (Corte Constitucional. Sentencia T$760,2008 c)$.

\subsubsection{Crecimiento de la Afiliación al Sistema.}

La segunda característica de la universalidad, ha sido el lento pero continuo crecimiento de la afiliación al Sistema General de Seguridad Social en Salud. La gráfica 1 muestra el crecimiento de la afiliación durante los últimos 20 años (1996-2016), el cual denota que durante los primeros siete años, si se considera la afiliación desde 1994, el Régimen Contributivo se mantuvo por encima de la afiliación al Régimen Subsidiado y, a partir del año 2004 el incremento de la afiliación al Régimen Subsidiado es intermitente y siempre revela cifras superiores a las del Contributivo. El valor de 2016 es con corte al mes de julio del mismo año, según dato del Sistema de Información SISPRO. Las cifras son calculadas sin incluir los denominados regímenes de excepción, los cuales alcanzan, según datos estimados del Ministerio de Salud y Protección Social (2015a), cerca del 5\%, valor que debe ser sumado para determinar la población total que, para cada año, está afiliada a un sistema de salud. 


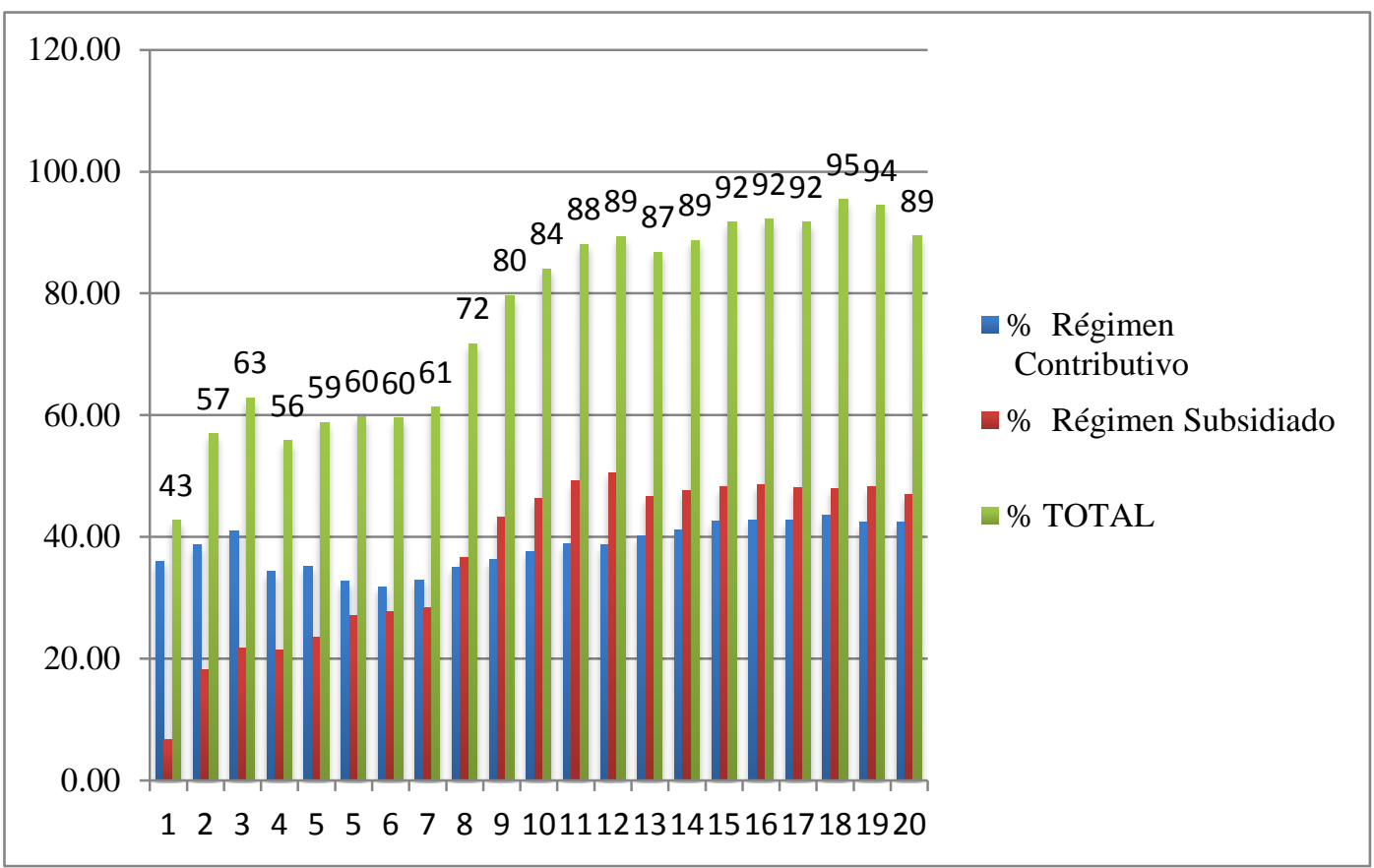

Figura 1: Afiliación al sistema general de seguridad social en salud. El cálculo no incluye las personas afiliadas a los regímenes especiales y de excepción (Fuerzas Militares, Policía Nacional, el Fondo de Prestaciones Sociales del Magisterio, Ecopetrol, y las universidades públicas u oficiales que se acogieron a la Ley 647 de 2001), el cual es cifrado, por el Ministerio de Salud y Protección Social, en cera al 5\%. Elaboración propia mediante la compilación de varias fuentes. ${ }^{22}$

El crecimiento en la afiliación al Sistema General de Seguridad Social en Salud tiene, al igual que en los temas atrás referenciados, en la jurisprudencia un papel determinante, ya que desde la primera década del presente siglo, el máximo Tribunal de lo Contencioso Administrativo señaló el incumplimiento del Gobierno Nacional frente a la cobertura universal (Consejo de Estado. Sala de lo Contencioso Administrativo. Sección Tercera, 2014), especialmente frente al Régimen Subsidiado por la manera como administró y manejó los recursos existentes en la cuenta de Solidaridad del Fondo de Solidaridad y Garantía, a pesar de existir excedentes financieros acumulados, entre los años 2000 y 2006, que no fueron utilizados en la ampliación de Cobertura (Consejo de Estado. Sala de lo Contencioso Administrativo. Sección Tercera, 2014).

22. Datos extraídos de las siguientes fuentes: del sitio Web del Ministerio de Salud y Protección Social; del DANE (2013); del artículo de Meza (2005); del artículo de Fresneda B. (2003); del informe de Peñaloza Q. (2001). 
La falta de inversión de los recursos de solidaridad, en el aumento de la afiliación al Régimen Subsidiado, estuvo centrada en el desconocimiento del Ministerio de Salud y Protección Social ${ }^{23}$ sobre el carácter de recursos parafiscales que acompaña los aportes de las personas privadas que están obligadas con el Fondo de Solidaridad y Garantía, y, junto con el Ministerio de Hacienda y Crédito Público, les otorgó la categoría de recursos del presupuesto nacional, lo que generó como consecuencia que la programación de los mismos y las autorizaciones de gasto estuvieran sometidas a las metas fiscales del Gobierno Nacional y a las restricciones propias del denominado espacio fiscal (Consejo de Estado. Sala de lo Contencioso Administrativo. Sección Tercera, 2014).

Las decisiones del Gobierno Nacional sobre el carácter de los recursos de salud y su adscripción, de algunas de las subcuentas del Fondo de Solidaridad y Garantía, como recursos del Presupuesto General de la Nación estaban en abierta contradicción con las decisiones de la jurisprudencia:

“...los recursos de solidaridad que percibe el Sistema de Seguridad Social en Salud, no entran a formar parte del presupuesto nacional, sino que, por su afectación, pertenecen al Sistema: Los de origen público porque ya han sido apropiados para el efecto y son de aplicación inmediata y los de origen privado por su carácter parafiscal. Desde ese punto de vista, los recursos parafiscales no se encuentran afectados directamente por los principios de universalidad presupuestal, ni coherencia macroeconómica, como lo afirman los demandados y, mucho menos, con el principio de unidad de caja (Consejo de Estado. Sala de lo Contencioso Administrativo. Sección Tercera, 2014).

23 Denominado Ministerio de Protección Social hasta el año 2011, por la fusión de los ministerios de Salud y de Trabajo y Seguridad Social ordenada por el artículo 5 de la Ley 790 de 2002. 
La jurisprudencia desde finales del siglo pasado aclaró la naturaleza de las mismas y la imposibilidad de considerar los recursos como fuente del presupuesto y, a su vez, como potenciales instrumentos afectos a las políticas macroeconómicas y, por consiguiente, objeto de restricciones fiscales:

Según las características de la cotización en seguridad social, se trata de una típica contribución parafiscal, distinta de los impuestos y las tasas. En efecto, constituye un gravamen fruto de la soberanía fiscal del Estado, que se cobra de manera obligatoria a un grupo de personas cuyas necesidades en salud se satisfacen con los recursos recaudados, pero que carece de una contraprestación equivalente al monto de la tarifa. Los recursos provenientes de la cotización de seguridad social no entran a engrosar las arcas del presupuesto Nacional, ya que se destinan a financiar el Sistema General de Seguridad Social en Salud (Corte Constitucional. Sentencia C-577, 1997a)

Tales pronunciamientos han sido reiterados entre otras, en las Sentencias:

C-1040 de 2003:

Dado su carácter parafiscal, los recursos de la seguridad social en salud tienen destinación específica, esto es, no pueden ser empleados para fines diferentes a la seguridad social. Así lo establece expresamente el artículo 48 de la Carta Política al disponer que "No se podrán destinar ni utilizar los recursos de las instituciones de la Seguridad Social para fines diferentes a ella (Corte Constitucional. Sentencia C-1040, 2003b).

C-262 de 2013:

... la destinación específica de los recursos parafiscales de la seguridad social ha sido entendida de manera amplia por esta Corporación, en el sentido que comprende, entre otros aspectos, la financiación parcial de las funciones de 
vigilancia y control que desarrolla la Superintendencia Nacional de Salud y los gastos administrativos de las EPS. Estas actividades tienen en común el ser necesarias para el adecuado y eficiente funcionamiento del SGSSS (Corte Constitucional, 2013a).

C-289 de 2014:

La exención parcial de aportes parafiscales, tiene como efecto relevar de una parte del pago del aporte al contribuyente empleador, lo que en efecto, implica una reducción del volumen de contribuciones parafiscales que en adelante reciban el SENA, el ICBF, y el Sistema de Seguridad Social en Salud. (Corte Constitucional, 2014).

El Máximo Tribunal Contitucional hace una extrema aseveración, al señalar que no es posible el manejo financiero de los recursos, del Fondo de Seguridad y Garantía, ni siquiera ante la necesidad de una reactivación económica:

Sobre el carácter absoluto de la citada prohibición la Corte[6] ha señalado que la prohibición contenida en el artículo 48 Superior no puede ser desconocida "ni aun en aras de la reactivación económica", lo que significa que los recursos destinados a atender las necesidades del servicio de salud y asegurar la efectividad del derecho a la salud no pueden ser objeto de acuerdos de pago con acreedores que conduzcan a que tales recursos no lleguen al destino ordenado en la Carta (Corte Constitucional. Sentencia C-1040, 2003b)

Las decisiones de la jurisprudencia, entre ellas, las de ordenar al Gobierno Nacional la no inclusión en el Presupuesto General de la Nación de los recursos de la Subcuenta de Solidaridad del Fondo de Solidaridad y Garantía, con el objeto de garantizar su legalidad con fines de apropiación, impulsan la ejecución de los recursos, 
principalmente de la misma, y aumentan, como se ve en la Gráfica 1, la afiliación en el Régimen Subsidiado.

El cumplimiento del principio de universalidad, durante cerca de veinte años, está principalmente asociado a la intervención de la Rama Judicial, en particular la Corte Constitucional y el Consejo de Estado, quienes han marcado la pauta y las directrices en torno a la ampliación de cobertura del Régimen Subsidiado, ya que el Régimen Contributivo depende de la capacidad de pago de los afiliados, la cual a su vez está asociada al desarrollo económico, el incremento del empleo y la consolidación de las empresas. Así lo reafirma la sentencia AP25000232500020030125202 del Consejo de Estado:

El incumplimiento de los plazos previstos en la regulación citada para alcanzar la Universalidad, impone la adopción de correctivos inmediatos, entre los cuales, aquéllos dirigidos a ordenar que se liberen los recursos de la subcuenta de solidaridad del FOSYGA, de las limitaciones presupuestales que de manera injustificada viene imponiendo el Ministerio de Hacienda y Crédito Público, en punto a evitar retardos en el gasto público en salud que con urgencia reclama la población menos favorecida (Consejo de Estado. Sala de lo Contencioso Administrativo. Sección Tercera, 2014).

El objetivo de quienes formulan, adoptan y ponen en funcionamiento el Sistema General de Seguridad Social en Salud es motivar el mutuo apoyo entre las personas con capacidad de pago y aquellas con dificultades de financiación para ingresar a la afiliación y a la prestación de los servicios de salud, a la vez que se plantearon la meta de lograr un plan de protección integral de la salud al año 2001, a través del progresivo incremento de la afiliación, la ampliación gradual de los beneficios y la incorporación 
simultánea de quienes componen el núcleo familiar de la persona afiliada (Ministerio de Salud, 1994b).

\subsubsection{Salud, Solidaridad y acciones sanitarias: Contradicciones en permanencia.}

Esta es una tercera característica del desarrollo del Sistema, que evidencia cómo la práctica estatal institucional y el comportamiento de los diferentes agentes del sistema han llevado a consolidar una visión que reduce la salud, y en consecuencia el principio de solidaridad, a la financiación de acciones sanitarias, especialmente las dirigidas al acceso a los servicios médicos, clínicos y a los procedimientos asociados a los mismos, los cuales se centran, claramente, en la atención de patologías y la superación de los síntomas, así como la meta de rescindir las enfermedades. Por ello, algunos autores consideran que el objetivo de maximizar la salud, bajo criterios de equidad y solidaridad, supone eliminar las barreras financieras de acceso, ofrecer la prestación efectiva de servicios a quienes lo solicitan, sin ningún tipo de discriminación, garantizar la calidad de los servicios, asignar los costos conforme a la capacidad financiera y, lograr que todas las personas tengan los mismos beneficios (Gutiérrez, Acosta, \& Alfonso, 2012).

Las decisiones y acciones del enfoque objetivo, en el que se encuentra el derecho a la salud, se expresan en las prácticas administrativas, económicas, jurisprudenciales, médicas y operativas realizadas durante las dos primeras décadas de existencia del Sistema General de Seguridad Social en Salud, tal como se afirma en Arias R., Paredes C., Santos, \& Duarte R. (2012):

El sistema real de salud, que trasciende al establecido en las normas, ha sido particularmente dinámico: a partir de la Carta Constitucional de 1991, el derecho a la salud ha evolucionado jurídicamente hasta convertirse en un derecho fundamental; implica millones de actividades (se estima más de 400 
millones de actividades para los dos regímenes) y transacciones en las que participan diferentes actores; tiene varios mercados (servicios médicos hospitalarios, actividades de apoyo, laboral); está sujeto a frecuentes innovaciones tecnológicas cada vez más costosas (más de 463 principio activos, alrededor de 736 medicamentos) y debe adaptarse a los cambios poblacionales y a la evolución epidemiológica de las poblaciones (p.31).

Dichas prácticas dejan a un lado la evidencia, incluso tantas veces reivindicada por los organismos multilaterales ${ }^{24}$, los gobiernos y la misma jurisprudencia de la Corte Constitucional, en las que se establece que el estado de salud está asociado, además del acceso a la prestación de servicios médicos, odontológicos, clínicos y las concretas intervenciones para la curación de las enfermedades, a los factores que inciden, determinan o impactan el bienestar de la persona, la familia, la comunidad y la sociedad, entre los cuales están los servicios públicos domiciliarios (especialmente agua potable y saneamiento), la nutrición y los hábitos alimenticios, el ejercicio físico, el empleo, la educación, la vivienda y el ambiente sano, los cuales deberían exigir el cumplimiento de una condición sine qua non en la aplicación del principio de solidaridad y en la inevitable intervención del Estado en la garantía de los derechos políticos, económicos, sociales y culturales. Así puede apreciarse en la cita que hace la Corte en la Sentencia C-548 de 1998:

El artículo primero constitucional "funda" el Estado colombiano en la solidaridad. Ello es un desarrollo de los conceptos de justicia y democracia participativa, consagrados ambos en el Preámbulo y en el artículo segundo de la Carta...

24 La Organización Mundial de la Salud instó a los Estados Miembros, en la 62 Asamblea Mundial de la Salud, celebrada en el año 2009, a tener en cuenta, entre otras, “...la equidad sanitaria en todas las políticas nacionales relativas a los determinantes sociales de la salud..." 
El nexo justicia-solidaridad es evidente, pues en un régimen de carencia de recursos suficientes, como Colombia, una parte de la sociedad civil está llamada a participar en la solución de las necesidades de los más pobres.

También es manifiesta la relación dignidad-solidaridad. Ellas son, respectivamente, un valor y un principio de los cuales se predica su total compatibilidad.

Es gracias a la solidaridad que se puede arribar a la dignidad, si se parte del supuesto de la realidad colombiana, enmarcada en un ámbito de desequilibrios sociales y territoriales.

La solución de las necesidades básicas insatisfechas de importantes sectores de la sociedad colombiana es un compromiso de todos, esto es, del Estado, la sociedad y los particulares.

El examen del principio de solidaridad, teniendo en cuenta la visión y práctica colombiana atrás señalada, muestra un incremento en el acceso a las prestaciones de servicios, la cual está motivada en el aumento de la afiliación (ver Gráfica 1) a los dos regímenes, particularmente el crecimiento del Subsidiado, la demanda inducida desde las aseguradoras y prestadoras (Arias R. et al., 2012), la extensión de los beneficios, generada por la justiciabilidad del derecho, sobre la cual la Sentencia T-760 de 2008 manifiesta:

Por esta razón, si bien es constitucional que democráticamente se establezca un trato diferencial en el goce efectivo del derecho a la salud entre aquellos que contribuyen al Sistema de Salud y aquellos que son beneficiarios por solidaridad, en razón a las capacidades financieras y administrativas de la sociedad y del Estado, éste ha de ser temporal. Como se ha reconocido internacionalmente, el derecho a la salud se 'desprende de la dignidad inherente 
de la persona humana'. No es posible, por lo tanto, aceptar indefinidamente que a las personas que menos recursos tienen en la sociedad sólo se les garantice el acceso a algunos de los servicios de salud que se consideran básicos. La obligación de unificar los planes de servicios de salud del régimen contributivo y subsidiado, surge pues, del deber constitucional de garantizar a toda persona el acceso a los servicios de salud en condiciones de universalidad y equidad (art. 49, CP; art. 2 y 12, PIDESC). De hecho, de acuerdo con el artículo $2^{\circ}$ del Pacto Internacional de Derechos Económicos, Sociales y Culturales, Colombia tiene la obligación de 'garantizar el ejercicio' del derecho a la salud (artículo 12 del Pacto), sin discriminación alguna, entre otras razones, por motivos de 'posición económica' (Corte Constitucional. Sentencia T-760, 2008c)

Así como también la racionalización y la “complementación de recursos” para el financiamiento de los servicios a través de pagos compartidos y cuotas moderadoras a los que están sometidas las personas del Régimen Contributivo ${ }^{25}$, el mejoramiento continuo de servicios hospitalarios resultado de programas oficiales ${ }^{26}$, el desarrollo y consolidación de procesos de habilitación y certificación de entidades hospitalarias, la mayor tendencia de la población a acceder y buscar la prestación de servicios reflejados en el crecimiento de la frecuencia de consulta por habitante, la cual paso de $1,8 \%$ en 1993 a 3 en el año 2010 (Arias R. et al., 2012), el incremento en el grado de protección

25 La Corte Constitucional afirmó, en la Sentencia C-542 de 1998, que los cobros utilizados como mecanismo de racionalización y de obtención de recursos no pueden ser argumento para impedir el acceso a los servicios de los afiliados o sus beneficiarios, cuando éstos carezcan de los dineros para cancelarlos, ya que el derecho a la salud supone el acceso oportuno a los servicios y, otra cosa son las reglas y procedimientos de cobro de ciertas erogaciones asociadas al racionalidad en la utilización del servicio.

26 El Programa de Apoyo a la Reforma en Salud estaba dirigido, entre otros componentes, a las instituciones con el fin de realizar actividades de fortalecimiento de hospitales. En el 2011 el Ministerio del Ramo anunció \$1 billón en medidas de liquidez para los hospitales en lo que restaba de la vigencia fiscal, \$800.000 millones encaminados al fortalecimiento de la red pública y la creación de Fondo de Garantías para el sector salud. En el 2015 se asignan \$49.321 millones para el fortalecimiento de la capacidad instalada de algunas Empresas Sociales del Estado. 
financiera y, los efectos del sistema en la reducción de la pobreza (Gutiérrez et al., 2012) .

\subsection{El pluralismo estructurado: Nuevas tendencias del Sistema.}

El diseño institucional del Sistema General de Seguridad Social en Salud partió de los supuestos de la complejidad del servicio público de salud y de la, inevitable, interrelación que existe entre los elementos y componentes que hacen parte de la garantía del derecho, con el fin de trascender los enfoques que centraban su mirada en dos factores: el financiamiento y la prestación de servicios, los cuales habían generado muchas de las preocupaciones de teóricos del tema y de los tomadores de decisión, al punto que la salud tenía una visión parcial dirigida preferencialmente a los problemas de gasto motivados en la atención de la enfermedad y, en cómo mejorar la eficiencia:

...los gobiernos tienen que fomentar un entorno económico que permita a las propias unidades familiares mejorar su nivel de salud... el gasto público en salud debería reorientarse hacia programas más eficaces en función delos costos que contribuyan en mayor medida a ayudar a los pobres... los gobiernos tienen que facilitar mayor diversidad y competencia en el financiamiento y la prestación de los servicios de salud (Banco Mundial, 1993b, p. iii).

En igual sentido se afirma que:

La Declaración del Milenio de las Naciones Unidas, firmada en septiembre de 2000, compromete a los líderes mundiales a luchar contra la pobreza, el hambre, las enfermedades, el analfabetismo, la degradación medioambiental y la discriminación de la mujer. Los ODM se derivan de esa Declaración. Cada ODM tiene metas fijadas para 2015, e indicadores para seguir los progresos realizados con respecto a las cifras de 1990. Varios de ellos están directamente 
relacionados con la salud (Organización Mundial de la Salud. Sala de Prensa, 2015);

Los críticos de las políticas públicas, las organizaciones no gubernamentales, estudiosos nacionales, sobre los cuales Vélez (2014) comenta:

Durante mucho tiempo el modelo biologista influyó la prestación de servicios de salud; su peso para entender y atender a la persona en sus procesos de enfermedad marcó indudablemente el saber de los trabajos en la salud en todos los niveles de atención (p.87)

Así como también las entidades del Estado, habían llegado, de tiempo atrás, a la necesidad de aceptar, analizar y profundizar sobre la complejidad del tema de la salud, con el fin de comprender la dinámica epidemiológica, la incidencia de los determinantes sociales, que menciona Londoño (1997) "acción intersectorial, de forma que se promuevan 'políticas saludables' que influyan en los factores sociales, económicos, ambientales y culturales que son determinantes del estado de salud" en el bienestar de las personas, los nuevos arreglos institucionales que permitieran articular y generar la debida interacción entre las diversas variables que incidían en el estado de la salud, la incorporación de políticas de participación que aborda el Banco Mundial (1997): "Por último, la participación de los usuarios, las encuestas entre los beneficiarios, la publicación de los criterios de referencia y otros mecanismos destinados a aumentar la participación ciudadana representan presiones externas para mejorar la prestación"(p.100), y el diseño de acciones con mayor impacto sobre la calidad de vida y, la protección y promoción de la salud.

La decisión de Colombia fue diseñar y adoptar un modelo basado en el pluralismo estructurado (Londoño, 1997), el cual debería contribuir a superar muchas de las deficiencias de los viejos sistemas de salud, entre los que sobresalían los problemas 
asociados al incremento del gastos, la debilidad fiscal para el financiamiento, la fragmentación de las formas de ingreso y atención en los servicios de salud, la existencia de incentivos adversos, la atención como beneficencia sin posibilidad de elección, los bajos niveles de calidad de la prestación, el acceso a mejores servicios basado en la capacidad de pago y la dispersión de las entidades estatales en varios sistemas de seguridad social, con débiles coberturas y limitada capacidad de gestión.

\subsubsection{Funciones esenciales del Pluralismo estructurado.}

El Pluralismo Estructurado considerada la existencia de un conjunto de funciones necesarias en el servicio público de salud: .- Financiamiento.- Modulación.Articulación y .- Prestación de Servicios de Salud, a partir de las cuales crea un sistema integrado con funciones en las que se separara el financiamiento de la prestación y, en la ejecución de cada una de las funciones se busca la especialización con la coordinación y articulación armónica de todas las entidades, sobre la base de generar información oportuna y cualificada a los usuarios de los servicios, quienes deben tomar decisiones informadas que impacten positivamente el mejoramiento de las prestación de los servicios.

La fragmentación institucional intentó ser superada a partir de la concepción de que la modulación, el financiamiento, la articulación y la prestación de servicios debían contribuir a superar la concepción de que el derecho y el servicio salud son más que el conjunto de organizaciones prestadoras y, que, en los mismos, se incluye al conjunto de agentes responsables de los procesos de dirección, coordinación, articulación y control, afiliación de usuarios y beneficiarios, promoción y prevención de la salud, investigación y generación de conocimiento científico, desarrollo y aplicación de tecnologías, sistemas de acreditación, los productores y comercializadores de fármacos y equipos de diagnóstico, los procedimientos relacionados con el cuidado, preservación y protección 
de la salud, los encaminados al diagnóstico, tratamiento, paliación y superación de la enfermedad y, los relativos al estudio de riesgos, acciones de prevención y actividades de salud pública. Un elemento clave de la institucionalidad es garantizar la coordinación de las autoridades del Sector Salud con las instancias estatales responsables de políticas $\mathrm{y}$ acciones sectoriales que tienen impacto sobre el bienestar, la vida $\mathrm{y}$, por ende, en el estado de salud de las poblaciones y las personas.

\subsubsection{Modulación}

La dirección, vigilancia y control del Sistema fue asignada a las entidades estatales responsables de la orientación política del Sistema de Seguridad Social Integral, a la Superintendencia Nacional de Salud y a un órgano colegiado, Consejo Nacional de Seguridad Social, encargado de la concertación de las decisiones esenciales en la prestación y el acceso efectivo al derecho a la salud. Este conjunto de entidades tenía la responsabilidad de modular el Sistema, es decir de establecer, implantar y monitorear el cumplimiento de las disposiciones legales e imprimir una dirección estratégica que articulara los diferentes agentes, procesos y acciones en perspectiva de lograr la garantía del derecho y la efectiva prestación de servicios.

La fragmentación del Sistema y la incapacidad de las autoridades responsables de la dirección y control para suprimir y evitar los incentivos perversos, los cuales han originado la apropiación de las rentas, por parte de algunos de los agentes, en detrimento de los fines perseguidos, así como la concentración de acciones de salud en el tratamiento de enfermedades, especialmente en actividades de alta complejidad que mantienen una visión curativa de la salud en lugar de desarrollar y consolidar acciones de prevención; el énfasis en la estabilidad y racionalidad financiera, cuya insistencia causó descuidos en el análisis de los riesgos de salud y, motivó la aparición o 
consolidación de barreras de entrada, especialmente a servicios específicos de tecnología avanzada (Ministerio de Salud y Protección Social, 2012).

El Ministerio de Salud y Protección Social hoy como rector cuasi único del Sistema $^{27}$, dada la supresión de la Comisión de Regulación de Salud, así como la pérdida del papel de concertación y decisión que debía jugar el Consejo Nacional de Seguridad Social en Salud, no ha logrado una interacción equilibrada, eficiente y equitativa entre todos los agentes, ya que las reglas son múltiples, se traslapan, en algunos casos crean confusión y, los incentivos no han sido adecuados, lo que da la sensación de una incapacidad permanente respecto del papel de modulador que le corresponde a esta instancia de dirección. Al respecto en el estudio del Ministerio de Salud y Protección Social (2012) se menciona:

Los esfuerzos legislativos a través de las Leyes 1122 de 2007 y 1438 de 2011 han ofrecido soluciones parciales que no han resuelto de manera estructural el problema de fragmentación dejando al propio Ministerio de Salud y Protección Social con muy limitada capacidad de rectoría y débiles mecanismos regulatorios para efectuar una ordenación del sistema (p.39).

El entonces Ministerio de Salud careció de la capacidad técnica y de acción para impedir la continuidad de barreras de acceso, especialmente en momentos que los servicios eran imprescindibles por la situación de enfermedad, lo que contribuyó al incremento de la justiciabilidad del derecho y, mostró la falta de acción directiva y correctiva sobre las entidades responsables de las acciones de promoción de la salud y prevención de las patologías, tales circunstancias reflejan el limitado y deficiente ejercicio de poder modulatorio del órgano rector.

27 La intervención del Ministerio de Hacienda y Crédito Público ha estado centrada en su papel de responsable de la política fiscal, especialmente del cumplimiento de los principios del Estatuto Presupuestal, en algunos casos en contravía de los fallos de las Altas Cortes, entre ellos los relacionados con la naturaleza parafiscal de los recursos del Fondo de Solidaridad y Garantía. 
El Sistema General de Seguridad Social en Salud aún no ha superado la organización por grupos sociales, dadas las restricciones objetivas de las poblaciones rurales y alejadas, así como de las poblaciones más pobres, para acceder oportuna y eficientemente a la prestación de servicios, además de las barreras que aún soportan por las deficiencias de gestión atribuible a diferentes agentes del Sistema y, al desconocimiento práctico de las diferencias territoriales, lo cual fomento la inequidad regional. En el estudio del Ministerio de Salud y Protección Social (2012) se hace referencia al respecto: "Las características de dispersión geográfica y la falta de oferta articulada de los servicios de salud, propias de las zonas rurales del país, configuran una de las principales barreras al acceso de la población rural” (p.40).

El ejercicio de la Función Pública frente a la prestación del servicio y la garantía del derecho a la salud muestra deficiencias en la dirección estratégica del Sistema, limitaciones en la gestión, asignación y control de la gestión de los recursos financieros, inflación normativa, fallas en la orientación, seguimiento y control de la actividad privada, disparidades en la aplicación y acatamiento de las reglas de juego por parte de los agentes, descuido en la protección del ejercicio del derecho fundamental, limitada reacción a las decisiones de la justicia y, particularmente, en la ejecución de acciones que contribuyan a corregir las fallas y violaciones que inciden en el cumplimiento de los fines del Estado relacionados con la cobertura, calidad, oportunidad y pertinencia de las acciones de salud y, el cumplimiento de las obligaciones de todos los agentes.

\subsubsection{Limitaciones que se han presentado a la Modulación. Las falencias de las} instancias de dirección del Sistema.

Incapacidad de reacción, adaptación y aprendizaje. Una de las mayores limitaciones de las autoridades responsables de la modulación fue su incapacidad de reacción, adaptación y aprendizaje sobre las causas y efectos de la justiciabilidad del 
derecho a la salud, particularmente la sorpresa constante que constituyó la clara, perceptible y continúa línea jurisprudencial de la Corte Constitucional en torno a la garantía del derecho, al pasar de considerarlo fundamental por asociación con otros derechos, desde finales del siglo XX, a su fundamentabilidad por sí mismo en el año 2008

El descuido de tareas claves, como la actualización de los planes de beneficios. Las instancias de dirección, vigilancia y control hicieron caso omiso a los hechos, situaciones y acciones que, motivadas por las Entidades Promotoras de Salud y las Instituciones Prestadoras de Servicios de Salud, incrementaron la búsqueda del amparo constitucional y, descuidaron tareas tan sensibles y claves como la actualización de los planes de beneficios, la adopción de un plan único obligatorio de salud, la utilización de las normas que les permitían exigir a los agentes del Sistema cumplir con sus obligaciones legales, el fortalecimiento de los mecanismos de coordinación y colaboración armónica con las demás instancias del Estado con el fin de impactar, positivamente, los determinantes sociales de la salud, la adopción y verificación del cumplimiento de directrices encaminadas a lograr cambios culturales en torno a la situación en salud, a través de actividades de promoción que motivaran cambios en los estilos de vida, al motivar un mejor cuidado de las personas sobre sí mismas, y la ausencia de gestión integral en materia de salud pública.

Ausencia de análisis acerca de la justiciabilidad del derecho. La incapacidad de analizar y aprender de la justiciabilidad del derecho para determinar los intereses en juego, las relaciones de los agentes, la probabilidad de asumir decisiones que contribuyeran a resolver los conflictos $\mathrm{y}$, esencialmente, tomar decisiones encaminadas a fortalecer el papel de modulador que articula, orienta y decide la mejor forma de garantizar el derecho y fortalecer la capacidad resolutiva de los agentes responsables de 
las funciones de financiamiento, articulación y prestación de servicios, llevó a concentrar las decisiones en torno a la prestación de los servicios, consolidó la cultura que equipara el derecho de salud con la superación de la enfermedad e incidió sobre los principios de equidad y eficiencia, al movilizar recursos hacia personas a las que les reconocían tratamientos y medicamentos específicos y, reflejó la ineficiencia de las autoridades del Sistema ante su impotencia para movilizar su capacidad de gestión en la solución previa y oportuna de cualquier contradicción, para poner en la cima de la gestión a la Corte Constitucional, quien, en protección de la garantía del derecho, llegó a dar órdenes administrativas y a asumir el papel de fiscalizador, sin que los organismos de control, ni la misma Corte, indagaran las características, causas y factores de tal situación, así los responsables de la Modulación marcharon impotentes a la zaga las decisiones judiciales.

\section{El creciente y desbordado acceso a la justicia para la obtención de} prestaciones económicas que inciden en la calidad de vida y en la salud. Los litigios generalmente estaban dirigidos a la obtención de prestaciones económicas particulares, sin que se encontraran acciones encaminadas a la supresión de problemas estructurales o de alta incidencia sobre la calidad de vida y las condiciones de salud públicas, verbigracia, la solución de servicios que impactan directamente a la salud, agua potable, saneamiento básico, ambiente, alimentación, conocimiento en las condiciones de vida, entre otros; por ello, haber permitido este tipo de solución, si bien contribuyó al acceso a los servicios, configuró una forma específica de protección que priorizó soluciones exclusivas a temas relacionados con la enfermedad y, lamentablemente, excluyó acciones de mayor impacto en la salud general. En este sentido Uprimny y Durán (2014) comentan: 
El litigio y la protección judicial de la salud en Colombia tienen efectos mixtos sobre la igualdad. La distribución de los beneficios individuales tiende a favorecer a las clases medias y altas. No obstante, los indicadores no son en todos los casos tan acentuados y tienen excepciones importantes... suelen tener impactos mucho más igualitarios los procesos de diagnóstico y reacción ante el litigio que tiende a rutinizarse o que se ha rutinizado y que ocurren en el ejecutivo, el legislativo y el judicial y que llevan a cambios estructurales que tienen efectos más allá de los litigantes... Además, algunas de estas decisiones estructurales,...han incorporado los tres elementos de una buena la (Sic) jurisprudencia dialógica... a saber una enunciación y protección fuerte de los derechos, pero con órdenes débiles y flexibles, acompañadas de un seguimiento fuerte y riguroso. Esto ha incrementado los potenciales democráticos de estas sentencias "estructurales pues esa modalidad de decisión tiene grandes virtudes: i) defienden forma vigorosa los derechos, en especial de las poblaciones vulnerables, con lo cual tienen un mayor potencial igualitario; pero ii) respeta la separación de poderes y la competencia técnica de los órganos reguladores ya que el juez no impone soluciones técnicas sino que señala metas a ser alcanzadas; en esa forma, iii) incrementa las posibilidades de que las decisiones adoptadas sean soluciones realistas que las autoridades pueden hacer efectivas, con lo cual aumenta la eficacia de la protección judicial; el seguimiento fuerte iv) evita que las autoridades políticas dilaten la solución delos problemas y su carácter participativo v) favorece la intervención ciudadana y la deliberación democrática, pues las soluciones concretas serán discutidas por las autoridades y los directamente afectados, con supervisión judicial. En esa forma los agentes 
sociales relevantes tienen capacidad mantener control sobre la actuación de las autoridades, profundizando el debate democrático (p.59-60)

El litigio se convirtió en el trámite más importante para la obtención de prestaciones con, al parecer, la complacencia y actividad de algunos de los agentes del sistema, a pesar de que muchas las exigencias estaban contempladas en los planes de beneficios $\mathrm{y}$, en otros casos, se habría podido acceder a las mismas si las autoridades administrativas tomaran, en aplicación de los principios y la jurisprudencia, las decisiones con oportunidad y razonabilidad a las que la garantía del derecho apuntaba con claridad. En este contexto, la rutina forjó en su yunque la tradición del amparo como camino de acceso a las prestaciones, al punto tal que las autoridades administrativas ni siquiera adoptaron medidas para estudiar, asimilar y validar el precedente judicial y actuar en consecuencia para ser congruentes con los principios de economía y eficiencia.

La solicitud, masificación, aceptación y consolidación de un trámite que involucra en círculo vicioso a la persona solicitante, el juez, la autoridades del Sector Salud, las EPS, las IPS, el Fondo de Solidaridad y Garantía, así como a los otros agentes, aumentó los costos de transacción cuyo impacto preferencial se da sobre los recursos del sistema, independientemente de que las prestaciones hayan sido negadas por entidades responsables de los planes de beneficios, cuyos contenidos, para efectos del conflicto, prefirieron ignorarse.

El acceso a la justicia fue el camino que recorrieron muchos pacientes que sentían vulnerados sus derechos y el apoyo de las entidades del Ministerio Público, especialmente de la Defensoría del Pueblo y las personerías distritales y municipales, no se hizo esperar, sin que ellas mismas motivaran a los organismos moduladores a 
aprender de la experiencia de la justiciabilidad y, por lo menos, se dieran acciones en la atención de personas de especial protección constitucional:

En relación con el derecho a la salud de las personas que hacen parte del grupo de los sujetos de especial protección constitucional es preciso considerar que a partir de normas constitucionales como los artículos 13, 44, 46 y 47, se impone mayor celo en el cumplimiento de los deberes de protección y garantía por parte de las autoridades y de los particulares en la atención de las enfermedades o alteraciones de salud que padezcan. Dentro de tales destinatarios se encuentran los niños, niñas y adolescentes y las personas de la tercera edad (Corte Constitucional. Sentencia T-056, 2015b).

Todo ello contribuyó a la mala imagen del servicio y opacó muchos de los importantes avances del Sistema General de Seguridad Social, entre otros:

El esfuerzo financiero que ha hecho el Estado Colombiano ubica al país como uno de los que más ha avanzado en asumir el costo directo del sistema de salud, con lo cual el gasto privado como porcentaje del gasto total en salud pasó de ser $52.3 \%$ en 1993 a $22 \%$ en $2011 \ldots$ Esto lo ubica mejor que otros países latinoamericanos y mejor que muchos países desarrollados (Ministerio de Salud y Protección Social, 2012, p. 37).

En materia de cobertura: "Los esfuerzos realizados en los últimos años lograron que el paíes avanzara al pasar del 24\% de cobertura en 1993, a una cobertura muy cercana a la universalización $(90,1 \%$ según encuesta de calidad de vida 2011)” (Ministerio de Salud y Protección Social, 2012, p. 35).

En materia de equidad:

El aumento en la cobertura disminuyó la enorme desigualdad inicial, no sólo entre niveles de ingreso sino también entre zonas geográficas. La afiliación en 
salud en el $20 \%$ más pobre de la población pasó de 4,3\% en 1993 a 87,0\% en 2011 y la afiliación en las zonas rurales pasó de 6,6\% en 1993 a cerca del 88\% en 2011 (ECV, cálculos MSPS). Así, la reforma al sistema de salud promovió una mayor progresividad y equidad en la distribución de subsidios. Estimaciones muestran que el sistema de salud disminuye la pobreza en 4,78 puntos porcentuales y reduce la desigualdad, medida por el coeficiente de Gini, en 2,54 (cálculo con base ECV 2008) (Ministerio de Salud y Protección Social, 2012, p. 39).

Y por último en materia de eficacia: La reforma de 1993 ha sido una de las más radicales que se ha implementado en los sistemas de salud y sus objetivos primordiales fueron la universalización del aseguramiento social, la protección financiera de las familias frente al gasto catastrófico derivado de los riesgos de salud y la equidad en el acceso a los servicios de salud. La evidencia muestra que la mayor parte de esos objetivos se lograron en los pasados 20 años.

El amparo constitucional siguió un camino individual dedicado a la protección del acceso a servicios médicos, hospitalarios, tratamientos y medicamentos, en el cual la Corte Constitucional valoró cuándo se negaba el reconocimiento de prestaciones, a pesar de estar incluidas en el Plan Obligatorio de Salud, ordenadas por el médico tratante o con argumentos diferentes a los estrictamente médicos, de donde invariablemente surgía la concesión de la solicitud y la orden de prestación inmediata de los servicios o medicamentos negados.

Igualmente, el máximo Tribunal Constitucional examinó la razonabilidad y justificación de la negación de prestaciones NO $\operatorname{POS}^{28}$ cuando todo indicaba que eran necesarias, indispensables y tenían carácter urgente, entre otras razones por la

28 Entre las que se encuentran medicamentos, dispositivos médicos, servicios médicos y prestaciones de salud. 
imposibilidad de los pacientes de asumir la financiación de las mismas. La Corte otorgaba la protección judicial y amparaba el derecho fundamental a la salud, con las siguientes consideraciones y argumentos: Necesidad de la prestación para recuperar o preservar la salud; evitar que la enfermedad altere la dignidad humana; prescripción médica que demuestre la necesidad del servicio o medicamento y, carencia, en el plan de beneficios, de una alternativa con igual o mejor efectividad y, la incapacidad económica del paciente o sus familiares para costear los servicios o medicamentos.

El litigio obró como incentivo negativo por la falencias de las autoridades en la aplicación de las políticas, planes y evaluación de la actualización y cumplimiento de las prestaciones a las que tenían derecho las personas, bien por estar en el régimen contributivo o, por pertenecer al régimen subsidiado, pues se trata de un derecho cuyo contenido, en materia de prestación de servicios, está prácticamente determinado en el campo de las ciencias médicas y, cuyas discrepancias deberían ser la excepción y no la regla. De hecho la Corte Constitucional sostuvo que no se puede interrumpir el servicio de salud a pacientes del régimen subsidiado, máxime si es una persona de especial protección constitucional y, en tal sentido, caracterizó como irrelevantes e inoponibles argumentos de tipo legal, administrativo, financiero o de problemas entre agentes del sistema, ya que, en defensa del derecho, prevalece la obligación de atender permanente y continuamente a la persona (Corte Constitucional. Sentencia C-T1167, 2003c).

\subsubsection{Desviación del Financiamiento del Sistema. Incumplimiento y desvío del rol} de las E.P.S. Desarticulación entre el financiamiento y la prestación de los servicios.

La administración y financiación del Sistema de Seguridad Social en Salud fue asignada al Fondo de Solidaridad y Garantía; a las Direcciones Seccionales, Distritales y Locales de Salud y a las Entidades Promotoras de Salud, éstas con un papel 
fundamental en la articulación entre el financiamiento y la prestación de los servicios, en su calidad de representantes de los intereses de los afiliados y beneficiarios.

Las Entidades Promotoras de Salud fueron concebidas como la instancia de articulación, especialmente porque a ellas les correspondía garantizar el vínculo, de doble vía, entre el financiamiento y la prestación, con un rol clave en el desarrollo y consolidación del Sistema: representación de los afiliados y beneficiarios; gestoras que contribuyen a superar eficazmente las asimetrías de información; compradoras de servicios de salud; representantes de los intereses de sus beneficiarios y generadoras de formación para ayudar a conocer las acciones de las personas en el cuidado, protección y preservación de la salud. En síntesis, ellas fueron concebidas como una institucionalidad que contribuiría a disminuir los costos del Sistema porque ellas estaban llamadas a generar las mejores prácticas entre sus afiliados y les dotaría de capacidad crítica para encaminar sus actividades familiares e individuales al bienestar integral.

El papel de las EPS fue concebido como agentes responsables de atraer el mayor número de afiliados en razón de su impacto sobre la calidad de la prestación de los servicios y no como filtros técnicos de exclusión de personas, basada en una selección adversa motivada en los riesgos, sin embargo, a lo largo de la historia del Sistema estas entidades han violado, y algunas de ellas continúan violando el derecho a la salud en varios momentos y circunstancias (Corte Constitucional. Sentencia T-760, 2008c), evidenciado en las siguientes prácticas:

a) Desconocer su papel como representante de los afiliados y beneficiarios al no intervenir, interceder y proponer, a las autoridades del Sistema, las acciones para evitar la vulneración del derecho y, con base en la jurisprudencia, ejecutar acciones inmediatas y oportunas para la autorización de servicios de salud. 
b) Utilizar de recursos de salud para fines distintos a los contemplados en las normas de la Seguridad Social en Salud, y en no pocos casos, en su propio beneficio, o en el de sus dueños, o accionistas, a pesar del carácter de destinación específica que tienen los mismos. En el caso de la Unidad de Pago por Capitación, expresó el Máximo Tribunal Constitucional:

La Unidad de Pago por Capitación no representa simplemente el pago por los servicios administrativos que prestan las EPS sino representa en especial, el cálculo de los costos para la prestación del servicio de salud en condiciones medias de calidad, tecnología y hotelería. Esto significa la prestación del servicio en condiciones de homogenización y optimización. La relación entre las entidades que pertenecen al sistema y los recursos que fluyen dentro del ciclo de prestación del servicio de salud, forman un conjunto inescindible... (Corte Constitucional. Sentencia C-828, 2001) ${ }^{29}$.

Así se ratifica la interdependencia entre funciones y agentes del SGSSS. A las EPS les son asignados solo aquellos recursos de la Unidad de Pago por Capitación destinados a los gastos administrativos, una vez que éstos, ingresen a su peculio.

c) Suponer que los afiliados y beneficiarios pertenecían, o pertenecen, exclusivamente al ámbito de su órbita de gestión, sin entender que todas las personas hacen parte del Sistema General de Seguridad Social en Salud.

d) Desconocer la importancia de informar periódicamente sobre los derechos y obligaciones de los afiliados, especialmente de quienes están sometidos a diagnósticos y tratamientos.

e) Omitir la libertad de selección e imponer restricciones a la movilidad del usuario entre EPS y, entre IPS.

29 Negrilla fuera de texto. 
f) Imponer sus propias cargas administrativas a los usuarios que supuestamente representaban.

g) Desconocer órdenes judiciales de prestación de servicios, a pesar de ser garantizado su pago con cargo a los recursos del Fondo de Solidaridad y Garantía.

h) Ignorar la importancia de adoptar trámites internos eficientes y eficaces para autorizar servicios a sus beneficiarios, independientemente de no estar incluidos en los planes de beneficios, en tanto, por la jurisprudencia, era posible su solicitud de pago al FOSYGA.

i) Suspender un tratamiento médico o el acceso a productos farmacéuticos formulados y autorizados.

j) Aprovechar los incentivos del sistema en los procedimientos de cobro de medicamentos y tratamientos no contemplados en el plan de beneficios y asumir, por esa vía, efectos negativos sobre la administración y distribución de recursos financieros, olvidando su papel de articuladoras para convertirse en defensoras de intereses particulares. Sobre el particular:

Existe evidencia que el desarrollo del sistema condujo a la consolidación de condiciones ineficientes de competencia entre EPS e IPS. Esto condujo a la generación de monopolios bilaterales en los que tanto el asegurador como el prestador cuentan con poder de mercado (Ministerio de Salud y Protección Social, 2012, p. 42).

k) Desconocer su papel como coadyuvantes del Sistema y, en consecuencia, no informar a las autoridades del Sistema sobre disposiciones que afectaban la buena marcha de los procesos y, al contrario, utilizar disposiciones legales en provecho de sus intereses particulares, en detrimento del derecho fundamental a la salud. 
1) Ignorar la actualización de la información de los afiliados y beneficiarios respecto a la situación socio-económica, sus condiciones de salud, tratamientos, medicamentos y demás datos que permitan identificar la situación epidemiológica, los principales riesgos y afectaciones y, las posibles acciones, con el fin de diseñar y adoptar programas específicos destinados a disminuir la carga de la enfermedad y motivar cambios en los hábitos de las personas en procura de una mejor calidad de vida y un alto estándar de salud.

La demora en el flujo de recursos, ha sido frecuente y reiterada, incide y continúa impactando, negativamente, la prestación de los servicios, ha desmejorado la calidad de la atención y aumentado el riesgo de deterioro, e incluso de la liquidación de instituciones prestadoras de servicios, especialmente de las Empresas Sociales del Estado, a las cuales el Gobierno les asignó, en no pocas oportunidades, la atención de personas, independientemente de la capacidad resolutiva hospitalaria.

El deterioro de las redes de servicios que debían organizar y garantizar las Entidades Promotoras de Salud, causado, entre otras razones, por los déficit en los flujos de recursos, las deficiencias administrativas y de gestión de algunas EPS, especialmente aquellas controladas por intereses económicos y políticos al margen de la legalidad.

La fragmentación de la prestación de los servicios basada en los menores costos de la atención originó discontinuidad en los tratamientos, deficiencias en la atención, incremento en los costos a cargo de los pacientes (transporte, alimentación, mayor tiempo del acompañante), mala calidad y, estimuló la percepción negativa en el servicio de salud. Así lo manifiesta Amat (2004) cuando menciona:

La Ley 100 no creo las bases para arreglar el problema? Sí, pero la creación de la libre competencia en salud, que también creó, originó una competencia 
desleal y eso va de la mano con el abuso de la posición dominante del que está comprando el servicio. Ellos están obligando a competir no por calidad sino por precio, y en la desesperación por subsistir, bajan precios, bajan ingresos y bajan calidad ${ }^{30}$. Se necesita un piso tarifario, se necesita que las EPS no construyan instituciones propias. No puede ser que mientras se cierran unos hospitales, se construyan otros. Eso es un contrasentido.

La introducción y consolidación de incentivos basados en la rentabilidad ha golpeado, y continúa golpeando, a las instituciones prestadoras de servicios de salud, particularmente a las Empresas Sociales del Estado, lo que ha originado el cierre de unidades necesarias para la atención, entre ellas urgencias, pediatría, medicina interna, entre otras, en favor de las unidades especializadas, con un alto componente tecnológico y de subespecialidad médica, todo lo cual ha aumentado los costos de los servicios (Ministerio de Salud y Protección Social, 2012), sin que se hayan redistribuido, internamente, las ganancias o contribuido a la estabilidad financiera de la entidad hospitalaria. Esta situación ha dado, a su vez, lugar a la disminución de la atención básica y, ha conducido a la enfermedad por los caminos de la alta especialidad, de tal manera que tener una enfermedad que requería atención especializada podría conducir a una mejor atención, que aquella que estaba en ciernes y, cuyo tratamiento exigía menores recursos.

30 Negrilla fuera de texto 


\section{Capitulo cuarto: Factores asociados a la gestión del Sistema General de Seguridad}

\section{Social en Salud.}

\subsection{Regulación, políticas, inspección, vigilancia y control y, otros factores asociados} al cumplimiento de las competencias del Sistema General de Seguridad Social en Salud.

Este apartado está dirigido a examinar factores asociados a la relación de la regulación, las políticas, las funciones de inspección, vigilancia y control, los recursos y la participación de las personas en el Sistema y, sus efectos sobre el derecho y los servicios de salud.

Regulación. La Asamblea Nacional Constituyente de Colombia da vía libre, en 1991, a una nueva Constitución que incorporó al sistema jurídico una innovadora y extensa carta de derechos y un modelo de Estado que busca, en la práctica, hacer efectivos los derechos de las personas a través de instituciones de carácter jurídico que tengan la capacidad de garantizar los derechos fundamentales de los todos los $\operatorname{asociados}^{31}$. En el mencionado grupo encuentran el derecho a la vida y la salud, razón por la cual, el Estado Colombiano adquirió la obligación, reiterada en la firma de pactos internacionales, de adoptar la regulación y las políticas indispensables para financiar, de manera sostenible, los servicios de salud y garantizar el flujo de recursos que permitan atender oportuna y eficientemente las necesidades en materia de salubridad de la población, así como el desarrollo de las respectivas políticas y financiación de proyectos relacionados con los determinantes sociales del estado de salud.

La regulación del funcionamiento del Sistema General de Seguridad Social en Salud debe estar ceñida a los principios adoptados por la Constitución de 1991 y las

31 Este modelo de Estado, de acuerdo al preámbulo de la Constitución, conocido como Estado Social de Derecho es el que ha dado su norte a la jurisprudencia de la Corte Constitucional. 
normas legales que determinan los componentes y flujos entre el Sistema, los agentes y los demás sectores; por consiguiente tales normas deben reflejar el respeto y la diligencia que las instituciones estatales, y las personas que desempeñan funciones públicas, tienen por la efectividad del derecho en su expresión amplia. Sin embargo, a pesar del marco constitucional, las disposiciones normativas y aplicación han sido históricamente objeto de críticas, ya que algunos autores la culpan de las fallas sistémicas que contribuirían a explicar la crisis de la salud en el país. A título de ejemplo sobre la Ley 1122 de 2007 se señaló:

...una de las primeras críticas a la Ley 1122 provienen del sector jurídico, que advierte sobre posibles fallos de orden constitucional y legal, porque cae en contradicciones con otras normas o en extralimitación al abordar asuntos no pertinentes. Otras objeciones provienen de sectores técnicos que afirman que en esta ley se tocan aspectos que se consideran ya reglamentados o resueltos en el sistema, otras incluso argumentan fallas en la redacción final del texto aprobado. (Restrepo V., 2007)

\section{Falencias de la función reguladora del Estado, en materia de salud.}

La revisión de la literatura apunta a concluir que la función de regulación del Estado, en concepto de algunos autores, está mal enfocada, al menos en varios aspectos:

Primera falencia. El enfoque económico, o de lucro, y la competencia. Esta primera falencia deviene del entendimiento de las distintas facetas que tiene la Constitución, pues, así como expresa varias garantías para los derechos de los asociados, busca un modelo basado en la libertad económica y por consiguiente en la competencia, modelo que afecta, inevitablemente, el diseño y la estructura general del Sistema General de Seguridad Social en Salud y su reglamentación, lo cual genera 
colisiones entre el derecho fundamental a la salud y el derecho a la libertad económica. Al respecto García V. \& Espinosa (2014) afirman:

Por ser una colisión inherente a la estructura del propio SGSSS, toda vez que el derecho fundamental a la salud, en su faceta de servicio público, permite la concurrencia en su prestación de actores públicos y privados. Esto crea de por sí una relación de tensión entre el derecho fundamental a la salud y el derecho a la libertad económica, es decir, entre una racionalidad social y una racionalidad de tipo económico (p.131).

En este sentido, el cuerpo normativo ha reglamentado y restringido la actividad de las Entidades Promotoras de Salud y las Instituciones Prestadoras de Servicios para orientar el sistema hacia la satisfacción de una parte prestacional, sustancia del derecho, y no, en esencia, al lucro, el cual constituye uno de los fines del derecho a la libertad económica. Sin embargo, al tratar las relaciones entre el derecho fundamental a la salud y la prestación de servicios, por parte de personas privadas, la Corte Constitucional ha señalado:

En otras palabras, si bien es cierto la Constitución permite la participación de los particulares, éstos deben sujetarse a las reglas que establezca el Estado -a través del Congreso y el Ejecutivo-, quien puede definir los alcances de su participación con sujeción a la Carta Política, y someterse a su vigilancia y control. Además, la jurisprudencia constitucional ha señalado que el poder de regulación de las libertades económicas en el ámbito del SGSSS es reforzado, en vista del interés público que reviste el servicio y su relación con la realización de varios derechos fundamentales, como la salud (Corte Constitucional. Sentencia C-262, 2013a). 
Empero, las colisiones, por su carácter estructural, subyacen cotidianamente y se inscriben en un escenario caracterizado por una demanda, de tendencia creciente, de servicios de salud frente a un "presupuesto escaso" y consecuentemente una Administración que enfrenta obligaciones signadas con el principio de eficiencia.

Hipertrofia legal. Prelación de las normas específicas, sobre los principios que informan el Sistema. La segunda está relacionado con la hipertrofia legal la cual es causada por la acción institucional y la reiterada creencia cultural que todo "vacío", limitación o problema relacionado con la organización, dirección, operación y atención de los servicios de salubridad se resuelve apelando a una norma que dedica sus temas a aspectos específicos y temas puntuales, dejando de lado los principios y los elementos sustanciales que pueden, por ellos mismos, orientar el estudio, análisis y toma de decisiones frente a cada una de las inquietudes y situaciones, inevitables, que plantean el ejercicio y la atención de las prestaciones de un derecho. Con relación a este aspecto Arias R. et al. (2012) afirman:

...infinidad de leyes, decretos y resoluciones que aparentemente constituyen una respuesta a los problemas puntuales, pero que finalmente terminan produciendo una saturación reglamentaria que obscurece el campo jurídico, permite la fácil transgresión a la ley, crea incertidumbre e inseguridad jurídica, eleva los costos de transacción y aumenta los litigios y controversias, congestionando los despachos judiciales y los entes de control sin que se resuelvan oportunamente los casos (p.52).

Es necesario advertir que la inflación normativa expresa muchos factores e intereses frente al ejercicio del Poder Público, los cuales no siempre atienden y obedecen a la solución de problemas prácticos del sistema, sino que, en algunos casos, se inscriben en el campo de la eficacia simbólica. El termino eficacia simbólica lo 
acuñan los investigadores García V. \& Espinosa (2014) para acercarse a aquellos efectos que tiene el derecho que no se pueden entender con el concepto clásico de eficacia instrumental definido por Hierro (2010), de esta maenra: "una norma es eficiente para alcanzar un estado de cosas propuesto, si, siendo su cumplimiento o aplicación un medio adecuado para obtener tal estado de cosas y no contradiciendo ningún principio del sistema” (p. 180), pues la eficacia simbólica consiste en “...utilizar aquello que el lenguaje jurídico evoca en sus textos, con el propósito de conseguir fines políticos diferentes de los plasmados en la norma misma a partir de su efecto comunicativo" (p.99).

Es decir, el campo de la eficacia simbólica, en el cual la norma más que solucionar un problema de carácter instrumental cumple sus objetivos por medio de la difusión de una "idea de legitimidad, de autoridad o justicia" (García V. \& Espinosa, 2014), útil para determinados actores políticos que buscan perpetuar su permanencia en el poder a través de la publicidad de dichos actos en poblaciones con potencial electoral.

En consecuencia la inflación normativa, y la hipertrofia legal que ella conlleva, expresa la falta de claridad de los objetivos de los organismos de regulación, su desconocimiento de las relaciones reales entre los agentes del sistema, su aislamiento de los afiliados, usuarios y beneficiarios, así como de sus representantes comunitarios, la carencia e interacción de estudios y diagnósticos con los prestadores de servicios y, el bajo de nivel de coordinación y concurrencia entre los entes estatales, quienes desconocen en la práctica el principio de colaboración armónica, factores que refuerzan la primacía de un propósito simbólico sobre los instrumentales y prácticos, cuyas consecuencias devienen en la excesiva imposición de procedimientos, trámites y requerimientos sobre los usuarios $\mathrm{y}$, el inevitable crecimiento los costos financieros y operativos para todos los agentes del Sistema General de Seguridad Social en Salud, 
además del inevitable aprovechamiento por parte de los capturadores de rentas y de quienes se han enquistado en las administraciones estatales territoriales para apoderarse de los recursos públicos, particularmente los de la salud. Garay \& Salcedo A. (2012) aseveran sobre el particular que: “Colombia es un ejemplo de adopción de modelos de descentralización que no han tenido en cuenta características que incluyen, entre otras, la acción de criminales poderosos" (p.48).

Fragmentación del Sistema. La tercera falencia, señalada de manera recurrente por varios autores (Martínez, 2013) y algunas entidades oficiales, es la fragmentación del sistema de salud que es un tema de afirmación recurrente en investigaciones académicas, así como en documentos oficiales del Ministerio rector del Ramo, el cual afirma:

Todos estos resultados muestran una tendencia sostenida a la resolución hospitalaria de la enfermedad, incremento del riesgo en salud y mayor gasto médico, lo cual genera como resultado la fragmentación de la atención médica, con los consecuentes efectos deletéreos sobre la salud y calidad de vida de personas, familias y comunidades, así como los sobrecostos generados por la estructura de costos, mucho más onerosa, de los escenarios de atención en urgencias de alta complejidad. Es también evidente que la prestación del servicio no está centrada en el paciente y cada prestador actúa de manera aislada con muchas limitaciones para el funcionamiento en red, lo cual deriva en mayor fraccionamiento y mayores costos en la atención. (Ministerio de Salud y Protección Social, 2016b, p. 17)

Esta fragmentación tiene su origen en la ampliación de la cobertura y la atención diferencial de servicios, motivada por los planes de beneficios resultantes de los regímenes Contributivo y Subsidiado, los cuales se institucionalizaron como alternativa 
para que toda persona participara en el servicio esencial de salud, se buscará, hacia el año 2000, la cobertura universal y, que todos los afiliados y beneficiarios recibieran las prestaciones de un único Plan Obligatorio de Salud («Ley 100 de 1993», Artículo 157).

La Ley 100 de 1993 expresa una nueva modalidad de operación del Sistema de Salud que busca conjugar las reglas del mercado con una configuración horizontal de agentes especializados, con el fin de consolidar un proceso ascendente de competencia y libre elección (Londoño, 2001), con una afiliación obligatoria de las personas con capacidad de pago en un ambiente de centralización en la gestión de los recursos financieros y la pluralidad de entidades organizadoras de las prestaciones, así como de las encargadas de la atención de las mismas.

El mencionado entorno, del denominado Régimen Contributivo, separó el financiamiento de la provisión de servicios e, igualmente, distinguió la compra de la producción de los servicios, en una perspectiva que buscaba dar poder de decisión a los afiliados y beneficiarios, motivar a las Entidades Promotoras de Salud a jugar un papel de investigación y generación de información para disminuir sustancialmente las asimetrías de información y dotar a los usuarios de capacidad consciente de elección, para concluir con un sistema de solidaridad que diera capacidad de decisión autónoma a los afiliados del Régimen Subsidiado y, en consecuencia, generara resultados positivos en el cuidado y protección de la salud, con base en instrumentos de regulación intencionalmente dirigidos a la creación y operación eficiente de mercados (Londoño, 2001).

La Ley 100 de 1993 asignó a tres agentes la regulación, a saber: al Consejo Nacional de Seguridad Social en Salud, al Ministerio de Salud y a la Superintendencia Nacional de Salud, entre los cuales asignó las competencias: Al primero, como máxima instancia de dirección y control. Al segundo la formulación de las políticas del Sector, 
las estrategias del Sistema, así como el diseño de planes, programas y normas para garantizar la calidad de los servicios. Al tercero, como responsable de vigilar, inspeccionar y controlar a los agentes del SGSSS.

En la gestión de las autoridades reguladoras. Varias falencias concurren en la gestión de las autoridades reguladoras que inevitablemente han tenido impacto sobre la eficiencia, eficacia y efectividad del papel del Estado en la prestación de los servicios de salud y en la garantía del derecho fundamental.

La primera está asociada al hecho objetivo de considerar que la salud se garantiza prioritariamente con la existencia de un sistema sanitario que logra el financiamiento equilibrado de una oferta completa de servicios de salud y motiva la intervención de prestadores en un mercado donde la competencia cumple el papel de garantizar la cobertura, calidad, pertinencia y oportunidad en la atención de las prestaciones $\mathrm{y}$, en consecuencia el cumplimiento del derecho. El resultado de esta práctica regulatoria sienta sus argumentos en la reiterada intervención de la Corte Constitucional que hace judicialmente válida la formula Derecho a la salud = prestación de servicios de salud, así la Corte Constitucional, en la Sentencia T-760 de 2008, indica:

En la presente sentencia, la Corte Constitucional aborda varios casos en los que se invoca la protección del derecho a la salud -concretamente, el acceso a servicios de salud que se requieren-, cuya solución ha sido clara y reiterada en la jurisprudencia de esta Corporación.

En la Sentencia T-121 de 2015 afirma: "La salud tiene dos facetas distintas, que se encuentran estrechamente ligadas: por una parte, se trata de un servicio público vigilado por el Estado; mientras que, por la otra, se configura en un derecho que ha sido reconocido por el legislador estatutario como fundamental, de lo que se predica, entre otras, su carácter de irrenunciable. Además de dicha condición, se desprende el acceso oportuno y de calidad a los servicios que se requieran para alcanzar el mejor nivel de salud posible. ${ }^{32}$

De otro lado, el Informe al Congreso 2014-2015, del Ministerio de Salud y Protección es bien diciente, sus temas están dedicados al Aseguramiento, afiliación e 
innovaciones al Modelo de Salud, Salud Pública -Promoción y Prevención-, Componentes de la Calidad en la Prestación de Servicios de Salud, Fortalecimiento Institucional, Sostenibilidad del Sistema de Salud y Promoción Social (Ministerio de Salud y Protección Social, 2015a).

Los avances normativos expresados en el Informe al Congreso 2014-2015, del Ministerio de Salud y Protección Social, señalan el aumento de la cobertura del Sistema, inclusión de jóvenes de 18 a 25 años como beneficiarios de los padres, independientemente que estén o no estudiando, eliminación de barreras de acceso con base en la movilidad de las personas entre los regímenes de afiliación, nuevo modelo de atención integral de salud en zonas dispersas, primacía de un enfoque de gestión del riesgo para priorizar la prevención, implementación de incentivos para todos los agentes del sistema para motivar que las acciones, desde el aseguramiento y la prestación, busquen garantizar el bienestar y la salud de la población en el territorio, reglamentación de la prestación de servicios a cargo del Estado en lugares de carencia de oferta privada y creación de una instancia de coordinación y asesoría dentro del Sistema General de Seguridad Social en Salud, entre cuyas funciones está la de asesorar y efectuar recomendaciones al Ministerio de Salud y Protección Social, y a las entidades que integran el Sector Administrativo de Salud y Protección Social en asuntos relacionados con los programas y proyectos que son de su competencia $y$, específicamente, en materia de prestación de servicios de salud, salud pública, aseguramiento en salud y promoción social en salud, que se presenten a su consideración (Ministerio de Salud y Protección Social, 2015a)

La segunda es la expresión objetiva sobre el desconocimiento práctico, aunque legalmente reconocido ${ }^{33}$, entre otras en la Ley Estatutaria de Salud, de los determinantes sociales y las actividades intersectoriales en la garantía del derecho a la salud, ya que para el Gobierno Nacional existe una clara diferencia entre lo que se entiende y cobija por salud, en particular la prestación de servicios médico - sanitarios y, de otro lado, los determinantes, los cuales en concepto del Ministro de Salud y Protección Social (Ministerio de Salud y Protección Social, 2013a), no pueden hacer parte del núcleo

33. La norma establece el deber del Estado adoptar políticas públicas dirigidas a lograr la reducción de las desigualdades de los determinantes sociales de la salud, promover el mejoramiento de la salud, prevenir la enfermedad, elevar el nivel de la calidad de vida $y$, orientar, las mencionadas políticas al logro de la equidad en salud. 
esencial del derecho por los efectos que tal concepción tendría sobre la estabilidad fiscal del Estado y, por consiguiente, constituyen un problema de los temas de desarrollo, olvidando que, son al fin y al cabo, los que tienen un mayor impacto cualitativo y cuantitativo sobre el estado de salud de la persona, la familia y la sociedad. Saltman (1997) al respecto manifiesta:

En este punto, la evidencia disponible muestra de manera abrumadora que la mayor parte de las actuaciones productoras de salud no proceden de los servicios médicos y clínicos, ni de los cuidados curativos, sino más bien de actividades intersectoriales... (p.18).

A pesar de las afirmaciones del Ministro de Salud y Protección Social la misma

Corte Constitucional asevera:

El derecho a la salud implica el acceso oportuno, eficaz, de calidad y en igualdad de condiciones a todos los servicios, facilidades, establecimientos y bienes que se requieran para garantizarlo. De igual manera, comprende la satisfacción de otros derechos vinculados con su realización efectiva, como ocurre con el saneamiento básico, el agua potable y la alimentación adecuada. Por ello, según el legislador estatutario, el sistema de salud: Es el conjunto articulado y armónico de principios y normas; políticas públicas; instituciones; competencias y procedimientos; facultades, obligaciones, derechos y deberes; financiamiento; controles; información y evaluación, que el Estado disponga para la garantía y materialización del derecho fundamental de la salud (Corte Constitucional. Sentencia T-121, 2015c).

El Ministerio de Salud y Protección Social, así como los demás agentes del Sistema General de Seguridad Social en Salud, deberían "dedicar" menos tiempo a la reflexión sobre los posibles efectos de la justiciabilidad del derecho, en particular el impacto fiscal que puede tener el amparo sobre temas relacionados con los determinantes sociales $\mathrm{y}$, asumir una acción coordinada y efectiva que integre las políticas públicas, los programas y los proyectos de carácter económico, social y 
cultural, en el marco de la colaboración armónica entre las entidades del Estado, con el fin de motivar y consolidar acciones públicas que mejoren las condiciones de vida de las poblaciones $\mathrm{y}$, concomitantemente, impacten el estado de salud positivo de la población, de tal manera que se eviten las decisiones previamente anunciadas, como la intervención que le ordenó la Corte Constitucional al Ministerio de Salud y a la Superintendencia Nacional de Salud en el caso del Departamento del Chocó.

Es claro que todo los esfuerzos han estado dirigidos a separar los determinantes sociales, de los servicios de salud, con el objeto, entre otros, de lograr una manejo estable de la situación fiscal, a pesar de la innegable evidencia fáctica de la incidencia de los mismos sobre la salud de las personas (Ministerio de Salud y Protección Social, 2013a), lo cual puede conducir a un incremento de los gastos y a agravar las preocupaciones que hoy acompañan a las autoridades del Sector Administrativo de Salud y Protección Social frente al crecimiento del gasto relacionado con las prestaciones de promoción y prevención, diagnóstico, tratamiento, paliación y rehabilitación.

La tercera se expresa en la manera como los gobiernos nacionales han realizado los procesos de coordinación, articulación, toma de decisiones y ejecución de sus políticas. La Ley 100 de 1993 creó el Consejo Nacional de Seguridad Social en Salud, órgano colegiado que como instancia participante en la dirección, vigilancia y control del Sistema, fue una verdadera instancia de participación y exposición de todos los agentes del Sistema y por consiguiente potencial mecanismo institucional para cohesionar y fortalecer la unidad de criterio, la vigilancia en el cumplimiento efectivo de las prestaciones, la autorregulación de sus copartícipes y, fue, esencialmente, el mecanismo para discutir, concertar y adoptar medidas oportunas y eficientes destinadas al cumplimiento de los principios del derecho a la salud, en tanto es responsable de 
definir el Plan Obligatorio de Salud, el monto de la cotización de los afiliados, el valor de la Unidad de Pago por Capitación, el régimen de pagos compartidos, los medicamentos esenciales y genéricos, los criterios de selección de beneficiarios del régimen subsidiado, el valor del subsidio por beneficiario de los afiliados al Régimen, la adopción de medidas para evitar la selección adversa y ejercer las funciones de Consejo de Administración del Fondo de Solidaridad y Garantía.

La expedición de normas legales, mecanismo preferido como respuesta permanente a las deficiencias administrativas y a los desafíos que imperan en la garantía del derecho a la salud, tienden a fortalecer el papel unívoco del Ministerio de Salud y Protección Social en el concierto del Sistema, ello acaeció precisamente con las competencias del Consejo Nacional de Seguridad Social en Salud, cuyas funciones, en principio, fueron asignadas a una Comisión de Regulación, en cuya composición desaparecen importantes agentes del sistema.

Otras varias situaciones expresan las falencias y limitaciones de los organismos encargados de la regulación, la dirección y el control del Sistema y del papel de sus agentes en el mismo, entre ellas merecen especial mención:

La falta de coordinación y colaboración armónica entre las entidades estatales en la comprensión, manejo y cumplimiento de los objetivos de la política, en unos casos por priorizar otras políticas sectoriales, no siempre ligadas al derecho a la salud ${ }^{34}$ e inconsecuentes con las acciones requeridas para actuar sobre factores que afectan a la salud, señalados por la Organización Mundial de la Salud, la Organización Panamericana de la Salud, el Comité de Derechos Económicos, Sociales y Culturales y

34 El manejo de los recursos del SGSSS estuvo atado, de manera explícita, hasta la vigencia fiscal de 2007 a la política de estabilidad fiscal, en contravía de la naturaleza parafiscal de los recursos. Igualmente, la inadecuada planeación financiera obró en detrimento de la universalidad, la solidaridad y la eficacia. 
diferentes autores que incluso van más allá en sus aseveraciones, como es el caso de Gañan Echavarría (2013) cuando afirma:

En la actualidad, tenemos suficiente evidencia para afirmar que las diferencias en salud que se observan entre las personas y los pueblos no son tanto un asunto médico, sino el reflejo de inequidades sociales injustas y evitables, arraigadas en estructuras sociales y sostenidas por sus dispositivos de control, entre los cuales se destacan la normatividad jurídica y las políticas económicas (p.xix)

Así mismo, la falta de visión, de las entidades oficiales del sector, para ejercer control e implementar las acciones sobre el comportamiento de aseguradores y prestadores, especialmente en temas asociados a la negación de prestaciones y, a las deficiencias, demostradas por las EPS, en las actividades de promoción y prevención a su cargo.

La pérdida de competencia reguladora del Ministerio de Salud y Protección Social - en su momento Ministerio de Protección Social - y de los mecanismos de concertación que tal acción exigía, que en concepto de González S. (2010) “Con ello también se sacrificaba una de las premisas del Sistema cual es el pluralismo estructurado" (p.107), a través del Consejo Nacional de Seguridad Social en Salud, por la creación de la Comisión de Regulación en Salud y el fuerte papel decisorio que, en la misma, jugaba el Ministerio de Hacienda y Crédito Público, generaron un arreglo institucional encaminado al control de costos y crearon otro tipo de barreras, de preferencia fiscales, que a la postre evitaron un análisis juicioso y estructural en la determinación de un único Plan Obligatorio de Salud para todos los afiliados, independientemente del régimen al que pertenecieran.

La adopción de un mecanismo regulador, en temas especialmente sensibles al acceso a prestaciones médicas y clínicas, compuesto por la instancias rectoras, de un 
lado, la de la política de hacienda y crédito público y, de otro, la de la protección social y, la vinculación de "tecnócratas" era una fiel copia de las comisiones de regulación existentes en materia de servicios públicos, los cuales tenían una tendencia en el estudio y decisiones completamente vertical, tal intento estaba llamado al fracaso, entre otras razones porque la Política Pública vigente, así como el modelo adoptado para su efectividad, partía de la necesidad de contar con la intervención de todos los agentes del sistema en la discusión, análisis y concertación de las decisiones que afectaran el acceso a los servicios de salud, aplicando y conservando principios esenciales a la Función Administrativa, entre ellos igualdad, buena fe, imparcialidad, participación y responsabilidad.

Al copiar una instancia organizativa de otra política, de otro sector y de otro modelo de gestión, se olvidaba la relación entre el arreglo institucional del Sistema, las responsabilidades de sus diferentes instancias $y$, la necesidad de examinar sistemáticamente las razones de los incumplimientos y deficiencias inter sistema y así se actuó de la manera menos efectiva, la cual obviamente terminó con la supresión de la instancia creada y la concentración de las funciones en el ente rector del Sector Salud y Protección, mediadas “obviamente” por el Ministerio de Hacienda y Crédito Público.

Las autoridades gubernamentales, sin la talanquera de un Consejo Nacional de Seguridad Social en Salud que obligaba a la concertación de la regulación y decisiones medulares en los temas de Salud, por haber quedado reducido a una simple instancia asesora, terminaron tomando el camino de mayores réditos políticos: la ampliación de cobertura, entre otras razones por los fallos del Consejo de Estado que exigieron utilizar los dineros del Fondo de Solidaridad y Garantía, teniendo en cuenta el carácter parafiscal de los recursos de la subcuenta de solidaridad. 
La conclusión de la decisión adoptada conduce a una paradoja: Ampliación de cobertura y menor equidad, por el acceso limitado al Plan Obligatorio de Salud de quienes ahora gozaban de afiliación al Régimen Subsidiado. Así el acceso a los servicios mantuvo sus ataduras a las decisiones de los jueces constitucionales, vía el amparo del derecho, y mostró, una vez más, la falta de visión y capacidad de gestión administrativa de los organismos de rectoría, dirección y control para impulsar acciones integrales que contribuyeran a superar las deficiencias en las que reiteradamente se encontraban las instancias responsables de la Función Administrativa, a pesar de su enumeración, y reiteración explícita, en múltiples sentencias de la Corte Constitucional. A título de ejemplo, por tratarse de recursos, sobre los que tantas veces se ha aseverado su finitud, frente a la Unidad de Pago por Capitación, el Máximo Tribunal Constitucional expresó:

No obstante, la Corte debe precisar que si el porcentaje de los gastos de administración genera excedentes, significa que la fijación de la UPC, que corresponde a los órganos rectores de la seguridad social[96], fue realizada con base en información desactualizada o no fiable, siendo responsabilidad de las entidades estatales que efectuaron el cálculo, evitar que los dineros de la salud entren, sin justificación suficiente, como recursos propios, a las arcas de las EPS a través de dicho rubro (Corte Constitucional. Sentencia C-262, 2013a).

El papel jugado por las entidades responsables del aseguramiento y de la prestación de servicios de salud, quienes dejaron atrás sus responsabilidades en materia de asesorar y contribuir a superar las asimetrías de información que afectan a sus beneficiarios, así como la negación de servicios y medicamentes, a pesar de estar contemplados en el Plan Obligatorio de Salud, y el impulso de atenciones de alta complejidad, tal como lo plantean Wagstaff y Cols (2015) "El sistema colombiano tiene 
los mejores resultados del continente en la combinación de reducción de riesgo financiero y acceso a servicios hospitalarios de alta complejidad" (citado por Ministerio de Salud y Protección Social, 2016, p. 8), las cuales envían una clara señal a los usuarios que les hace creer que el derecho a la salud es sinónimo de intervenciones biomédicas, en detrimento de acciones de calidad de vida y estilos saludables en las familias, comunidades y regiones, acciones de promoción y prevención, y cuidado del ambiente, variables éstas últimas que tienen un fuerte impacto sobre las condiciones y estado de salud de las personas, tal como lo señala Caines (1997): “...la evidencia disponible muestra de manera abrumadora que la mayor parte de las actuaciones productoras de salud no proceden de los servicios médicos y clínicos, ni de los cuidados curativos..." (p.18).

La carencia de acciones de promoción y prevención, unida a las bajas actividades de salud pública, y el desarrollo de una cultura social, promocionada por las Entidades Promotoras de Salud, que da origen a la preferencia por la atención hospitalaria de alta complejidad, reflejada en tasas de ocupación del 97\% en el segundo nivel y del $91 \%$ en el tercer nivel, mientras que el primer nivel tiene un escaso $40 \%$, todos ellos en el período 2007 - 2012 ( Ministerio de Salud y Protección Social. Política de Atención Integral en Salud, 2016).

La crisis financiera de las entidades hospitalarias motivada, entre otras razones, por el comportamiento de los aseguradores y el manejo financiero de los recursos, sobre los cuales se crearon trámites de hecho y altos costos de transacción. Estas conductas tienen un impacto negativo mayor en las Empresas Sociales del Estado por las pesadas cargas financieras con las que iniciaron su gestión, resultado de deudas pasadas sin una solución estructural y, las políticas coyunturales que intentaron solventar la crisis en la prestación de los servicios por medio de mecanismos de subsidio a la oferta, lo que 
obligó a muchos hospitales a prestar atenciones sin que les fueran cancelados los servicios oportunamente, a más de los problemas asociados a gestión, administración de personal y capacidad resolutiva. Al respecto González S. (2010) señala:

Los hospitales públicos entraron en un proceso de dificultades aún mayor al periodo anterior de entrada en vigencia de la reforma, lo que se explica esencialmente en las nuevas reglas de eficiencia implementadas, que no tuvieron en cuenta la situación histórica de estas instituciones, como sus pasivos, ni tampoco la dificultad para recortar costos o vérselas con otras exigencias del nuevo Sistema frente a las cuales no tenían ninguna compensación económica ni cultura corporativa ( $\mathrm{p} .107)$.

Muchas entidades hospitalarias ante los procesos de reestructuración que disminuyeron sus plantas de personal y el incremento de la demanda de servicios optaron por formas de contratación (cooperativas de trabajo asociado, contratación de servicios) que violaban flagrantemente las normas de derecho laboral. Tal forma de solución, a las necesidades de personal, se volvió tan usual en las entidades estatales que la Corte Constitucional se vio obligada a pronunciarse sobre el tema y conminó, entre otras entidades al Rector del Sector de la Protección Social, en los siguientes términos:

A pesar de la prohibición de vincular mediante contratos de prestación de servicios a personas que desempeñan funciones permanentes en la administración pública, en la actualidad se ha implantado como práctica usual en las relaciones laborales con el Estado la reducción de las plantas de personal de las entidades públicas, el aumento de contratos de prestación de servicios para el desempeño de funciones permanentes de la administración y de lo que ahora es un concepto acuñado y públicamente reconocido: la suscripción de "nóminas 
paralelas" o designación de una gran cantidad de personas que trabajan durante largos períodos en las entidades públicas en forma directa o mediante las cooperativas de trabajadores, empresas de servicios temporales o los denominados outsoursing, por lo que la realidad fáctica se muestra en un contexto distinto al que la norma acusada describe, pues se ubica en una posición irregular y abiertamente contraria a la Constitución, desviación práctica que desborda el control de constitucionalidad abstracto y su corrección corresponde a los jueces contencioso administrativos, o, excepcionalmente, al juez constitucional por vía de la acción de tutela; práctica ilegal que evidencia una manifiesta inconstitucionalidad que la Corte Constitucional no puede pasar inadvertida, pues afecta un tema estructural en la Carta de 1991, cual es el de la carrera administrativa como instrumento esencial para que el mérito sea la única regla de acceso y permanencia en la función pública, por lo que se insta a los órganos de control a cumplir el deber jurídico constitucional de exigir la aplicación de la regla prevista en la norma acusada y, en caso de incumplimiento, imponer las sanciones que la ley ha dispuesto para el efecto, y se conmina a la Contraloría General de la República, a la Procuraduría General de la Nación y al Ministerio de la Protección Social a que adelanten estudios completos e integrales de la actual situación de la contratación pública de prestación de servicios, en aras de impedir la aplicación abusiva de figuras constitucionalmente válidas (Corte Constitucional. Sentencia C-614, 2009).

La Ley 1122 de 2007. Falencias que ella intentó corregir. El escenario precedente a la expedición de la Ley 1122 del 2007 tenía, aparentemente, un consenso frente a los problemas del Sistema, entre los que destacan la inflación normativa, el incumplimiento en el logro de la cobertura universal, la carencia de un Plan Obligatorio 
de Salud unificado, los deficientes resultados en materia de salud pública, la selección adversa y las barreras de accesibilidad, el galimatías en que se había convertido el flujo de recursos cuya incidencia amenazaba la estabilidad financiera de Instituciones Prestadoras de Servicios de salud y Empresas Sociales del Estado, la innegable captura de rentas por agentes internos y externos al Sistema, la crisis hospitalaria y, la influencia de sectores ajenos a la salud en la gestión de los servicios a nivel de las entidades territoriales.

La mencionada norma realizó ajustes al Sistema relativos a la dirección, universalización, financiación, equilibrio entre actores, racionalización y mejoramiento de la prestación de los servicios, fortalecimiento de los programas de salud pública, así como en las funciones de inspección, vigilancia y control, además de la introducción de la organización de redes para la prestación de los servicios. De manera particular, creó la Comisión de Regulación en Salud (conformada por los ministros de Protección Social y de Hacienda y Crédito Pública, además de cinco expertos) a quien asignó la mayoría de las funciones del Consejo Nacional de Seguridad Social en Salud y, posteriormente, el Decreto 2560 de 2012 ordenó la liquidación de la mencionada Comisión, como consecuencia de un informe de gestión administrativa, dando lugar al traslado de sus competencias al Ministerio de Salud y Protección Social, con lo que se terminó cualquier mecanismo de concertación colegiada permanente de las más importantes decisiones en materia de regulación para el Sistema General de Seguridad Social en Salud $^{35}$, así la concertación de la políticas y acciones estructurales perdía de hecho cualquier participación directa de los diferentes agentes y, específicamente de las

35 El fracaso de la Comisión de Regulación en Salud da cuenta del papel jugado por los ministerios rectores (Protección Social y, Hacienda y Crédito Público) y los expertos en la resolución de problemas de regulación tantas veces advertidos por la Corte Constitucional, sin que se puedan atribuir las falencias administrativas y de gestión, en esa materia, a otros agentes. 
personas para quienes, en todos los niveles, su relación con su propia salud era una extraña en manos ajenas.

La cuarta se expresa en los cambios tardíos y en la imposibilidad práctica, para utilizar los servicios, a la que se ven abocados los afiliados y beneficiarios del Sistema, bien por la falta de actualización de las prestaciones, a las que pueden tener acceso, como consecuencia del desarrollo de tecnologías médicas, creación de nuevos medicamentos, diseño y adopción de nuevos protocolos médicos, desarrollo de nuevas terapias o por la posibilidad de acceder a medicinas alternativas. El artículo 19 de la Ley 1164 de 2007 (Talento Humano en Salud) señala que los profesionales, autorizados para ejercer una profesión de la salud, pueden utilizar la medicina alternativa y los procedimientos de las terapias alternativas y complementarias en el ámbito de su disciplina; sin que tales sobre tales servicios los afiliados y beneficiarios del Sistema tenga conocimiento, cuenten con asesoría y puedan acceder a los mismos como parte del Plan de Beneficios («Ley 1164 de 2007»).

Las características descritas son parte de las razones que han llevado a la Corte Constitucional a aseverar, en innumerables tutelas, que se viola el derecho a la salud por el desconocimiento y la incertidumbre, a la que se ven sometidas las personas que hacen parte del Sistema, sobre la cobertura de servicios, sin que pueda aducirse como fundamento el tiempo y los procedimientos que debe acotar el regulador para determinar y actualizar oportunamente los contenidos y configuraciones del Plan Obligatorio de Salud.

La historia de las decisiones relacionadas con el amparo del Derecho a la Salud deberían permitir al regulador entender que la garantía de la salud pasa, por lo menos en el ámbito de la justiciabilidad del derecho, por el acceso a todas las prestaciones, cuando las mismas son requeridas para garantizar la salud y, al mismo tiempo, aceptar que la literatura internacional, de tiempo atrás, asevera que el paquete básico de servicios acaba siendo siempre un paquete general (Saltman, Richard. Reformas sanitarias y equidad, 1997), además de valorar el impacto que tendrían políticas articuladas e 
integradas, bajo el principio de colaboración armónica de las entidades estatales, sobre el mejoramiento sostenido de la calidad de vida y, por contera, de la salud.

\subsection{Formulación de Políticas}

La política Pública de salud adoptada, desde principios de los años 90 del siglo pasado, refleja muchos de los cambios institucionales de la intervención del Estado y expresa, por sí misma, las múltiples concurrencias en una materia que tiene características cosmopolitas, nacionales, territoriales, familiares e individuales, en tanto la salud constituye uno de los derechos en cuya situación están inmersas acciones que pueden partir del individuo al mundo globalizado y se devuelven a éste con una fuerte carga de contenido universal.

La salud del individuo está, en consecuencia, asociada a múltiples y complejos elementos interrelacionados, entre ellos su comportamiento, costumbres, condiciones de vida, relaciones familiares y sociales, desarrollos científicos y tecnológicos, afectaciones del mercado al que concurre y sobre el cual existen presiones de agentes que juegan en el concierto mundial y, en general, por las decisiones internacionales relativas a la producción de conocimiento, tecnologías, medicamentos y condiciones de comercialización de los servicios relacionados con la salubridad. De hecho la literatura sobre las enfermedades y las posibles curas dejan perplejo a la persona más ilustrada en el campo de la salud humana y, en cierto sentido, presenta una de las paradojas del mundo de la información: la posibilidad de superar la asimetría de la información con el riesgo de naufragio en el mundo de los datos.

La política pública de los últimos veinte años combina varios instrumentos de gestión estatal, entre los que sobresalen la adopción de un modelo de competencia regulada, el fortalecimiento de recursos para el financiamiento de las prestaciones y acciones, la separación de la provisión de servicios de las fuentes de financiamiento, el 
fortalecimiento legal de los procesos de descentralización en la asignación de recursos y competencias, la creación de mecanismos de participación social y comunitaria y, la transformación del concepto de salud de caridad (fuertemente golpeado desde la expedición de la Ley 10 de 1990, a pesar de su visión asistencialista) al ejercicio de un derecho autónomo.

La política pública sentó sus caudales en la configuración de un sistema de carácter universal, solidario y eficiente, a partir del cambio estructural del acceso y prestación de servicios de salud, el fortalecimiento de las entidades territoriales en competencias relacionadas con los servicios de salud (iniciado con la Ley 10 de 1990), la adopción de mecanismos de competencia entre entidades aseguradoras y prestadoras de los servicios, la adopción del principio de libre escogencia del asegurador y el prestador, la paulatina sustitución de los subsidios de oferta a favor de los de demanda, el desarrollo del principio de equidad y, la adopción de mecanismos institucionales de concertación de las decisiones del sistema, a través de la participación en una instancia plural de las entidades estatales, los aseguradores, los prestadores, los representantes de trabajadores y pensionados. La Corte Constitucional ratifica tales aseveraciones, al señalar en la Sentencia C-463 de 2008:

Para la Corte Constitucional la seguridad social en salud es un servicio público inherente a la finalidad social del Estado, cuya prestación debe llevarse a cabo con fundamento en las normas constitucionales y en los principios de universalidad, solidaridad y eficacia. De acuerdo con el principio de universalidad todas las personas en condiciones de igualdad deben estar amparadas frente a todos los riegos derivados del aseguramiento en salud, bien sea para la prevención o promoción de la salud, o bien para la protección o la recuperación de la misma. En cuanto al principio de solidaridad se manifiesta en 
dos subreglas: en el deber de los sectores con mayores recursos económicos de contribuir al financiamiento de la seguridad social de las personas de escasos ingresos, y en la obligación de la sociedad entera o de alguna parte de ella, de colaborar en la protección de la seguridad social de las personas que por diversas circunstancias están imposibilitadas para procurarse su propio sustento y el de su familia. Por último, el principio de eficiencia en materia de salud hace relación al arte de la mejor utilización y maximización de los recursos financieros disponibles para lograr y asegurar la mejor prestación de los servicios de salud a toda la población a que da derecho la seguridad social en salud. (Corte Constitucional. Sentencia C-463, 2008a) y (Corte Constitucional. Sentencia C$542,1998 b)$

La institucionalización de la concertación entre agentes del sistema, las disposiciones que fijan la capacidad de regulación, las herramientas de organización y gestión de los agentes intervinientes, el papel asignado a las entidades estatales prestadoras de servicios de salud, la concentración de las fuentes de financiamiento y, los mecanismos de distribución y asignación de los recursos, permiten señalar que el Sistema General de Seguridad Social en Salud constituye una forma de intervención pública particular, que si bien introduce mecanismos de mercado que inducen la competencia, opera sobre la base de establecer la afiliación obligatoria al sistema, de tal manera que el afiliado y sus beneficiarios son concentrados en una Institución:

Además de constituir un derecho, la afiliación a este Sistema se convierte en una obligación para todos los habitantes, la cual se concreta mediante el pago de la cotización reglamentaria o a través del subsidio financiado con recursos fiscales, de solidaridad y los ingresos propios de los entes territoriales (Ley 100/93, art. 156-b), por medio del régimen contributivo o subsidiado o como participantes 
vinculados, en forma temporal (art. 157) (Corte Constitucional. Sentencia C$542,1998 b)$.

Dentro de dicha institución se puede ejercer el principio de libre escogencia; evitar la selección adversa; fijar el precio que paga (Unidad de Pago por Capitación) el sistema a las entidades promotoras de salud, sin dejar al arbitrio del mercado tal posibilidad; reglar el Plan Obligatorio de Salud que contempla las prestaciones a las que tienen acceso los afiliados y sus beneficiarios, y la adopción de incentivos encaminados a superar las condiciones de ineficiencia en la asignación y utilización de recursos. La Corte Constitucional sobre en particular, en la Sentencia T-797 de 2008, señala:

El rechazo de una solicitud de afiliación comporta una violación del derecho a la igualdad de las personas, al tiempo que atenta contra los derechos a la salud, la libertad de escogencia, la autonomía individual y la dignidad humana, por lo que aparece como una situación censurable constitucionalmente por comportar, en principio, una selección de riesgos del administrador del sistema de salud. En estos escenarios, la autoridad administrativa, el juez ordinario o el juez de tutela que conozca del rechazo de la solicitud de afiliación conforme a los mecanismos legales desatados por el afectado, debe valorar con estricto detenimiento las pruebas presentadas por las partes, como quiera que, prima facie, el diseño institucional comprende de forma idónea un espectro amplio de situaciones que enfrentan los aseguradores, a las que acompasa instrumentos legales y reglamentarios para garantizar la sostenibilidad financiera del sistema en el largo plazo, sin sacrificar la efectividad de los derechos de las personas, de manera que preliminarmente resulta inadmisible el rechazo de una solicitud de afiliación, inclusive bajo el 
argumento de selección adversa (Corte Constitucional. Sentencia T-797, $2008 \mathrm{~d}) .^{36}$

La política adoptada da un fuerte peso al papel de las entidades del Sector Salud, dado que ellas son responsables de regular y controlar el sistema, en virtud del cuasi monopolio estatal sobre la afiliación, el Plan Obligatorio de Salud, la Unidad de Pago por capitación y los incentivos. En consecuencia, los instrumentos de la política pública exigían "...decisiones políticas fuertes para regular el sistema y controlarlo..." (González S., 2010, p. 106).

Los objetivos centrales de la política pública, expresados en la Ley 100 de 1993 y sus posteriores reformas, tienen un relativo buen balance, en especial los referidos a la expansión de la protección financiera de las familias, al lograr reducir, el gasto de bolsillo en la compra de prestaciones de salud, así lo señalan Pérez \& Silva U. (2015):

Colombia es uno de los países latinoamericanos en donde la financiación del gasto en salud por parte de los hogares es de las más bajas, lo que significa una menor afectación a la capacidad de pago de las familias. En Colombia estos pagos representan el $64 \%$ de los gastos privados y el $15,9 \%$ del gasto total en salud (p.2).

El gasto decrece de la cifra del 43\%, existente en 1995, al $14 \%$ en 2014 (Ministerio de Salud y Protección Social, 2016b), entre otras razones por el crecimiento del aseguramiento y la prestación de los servicios de salud, sustentadas, independientemente de la autoridad estatal que ordenó las prestaciones, en el incremento del gasto total en salud que pasó del 5,9\% del PIB en 2000 al 6,5\% en 2011, equivalente a una variación cercana al 10\%, a pesar que Colombia continúa teniendo

36. Negrilla fuera de texto. 
hogares con una alta vulnerabilidad al gasto catastrófico en salud. Pérez \& Silva U. (2015) lo refieren así:

Los hallazgos dejan ver un sector de la salud fortalecido y que ha venido evolucionando en forma positiva durante la última década, período durante el cual aumentó su participación en el PIB. Aunque a este respecto el país está aún por debajo del promedio mundial, Colombia se destaca por la participación del sector público en el gasto total en salud, ubicándose muy por encima de las demás regiones del mundo, incluso de Europa (p.36).

Las cifras del período 2005 - 2012 muestran que los indicadores sobre la expectativa de vida han crecido y se han reducido los de mortalidad, especialmente la neonatal e infantil, ésta última en razón a las caídas del más del 50\% en enfermedades relacionadas con el sistema respiratorio, infecciosas, endocrinas, del sistema nervioso, digestivas y hematológicas y lesiones por causas externas, mientras que el único incremento ocurre por causas atribuibles al cáncer infantil (Ministerio de Salud y Protección Social, 2014). Es claro el cambio del patrón epidemiológico el cual camina hacia “...causas de mortalidad de etiología compleja, relacionada con los factores ambientales y de estilos de vida, propios de sociedades más urbanizadas" (Ministerio de Salud y Protección Social, 2016b, p. 9). 
Tabla 1

Recobros de pagos 1997-2014

\begin{tabular}{cc}
\hline A ÑO & $\begin{array}{c}\text { VALOR APROBADO } \\
\text { (\$Miles de Millones) }\end{array}$ \\
$1997-2000$ & 4 \\
2001 & 5 \\
2002 & 8 \\
2003 & 45 \\
2004 & 90 \\
2005 & 119 \\
2006 & 264 \\
2007 & 644 \\
2008 & 1.285 \\
2009 & 1.795 \\
2010 & 2.351 \\
2011 & 2.030 \\
2012 & 1.742 \\
2013 & 2.371 \\
2014 & 2.136 \\
\hline
\end{tabular}

Los datos fueron generados de la información del (Ministerio de Salud y Protección Social, 2016, p. 9).

Sin embargo, los resultados muestran que las entidades administrativas tienen una tendencia a la baja capacidad de gestión, magros resultados y poca reacción al mejoramiento, ya que, en múltiples momentos y casos, fueron desbordadas por los agentes aseguradores y prestadores de servicios y, en general, fueron pasivas, a tal punto que fue la Corte Constitucional la que motivó el cumplimiento de muchas de las prestaciones, creó paradigmas en torno a la fundamentabilidad del derecho y asumió un papel activo en el acceso real, de afiliados y beneficiarios, a los servicios de salud.

La explosión de los cobros por prestaciones que realizaban las Entidades Promotoras de Salud que no estaban contempladas en el Plan Obligatorio de Salud, conocidos como recobros, y que por diversas razones, entre ellas las decisiones de los jueces de tutela crearon un escenario de gasto de facto, el cual, a pesar de los fallos y de la jurisprudencia, se desatendió y dejó crecer, entre otras razones, por los fallos de tutela 
que amparaban servicios contemplados en el POS, negados por las aseguradoras, el creciente acceso a prestaciones NO POS y las políticas relacionadas con el manejo de medicamentos, de las cuales la libertad de precios fue tal vez la de mayor impacto negativo sobre los recursos del Fondo de Solidaridad y Garantía. El siguiente cuadro muestra el crecimiento de los recobros y su costo por vigencia fiscal, sin mencionar los costos administrativos de la gestión de los trámites y fenómenos de corrupción anexos a la masificación de cobros de prestaciones NO POS.

El incumplimiento en la actualización del plan de beneficios; obviamente el fraccionamiento de las prestaciones en varios planes con los efectos que sobre la equidad tiene tal decisión, y las actuaciones de las Entidades Promotoras de Salud sobre las rentas del Fondo de Solidaridad y Garantía, motivan, de un lado, demandas de prestaciones no incluidas y el acceso a todas las opciones potenciales que una persona puede encontrar en el mercado de servicios para paliar o curar su enfermedad, sin que las autoridades administrativas hayan adoptado acciones planificadas, fuertes $\mathrm{y}$ concretas que permitieran contrarrestar el caótico flujo de demandas por prestaciones y la inevitable bola de nieve que ello generó, a pesar de contar con los mecanismos institucionales para llamar la atención y sancionar EPS que negaban servicios y medicamentos ${ }^{37}$, y concertar la solución articulada a los diferentes problemas asociados a la planeación, programación, articulación y control que liga la gestión del Sistema General de Seguridad Social en Salud.

Las cifras muestran cómo los recobros pasaron de cerca de 1.300 millones de pesos en el año 2001 a un billón de pesos en 2008, a precios constantes de 2008, tal crecimiento del gasto debería generar alarmas fiscales y acciones inmediatas,

37 Muchas de las inquietudes sobre el comportamiento de las EPS estaban relacionadas con la utilización de los diferentes nombres o presentaciones de los medicamentos, lo que permitía encontrar un sustituto en el Plan Obligatorio, sin embargo, las entidades se descargaban de este gasto y lo cobraban al FOSYGA. 
estructurales y de largo plazo, por parte de los organismos responsables de la política pública. Sin embargo, el crecimiento se fue dando como un flujo normal que congestionó la administración del FOSYGA, y las prestaciones fueron creciendo, sin que se adoptaran soluciones estructurales en las cuales se comprometieran a todos los agentes del sistema, tal como suponía el pluralismo estructurado en el que se basaba el sistema $^{38 .}$

Las dificultades en la atención de los recobros también han estado asociadas a las deficiencias operativas en el flujo de recursos para los pagos a los agentes del sistema, a pesar de que las entidades encargadas de los negocios fiduciarios, según los resultados contractuales, tenían manejo competente de las mesas de dinero y rentabilidad de los portafolios, entre otras razones por la baja capacidad instalada, la carencia de sistemas adecuados de información, deficiencias en la gestión documental y poco personal para responder por unas operaciones que, con el tiempo, adquirían mayor complejidad. En el informe de Auditoria presentado por la Contraloría General se lee:

“...el Consorcio encargado del recaudo, administración y pago de los recursos del Fosyga autoriza desembolsos de los recursos del SGSSS, sin llenar los requisitos exigidos por las normas legales vigentes sobre el manejo de las EPS a las cuentas por cobrar por concepto de recobros al Fosyga, lo que evidenció que todas las solicitudes son contabilizadas como deuda real, sin determinar si existe aprobación del consorcio. En el período analizado, esos recobros pasan de $\$ 3.456$ millones a $\$ 226.842$ millones: un crecimiento del $6.464 \%$, o de 66 veces (Contraloría General de la República, 2007).

38 De hecho las principales patologías por la que se hacían recobros debían permitir al Ministerio de la Protección Social, a las EPS y a las instituciones prestadoras de servicios impulsar acciones específicas a grupos clave de la población para prevenir, tratar, superar y mitigar los efectos de las enfermedades, entre ellas SIDA, hipertensión arterial, enfermedad coronaria y cáncer. Muchas de ellas asociadas al "desarrollo" y la urbanización de las poblaciones. Otro tema son los costos de los diagnósticos, los cuales, en algunos casos presentaban cifras absurdas en el mercado de servicios de salud. 
Los niveles de evasión y elusión de aportes al Sistema obraron en detrimento de los recursos del SGSSS, especialmente por el impacto negativo sobre la ampliación de la cobertura y el acceso a los servicios para las personas y poblaciones más pobres.

La carencia de controles y acciones oportunas y contundentes permitió que los recursos de la salud, asignados a las entidades territoriales, fueran capturados por grupos al margen de la ley y políticos, quienes los utilizaron en favor de sus intereses y en la toma objetiva de algunas administraciones territoriales. La revista Semana describe dicho fenómeno, así:

La fuerte influencia de grupos al margen de la ley impuso gobernantes al servicio de intereses ajenos a los de los habitantes de muchos municipios del país. "Durante sus cinco años de existencia la Estructura de Apoyo de la Fiscalía creada para investigar los nexos de políticos con las autodefensas ha vinculado a más de 470 funcionarios en procesos de concierto para delinquir (Semana, 2012).

La política pública de salud, en particular el Sistema General de Seguridad Social fue transitando la senda de una crisis que muchos consideraron inducida, así lo expresa González S. (2010):

Así, esta fue otra opción de política pública que antecede a la emergencia y que fue auto inducida por el Gobierno Nacional. ¡Menos dinero para salud, tanto de recursos a la oferta como de subsidios a la demanda, para las entidades territoriales y la red hospitalaria pública!. Se estaba echando la suerte de la presión fiscal posterior (p.109).

Especialmente en el manejo de los recursos dentro de la órbita de las políticas del Ministerio de Hacienda y Crédito Público, particularmente, la inversión de los recursos del Sistema en TES, Bonos y títulos de deuda, en una cifra que se acercaba a 
los 5,1 billones en el año 2007 y que en el 2009 frisaba la cifra de los 6 billones, la baja ejecución de las subcuentas de Solidaridad y ECAT, aunados al conjunto de limitaciones y deficiencias señaladas, dan origen a una emergencia social que, con base en facultades del Gobierno Nacional, intentó la redefinición de la política pública y, obviamente, del Sistema General de Seguridad Social en Salud, en variados temas, entre ellos los planes de beneficios, la financiación de los servicios, los criterios del gasto social en salud, la estructura institucional, entre otros.

La Emergencia Social: Decreto 4975 de 2009. El Gobierno Nacional acudió al artículo 215 de la Constitución Nacional para declarar, en el año 2009, el Estado de Emergencia Social («Decreto 4975 de 2009») asociada a servicios públicos de la seguridad social y la atención en salud, con base en argumentos como el reconocimiento de la jurisprudencia constitucional de la salud como un derecho fundamental autónomo; las obligaciones del Sistema General de Seguridad Social en Salud relacionadas con el suministro de medicamentos y servicios no incluidos en los planes de beneficios; la carencia de mecanismos para identificar adecuadamente situaciones de abuso en la demanda de servicios NO POS; el hecho de que dichos servicios no fueron previstos en la Ley 100 de 1993 y, por consiguiente no estaban contemplados en los cálculos económicos y, el crecimiento generalizado de los mismos, en concepto del Gobierno de manera sobreviniente e inusitada, lo cual habían puesto en riesgo el equilibrio financiero del Sistema y afectado el aseguramiento con grave deterioro de la liquidez de las Entidades Promotoras de Salud e Instituciones Prestadoras de Servicios de Salud, así como la sostenibilidad del SGSSS y, por ende, la amenaza contra la viabilidad y continuidad en la prestación del servicio público de salud y, las potenciales afectaciones sobre el goce efectivo del derecho a la salud y la vida. 
El Gobierno reconoció, a su vez, en los considerandos del decreto que en los regímenes Contributivo y Subsidiado observaba que algunos reguladores y agentes del Sistema de Seguridad Social en Salud incentivaban la demanda o la oferta de servicios de salud por fuera de los contenidos señalados en los planes de beneficios, sin consideración a criterios de efectividad, sostenibilidad, costo eficiencia, racionalidad en el uso de los servicios y recursos, sin tener en cuenta la propia capacidad socioeconómica de los pacientes, todo los cual contribuía al aumento acelerado en la demanda de servicios y medicamentos no incluidos en los planes de beneficios y, por ello, al incremento ostensible de los costos del SGSSS.

El Gobierno presentó, entre sus argumentos de sustentación de la emergencia social, el número de recobros presentados al FOSYGA, en el Régimen Contributivo, por eventos NO POS cuyo número pasó de 835.000 en 2007, con un valor girado de \$626 mil millones, a cerca de 2.000.000 de recobros por cuantía de \$1.85 billones en 2009, cifras a partir de las cuales señaló la afectación del principio de equidad, en tanto, durante el año 2009, 376.000 personas afiliadas al Régimen Contributivo lograron beneficios no incluidos en el POS por un valor cercano a $\$ 1.8$ billones, mientras que el aseguramiento para los cerca de 18 millones de afiliados a dicho régimen tenía un estimado para el mismo año de 10 billones de pesos («Decreto 4975 de 2009»).

Es interesante encontrar en los considerandos del mencionado Decreto de Emergencia Social un conjunto de argumentos que muestran el conocimiento y claridad de las autoridades respecto de los problemas del Sistema General de Seguridad Social en Salud, la mayoría de ellos asociados a la dirección, orientación y control que estaba en cabeza, precisamente, de los organismos rectores del Sistema y que, en una medida significativa, reflejaba las deficiencias y limitaciones en términos de gestión, ellos son: 
El valor del recobro de los medicamentos excedía el precio de venta de los laboratorios y, en algunos casos, el número de medicamentos recobrados era superior al número de unidades oficialmente reportadas como vendidas por los laboratorios.

En el Régimen Subsidiado se evidenciaba el incremento en la demanda de servicios y medicamentos no incluidos en el Plan Obligatorio de Salud.

Las autoridades territoriales informaron sobre los incrementos significativos en el número de medicamentos y servicios NO POS y preveían un grave déficit de recursos que afectaría negativamente la prestación de servicios, con impacto sobre personas pobres y vulnerables no aseguradas. La cuantificación del déficit, por parte de las entidades territoriales, para la prestación de servicios de salud, mostraba su ascenso al pasar de $\$ 409.187$ millones en 2008 a un valor estimado de $\$ 885,237$ millones en 2009.

La dinámica y "mayor complejidad" adquirida por el Sistema General de Seguridad Social en Salud frente al flujo de recursos acreditó que los procedimientos y mecanismos para su distribución y giro creaban cargas administrativas innecesarias, conllevaban a ineficiencias y desvíos, que perjudicaban a los diferentes agentes del Sistema, incrementaban los costos de financiación y hacían evidente la grave situación de iliquidez, factor que impactó a todo el sistema, a pesar de que, entre las causas, se encontraba precisamente:

1.- La manera como cada agente cumplía su papel y, la tendencia de los privados a concentrar sus acciones en el aumento de su rentabilidad.

2.- La profundización de la crisis financiera explicada por las limitaciones del proceso de giro de los recursos el cual, según afirmaciones del Gobierno, amenazaba "grave e inminentemente la continuidad en la prestación del servicio de salud" y 
específicamente su impacto sobre la estabilidad fiscal de Hospitales y Clínicas y, el consecuente incremento de la cartera hospitalaria.

El incremento de la cartera con las Entidades Promotoras de Salud del Régimen Contributivo explicado por el Gobierno como resultado de la prestación de los servicios incluidos y no incluidos en los planes de beneficios.

3.- Las medidas que justificaban la declaratoria de la emergencia social tenían un carácter eminente administrativo y financiero, reflejaban la gestión de los organismos estatales competentes, y no evidenciaban una estrategia para integrar todos los factores asociados al derecho fundamental a la salud y, más bien apuntaban a resolver temas procedimentales, de control y manejo al acceso de servicios biomédicos y a racionalizar la "crisis" con base en acciones para las cuales, en un importante número de situaciones, existían disposiciones que permitían, sobre la base de la colaboración armónica entre las entidades estatales, afrontar viejos problemas a los que se les dio un nuevo ropaje.

Las medidas que hacían parte de los considerandos de decreto de emergencia social contemplaban, las siguientes acciones:

a) La adopción de regulación sobre la forma de acceso, condiciones, límites, fuentes de financiación y mecanismos para la prestación de servicios de salud y provisión de medicamentos no incluidos en los Planes Obligatorios de Salud de los regímenes Contributivo y Subsidiado del Sistema General de Seguridad Social en Salud.

b) La creación de las condiciones institucionales, financieras, fiscales y operativas para la unificación de los Planes Obligatorios de Salud.

c) La adopción medidas encaminadas a procurar el acceso oportuno y efectivo a los servicios previstos en los planes de beneficios, las actividades de promoción y 
prevención, y la universalidad del aseguramiento, a toda la población, en especial la más pobre y/o vulnerable, a fin de garantizarles el goce efectivo del derecho a la salud

d) La creación de instrumentos que permitieran lograr mayor equidad, oportunidad y transparencia en la distribución, asignación y flujo de los recursos en los dos regímenes, para evitar y corregir las fallas, demoras y desviaciones injustificadas en el uso de los recursos y, la adopción de reglas de priorización de la destinación recursos y el cumplimiento de sus objetivos

e) La adopción de medidas excepcionales para reasignar, redistribuir y racionalizar los recursos y las fuentes de financiación del Sistema o del sector salud, fortalecer mecanismos de control contra la evasión y elusión de obligaciones parafiscales y demás rentas que financian el sector.

f) La optimización de los recursos existentes y la generación de nuevos recursos para "evitar la crisis fiscal del Sistema".

g) La adopción de un marco regulatorio y el fortalecimiento de la Comisión de Regulación en Salud, para que las decisiones que inciden en los contenidos de los planes de beneficios $y$, en el equilibrio financiero, se armonizaran con los principios constitucionales que regulan el Sistema.

h) La implementación de criterios que permitieran a los médicos tratantes seguir parámetros, aceptados por la comunidad médica, con el fin de que los servicios de salud beneficiaran a los usuarios dentro de criterios de racionalidad, costoefectividad y evidencia técnico-científica, dentro de condiciones medias de calidad y tecnologías existentes en el país.

i) La adopción de medidas destinadas a revisar y racionalizar la actuación de los diversos reguladores y agentes del Sistema, entre otros, médicos tratantes, 
usuarios con y sin capacidad de pago, empleadores, Entidades Promotoras de Salud, Instituciones Prestadoras de Servicios de Salud y diversos proveedores de bienes y servicios asociados a dicha prestación, en materia de ordenación, acceso, suministro y reconocimiento de servicios y medicamentos incluidos o no en los planes de beneficios, así como la implementación de disposiciones preventivas, de recuperación de recursos, y punitivas que permitieran determinar y castigar la responsabilidad de quienes incurrieran en conductas fraudulentas, inseguras o ilegales.

j) La aprobación de medidas para que los recursos del Sistema fueran incorporados en su flujo, cumplieran sus fines constitucionales y fuera posible resolver las controversias presentadas entre los diferentes actores del Sistema.

En este aspecto, las confesiones gubernamentales son bien dicientes («Decreto 4975 de 2009»): La existencia de casos en los cuales los recursos del Sistema General de Seguridad Social en Salud y del sector salud eran destinados a fines diferentes a los mismos; la carencia de mecanismos expeditos para la solución de controversias entre los diferentes actores del Sistema; las limitaciones que presentaba la población del Régimen Subsidiado en la territorialidad del aseguramiento las cuales impedían el acceso a los servicios de salud $\mathrm{y}$, como cenit, el reconocimiento explícito de las autoridades administrativas sobre que tales hechos desbordaban la capacidad y los mecanismos preventivos, sancionatorios y de naturaleza jurisdiccional de los que disponía el Sistema de Inspección, Vigilancia y Control del Sector de la Protección Social requeridos en la "protección eficaz del goce efectivo del derecho a la salud", convirtiendo tal derecho en un simple acceso a la afiliación y a la prestación de atenciones biomédicas.

Tales confesiones en parte reflejan que la "crisis" era el resultado de la acumulación de problemas de dirección, orientación, regulación y control de las 
autoridades y, concretamente, atribuible, en un alto porcentaje a la falta de gestión de órganos rectores del Sistema, así como al aprovechamiento de agentes privados ante la ausencia institucional de la acción estatal; por consiguiente, el intento de reforma, apoyado en una emergencia social, constituía un perdón consensuado que no relevaba las verdaderas causas, por las que nadie respondía, ni ha respondido, de una situación sobre la cual el Gobierno ya había planteado una reforma que culminó en la expedición de la Ley 1122 de 2007, con modificaciones al Sistema General de Seguridad Social en Salud en materias de dirección y regulación, financiamiento, aseguramiento, prestación de servicios de salud, salud pública, e inspección vigilancia y control y, cuyos resultados, a dos años de expedida, fue la declaratoria de una emergencia social, lo que necesariamente llega a concluir que el tratamiento, adoptado por las autoridades estatales, había agudizado la enfermedad del paciente, en concreto, la cura fue peor que la enfermedad y, el mismo Gobierno Nacional anunciaba, como médico en vela, que el paciente, al cabo de varias meses de la reforma adoptada en 2007, presentaba los estertores que precedían a la muerte.

Lo cierto del diagnóstico del Gobierno y su justificación de la crisis para motivar la mencionada emergencia social es que los factores asociados a la gestión administrativa, financiera y operativa; la tendencia institucionalizada a articular el gasto del Sistema General de Seguridad Social en Salud a la política fiscal; las decisiones en la disminución de recursos hacia las entidades territoriales y la mayor carga en funciones relacionadas con la afiliación y la atención de los servicios y, la falta de acciones eficaces de inspección, vigilancia y control sobre los agentes aseguradores y prestadores; el comportamiento errático en la regulación y la predilección, aceptada por todas las instancias componentes del Sistema General de Seguridad Social en Salud (incluida la justicia constitucional), en la concentración de la atención de la enfermedad, 
en detrimento de las actividades de promoción, prevención, especialmente en acciones que motiven estilos de vida saludable, revelan problemas asociados a gestión deficiente en el ejercicio de la Función Administrativa y la impotencia estatal para lograr niveles de eficiencia, eficacia y efectividad en la prestación de servicios, pese a haber adoptado un mecanismo jerárquico, copiado de la regulación en el control de los servicios públicos domiciliarios, como la Comisión de Regulación de Salud.

La crisis de la Política de Salud, particularmente del Sistema General de Seguridad Social en Salud, expresa claramente las deficiencias de dirección, gerencia y control y, en general no están asociadas a sus componentes, entre otras razones porque las reformas adoptadas, la emergencia social adoptada y declarada inconstitucional por la Corte Constitucional y, la Ley Estatutaria de Salud están dirigidas a resolver problemas de gestión y operación y, en la última, a realizar énfasis diferentes frente a las condiciones y situaciones que influyen y condicionan la salud, sin que ninguna de ellas propenda por un modelo que integre la totalidad de los componentes asociados al estado de salud y bienestar de las personas, a pesar de su reconocimiento teórico y, en ese camino, los componentes sectoriales continúan con una autonomía que no está acompañada de la colaboración armónica entre los entes estatales, por eso las propuestas institucionales más que apuntar a la garantía, del derecho fundamental a salud, se encaminan a lograr la cobertura universal de la afiliación y la prestación de los servicios de salud en un marco de estabilidad fiscal, tal cual lo revelan la exposición de los proyectos normativos.

\subsection{Inspección, vigilancia y control}

Una de las falencias históricas que contribuyó al desconocimiento del derecho a la salud, fue la desconfianza que generó en los pacientes y abrió la senda de la captura de rentas, por causa de las deficientes medidas y acciones, de las instancias responsables 
de las funciones de inspección y vigilancia sobre las Entidades Promotoras de Salud, en temas tan sensibles como la obligación de éstas de proveer oportunamente los servicios de salud incluidos en el Plan Obligatorio de Salud. Desde muy temprano la Corte Constitucional señaló, verbigracia en la Sentencia C-112 de 1998:

...que las personas están afiliadas al Sistema General de Seguridad Social en Salud, en ningún caso a una EPS, por lo que el pago por el costo de servicios no incluidos en el Plan Obligatorio de Salud es responsabilidad del Fondo de Solidaridad y Garantía. Por consiguiente, es injustificable que los organismos de control no hayan utilizado sus competencias para garantizar, al menos, las prestaciones incluidas en el POS y evitar su indebido cobro (Corte Constitucional Sentencia C-112, 1998a).

Uno de los puntos de mayor sensibilidad, tanto en la doctrina como en la gestión, es el ejercicio constante y efectivo de las funciones de inspección, vigilancia y control en el Sistema General de Seguridad Social en Salud. Así lo expresan Restrepo Z., Atehortua B., \& Rodriguez Acosta (2008):

...la salud se ha convertido en uno de los sectores sociales con mayor interés económico y político en todo el mundo, debido especialmente, a su incidencia en el bienestar y crecimiento económico, así como por las necesidades en materia de recursos que requiere para su funcionamiento (p.10).

El artículo 230 de la ley 100 de 1993 encargó la función de inspección vigilancia y control, entre otras entidades a la Superintendencia Nacional de Salud, cuyas funciones fueron fortalecidas por las Leyes 715 de 2001, 1122 de 2007 y 1438 de 2011, las dos a últimas le otorgaron funciones jurisdiccionales en asuntos de cobertura de los procedimientos, actividades e intervenciones del Plan Obligatorio de Salud cuando su negativa ponga en riesgo o amenace la salud del usuario, el reconocimiento 
económico de los gastos en que haya incurrido el afiliado por concepto de atención de urgencias, en casos específicamente señalados en la norma referenciada, la resolución de los conflictos que se suscitan por discusiones asociadas a la multiafiliación y las controversias sobre el principio de libre elección, que se den entre afiliados y beneficiarios y, las entidades aseguradoras y las prestadoras de servicios de salud, así como los litigios relacionados con la movilidad dentro del Sistema.

El arreglo institucional del ejercicio de la inspección, vigilancia y control comprendía, según la Ley 100 de 1993, a las instituciones rectoras del Sistema, por competencias de control y a las entidades territoriales en las que se depositaban funciones de supervisión y control de recaudo, hacer cumplir las normas de orden sanitario y desarrollar labores de inspección, vigilancia y control de las instituciones que prestan servicios de salud, e informar a las autoridades competentes sobre la inobservancia de las normas de obligatorio cumplimiento. La organización y gestión de este importante núcleo de la gestión estatal para garantizar la prestación de los servicios de salud carecía de una instancia que orientara, coordinara y controlara la inspección, vigilancia y control, hasta la expedición de la Ley 1122 de 2007, la cual creó el Sistema de Inspección, Vigilancia y Control, a cuya cabeza designó a la Superintendencia Nacional de Salud.

La organización y asignación de funciones en el campo de la supervisión forman parte de las explicaciones sobre las deficiencias y limitaciones del cumplimiento de las responsabilidades a cargo de los agentes del sistema, por cuanto la carencia de un sistema de inspección, vigilancia y control, la dispersión del ejercicio de las mencionadas funciones entre varios entes estatales sin un norte claro y delimitado, la proliferación de funciones, en algunos casos duplicadas, entre los agentes estatales rectores del Sistema, las debilidades institucionales de muchas de las entidades 
territoriales que les impedía asumir técnica y operativamente la inspección, el conflicto de intereses de funcionarios de los distritos y municipios, al ejercer simultáneamente funciones de afiliación, administración de recursos, giros, prestación de servicios y la inspección, vigilancia y control ${ }^{39} \mathrm{y}$, la injerencia de estamentos directamente vinculados a la Rama legislativa, dan como resultado la imposibilidad de conocer los responsables de los problemas del sistema, hacen nugatorias las normas administrativas en materia sancionatoria y las orientadas a lograr por parte de los agentes del sistema el cumplimiento efectivo de sus competencias y, relevan una debilidad creciente de las autoridades administrativas en el cumplimiento de los fines del Estado relacionados con la garantía del Derecho y la Prestación de los Servicios de Salud, a pesar de contar con los instrumentos legales pertinentes, en cuyos argumentos, con el paso del tiempo, la máxima instancia de control constitucional tuvo razón. La Corte Constitucional anotó, al señalar la imposibilidad de permitir que continuaran vigentes algunos decretos sustentados en la norma que declaró la emergencia social, lo siguiente:

...se presentan situaciones de abuso, ineficiencia administrativa y corrupción que desequilibran aún más la sostenibilidad financiera del sistema, por lo que debe controlarse el destino de los recursos públicos... se dispone de un marco de competencias ordinarias a corto, mediano y largo plazo, suficientes para prevenir y corregir la problemática en salud con oportunidad y eficiencia... (Corte Constitucional. Sentencia C-253, 2010).

El sinnúmero de funciones asignadas a la Superintendencia Nacional de Salud, las entidades territoriales y otras instancias estatales, en el campo de la supervisión, sin

39 El proceso de recepción de recursos del Sistema General de Participaciones, la supervisión de traslados financieros de los entes territoriales a sus respectivos Fondos de Salud, de éstos a las Administradoras del Régimen subsidiado y, de éstas, a las instituciones prestadoras de servicios y a las Empresas Sociales del Estado, son apenas un ejemplo del laberinto institucional que mueve el flujo de dineros, los tiempos que genera, los costos en los que se incurren y las múltiples instancias que participan. Y en este ciclo participan, en muchos casos, empleados que cumplen todas las competencias, así que nadie ronda, efectivamente, qué ocurre en esa maraña. 
una clara articulación que cohesionara y articulara el ejercicio de la inspección, vigilancia y control, la limitación de recursos asignados, las observaciones y órdenes de la Corte Constitucional que iban in crescendo y el interés del entonces Ministerio de la Protección Social por corregir las fallas de la supervisión, crearon mayor confusión respecto de la responsabilidad en la rectoría de las funciones, forjaron una concentración de las actividades de la Superintendencia en áreas de acción específica, sin que se pueda aseverar que eran las más sensibles o aptas para lograr un mejor cumplimiento de los agentes del sistema, crearon un laberinto respecto del quehacer de las entidades territoriales, así como del comportamiento de las funciones claves del sistema y minaron la credibilidad de la inspección, vigilancia y control, a tal punto que, a pesar de haber sido considerado el tema en la reforma de 2007 (Capítulo VII de la Ley 1122), se convirtió en otra de las justificaciones de la denominada emergencia social declarada en el año 2009, basada en la incapacidad y la falta de mecanismos para la protección eficaz del goce efectivo del derecho a la salud. La Sentencia C-252 de 2010 asevera:

Entonces, cómo es posible sostener bajo una modalidad decisoria ultra activa, que luego de la comprobación constitucional de la inacción del Estado para establecer unas políticas profundas, serías y estables en salud reconocida además por los actores de la salud, del desgreño administrativo y corrupción campante sobre los recursos de la salud expuesta por el Gobierno y aceptada igualmente por los agentes de la salud...(Corte Constitucional. Sentencia C-252, 2010).

La historia de la Superintendencia de Salud muestra una entidad débil, otros organismos de supervisión desprovistos de planes y agendas articulados hacia objetivos comunes, incluso los principios de la Función Pública parecen desconocidos a quienes, en las entidades territoriales, tenían funciones de inspección, vigilancia y control y, los 
organismos de control fiscal, fuera de señalar, en algunos casos, falencias en sus periódicos informes de auditoría' tampoco lograron promover una mejor actuación de los mencionados entes, a tal punto que los agentes del sistema, especialmente los responsables del aseguramiento y de las prestaciones sociales desconocían, en general, las actuaciones de quienes estaban obligados a ejercer control. Así lo revela Arias R. et al. (2012): “...tradicionalmente, la inspección, control y vigilancia han sido débiles o ausentes en la mayoría de las entidades que deberían ser vigiladas" (p.58).

La supervisión del cumplimiento de los estándares de calidad en la prestación de los servicios de salud es otro indicador de las deficiencias del ejercicio de las funciones de inspección, vigilancia y control, motivada por la multiplicidad, diversidad y complejidad de las normas del Sistema General de Seguridad Social en Salud, la baja capacidad técnica, la deficiente capacitación y el desconocimiento de las normas e instrumentos de supervisión, por buena parte de los funcionarios de las entidades territoriales. A ello debe agregarse las funciones que, simultáneamente, ejercen dichos funcionarios en materia de control, entre otras actividades la verificación del cumplimiento de los requisitos mínimos de las propias Empresas Sociales del Estado del gobierno territorial, la vigilancia respecto de la asignación de los subsidios a la oferta, la cual fue tomada por prohijados de políticos en los departamentos, distritos y municipios y, como corolario, la incidencia de oscuros intereses que tomaron y controlaron instituciones públicas; todo lo cual conduce al limitado, débil y, a veces, inexistente ejercicio de la inspección, vigilancia y control. Al respecto Garay \& Salcedo A. (2012) manifiestan:

En este sentido, la búsqueda de control territorial y los factores económicos relacionados con el presupuesto público son útiles para explicar el interés de los 
grupos paramilitares por controlar instituciones e instancias de decisión pública en los niveles locales y regionales (p.103).

La carencia de un sistema de información que permitiera obtener datos, cifras e indicadores de calidad, oportunos, pertinentes y que lograran una cobertura sustancial actuaba contra los fines de la supervisión, limitaba el intercambio de información y la caracterización de procesos, procedimientos, áreas y actividades de riesgo frente al cumplimiento de las obligaciones de los distintos agentes del sistema; por ello, resultaban más limitadas las acciones de planeación, programación, ejecución y validación de las funciones de inspección, vigilancia y control y, aquellas que eran ejecutadas obedecían, en un buen número de casos, a la rutina del ejercicio de actividades, cuya extensión e impacto era imposible prever, dado que no correspondían a una acción planificada por parte de los ejecutores.

\subsection{Medicamentos: Un camino desconocido y tortuoso}

La política pública de salud sobre los medicamentos ha tenido en la iniciativa privada, particularmente en lo referente a patentes, uno de los elementos de mayor incidencia en los costos de adquisición de los farmacéuticos requeridos por los pacientes y, comporta múltiples barreras que inciden en la disponibilidad y acceso a los mismos.

El tema de acceso a medicamentos como elemento sustancial de las prestaciones del servicio de salud tiene múltiples aristas que pueden afectar la calidad de vida, el estado de salud y la recuperación de una persona frente a las consecuencias de una patología individual o social. En efecto, al parecer, concurren dos derechos que, en múltiples, momentos exigen la intervención de la administración o los jueces ${ }^{40}$, de

40 Las tensiones entre los mencionados derechos trascienden las barreras nacionales y se instalan en el campo del comercio internacional, donde los Estados que tienen empresas productoras pueden imponer condiciones de transacción que inevitablemente afectan los precios hacia el alza y afectan la capacidad de compra de las personas. 
acuerdo con sus competencias, para dirimir los "intereses" en conflicto y dar preferencia a la salud o a la iniciativa privada que produce, comercializa y vende productos farmacéuticos.

Los medicamentos constituyen bienes preciados en el campo del diagnóstico, tratamiento y superación de las enfermedades y, el acceso a los mismos está precedido, según algunos investigadores, de una tensión, al menos entre dos derechos de un lado, la libertad económica y las restricciones que las patentes determinan, como incentivo a la investigación y el desarrollo científico-tecnológico, sobre la producción y comercialización de bienes que, por su connotación en el bienestar e impacto sobre las personas son públicos y, de otro lado, el acceso a las mismos, por parte de los pacientes, como insumo imprescindible, al menos desde la óptica médica, en la superación de patologías y recuperación de la salud. La OMC (Organización Mundial del Comercio) manifiesta: "La mayor parte del valor de los medicamentos y otros productos nuevos de alta tecnología reside en la cantidad de invención, innovación, investigación, diseño y pruebas que requieren" (Acuerdo sobre los Aspectos de los Derechos de Propiedad Intelectual, 2000)

Los argumentos sobre los que se cimenta la lógica de otorgar patentes parten, entre otros, de la idea del alto costo que implica la investigación y desarrollo de principios activos, su aplicación, estandarización, prueba, aprobación y comercialización, lo que, en concepto de algunos autores, hace necesario crear condiciones jurídicas específicas que permitan estimular la iniciativa privada hacia el estudio, descubrimiento y producción de medicamentos. Al respecto Pinzón Camargo (2011) señala:

Se trata del sistema de Investigación y Desarrollo (I+D), el cual es protegido por el sistema de propiedad intelectual, en concreto por el sistema de patentes, y es 
el encargado de proveer nuevos y mejores medicamentos para atender las necesidades en materia de salud de la sociedad mundial." Pinzón, Mario. Medicamentos y patentes (p.17).

Es clara la internacionalización e incidencia, sobre el derecho a la salud, de las disposiciones que regulan la aplicación del derecho a la propiedad intelectual, por la exigencia de algunos Estados y la presión de quienes aducen los altos costos en los que incurren para generar el conocimiento y desarrollo de nuevos productos, tal como el Acuerdo sobre los Aspectos de Derechos de Propiedad Intelectual relacionados con el Comercio (ADPIC), cuya aplicación permite la protección de los intereses de las empresas farmacéuticas, sin que se opongan, a las mismas, el interés social y, particularmente, la importancia del derecho fundamental a la salud, en los diferentes contextos territoriales, nacionales e internacionales, a pesar de algunas cesiones formales expresadas en los tratados de libre comercio. La Sentencia C-751 de 2008 señala al respecto:

En los tratados de libre comercio se pueden ver los efectos de las disposiciones sobre los medicamentos destinados a las personas, ya que allí se "excluyen" únicamente del tratamiento de las garantías comerciales los medicamentos asociados a problemas de salud pública, a título de ejemplo: "Colombia como Estados Unidos se comprometen a realizar sus mejores esfuerzos para tramitar de la manera más expedita posible las solicitudes de patentes y de aprobación de comercialización, a fin de evitar retrasos irrazonables, estableciéndose la obligación de las Partes de instituir los mecanismos de compensación por retrasos irrazonables, $\mathrm{y}$ en el caso de patentes relativas a productos farmacéuticos, el Protocolo flexibiliza las reglas fijadas por el Acuerdo de Promoción Comercial. La modificación introducida por el Protocolo 
expresamente señala que el capítulo16 puede y debe ser interpretado y aplicado de manera que garantice el derecho de las Partes a proteger la salud pública y para promover el acceso a los medicamentos. Esta posibilidad garantiza la prevalencia del interés general en materia de salud pública y de acceso a medicamentos, lo cual a su vez, asegura que el titular de la patente cumpla con sus deberes sociales. Asimismo, reiterar la facultad que tiene cada Estado Parte de adoptar medidas en situaciones de crisis de salud pública y de conceder licencias obligatorias e importar medicamentos legítimamente introducidos en terceros países sin autorización del titular de la patente ${ }^{41}$. (Corte Constitucional. Sentencia C-751, 2008b).

Lo anterior debido a que el acceso a los medicamentos depende de industrias productoras con asiento en los países desarrollados (Herrera S. \& Dìaz, 2013, p. 33).

El tema de la importancia de los principios activos, en el tratamiento y superación de las enfermedades, es reforzado por la literatura médica y oficial, las políticas públicas, las normas del Sistema General de Seguridad Social en Salud, los responsables de las entidades de regulación, dirección y control, los profesionales de la salud y el convencimiento de las personas que acceden a los servicios de salud, especialmente a las consultas con médicos generales y especializados, en tanto todos parten del supuesto generalizado y culturalmente arraigado de que los medicamentos son imprescindibles para el tratamiento y superación de las enfermedades. Al respecto Pinzón Camargo (2011) escribe:

Es claro que una de las variables que coadyuvan a lograr la salud en los términos establecidos en la constitución de la OMS, son los medicamentos y, en concreto,

41 Negrilla fuera de texto, 
su acceso por parte de la población que los necesita, no solo como agentes curativos sino también como medios preventivos (p.16).

Tal paradigma acompaña con fuerza inusitada la regulación y cada uno de los componentes del Sistema General de Seguridad Social en Salud, así como el amparo al derecho fundamental a la salud. En la Sentencia T-073 de 2013 se resalta:

Todo ciudadano puede acceder a cualquier tratamiento o medicamento, siempre y cuando (i) se encuentre contemplado en el POS, (ii) sea ordenado por el médico tratante, generalmente adscrito a la entidad promotora del servicio, (iii) sea indispensable para garantizar el derecho a la salud del paciente, y (iv) sea solicitado previamente a la entidad encargada de la prestación del servicio de salud. (Corte Constitucional. Sentencia T-073, 2013b).

Mientras que las entidades responsables de la salud, carecen objetivamente de expertos y procedimientos que evalúen la validez científica y los resultados empíricos sobre las afirmaciones de que algunos medicamentos y tratamientos son más nocivos y tienen efectos perversos sobre la salud. Algunos investigadores, sobre el particular, manifiestan:

Todas las drogas, sostuvo una vez Paracelso, el médico del siglo XVI, son venenos disfrazados. La quimioterapia del cáncer, consumida por su feroz obsesión de borrar la célula cancerosa, encontró sus raíces en la lógica inversa: todos los venenos podrían ser drogas disfrazadas (Mukherjee, 2011, p. 124). Los medicamentos son una fuente significativa de estresantes inmunológicos... Se han descrito propiedades inmunotóxicas en todas y cada una de las medicinas de los siguientes grupos: antibióticos, antivirales, antimicóticos, antiparasitarios; tranquilizantes, antipsicóticos... medicamentos gastrointestinales; antitiroideos y hormonas sexuales, incluyendo los contraceptivos orales; antialérgicos, 
broncodilatadores, anticoagulantes... también en las medicinas inmunosupresoras e inmunomoduladoras como los antitumorales y los medicamentos para evitar el rechazo de trasplantes (Giraldo, 2002, pp. 24-25).

Los medicamentos han jugado un papel importante en el incremento del gasto del Sistema General de Seguridad Social en Salud ${ }^{42}$ y, son, al mismo tiempo, uno de los temas donde más intereses se juegan, a tal punto que las relaciones entre diagnóstico, formulación, entrega y consumo de medicamentos está mediada por diferentes agentes, señales encontradas de información, amenazas de poderosas empresas de la industria farmacéutica, para quienes lo más importante son sus ventas, y la propaganda masiva que intenta demostrar la calidad e importancia de determinado medicamento en la salud de las personas. Con relación a las ventas, Angell \& Freire (2006) afirman:

El hecho más asombroso de 2002 es que las ganancias de las diez compañías farmacéuticas en Fortune 500 (35,9 mil millones de dólares) sumaban más que las ganancias de todas las otras 490 empresas juntas $(33,7$ mil millones de dólares) (p.33).

Una carta de la embajada colombiana en ese país enviada al Minsalud, deja ver que la iniciativa para reducir el costo de ese medicamento, clave para la leucemia mieloide crónica, toca profundos intereses comerciales que generan presiones diplomáticas (Redacción Vivir, 2016).

Con relación a la publicidad de los medicamentos, Angell \& Freire (2006) mencionan:

“... nos enteramos que en el 2001 la industria confesó haber gastado diecinueve mil millones de dólares en publicidad... Como en todos los negocios, las compañías farmacéuticas afirman que su publicidad también es didáctica. Dicen,

42 Ver tema de recobros. 
por ejemplo, que al ver avisos comerciales DTC, la gente se entera de enfermedades que no sabía que tenía... (p.148).

Los resultados de los objetivos adoptados por la Ley 100 de 1993, y las normas que delimitan y caracterizan al Sistema General de Seguridad Social en Salud, están asociados, en consecuencia, al comercio internacional y nacional de medicamentos, con mayor compromiso legal desde la suscripción de tratados internacionales que definen el trámite de patentes de productos farmacéuticos $\mathrm{y}$, convierten ciertas prácticas internacionales en normas de las relaciones comerciales entre los países que suscriben tales pactos, pese a que los mismos admiten interpretaciones y aplicaciones que teóricamente garantizan, en principio, el derecho de protección de la salud pública y el acceso a los medicamentos ${ }^{43}$.

Obstáculos y restricciones al desarrollo de la política. El desarrollo de la política y el cumplimiento de las normas del Sistema General de Seguridad Social en Salud, en materia de farmacéuticos, enfrenta restricciones, obstáculos, decisiones judiciales y comportamientos contradictorios de los agentes que han incidido de manera directa sobre los costos, la estabilidad financiera del Sistema y el acceso efectivo, por parte de los pacientes, ellos son:

a.- La imposibilidad real de conocer los costos en los cuales incurren las compañías farmacéuticas en la investigación, desarrollo, creación y comercialización de un medicamento. Los gastos de las compañías de la industria farmacéutica, en esta materia y otras, nunca son de conocimiento público, están rodeados de un aureola de secretismo a pesar de estar relacionados con la producción de principios activos que son considerados esenciales en la salud humana y que con el tiempo, al momento de expirar

43 Ver el capítulo 16 del protocolo que modifica el tratado de libre comercio entre Colombia y Estados Unidos. 
la patente, obligan a la compañía a relevar la fórmula del medicamento para su producción como genérico.

La literatura especializada cuestiona la realidad de la aseveración que hacen las compañías sobre los costos en los que incurren para crear nuevos farmacéuticos, entre otras razones porque la investigación y desarrollo son un componente proporcionalmente pequeño en los gastos de las compañías farmacéuticas, la innovación en las mismas es relativa y, en los últimos años no han creado, con cargo a sus recursos, medicamentos nuevos, mientras que las drogas que han salido al mercado provienen de investigaciones académicas, compañías biotécnicas o de los Institutos Nacionales de Salud, casi todos ubicados en Estados Unidos (Angell \& Freire, 2006).

b.- La mayoría de medicamentos presentados como nuevos son farmacéuticos basados en los principios activos de drogas cuyas patentes están por vencer, a las cuales las compañías les hacen cambios en una molécula, y las muestran como innovación, sin que las autoridades públicas tengan la capacidad de controlar tal hecho y, en consecuencia, terminan otorgando una nueva patente a un viejo medicamento en una presentación nueva, es lo que se conoce como medicamento "yo también" o "soy el mismo".

c.- La confianza de los países importadores de medicamentos, especialmente de aquellos provenientes de Estados Unidos, en las patentes y el derecho exclusivo de comercialización, aprobados por la Administración de Alimentos y Drogas, los tratados suscritos y el flujo comercial de los mismos, genera poco interés en la determinación del valor real de tales productos $\mathrm{y}$, contribuye a la poca claridad sobre los factores que determinan el precio.

d.- Uno de los más importantes efectos sobre los precios de los medicamentos es el poder de las empresas farmacéuticas para incidir sobre la oferta disponible y controlar 
el flujo de los productos, tal poder lo han hecho sentir en todo el mundo, sin que incluso un país como Estados Unidos estuviera exento de dicha situación, cuando fue utilizado por compañías extranjeras. Así lo expresan Angell \& Freire (2006): "Las grandes farmacéuticas tomaron represalias. Primero fue GlaxoSmithKline. El gigante británico de medicamentos empezó a exigir a las farmacias canadienses no vender medicamentos en los Estados Unidos como condición para recibir los embarques..." (p.243). Colombia no ha escapado a este fenómeno y, al contrario, precisamente por la libertad de precios "controlada" adoptada, en el año 2006, el efecto sobre el valor de los precios fue altísimo a favor de los productores y desastroso para el Sistema General de Seguridad Social en Salud, además de las amenazas que recibe el país cuando el Gobierno toma medidas para autorizar la entrada, al mercado nacional, de nuevos laboratorios y productos. Al respecto la revista Semana manifestó:

La industria farmacéutica del país podría estar en graves aprietos. Hace unas semanas PhRMA, el gremio de las multinacionales de este sector en Estados Unidos, pidió a la Oficina de Comercio de ese país (USTR) incluir a Colombia en la lista 'negra' de países que tienen prácticas de propiedad intelectual inadecuadas... Eso no es todo. Si Colombia apareciera en el listado, según el presidente Afidro, indirectamente se enviaría una señal a los inversionistas extranjeros del sector farmacéutico de que en el país no hay medidas suficientes de protección (Semana, 2016b) ${ }^{44}$.

e.- Otra circunstancia importante sobre el valor de los medicamentos está asociada al poder que ejercen los gobiernos de los países donde las industrias farmacéuticas son poderosas. Ejemplo de ello, es el apoyo que las administraciones de los presidentes Clinton y Bush le dieron a la industria de los medicamentos cuando los

44 Negrillas fuera de texto. 
países del tercer mundo se quejaron de los precios tan altos de las medicinas para tratar el SIDA, a pesar de las expresiones de diferentes científicos sobre la inutilidad de los fármacos, los cuales, en su concepto, producían más daño que recuperación:

La concepción infecciosa y viral del sida comenzó, pues, como un error metodológico de los investigadores. Sin embargo, hoy en día las compañías farmacéuticas y las entidades prestamistas internacionales, como el Banco Mundial, se benefician enormemente del error cometido. A la industria de las drogas solamente le interesa vender medicamentos antirretrovirales, antibióticos y otros fármacos, sin importarle su potencial tóxico (Giraldo, 2002, p. 120).

La existencia de otras opciones, las cuales han sido intencionalmente desconocidas, sin que los gobiernos, la academia y los médicos las estudien y confronten, y muchos menos que las personas afectadas puedan conocerlas y con plena conciencia tomen una decisión informada sobre los tratamientos relacionados con su enfermedad. El mismo Giraldo (2002) afirma:

Tres principios básicos deben regir el tratamiento de los enfermos con sida: a) suspender y evitar al máximo las exposiciones a agentes estresantes; b) desintoxicar los sistemas inmunológicos y los demás sistemas corporales de dichos pacientes usando, por ejemplo, agentes quelantes, antioxidantes, dietas desintoxicantes, ayunos, etc., y c) estimular el sistema inmunológico con el uso, por ejemplo, de vitaminas del complejo B, factores de crecimiento, linfoquinas, acupuntura, etc... (p.114).

f.- Las políticas gubernamentales en materia de control de precios y aseguramiento de la disponibilidad de medicamentos han sido contradictorias, en efecto se encuentran decisiones que en determinados períodos ponen bajo control el valor de los medicamentos y, en otros se decide lo opuesto, sin que haya existido una política de 
Estado, de largo plazo, que permita seguridad jurídica a los agentes del Sistema, especialmente a los pacientes, en torno al valor y disponibilidad de los medicamentos, con lo cual los mayores efectos financieros se producen sobre los recursos del Fondo de Solidaridad y Garantía y, obviamente, su incidencia merma la equidad del sistema.

El año 2002 registró un incremento importante de los recobros ${ }^{45}$, cuya principal fuente de gasto se originó en los medicamentos, por lo que el Gobierno decidió pasar una cantidad importante de medicamentos, comercializados por cerca de 25 laboratorios, al régimen de libertad regulada por "olvidar" su responsabilidad de reportar datos y congeló los precios de tres compañías, a quienes desautorizó cualquier incremento, durante seis meses, con el argumento de que sus precios tenían un incremento injustificado (Comisión Nacional de Precios de Medicamentos, 2002a); posteriormente, elevó a 132 el número de fármacos sometidos al régimen de control directo (Comisión Nacional de Precios de Medicamentos, 2002b).

La Comisión Nacional de Precios de Medicamentos tomó otro rumbo (Comisión Nacional de Precios de Medicamentos, 2003) al eliminar la discriminación de las causales de sanción, disminuir el período de sanción a tres meses, antes de cumplir las propias órdenes que el año anterior había emitido en sendos actos administrativos.

Las señales del regulador al renunciar a los controles de precios y permitir la libertad del mercado, como lo expresan Hernandez Florez, Aristizabal D., Vacca G., \& Mora G., (2009),

La Asamblea Mundial de la Salud y la Pandemia de Influenza por virus nuevo, celebrada del 18 al 22 de mayo de 2009, recomendaba, entre otras acciones, priorizar las estrategias más relevantes para mitigar el impacto de la pandemia

45 Ver Recobros. 
por virus nuevo de la influenza A $(\mathrm{H} 1 \mathrm{~N} 1)$ frente a "los intereses comerciales de productores de medicamentos y otros insumos para la atención de esta situación.

Las condiciones del manejo y regulación de los precios de los medicamentos motivaron un incremento injustificado de los mismos, a tal punto que los costos siempre estuvieron por encima del valor promedio de los precios internacionales. Al respecto la Federación Médica Colombiana envió una carta a la Corte Constitucional en la cual manifestó:

...la Circular 04 de 2006 inutilizó la regulación de precios de medicamentos en Colombia. En lugar de hacer efectiva una normatividad simple (que fijaba el régimen de control directo automático para moléculas con menos de 3 oferentes que podían abusar de su posición dominante en el mercado y control directo o régimen de libertad regulada - con precios de referencia- para los medicamentos que incrementaban excesiva e irracionalmente sus precios) la reemplazó con un nuevo régimen, que en la práctica resultó claramente favorable a los intereses de la farmacéuticas y catastrófico para la salud pública... (Federación Médica Colombiana, 2012).

De esta manera se creó una verdadera feria con los recursos del FOSYGA al permitir, por canales legales y extralegales, el incremento de los costos y la demanda por medicamentos de marca, sin que se aplicaran los instrumentos científico-técnicos de supervisión y control propios de los organismos de regulación. En un informe publicado por El Tiempo el 3 de marzo de 2008 se mencionó:

...una nota sobre los productos más recobrados al FOSYGA desde abril de 2006 hasta el 12 dic. 2007. Este informe no destacó suficientemente el papel de Rituximab (Mabthera ${ }^{\circledR}$ de Roche) que tuvo 3.280 recobros por un valor aproximado de 15.600 millones. Si Rituximab -que ni se menciona en los 
recobros de 2002 a 2005- aparece en 2006-2007 con semejante valor recobrado, ¿cómo evolucionará este fenómeno cuando estos pacientes recobren con Ibritumomab (Zevamab® de Bayer-Schering) que acaba de ingresar al mercado con un precio institucional de 33 millones? (Observatorio del Medicamento en Colombia, 2008)

La ausencia de verificación y comprobación de la calidad y efectividad de los medicamentos por la baja capacidad científica y técnica de la entidad competente y, la credibilidad en los estudios presentados por compañías farmacéuticas, los cuales muchas veces no cumplen los estándares internacionales para validar el conocimiento científico y muchos pueden estar sesgados y sus soportes científicos manipulados ${ }^{46}$, son condiciones en las que la validez de los estudios, la calidad del medicamento, su efecto sobre la recuperación del paciente y la verdad sobre el acceso a una fuente de salud quedan al albur de una realidad desconocida para las autoridades públicas, las instituciones prestadoras de servicios, los médicos $\mathrm{y}$, en creciente medida, para el atribulado paciente, cuya salud está claramente comprometida por la calidad, capacidad, profundidad de conocimientos y experiencia con la que, el profesional de la salud lo atiende. Con relación a este fenómeno, dos autores han manifestado sus opiniones. Por una parte Agin (2007) se señala que:

“... los hechos nos demuestran que existe una parte considerable de la producción científica donde abundan los datos falsos y que aparece año tras año en centenares o quizás miles de publicaciones especializadas. Por ejemplo, el Office of Research Integrity (OFI), un departamento que vela por la fiabilidad

46 “... las compañías exigían a los investigadores que compararan la nueva droga con un placebo... Y no con una roca más antigua. Así, la nueva droga parecería eficaz a pesar que en realidad quizá fuera peor que la anterior. Hay otras maneras de manipular una investigación y no todas pueden ser detectadas, ni siquiera por expertos... A veces las compañías no permiten que los investigadores publiquen ni siquiera parte sus resultados si estos no son favorables a los fármacos de la empresa." Angell, Macia. La verdad acerca de la industria farmacéutica. P.22. 
de los resultados de las diversas líneas de investigación y que depende del Instituto Nacional de Salud Pública de Estados Unidos (NIH) prepara informes anuales sobre los casos de falseamiento de datos de los que tiene noticia. Entre 1993 y 1997, sesenta y un científicos fueron hallados culpables de tales actividades. El número de casos inspeccionados por el NIH durante ese período frisó los 150.000. Tales cifras arrojan un pequeño porcentaje sobre el total de la producción científica (apenas un $0,0004 \%$ de todos los artículos publicados), si se acepta que cada informe se basa en una cantidad similar de documentos. Sin embargo, este índice de falsificación se refiere sólo a las actividades realizadas en el campo la biomedicina en Estados Unidos, pues ésa es la jurisdicción del NIH, por lo que no se puede conocer con certeza hasta qué punto estas actividades afectan al desarrollo de otras disciplinas (p.51).

Así mismo, Angell \& Freire (2006) expresan que:

.. las compañías exigían a los investigadores que compararan la nueva droga con un placebo... Y no con una roca más antigua. Así, la nueva droga parecería eficaz a pesar que en realidad quizá fuera peor que la anterior. Hay otras maneras de manipular una investigación y no todas pueden ser detectadas, ni siquiera por expertos... A veces las compañías no permiten que los investigadores publiquen ni siquiera parte sus resultados si estos no son favorables a los fármacos de la empresa (p. 22)

El campo de la evidencia científica en materia de medicamentos debe considerar, en consecuencia, que existen innumerables interrogantes, controversias y limitaciones, las cuales no se pueden negar si se trata de garantizar el derecho a la salud, que van de las razones por las que aparece la enfermedad, transitan por las obligaciones metodológicas de probar la existencia de una causa, continuan por el inhóspito camino 
de "aislar" el agente, prosiguen con la búsqueda de tratamientos y tecnologías que eliminen la causa, se extienden por las pruebas de laboratorio en conejillos de indias, marchan, como se indicó atrás, por las aprobaciones de patentes y se encaminan a diagnosticar y tratar al paciente con los medicamentos y tecnologías "científicos", sin la certeza de la cura, entre otras razones porque los mismos medicamentos, generalmente, tienen efectos que pueden generar mayores desequilibrios en el sistema inmunológico, aumentar las enfermedades y causar la muerte.

El tema quedaría como una simple referencia a un drama shakesperiano de no ser por la cruda realidad que viven muchos pacientes aquí y allende de las fronteras con los medicamentos que consumen, previa formulación de un médico autorizado, los cuales muchas veces tienen efectos totalmente contrarios al deseo que acompaña a una persona para superar la enfermedad, con el agravante de que tales situaciones tienden a no ser investigadas $\mathrm{y}$, en muchos casos, a ser olvidadas con silencios que, si bien pueden no ser intencionales, resultan culpables ante el desconocimiento generalizado y la indolencia causada por la falta de seguimiento e indagación.

Medicamentos como Vioxx (rofecoxib) utilizado para tratamientos de artritis, artrosis y dolor agudo, el fármaco para combatir el colesterol conocido como Lipobay /Baycol de Bayer, la Talidomida medicamento utilizado durante la década del 50 para el tratamiento de náuseas y como sedante, hoy día formulado para casos de mieloma (cáncer de hueso), han tenido sobre la salud consecuencias negativas sobre la salud; el primero, generó mayores riesgos de infartos de miocardio y cerebrales, el segundo, provocó fallecimientos que obligaron a la empresa productora a retirarlo del mercado y, el tercero, causó degeneración física (Jara, 2009, pp. 26-43). De dichos casos no es posible aseverar que los medicamentos son, per se, causantes de mayores enfermedades o del empeoramiento de la salud, se trata de señalar la carencia de información 
actualizada que permita conocer los riesgos de consumir medicamentos, informar a los pacientes y asumir acciones de salud pública que velen por la integridad de los tratamientos $\mathrm{y}$, se indague con la debida rigurosidad las consecuencias que los tratamientos han generado en otros países, sus potenciales efectos en la salud de las personas a quienes se les receta y, en cumplimiento de los derechos a la vida, salud e información, contar con fuentes y mecanismos de acceso oportuno a datos relevantes.

En este sentido, una de las mayores ironías de los tratamientos se aloja en las clínicas, en las cuales existen diferentes riesgos asociados a la morbilidad y mortalidad intrahospitalaria: "algunos productos utilizados habitualmente en los hospitales, como las bolsas de soluciones intravenosas, tienen en su composición sustancias peligrosas para la salud. Son huéspedes tóxicos" (Jara, 2009, p. 51). De otra parte, Nodarse manifiesta:

Las Infecciones Intrahospitalarias ...constituyen actualmente un importante problema de salud a nivel mundial, no solo para los pacientes sino también para su familia, la comunidad y el estado. Afectan a todas las instituciones hospitalarias y resultan una de las principales causas de morbilidad y mortalidad, así como un pesado gravamen a los costos de salud. Las complicaciones infecciosas entrañan sobrecostos ligados a la prolongación de la estadía hospitalaria (1 millón de días en hospitalización suplementaria cada año es una cifra constantemente citada); están asociadas también con los antibióticos costosos, las reintervenciones quirúrgicas, sin contar con los costos sociales dados por pérdidas de salarios, de producción, etc. Los estimados, basados en datos de prevalencia indican que aproximadamente el $5 \%$ de los pacientes ingresados en los hospitales contraen una infección que cualquiera que sea su naturaleza, multiplica por 2 la carga de cuidados de enfermería, por 3 el costo de los medicamentos y por 7 los exámenes a realizar. ... Más importante aún son los 
costos en vidas humanas cobradas por las infecciones nosocomiales. Si se estima que la infección es la causa de muerte en 1 a $3 \%$ de los pacientes ingresados, se tendrán cifras tan impresionantes como las reportadas en Estados Unidos de 25 a 100 mil muertes anuales. ${ }^{47}$

g.- La incidencia de las empresas farmacéuticas en los funcionarios de salud, especialmente sobre los médicos, es muy alta y no está, necesariamente, ligada a intercambiar conocimientos, explicar y demostrar la efectividad de los medicamentos; más bien se trata de conquistar y convencerlos, por diversos mecanismos, para que formulen los productos que ponen las farmacéuticas a disposición en el mercado.

Varias estrategias son utilizadas por las empresas farmacéuticas: La entrega de "Muestras Gratis"48 acompañadas de los visitadores quienes "explican" la importancia del producto, para que los médicos entreguen el fármaco al paciente, uno y otro quedan "enganchados" y, en consecuencia las prescripciones fluyen sin esfuerzo; la utilización de comerciales y personajes de reconocida fama quienes muestran los efectos positivos que ha tenido el medicamento sobre su estado de salud; regalos lujosos a los médicos; financiación de congresos y seminarios, dedicados, entre otros, al convencimiento de la importancia de formular los productos de la compañía y, en general, acciones de seguimiento para verificar que el médico formula los productos de la compañía, en caso contrario adoptar acciones "necesarias" que los convenzan de la importancia del medicamento para sus pacientes. Con respecto a las muestras gratis y los visitadores, Angell \& Freire (2006) comentan:

“... se encuentran por todos lados en el mundo de la medicina... Caminan por los pasillos de casi todos los hospitales importantes del país, al acecho de la

47 Negrillas fuera de texto.

48 Las empresas incorporan los costos de estas acciones obviamente al precio de los medicamentos, no existe prueba o certeza alguna que permita deducir o verificar que lo descuenten de las ganancias de las compañías. El valor de los gastos en publicidad es más desconocido que los principios activos y las fórmulas de sus medicamentos patentados. 
oportunidad de hablar con el equipo médico, abriéndose camino con obsequios... Las reuniones con los médicos en sus consultorios son muy provechosas para las compañías farmacéuticas, y provechosas también para los médicos. Es una relación simbiótica (p.149).

Las compañías fabricantes de medicamentos entregaron, durante 2001 en Estados Estados Unidos, "muestras gratis" por once mil millones de dólares.

La solución implementada por el Gobierno Nacional, frente a esta relación médicos - empresas farmacéuticas, fue, como ha sido constante en la "solución" de los problemas del Sistema General de Seguridad Social en Salud, el adoptar una norma que, al dar una redacción diferente a normativas anteriores, determina la expresa prohibición, contenida en la Ley Estatutaria de Salud, de promover u otorgar cualquier tipo de prebendas o dádivas a profesionales y trabajadores de la salud por parte de proveedores, empresas farmacéuticas, productoras, distribuidoras o comercializadoras de medicamentos, insumos, dispositivos o equipos médicos o similares ${ }^{49}$. En consecuencia, en lugar de redactar una nueva prohibición, las autoridades públicas deberían indagar las razones por las cuales las "viejas" prescripciones no se cumplen y buscar los mecanismos que permitan su efectividad.

h.- La adopción de mecanismos administrativos para la solución de controversias relacionadas con tratamientos y medicamentos constituye un elemento que incorpora ineficiencias en el Sistema, crea inequidades y puede afectar negativamente al paciente, respecto a su estabilización, recuperación y la superación de la enfermedad.

En un campo tan controversial como el de la salud humana afectado por innumerables variables, además de la denominada “transición epidemiológica” del país,

49 El artículo 40 de la Ley 23 de 1981 prohíbe al médico en ejercicio recibir beneficios comerciales de farmacias, laboratorios, ópticas, establecimientos ortopédicos y demás organizaciones o instituciones similares encargadas del suministro de elementos susceptibles de prescripción médica. 
pretender que la resolución de conflictos, por diagnósticos y alternativas terapéuticas generadas a partir de la atención, se resuelve administrativamente a través de juntas médicas de la red de prestadores de servicios de salud plantea una serie de contradicciones, independientemente de los criterios de razonabilidad científica con los que actúe la mencionada instancia. Tales contradicciones se expresan en las afectaciones a los principios de buena fe y confianza legítima que acompaña la relación médico- paciente, y, la de aquél con las organizaciones para las cuales trabaja, las que son responsables de su selección y de la adopción de mecanismos que permitan evaluar su mérito y determinar el nivel de calidad de su ejercicio profesional y, las propias disposiciones del Estado que determinan cómo, cuándo y bajo qué circunstancias, requisitos, pruebas y experiencia se autoriza el ejercicio de las profesiones de la salud.

La actuación de los profesionales de la salud no puede valorarse como única, solitaria exclusiva y aislada del sistema, ya que las propias normas plantean, de tiempo atrás, varios enfoques que contempla la política pública de salud, la prestación de los servicios y la garantía de los derechos; en tanto la atención debe estar orientada al conocimiento actualizado de la situación de salud, las acciones de promoción y prevención y las actividades de superación y mitigación de la enfermedad de una persona, su familia y su comunidad, a través de diferentes programas y acciones, entre ellos, la Atención Primaria en Salud, Salud Familiar y Comunitaria, Articulación de las Actividades Individuales y Colectivas, Enfoque Poblacional y Diferencial, Análisis de Determinantes Sociales de Salud, Evaluación Tecnológica, Fortalecimiento de la Prevención de Riesgos Laborales, Sistemas de Garantía de Calidad en Salud y Salud Ocupacional y Riesgos Laborales. Es decir que el sistema debería contar con la información suficiente, oportuna y de calidad que permita establecer las necesidades de 
una persona en un evento particular y justificar los diagnósticos y tratamientos que el médico propone en un momento específico de la vida de una persona.

i.- La tendencia del Estado Colombiano, particularmente a iniciativa del Gobierno Nacional, de adoptar medidas legislativas para tratar temas de salud pública e inflexibilizar las acciones de prevención, promoción y los tratamientos, a pesar de la experiencia que señala el inevitable avance de la ciencia en diferentes campos del diagnóstico y el tratamiento de las enfermedades, además de la imposibilidad de declarar normativamente cuáles son los procedimientos y acciones definitivas frente a determinada patología, cuyas características, condiciones, causas e influencia sobre el estado de salud pueden tener permanentes discusiones, en el ámbito científico, y proveer diferentes protocolos de diagnóstico, tratamiento y superación.

La Ley 1626 de 2013 aprobó la garantía de la vacunación gratuita y obligatoria, a la población colombiana, contra el cáncer cérvico uterino; decisión normativa que llevaría a concluir que todo tratamiento, por lo menos cada vez que sea creada una vacuna, debería estar previamente aprobado en una ley, desconociendo varios elementos institucionales y de gestión del Sistema General de Seguridad, así como la libertad de la persona humana para decidir en torno a su salud, ellos son:

- El Sistema General de Seguridad Social en Salud cuenta con los mecanismos e instrumentos institucionales para definir el contenido del Plan Obligatorio de Salud, otra cosa es que las autoridades responsables no actualicen el Plan de beneficios y no reaccionen oportunamente a las necesidades en materia de salud, así como a las demandas identificadas en la información sobre la situación epidemiológica y, particularmente, a las señales de la morbimortalidad.

- Las discusiones sobre los diagnósticos, tratamientos y avances en el campo de la medicina, por lo menos en la comunidad científica, deberían recordarles a las 
autoridades públicas la importancia de contar con instrumentos flexibles que permitan una adecuación oportuna y pertinente a los desarrollos y aplicaciones científicotécnicos, con el fin de evitar inflexibilidades que van en detrimento de la salud y pueden causar efectos económicos negativos. Al respecto Nosman (1999, citado por Jara 2009) asevera:

Anualmente se retiran del mercado unos 500 fármacos por sus efectos secundarios no previstos o poca fiabilidad, tras haber usado como aval legal la experimentación en animales. En 1997, Italia prohibió una vacuna obtenida con cultivo del cerebro de buey, por su posibilidad de contener dosis de encefalopatía espongiforme, el famoso mal de las vacas locas. Millones de cápsulas farmacéuticas, realizadas con gelatina obtenida de las articulaciones de las vacas, fueron retiradas de los laboratorios españoles (p.191).

El derecho de toda persona a elegir libremente la Entidad Promotora de Salud a la que se afilia, la Institución Prestadora de Servicios de salud a la que acudirá y el médico con el cual está dispuesto a tratar los temas de su salud y las consecuentes acciones, pero sobre todo, la autonomía e independencia de la persona humana para decidir su proyecto de vida, el tipo de medicina, la aceptación de tratamientos y el sometimiento a los mismos, impide que una norma haga obligatorias, de manera indiscriminada a toda la población, una acción particular de salud. La Corte Constitucional al tratar el tema decidió, en la Sentencia C-752 de 2015:

...inhibirse sobre la expresión "y obligatoria" por ineptitud sustantiva de la demanda. Sin embargo, algunos magistrados al salvar el voto, reconocieron la importancia de fallar de fondo para reiterar que la misma Corte Constitucional, en sus sentencias, ha señalado que los títulos de las normas no tienen consecuencias jurídicas, ni son vinculantes, además en el trámite legislativo fue 
retirada expresamente dicha obligatoriedad. En consecuencia ¿Cuáles son las verdaderas razones para adoptar una ley sobre la vacunación gratuita “... a todas las niñas entre cuarto grado de básica primaria y séptimo grado de básica secundaria"? (Corte Constitucional. Sentencia C-752, 2015a).

- Las discusiones sobre los efectos nocivos de vacunas como Gardasil, ya que el desarrollo del programa de inmunización contra el Virus del Papiloma Humano llevó a conocer el debate existente sobre los efectos secundarios de la vacuna y las inquietudes que, en distintos ámbitos, produce la masificación y comercialización de la vacuna. Al respecto, Fernández \& Perilla S. (2014) manifiestan:

Pero a pesar de sus anunciados beneficios, poco después de que la Administración Federal de Alimentos y Medicamentos (FDA) de Estados Unidos dio vía libre a su comercialización, se reactivaron grupos antivacuna, que no solo cuestionaron la rapidez con la que fue aprobada, sino su pronta masificación. Solo Gardasil ha obtenido registros sanitarios en más de 130 países.

Con evidencia científica en la mano, y el aval de autoridades como la Organización Mundial de la Salud y la Agencia Europea del Medicamento, MSD logró el ingreso de la vacuna a los esquemas de inmunización de decenas de países, incluido Colombia. Pero la campaña no se restringió a la promoción; según expertos consultados por The New York Times, en agosto del 2008, eso se acompañó de fuertes presiones de la industria y los políticos.

En diciembre de 2015 la Asociación de Afectadas por la Vacuna del Papiloma describían los efectos, del mencionado medicamento, en los siguientes términos: discapacitadas 1.406; muertes 242; No recuperados 8.121; Pruebas papanicolau anormales 606; displasia cervical 268; cáncer cervical 104; amenaza de vida 
716; visitas a Urgencias 13.065; hospitalizaciones 4.144; permanencia alargada en el hospital 280; notificaciones serias 5.647; y notificaciones de reacciones adversas 42.635. (Asociación de Afectadas por la Vacuna del Papiloma, 2016)

El Ministro de Salud señaló, el 25 de agosto de 2015, ante algunos interrogantes y movilizaciones generados por enfermedades de un grupo de niñas del Municipio del Carmen de Bolívar, en las cuales se aducía como causa de las mismas la vacunación contra el Virus del Papiloma Humano, que la política de vacunación era una política pública seria, en razón a que las decisiones eran tomadas por un comité independiente con base en la evidencia, en criterios objetivos, con base en la mejor información disponible sobre la relación costo-beneficio, el acompañamiento de las Sociedades Científicas, buscando mejorar los resultados en salud 25 años en el futuro y, la garantía del financiamiento (Gaviria, 2015). Sin embargo, no formuló, ni tuvo en cuenta, varias situaciones y observaciones, que incluso fueron generadas desde el mundo de la academia. En primer lugar, la Carta de la Academia Nacional de Medicina de Colombia solicitando cambiar el protocolo para la aplicación de la vacuna, pues podía generar graves efectos secundarios(Academia Nacional de Medicina, 2016). En segundo lugar, el III Simposio Colombiano de Autoinmunidad expresó que la vacuna está relacionada con muchas enfermedades autoinmunes:

La opinión contraria (contra mi posición) es que todos los síntomas y signos que se manifiestan en las chicas post- vacuna VPH fueron los resultados de las reacciones psicosomáticas", dijo el patólogo. "No creo que las reacciones psicosomáticas puedan causar la muerte súbita inesperada en el sueño, o lesiones inflamatorias en el cerebro como lo demuestra la imagen de resonancia magnética y la histopatología de biopsia cerebral con linfocitos perivasculares y 
macrófagos y la desmielinización”, concluyó el Dr. Ha, según SANE Vax (Gubin, 2015).

j.- El papel jugado por la Corte Constitucional en sus decisiones sobre el amparo del Derecho Fundamental a la Salud definió elementos sustanciales que determinaron un crecimiento de la demanda de medicamentos, especialmente de marca. Una de las primeras aseveraciones del Máximo Tribunal fue señalar la ausencia de una regulación clara que permitiera hacer efectivo el acceso a prestaciones no incluidas en el Plan Obligatorio de Salud, especialmente a medicamentos ordenados por los médicos tratantes.

La Corte Constitucional decidió los criterios que deben tener en cuenta los médicos tratantes y el Comité Científico Técnico en la formulación y autorización de un medicamento de marca, entre los cuales señaló: La calidad, seguridad, eficacia y comodidad para el paciente, con base en la experticia y conocimiento clínico de éste por parte del médico; la prevalencia de la formulación del médico tratante, salvo la decisión del Comité Técnico Científico basada en los dictámenes de médicos expertos en el área de la especialidad, en tanto, para el Máximo Tribunal, se trata de demostrar que el fármaco genérico tenga la misma eficacia; la autorización a las Entidades Promotoras de Salud para reemplazar un medicamento de marca, siempre y cuando se garantice la calidad, seguridad, eficacia y comodidad del paciente y, como criterio central, se debe sustentar una decisión en la opinión científica de expertos, así como en la historia clínica en perspectiva de los efectos concretos del tratamiento en la salud de la persona atendida. (Corte Constitucional. Sentencia T-760, 2008c).

Las decisiones de la Corte Constitucional que tenían por objeto garantizar el acceso a prestaciones NO POS, en desarrollo del amparo, en casos concretos, generaron teórica y prácticamente una nueva manera de actualizar el Plan Obligatorio de Salud, 
determinaron los criterios de actualización de los medicamentos sin el debido estudio y rigurosidad que supone el acceso a los fármacos y, la Corte Constitucional en lugar de exigir investigaciones sobre las conductas y casos de incumplimiento de las autoridades y sus efectos sobre la salud, creó un nuevo mecanismo administrativo, vía judicial, que dio patente a todos los agentes para, a pesar de estar incumpliendo sus obligaciones y deberes, poner sus intereses por encima de los fines del Estado en el campo de la prestación de servicios y el derecho a la salud.

En consecuencia, los factores externos implicados en la creación, producción, comercialización, transporte y entrega, al igual que los intereses de las empresas productoras de fármacos y su deseo de protección de las patentes, como instrumento de fijación y obtención de precios altos, no tuvieron ninguna consideración en los estudios y fallos del Máximo Tribunal Constitucional.

\subsection{Estabilidad, eficiencia $y$ eficacia afectadas por destinación diferente de los recursos de salud.}

Una de las afirmaciones cotidianas, en círculos gubernamentales, médicos, académicos, organizaciones aseguradoras y prestadoras de servicios de salud, medios de comunicación, así como de representantes de trabajadores, pensionados y usuarios de servicios, es que el problema económico clave de la salud es cómo hacer compatible el acceso a los servicios de salud con la escasez de fuentes de financiamiento, dado que los beneficios tienden a ser infinitos, mientras que la financiación de los mismos encuentra barreras en los recursos fiscales y parafiscales y la capacidad de gasto de las personas. Al respecto afirma Rodríguez (2015):

Hay tres problemas centrales en el sistema de salud: el primero se refiere a la baja cobertura del régimen contributivo, ligada al régimen económico vigente que no expande el empleo formal asalariado, lo precariza e impone deterioro 
salarial a los trabajadores; el segundo atañe a la limitada financiación derivada de las restricciones de "la dictadura fiscal", y el tercero corresponde a la corrupción y la débil regulación a los intereses privados, soportadas por un régimen político con fuerte presencia clientelista. ${ }^{50}$

Las aseveraciones tienen un fuerte contraste con la historia de la financiación del Sistema General de Seguridad Social en Salud, en particular con el Fondo de Solidaridad y Garantía, ya que, de tiempo atrás, diversos estamentos denuncian que los recursos de salud no siempre se destinan a los fines previstos y existen problemas relacionados con la eficiencia institucional y, el trámite y flujo de recursos. Al respecto, el periódico El Tiempo publicó en el año 2000:

Los que se estaban quedando con la platica, los intermediarios, los que negociaban con la salud, todos van a tener que rendir cuentas. Algunos podrán hasta terminar en la cárcel, dijo el Ministro quien insistió en que en el futuro la eficiencia es la clave.".

Otra de las conclusiones, según Roberto Esguerra Gutiérrez, de la ACHC, es que el futuro del sector se ve favorable, a pesar de lo que hoy pasa. Hay todavía muchas cosas por mejorar, pero se están tomando medidas. Hay perspectivas para la solución de problemas como la evasión, el flujo de dineros, ideas importantes como los decretos recientes e interés de todas las instituciones, afirmó.

"El gran problema de fondo, además, es la falta de eficiencia de algunas instituciones." (Redacción El Tiempo, 2000). ${ }^{51}$

Sin desconocer que existen en Colombia, de tiempo atrás, fenómenos culturales y sociales ${ }^{52}$ que tienen incidencia sobre el destino de los recursos. 
El Sistema General de Seguridad Social en Salud ha tenido, durante el período de su existencia, procesos críticos que muestran con claridad factores asociados a la asignación, gestión y destino de los recursos parafiscales, entre ellos la evasión y elusión de aportes, las transacciones relacionadas con la compensación, la afiliación múltiple, el pago de eventos catastróficos y accidentes de tránsito, la inspección, vigilancia y control sobre el destino final de los recursos de las diferentes cuentas del Fondo de Solidaridad y Garantía y, las interacciones entre las autoridades del Sistema con los organismos de control para determinar responsabilidades en el desvío, sustracción o incautación de los recursos de salud.

La afiliación al Sistema Integral de Seguridad Social en Salud es obligatoria para todas las personas, independientemente de su capacidad de pago y de los mecanismos que implante el Estado para financiar a las personas que no poseen recursos, mientras que existe libertad en la selección de la Entidad Promotora de Salud, la Institución Prestadora de Servicios y los profesionales de la salud que atenderán cualquier evento; en consecuencia no existe competencia en términos del pago por afiliación, dado el cuasi monopolio del Estado en el ingreso, la determinación de la cotización conforme a parámetros legales previamente establecidos y el pago expresado en la Unidad de Pago por Capitación, que independientemente de las condiciones de gestión, reciben las EPS. De donde se desprende que, en términos de financiamiento, las actividades están orientadas a que las personas con relación laboral y aquellas con capacidad de pago, en el caso de las independientes, sean afiliadas al Sistema,

52 La cultura social asocia estar bien a los dictados que surgen de los avances y aplicación de la tecnología y, considera que la corrupción es connatural a quienes se desempeñan o tienen negocios relacionados con el Estado, olvidando la relación entre narcotráfico, crimen organizado y corrupción, incluso excluyendo, en algunos casos, a grupos armados al margen de la ley, al considerar que sus "ideales" los habilitan, a ellos y sus "aliados políticos", para cometer crímenes y eximirlos de cualquier responsabilidad. 
contribuyan teniendo en cuenta el ingreso base de cotización real y cancelen el respectivo valor de la liquidación.

Los responsables de afiliar, cotizar, liquidar y cancelar el monto de los aportes se enfrentan a varias incertidumbres, las cuales les impiden determinar cuándo se necesitarán los servicios de salud, qué enfermedades se enfrentarán y bajo qué condiciones serán atendidas las personas, como tampoco conocen, en principio, la capacidad de control y sanción que las entidades estatales tendrán sobre ellas, en caso de decidir evadir sus responsabilidades con el Sistema.

El mencionado escenario refleja el inicio del Sistema General de Seguridad Social, en el cual la asimetría de información y la incertidumbre de los agentes, respecto de las consecuencias reales del incumplimiento de sus obligaciones, exigían una fuerte, oportuna, pertinente y cualitativa intervención de las autoridades de regulación, dirección y control, para estimular el cumplimiento de las obligaciones y deberes de todos los agentes; en consecuencia, el efecto demostrativo de las autoridades estatales era clave en cada uno de los procesos, especialmente en lo relacionado con el cumplimiento de las obligaciones de financiamiento, la garantía de acceso oportuno a las prestaciones del plan de beneficios y, la ejecución de las acciones de promoción y prevención. Sin embargo, varios eventos concurrieron en el envío de señales contradictorias y generaron comportamientos desiguales entre los diferentes agentes del Sistema, ellos son:

a.- La existencia de múltiples planes de beneficios ${ }^{53}$, además de la atención vía la oferta hospitalaria, preferencialmente con instituciones estatales, el fortalecimiento de planes privados de salud, que con el tiempo adquieren significativa importancia e

53 Definidos en el Decreto 806 de 1998 como Plan de Atención Básica en Salud, PAB, Plan Obligatorio de Salud del Régimen Contributivo -POS-, Plan Obligatorio de Salud del Régimen Subsidiado -POSS-, Atención en accidentes de tránsito y eventos catastróficos y, Atención inicial de urgencias. 
introducen diferencias en la atención hospitalaria, especialmente en acceso a tecnologías especializadas, médicos especialistas y mejor hotelería. El artículo 3 del Decreto 1938 de 1994 define los planes complementarios como el:

“... conjunto de servicios de salud contratados mediante la modalidad de prepago que garantizan la atención en el evento de requerirse actividades, procedimientos o intervenciones no incluidas en el plan obligatorio de salud o que garantizan condiciones diferentes o adicionales de hotelería o tecnología o cualquier otra característica en la prestación de un servicio incluido en el POS y descrito en el manual de actividades, intervenciones y procedimientos, que podrán ser ofrecidos por las EPS, o por las entidades que sin convertirse en EPS deseen hacerlo, siempre y cuando cumplan con los requisitos establecidos en la normatividad vigente para las empresas de medicina prepagada. Mientras que el Decreto 806 de 1998 los concibió como planes adicionales de salud, en los siguientes términos: Planes de atención complementaria en salud, planes de medicina prepagada y, pólizas de salud («Decreto 1938 de 1994»)

De otra parte el Tribunal Constitucional asevera que: "El Plan Complementario de Salud es independiente del plan obligatorio; es libremente contratado por el afiliado, opera como adicional al plan obligatorio y debe ser pagado en su totalidad por el afiliado con recursos distintos de las cotizaciones obligatorias" (Corte Constitucional. Sentencia C-112, 1998a)

b.- El sistema de incentivos sobre las Entidades Promotoras de Salud ha sido inapropiado en la medida que ellas no desarrollaban acciones estratégicas de afiliación al Sistema, carecían de instrumentos u "olvidaban" la necesidad de verificar los ingresos reales de quienes acceden al sistema, especialmente de los independientes, y no estaban interesadas en afiliar ciertos segmentos de la población, especialmente los de mayor 
riesgo de enfermedad y, en todo caso, recibían el mismo pago por persona (UPC) y, cualquier prestación por fuera del Plan Obligatorio de Salud sería cobrada al Fondo de Solidaridad y Garantía, con lo cual incluso motivaron acciones de amparo a favor de sus intereses. Esto se puede corroborar a través del informe de la Defensoría del Pueblo, en donde menciona:

Aunque entre 2013, cuando se registraron 115.147 acciones de tutela en materia de salud, y 2014 el incremento fue de 2,7\%, el panorama llama la atención en el marco de la conmemoración del Día Mundial de la Salud, dado que el 70\% de las solicitudes de los ciudadanos en materia de violaciones a su derecho fundamental a la salud está relacionado con solicitudes ya incluidas en el Plan Obligatorio de Salud (POS).

\section{Al respecto la Defensoría del Pueblo reiteró su llamado a las Entidades Prestadoras de Salud (EPS) para que cumplan con su obligación, tanto legal} como moral, de garantizar de manera oportuna el aseguramiento y la prestación de los servicios contemplados en el POS, y evitar que sean los jueces de la República quienes, a través de los fallos de tutela, terminen coadministrando la salud (Defensoría del Pueblo, 2015). ${ }^{54}$

Además del mencionado amparo a favor de sus intereses, tampoco fueron ejemplo de gestión en las acciones de promoción y prevención: “La mayoría de las EPS incluidas en el estudio de la referencia presentan deficiencias en cuanto a la invitación que deben cursar a sus usuarios para que participen en actividades de promoción y prevención...” (Defensoría del Pueblo., 2005, p. 29)

c.- El desarrollo de la descentralización, particularmente la asignación de competencias y recursos en el ámbito del servicio público de salud, ha tenido impacto

54 Negrillas fuera de textos. 
en la garantía del derecho, entre otras razones por la inevitable disminución de la capacidad centralizadora de la Nación, el aumento del poder en los ámbitos territoriales, sin que se hayan previsto los efectos de las bajas capacidades institucionales, las deficiencias de la gestión, la incidencia de factores extraños al mérito en el acceso a los empleos territoriales, el mantenimiento de criterios patrimoniales en el manejo de las administraciones, la creencia popular, fuertemente arraigada en algunas poblaciones, que los servicios son una beneficencia, cuya dádiva es resultado de la intervención de algún agente poderoso del territorio $\mathrm{y}$, el desconocimiento, de una realidad permanentemente latente de las relaciones ilegales entre servidores públicos e intereses oscuros que degradan el patrimonio, corrompen las instituciones y hacen de la garantía de los derechos fundamentales una completa falacia. El fenómeno es caracterizado por Garay \& Salcedo A. (2012) de la siguiente manera:

Un subsecuente proceso, denominado Reconfiguración Cooptada del Estado (RcdE), sucede en situaciones de corrupción avanzada y compleja, y presenta las siguientes características: i) participación de individuos y grupos sociales legales e ilegales; ii) beneficios perseguidos no sólo de carácter económico sino penal e incluso de legitimación social; iii) coerción y establecimiento de alianzas políticas que complementan o sustituyen el soborno y, iv) afectación de diferentes ramas del poder público y distintos niveles de la administración (p.36).

d.- Las políticas y acciones del hoy Ministerio de Salud y Protección Social ${ }^{55}$ desconocieron en la práctica, a pesar de los reiterados diagnósticos, las diferencias de desarrollo económico, social, político, administrativo y de capacidad institucional entre los diferentes Departamentos, así como éstos y aquél no lograron, en desarrollo de sus

55 La última denominación cobija, para efectos de la aseveración, las antiguas acepciones de Ministerio de la Protección Social y Ministerio de Salud. 
competencias, de rectoría, coordinación, articulación y control, conocer las necesidades de los municipios y ejecutar acciones diferenciadas destinadas a mejorar la capacidad resolutiva y operativa de los entes territoriales en la dirección y prestación de servicios de salud a su cargo y, a pesar de esta vieja realidad aún se mantiene el diagnóstico, sin que se haya superado tal situación, por ello:

Los malos resultados en salud tienen una correlación clara con las zonas del país más pobres, con mayor penetración del conflicto armado y mayor dificultad geográfica en el acceso. Mejorar los resultados en salud en estas áreas es un reto en el diseño de políticas públicas dirigidas a mejorar los determinantes del estado de salud de estas poblaciones (Ministerio de Salud y Protección Social, 2012, p. 42).

La situación ha llegado a tal punto que es, de nuevo, la Corte Constitucional la que ordena acciones para superar problemas de salud en las entidades territoriales ${ }^{56}$

e.- Las deficiencias y trabas en la gestión y flujo de los recursos, particularmente entre los agentes del Sistema, crearon caos e ineficiencias que incidieron en la crisis financiera de muchas de las entidades, especialmente de las Empresas Sociales del Estado y de Instituciones Prestadoras de Servicios de Salud, generaron rupturas en el estudio, asociación y respuesta integrada de los riesgos, originaron una cascada de acciones legales, algunas ilegítimas, cuyo resultado, en concepto del Ministerio de Salud y Protección Social, es la limitada legitimidad del sistema. El estudio del Ministerio revela:

Estos problemas han determinado una situación de crisis sistémica donde los diferentes intentos de resolución han encontrado que la capacidad de agenciamiento de intereses de los agentes se ha sobrepuesto a la capacidad

56 El caso de la orden al Ministerio de Salud y Protección Social y a la Superintendencia Nacional de Salud, para desarrollar acciones específicas en el Departamento del Chocó, es una muestra evidente. 
regulatoria del Ministerio de Salud y Protección Social. Los esfuerzos legislativos a través de las Leyes 1122 de 2007 y 1438 de 2011 han ofrecido soluciones parciales que no han resuelto de manera estructural el problema de fragmentación dejando al propio Ministerio de Salud y Protección Social con muy limitada capacidad de rectoría y débiles mecanismos regulatorios para efectuar una ordenación del sistema (Ministerio de Salud y Protección Social, 2012, p. 39) $)^{57}$.

f.- La decisión temprana de la Corte Constitucional de ordenar la atención de las personas, independientemente del pago de la cotización, como mecanismo de protección y garantía del derecho a la salud, sin solicitar u ordenar las investigaciones destinadas a establecer las causas de los incumplimientos, la deficiencia en las actuaciones administrativas de las autoridades para lograr el cumplimiento en la afiliación, la determinación del ingreso base de cotización real, la liquidación y el pago de los aportes, así como indagar qué acciones adelantaban los organismos reguladores, rectores y controladores para evitar el incumplimiento de las obligaciones con el Sistema y su impacto negativo sobre el estado de salud y la atención de las personas. En este sentido, la actuación del Máximo Tribunal Constitucional se convirtió en una actividad regular, recurrente y siempre esperada en la determinación del acceso a los servicios, lo que ha reflejado, más que la defensa del derecho fundamental, las deficiencias en el cumplimiento de las responsabilidades de agentes del Sistema. Al respecto el Tribunal Constitucional afirma:

Respecto de la salud y la seguridad social la jurisprudencia ha precisado que la continuidad en su prestación garantiza el derecho de los usuarios a recibirlo de manera oportuna y prohíbe a las entidades responsables realizar actos u omitir 
obligaciones que afecten sus garantías fundamentales. En tal sentido, esta Corporación ha sido enfática en señalar que las razones de índole administrativo o aquellas relacionadas con el incumplimiento de las obligaciones de los empleadores o empresas contratantes con las E.P.S. no son aceptables para negar la atención médica ya iniciada (Corte Constitucional. Sentencia T-128, 2005b).

g.- La Corte Constitucional impuso también parámetros de evaluación obligatoria, a cargo de los organismos de control, sobre las Entidades Promotoras de Salud, entre ellos determinar si se negaban a autorizar oportunamente servicios de salud incluidos o excluidos en el Plan Obligatorio de Salud, requeridos con necesidad y que no pudieran ser costeados por el paciente; si no autorizaban oportunamente servicios de salud con el argumento de que no se hubiera presentado la solicitud respectiva ante el Comité Técnico Científico -CTC-; si negaban autorizaciones oportunas de servicios de salud con sujeción al principio de integralidad; si negaban la prestación oportuna de servicios de salud ordenados por un médico que no estaba adscrito a la entidad responsable de la prestación, pero hace parte del sistema de salud, sin que su concepto hubiese sido desvirtuado con base en razones científicas; si negaban servicios de salud cuando se requeriría que la persona se desplazara; si negaban servicios de salud de alto costo para tratar enfermedades catastróficas, así como sus exámenes diagnósticos; si se negaban autorizaciones requeridas por menores para su adecuado desarrollo y que no podían ser costeados por sus tutores; si se negaban a autorizar servicios que se requerían con necesidad, supeditando su prestación al pago de una cuota moderadora; si no se autorizaban incapacidades laborales derivadas del estado de salud de la persona con el argumento de que en el pasado no se cumplió con la obligación de cancelar los aportes de salud dentro del plazo establecido para ello; si se impedía la afiliación de personas, a pesar de cumplir con el tiempo para el traslado; si interrumpían el suministro de 
servicios de salud, porque ya transcurrió el mes luego del momento en que la persona dejó de cotizar; si cobraban copagos a personas que padecen una enfermedad catastrófica o de alto costo y, si se negaban a autorizar servicios de salud ordenados por un fallo de amparo (Corte Constitucional. Sentencia T-760, 2008c).

Ese cúmulo de tareas minuciosas, sustentadas en la protección de casos específicos, además de las innumerables y extensas funciones de control, en lugar de motivar planes y acciones estratégicas en la supervisión pudo incrementar los desvíos del ejercicio de la inspección, vigilancia y control sobre los elementos fundamentales y claves del Sistema, para concentrarse en situaciones específicas, con lo cual, al parecer, se contribuyó a afectar la capacidad de planificación, gestión y operación de las autoridades administrativas. El Ente Rector, en el informe final del proyecto llevado a cabo en el año 2004, señaló en esta materia:

A la SNS le han sido asignadas funciones más allá de las que puede realizar tanto desde el punto de vista de los recursos como de la propia concepción organizativa de la IVC. Aún si la limitante de recursos no existiera, las funciones asignadas son desmedidas dado que ellas implican la realización de la IVC de manera directa, en un universo excesivamente extenso, complejo que escapa al alcance de una entidad por eficiente que ella sea (Ministerio de la Protección Social, 2004, p. 124).

h.- La baja y escasa participación de los afiliados y beneficiarios en las diferentes instancias de planeación, control, ejecución y evaluación de las políticas, planes, programas y acciones de salud, a pesar, o tal vez por ello, de la inflacionaria normativa sobre participación y control social, la cual multiplica los mecanismos de organización (veedurías ciudadanas, organizaciones de usuarios, comités de participación comunitaria, participación ciudadana, juntas de acción comunal, 
representación de los usuarios en las juntas directivas de algunas entidades del Sector Salud, entre otras.), contribuye a la atomización de intereses, crea micro poderes cuyos intereses pueden estar asociados a objetivos diferentes a los del derecho fundamental a la salud y, en la práctica, han impedido articular y encauzar las necesidades y demandas de las personas, las cuales, están convencidas culturalmente de que la vía más expedita y efectiva es la tutela, a pesar de las peticiones, quejas y reclamos que reciben periódicamente las entidades del SGSSS, las cuales tampoco, al parecer, han sido tenidas en cuenta como fuente de información para diagnosticar y superar limitaciones en la organización y gestión de los servicios de salud y, evitar fugas importantes en la destinación y ejecución de recursos. Es difícil encontrar un estudio que compile, sistematice, analice y caracterice las peticiones, quejas y reclamos de todas las entidades del Sistema General de Seguridad Social en Salud. Lo que se encuentra son los informes que cada entidad debe elaborar por obligación legal. Una relativa excepción es el Informe Piloto de quejas o escucha activa del usuario, elaborado por el Programa de Apoyo a la Reforma de Salud, crédito BID 910/OC-CO, del Ministerio de Salud, en junio de 2001; en el cual se señala:

Entonces, es importante buscar herramientas que motiven a las instituciones, tanto EPS como IPS, para que aprendan a dar respuesta a las inquietudes, opiniones, sugerencias y/o quejas de sus usuarios, lo que les traerá un beneficio económico, por el incremento en el número de afiliados al hacer los cambios sugeridos y deseados por sus usuarios, (que son quienes constituyen el motivo por el cual éstas funcionan) Estos procesos ya están reglamentados, pero en la actualidad muchas organizaciones no lo siguen o los hacen solamente para 
cumplir con un requisito legal. (Ministerio de Salud. Programa de Apoyo a la Reforma de Salud, 2001, pp. 10-11). ${ }^{58}$

i.- La capacidad de decisión individual de los afiliados y beneficiarios del Sistema ha sido, en general, muy baja por el desconocimiento de elementos claves en la toma de decisiones: Las competencias, atributos y obligaciones de las EPS, las IPS, las calidades y cualidades del personal de salud a quien puede acudir ante la necesidad de una atención, el papel de los órganos de dirección y control del Sistema y, las obligaciones de entidades de otros sectores respecto de los determinantes sociales y, qué decir de su comprensión de las demás instancias, las cuales aparecen, a su vista, como un engranaje difícil de asir y afianzar en beneficio de la garantía de su derecho y, al mismo tiempo, en discernimiento de sus obligaciones, especialmente respecto del cuidado, preservación y protección de su propia persona, sin mencionar la imposibilidad real, por la falta de información clara, oportuna y concreta, además de la respectiva capacitación, para ejercer el control social sobre la planeación, destino, administración y uso de los recursos del sistema, del cual él es un aportante.

La persona que participa en el Sistema de Seguridad Social en Salud parece todo menos un agente que defiende y escoge, para sí misma, racionalmente en el mercado de servicios de salud, entre otras razones, porque las responsabilidades que fueron asignadas a las EPS, como instancias claves en la superación de la asimetría de información, compradoras de servicios, en nombre de sus afiliados y beneficiarios (Londoño, 2001), gestoras de la promoción y protección de la salud y, acompañantes en la detección y superación de la enfermedad, han sido pobremente cumplidas y, se han trastocado en actividades que las convirtieron en capturadoras de rentas: "el desarrollo del modelo derivó en diferentes problemas especialmente concentrados en la 
fragmentación del modelo de salud con incentivos de los agentes hacia la extracción de rentas en demerito de los objetivos de salud de la población" (Ministerio de Salud y Protección Social, 2012, p. 39)

\subsection{El lado oscuro en la apropiación de recursos de la salud.}

La aseveración sobre la mayor capacidad de agenciamiento de los intereses de los partícipes privados del Sistema General de Seguridad Social en Salud que, según el estudio del Ministerio de Salud y Protección Social, se ha sobrepuesto a la gestión regulatoria del órgano rector de la política, si bien son ciertos, ocultan, al mismo tiempo, fenómenos importantes y claves en el destino de los recursos de salud, los cuales, de tiempo atrás, a pesar de los discursos, la adopción de disposiciones legales, algunos intentos de fortalecimiento del principio de transparencia y acciones específicas de las autoridades penales, permean la sociedad colombiana y ha creado poderes irregulares con fuertes influencias en toda la cadena del Sistema General de Seguridad Social en Salud. El estudio del Ministerio de Salud y Protección Social (2012) así lo devela:

El "Estudio sobre el modo de gestionar la salud en Colombia" es un esfuerzo académico hecho por el Ministerio de Salud y Protección Social para hacer un análisis prospectivo sobre la forma idónea de gestionar la salud de los colombianos. Si bien representa una recopilación y un menú de recomendaciones, en ningún momento representa la posición del Ministerio. (p.3). ${ }^{59}$

El narcotráfico y, especialmente, la corrupción son fenómenos que a través de sus mecanismos de organización, poder de destrucción y sometimiento de comunidades, desde antes de la adopción y operación del Sistema General de Seguridad

59 Negrilla fuera del texto 
Social en Salud, sometieron a algunas de las entidades territoriales a sus dictados, con el objeto de apoderarse de los recursos públicos, consolidar su poderío y obtener reconocimiento y aceptación social, sin que se puede aseverar que tales fenómenos han desaparecido, más bien han cambiado las formas y mecanismos de su acción, pero su incidencia sobre vastas áreas ha sido permanente y continúa incólume. Varias son los estudios que reflejan este fenómeno:

Así, la frágil institucionalidad le permitió al narcotráfico combinar el empleo de la intimidación y del soborno para establecer conexiones con diferentes segmentos de la sociedad y de la actividad económica. Pero en la medida en que esto se producía, también se deslegitimaba la institucionalidad tradicional...

El narcotráfico desarrolló también redes sociales de apoyo tanto en Colombia como en el extranjero... (Rocha, 2000, p. 44).

Hoy todavía se aprecian los escollos para la descentralización, no sólo técnicos, sino políticos, relacionados con las viejas prácticas clientelistas del Estado, o con la simple y franca corrupción incontrolable, o con el conflicto armado cada vez más extendido (Hernández, 2002, p. 994)

Cuando la evidencia empírica se analiza con detalle, se encuentra una transformación radical en la estructura del narcotráfico. Dicha transformación consiste, principalmente, en una mayor participación de narcotraficantes mexicanos que han asumido la tarea de ingresar en Estados Unidos las drogas ilegales producidas en Colombia... (Garay \& Salcedo A., 2012, p. 16).

Tras presentar un balance de los esfuerzos que ha emprendido para el saneamiento del sector de la salud, el economista antioqueño60, que está al frente de la cartera desde septiembre de 2012, señaló que el sistema está "bien

60 El Heraldo. 28 de marzo de 2016. 


\section{diseñado" pero que ha estado aquejado por dos grandes males: la} corrupción, en parte por problemas de supervisión, y el exceso de gasto, por la “incorporación desordenada de las innovaciones farmacéuticas. ${ }^{61}$

En este escenario han transitado y usufructuado narcotraficantes, paramilitares, guerrilleros, políticos, militares y servidores públicos, algunos de los cuales han pasado de un grupo a otro, o han ocupado simultáneamente algunas de esas calidades. También han sido varias las publicaciones en torno a este suceso: "La Fiscalía descubrió una red criminal de 35 implicados -17 de ellos militares activos- que le habrían robado al sistema de salud $\$ 24.000$ millones en tres años” (Semana, 2015)

Al hacer el balance en materia de salud durante los últimos cinco años, el presidente Juan Manuel Santos dijo que se estima que entre el 2002 y el 2010 unos 530.000 millones de pesos de recursos de la salud quedaron en manos de paramilitares, situación que se frenó gracias al giro directo (El Tiempo. Redacción Salud, 2015).

La gobernabilidad se ha visto comprometida, especialmente en las entidades territoriales, además de los argumentos que más adelante se mencionan, por la restringida autonomía que, en la práctica, tienen los secretarios de salud de las gobernaciones y municipios, los gerentes de las Empresas Sociales del Estado y el personal encargado de ejercer funciones de inspección, vigilancia y control.

La influencia más fuerte sobre la gobernabilidad se produce en las instancias directivas de la Empresas Sociales del Estado, las cuales, a pesar de gozar de la autonomía que la ley predica de las mismas, queda comprometida en los procesos de selección de los gerentes, en los que la fuerte incidencia de los intereses "políticos" termina adscribiendo, al área de influencia del "cacique político", a los mencionados

61 Negrilla fuera de texto. 
directivos, quienes en su gestión desconocen la naturaleza de la Función Pública, sus obligaciones y la obligación de prestar servicios de salud eficientes que contribuyan a la garantía del Derecho Fundamental. El 28 de marzo de 2016 se expidió la circular conjunta (Procuraduría General de la Nación, Ministerios de Educación Nacional y Salud y Protección Social y, Departamento Administrativo de la Función Pública) 10001-2016, la cual busca superar las incidencias políticas y las deficiencias en los concursos de méritos para la selección de gerentes de la Empresas Sociales del Estado.

Las deficiencias y barreras en el flujo de recursos que crearon múltiples mecanismos formales de control, sin que la capacidad de gestión de las autoridades intervinientes contribuyera a superar las barreras que afectaban la recepción, trámite, liquidación y giro de las cuentas, lo que originó, entre otros, riesgos de corrupción y la apropiación indebida de recursos por agentes propios o ajenos al Sistema de Seguridad Social en Salud. El periódico El Tiempo informa al respecto:

El saqueo al sector salud es superior a los 4,5 billones de pesos, hecho que generó la orden de captura hacia las 3:00 a.m. de los primeros cinco implicados por parte del juez 48 de control de garantías. Las cinco capturas de este lunes son apenas el primer capítulo de un mega escándalo de corrupción. (El Tiempo, 2011)

El clientelismo político tiene carta de ciudadanía y una impresionante influencia en las instancias de decisión, en todos los niveles. El propio Superintendente Nacional de Salud denunció a dos miembros del Congreso de Colombia por solicitarle el nombramiento de una persona como interventora de una EPS Varias fuentes han informado sobre estos sucesos:

Un Congresista remitió el siguiente mensaje al Presidente de la EPS SALUCOOP: ““"Buenas noches, te envío el texto definitivo del proyecto 
aprobado en las comisiones séptimas, te quiero molestar porque hace 2 meses, no han vuelto a consignar, NIT 804010319-3. Muchas gracias (Coronell, $2015) .^{62}$

Lo mismo ha ocurrido con los intereses que sobre la salud tienen congresistas y políticos. Esto sin contar el largo listado de intereses que gobernadores y alcaldes han tenido en hospitales y EPS del régimen subsidiado. Incluso en los corrillos del Capitolio se hablaba de la bancada que Saludcoop llegó a tener a su servicio en el Senado o de lo que hizo el cartel de la contratación con los hospitales de Bogotá, que pasaron de ser un modelo de gestión regional a una cloaca de burocracia y corrupción (Semana, 2013).

Por consiguiente, la costumbre de asignar empleos a los congresistas, según su influencia para los proyectos del gobierno y la dependencia que los funcionarios, así elegidos, tienen de los senadores y representantes distorsiona el ejercicio de las funciones, compromete la autonomía de quienes deciden a nombre de las entidades y, mantiene la "patente de corso" para aquellos que creen que "poseen" la entidad porque la tienen "asignada": "Según los documentos que reposan en el computador de la Secretaría General de la Presidencia, el senador y expresidente del Congreso, Roy Barreras, habría influenciado para el nombramiento de seis altos funcionarios de Caprecom" (Las2orillas, 2013).

La rendición de cuentas, como muchas de las obligaciones relacionadas con el principio de transparencia, se obedece, pero no se cumple. La presentación formal de cuentas (Comité de Apoyo Técnico en la Política de Rendición de Cuentas, 2014), hace énfasis sobre temas y cifras que contribuyen a dar la sensación pública de “cumplimiento", pero que esconden información valiosa sobre manejo, administración,

62 Negrilla fuera de texto. 
gestión, situación y gasto de recursos, en unos sistemas de información contable poco conocidos, carentes de análisis y de presentación de la realidad de las operaciones, sus costos y, en general, sin caracterizar el flujo de dineros, los proveedores, la oportunidad, calidad, cuantía y pertinencia de la compra, los mecanismos de diagnóstico de las necesidades, las formas de adquisición de los insumos, bienes y elementos que utiliza la entidad. Aquí la forma sustituye el contenido y, aparentemente el cumplimiento "legal" de la regla, libra de toda responsabilidad a los agentes del sistema; por ello, se presentan a la opinión gestiones perfectas, sin que se pueda ver dónde y por qué los recursos terminan siendo destinados indebidamente $\mathrm{y}$, aún menos, sin poder conocer los responsables.

La baja capacidad de gestión de las entidades encargadas de la inspección, vigilancia y control impide la adopción, actualización y operación de herramientas que permitan contar con sistemas de información para ejecutar actuaciones oportunas, relevantes y de impacto sobre el cumplimiento de las obligaciones de los agentes del Sistema:

La deficiente ejecución del presupuesto y del avance de los proyectos de inversión propuestos, y concretamente el proyecto de "Diseño, Implantación e Implementación del Sistema de Información de la SNS" con una ejecución del14\%, ponen a la entidad en una situación desventajosa frente a sus vigilados y usuarios, al no alcanzar un nivel superior en la aplicación de los principios de eficiencia, eficacia y economía, que beneficien y tengan impacto favorable en la comunidad y en el cumplimiento de sus metas y objetivos (Contraloría General de la República, 2015, p. 10). 
Lo anterior, aunado al déficit de personal y de recursos y, baja aplicación de actividades preventivas, aumenta los riesgos de corrupción y disminuye la capacidad de disuasión. Sobre estas limitaciones se puede aseverar que:

El desarrollo de un modelo preventivo de la inspección, vigilancia y control no ha sido adecuado. Se siguen presentando debilidades en el monitoreo, sistema de información y alarmas, en el control de riesgos y en el análisis de la información derivada de los controles existentes (Contraloría General de la República, 2015, p. 12).

Aunque ya van cerca de 20 condenas por las trampas con la plata de la salud de todos los colombianos, un informe de la Contraloría General conocido por EL TIEMPO revela que esas irregularidades no son cosa del pasado y se siguen presentando en varias regiones, especialmente en proyectos desarrollados con dinero de las regalías departamentales y municipales (El Tiempo. Justicia, 2016) El constante, continúo e inveterado cobro de servicios y tecnologías en salud contempladas en los Planes de Beneficios de los regímenes Contributivo y Subsidiado, sin que las autoridades, después de más de doce años, hayan encontrado la fórmula para evitar ser timadas por los agentes del sistema a quienes controla. Así lo revela un informe de El Tiempo:

En las auditorías a las cuentas de la salud en el 2015, la Contraloría encontró que IPS y EPS le siguen cobrando al Fosyga los tratamientos y medicamentos que deben entregar a pacientes sin ningún tipo de cortapisa, pues están incluidos en las coberturas de los regímenes contributivo y subsidiado. Las debilidades en el control de esos recursos y las trampas de funcionarios de la salud siguen llevando al desvío de recursos que deberían servir para atender los males de los colombianos (El Tiempo. Justicia, 2016). 
Las falencias del proceso de compensación asociadas a pagos por afiliados repetidos o con multiafiliación, los cuales ascienden, en el año 2014, a 41.348 grupos, entre los cuales existen registros de los regímenes Contributivo y Subsidiado. El reporte muestra afiliados fallecidos con 11.028 registros en el Régimen Contributivo y 3.922 en el Subsidiado, a más de la multiafiliación con los regímenes de excepción y la existencia de pensionados afiliados en el Régimen Subsidiado (Contraloría General de la República, 2015).

La revisión documental sobre algunas cuentas de cobro, por las prestaciones en salud, muestran una tendencia a reclamar un mayor valor, por el servicio atendido, que el registrado por el personal de la salud, en las notas sobre los tratamientos y cantidades de medicamentos aplicados a los pacientes: “...existe un menor valor en cuanto a las cantidades aplicadas a los pacientes con respecto a lo facturado, lo que genera un mayor valor pagado en la suma de 524’443.000 pesos” (Contraloría General de la República, 2015).

El aspecto crucial en la toma de los recursos de Salud se presenta con la instauración y consolidación de redes ilícitas que han reconfigurado la institucionalidad de las entidades territoriales, sin desconocer su incidencia en algunas de las instancias del Poder Público. Estas redes tienen las siguientes características (Garay \& Salcedo A., 2012):

Confluencia y articulación de intereses de personas y grupos, legales e ilegales, hacia objetivos e intereses estatales:

El pacto fue conocido como el de Barranco de Loba, y en esta reunión, convocada por el ex jefe paramilitar 'Ernesto Báez', asistieron ex alcaldes, alcaldes, candidatos a alcaldes, ex concejales, concejales y aspirantes a concejales, así como algunos aspirantes a la Asamblea Departamental, delegados 
de los comandantes de las autodefensas, miembros de movimientos como No al despeje y Asocipaz. También se asegura que estuvieron presentes senadores, ex senadores y otros políticos de relevancia en Bolívar, entre ellos Blel Saad...

El propósito de dicha reunión era notificar a los asistentes que en los movimientos de autodefensa existía la voluntad de apoyar candidatos únicos a las alcaldías y a la gobernación. Se acordó que entre los asistentes debían elegir a los candidatos, y los que fueran descalificados debían renunciar a sus aspiraciones. Quien desatendiera esta directriz se exponía a una 'sanción' (Verdad Abierta, 2010).

Conciencia y compromiso con la intención de captar diferentes tipos de beneficios, entre los que se encuentran los económicos, el prestigio social y político y, la protección contra cualquier amenaza (penal, civil, administrativa, etc.):

Uno de estos casos es el de la ESP indígena Manexca, que atiende a más de 250.000 usuarios de esas comunidades en los departamentos de Sucre y Córdoba. El líder indígena Pedro Pestana Rojas, quien era su director, fue condenado por aliarse con los paramilitares de los Montes de María, encabezados por 'Cadena' y 'Diego Vecino', para desviar dineros de la EPS hacia las arcas de las Auc. Sin embargo, Pestana logró su libertad el año pasado, tras una polémica decisión judicial (El Tiempo. Justicia, 2015)

Utilización de la amenaza, la coerción, el chantaje, la violencia, la desaparición o la muerte a través de organizaciones criminales al servicio del grupo de poder:

“...el dominio territorial que durante una década ejercieron los ejércitos privados paramilitares avanzó hacia la captura de los estados locales y regionales y la cooptación o subordinación de las capas políticas y administrativas en grandes 
regiones del país, en proporción a su fortaleza relativa. Siguiendo las tradiciones clientelistas de corrupción electoral, los jefes paramilitares presionaron la escogencia de candidatos a los altos cargos de representación popular en el congreso, las asambleas departamentales, las gobernaciones y alcaldías, los consejos (SIC) municipales y exigieron como contraprestación el otorgamiento de contratos, la desviación de recursos públicos y el nombramiento de personas escogidas para privatizar los beneficios de la acción estatal (Reyes P., Duica A., \& Pedraza, 2009, p. 2)..

Alianzas políticas con diferentes fuerzas, independientemente de la ideología, para garantizar la incidencia o imposición de decisiones que favorecen sus intereses.

Incorporación de personas con influencia en diferentes medios y contactos en instancias claves de decisión: "Ex director del DAS ... tuvo nexos con paramilitares, que rozaron con pertenencia al grupo "...se incrustó en la empresa criminal de las autodefensas, las ayudó en su fortalecimiento, en su consolidación y expansión...” (El Tiempo, 2007).

La multiplicidad de intereses adversos y extraños al Sistema General de Seguridad Social en Salud creó una completa parainstitucionalidad, en la que participaron agentes propios y foráneos, con organizaciones, jerarquías, reglas, ritos, roles y parafernalias propias de un Estado Mafioso, el cual, al estilo de lo que Ferrajoli (2014) llama la expansión de la ilegalidad:

“... la expansión de la ilegalidad en la vida pública que ha afectado, en años pasados, al conjunto de los partidos, la administración pública, al empresariado, al sistema bancario, y, al mismo tiempo, a extensas capas de población ligadas al mundo de la política por tupidas relaciones clientelares e implicadas de distintas maneras, por convivencia o incluso sólo por resignación, en la práctica de la 
corrupción. Así, tras la fachada del estado de derecho, se ha desarrollado un infraestado clandestino, con sus propios códigos y sus propios impuestos, organizado en centros de poder ocultos y a menudo en connivencia con los poderes mafiosos, y, por consiguiente, en contradicción con todos los principios de la democracia: desde el de la legalidad al de publicidad y transparencia, del de representatividad a los de responsabilidad política y control popular de funcionamiento del poder (p.9).

Ello creó una realidad territorial especializada sobre el acceso, la prestación, el cuidado y la prestación de los servicios de salud que ahogó la capacidad de las fuerzas vivas de la democracia para hacer efectivo el derecho fundamental y, lo trastocó y consolidó en una acción de caridad, a la cual acuden apesadumbradas las personas, en lenta letanía, para dar gracias a quienes desde su pedestal fungen como dueños y señores del derecho fundamental a la salud. Este fenómeno está lejos de haberse caracterizado, desnudado y superado, ya que tirios y troyanos se encuentran enfrascados en la pertinencia y validez del modelo de Seguridad Social en Salud, mientras los capturadores de rentas disfrutan de los recursos apropiados y, contribuyen a atizar la hoguera de un debate que deja por fuera lo esencial: el conocimiento, apropiación, cuidado y preservación de la salud por quien debería ser uno de los principales gestores de su propio bienestar: la persona humana.

\subsection{Derecho, información y participación}

La Ley 1751 de 2015 (Estatutaria de Salud) señala la accesibilidad como uno de los elementos esenciales del derecho fundamental, la cual supone la disposición de información clara, apropiada y suficiente que permita, a la persona, tomar decisiones libres, conscientes e informadas respecto de los procedimientos que le van a practicar y 
los riesgos a los que estará sometida, sin que esté obligada a recibir tratamientos contra su propia voluntad.

El derecho a la información supone, también, la posibilidad de conocer los trámites, mecanismos e instrumentos que le permitan presentar reclamaciones, quejas, sugerencias; solicitar y recibir explicaciones sobre los costos de los tratamientos; expresar la voluntad sobre la aceptación o negación de la donación de sus órganos; evitar cualquier trato que afecte su dignidad humana; negarse a soportar el sufrimiento innecesario, cuando existen tratamientos, así como disponer del conocimiento de los mismos; estar al tanto de las cargas administrativas de las entidades del Sistema General de Seguridad Social en Salud, las cuales no tiene por qué asumir y, conocer los medios expeditos de comunicación de que disponen las instituciones, de tal manera que reciba respuesta en los términos establecidos en las disposiciones legales.

El complemento del derecho de acceso a la información está relacionado con la obligación del Estado y las instituciones del Sistema General de Seguridad Social en Salud para recibir datos, cifras y conocimientos que permitan, a las personas, participar en la formulación de las políticas y planes del Sector Salud y Protección Social; deliberar en las instancias de decisión, seguimiento y evaluación del SGSSS; participar en las actividades de promoción y prevención; hacer parte de las instancias que toman decisiones sobre la inclusión o exclusión de servicios y tecnologías; ser partícipe en la determinación de las prioridades de salud, así como en las decisiones que limitan o restringen las condiciones de acceso a los servicios de salud y, participar en la evaluación de los resultados de las políticas, planes, programas y proyectos asociados al cuidado, protección y recuperación de la salud.

Es claro que el acceso a la información y la participación son dos principios correlacionados que, en teoría, están garantizados por la Constitución Política, la Ley 
Estatutaria de Salud y, la multiplicidad de leyes y disposiciones reglamentarias, sin que pueda comprobarse, por lo menos con los datos disponibles, el efectivo acceso a información clave sobre los factores que inciden en el estado de salud de la persona, la comunidad y la sociedad y, menos aún, la real y concreta participación en las instancias y términos atrás referenciados. Al respecto, la Corte Constitucional desde comienzos de la última década del Siglo XX reivindicó la participación ciudadana como una expresión del modelo de organización social, al afirmar:

“El principio de participación democrática expresa no sólo un sistema de toma de decisiones, sino un modelo de comportamiento social y político, fundamentado en los principios del pluralismo, la tolerancia, la protección de los derechos y libertades así como en una gran responsabilidad de los ciudadanos en la definición del destino colectivo (Corte Constitucional. Sentencia C-180, 1994a).

Un ejemplo, al canto, de la política y acciones de la participación proviene del Informe al Congreso, presentado por el Ministerio de Salud y Protección Social para el período 2015-2016 (Ministerio de Salud y Protección Social, 2016a), el cual contiene en diferentes apartados el tema de la participación, con los siguientes resultados: Las orientaciones conceptuales y metodológicas a equipos de salud materna e infantil de las Direcciones Territoriales en Salud, con el fortalecimiento de la participación y movilización social de familias y comunidades, a través de 8 sesiones; la participación del Ente Rector del Sector en las mesas de la Comisión Intersectorial Alimentaria y Nutricional, orientada a mantener la gestión territorial, la dinamización de la participación social y comunitaria; la generación de rutas destinadas a responder en situaciones de emergencias; los lineamientos de política pública para grupos étnicos y la elaboración del anexo étnico al PNSAN 2012-2019, con la participación, 
socialización y validación de comunidades indígenas y afrodescendientes; la atención de la Orden 15 del Auto 073 de 2014 de la Corte Constitucional, a través de un convenio que busca garantizar la participación activa de las comunidades negras en los territorios colectivos y ancestrales de Nariño, el cual permitió conocer los posibles impactos en la salud de las actividades de exploración y explotación minera en los territorios colectivos $\mathrm{y}$ ancestrales de comunidades negras de la mencionada entidad territorial y, señalar la necesidad de capacitación, información y rendición de cuentas, con el objeto de logar la comprensión y participación en el Sistema de Salud; la participación de más de 2.500 personas a formulación del Plan Nacional de Mejoramiento de la Calidad en Salud 2016-2021; la promoción de la participación social y ciudadana, en espacios de participación y control social, para garantizar la prestación del servicio a los afiliados y beneficiarios del sistema, en materia de prevención y atención de emergencias y desastres; la ejecución del Proyecto de Participación Social, el cual tenía como objetivo definir espacios y formas de participación, a través de transferencias de recursos, a tres entidades territoriales; el fortalecimiento de la asistencia técnica y la capacidad institucional en participación y control social en el territorio nacional; el fortalecimiento de los procesos de organización para garantizar la participación de las personas en situación de discapacidad; la asignación de recursos financieros destinados a la adaptación social, laboral y familiar del inimputable y la psico educación de los pacientes y su familias, con el objeto de concientizar sobre la enfermedad y, lograr su participación activa en el proceso de rehabilitación; el avance en el proceso de actualización de Política Colombiana de Envejecimiento Humano y Vejez, siguiendo la estructura de la política nacional formulada a finales del año 2007 respecto a los objetivos, ejes estratégicos y líneas de acción, considerando referentes nacionales e internacionales y con amplia participación social y ciudadana, con el objeto de dotar de 
legitimidad social a la política; la revisión y ajuste del decreto de Habilitación de las EPS Indígenas, con participación de representantes de dichas entidades, autoridades indígenas y subcomisionados de salud; la realización del Foro "Situación de Salud de las Comunidades Afro, Negras, Palanqueras y Raizales”, encaminado a fortalecer la participación de las comunidades afrocolombianas, negras, raizales y palenqueras, y, el diseño de una propuesta del procedimiento técnico científico, con base en la información obtenida de 14 líderes de opinión del Sistema General de Seguridad Social en Salud, el diálogo adelantado en siete (7) ciudades con diferentes agentes.

\subsection{Alternativas recientes y continuidad de mitos}

El artículo 65, del Plan Nacional de Desarrollo 2014-2018, señala al Ministerio de Salud y Protección Social como el responsable de definir, con base en la Ley Estatutaria de Salud y demás disposiciones legales, la política en salud dirigida a la población residente en Colombia, la cual, por la norma en mención, se convierte en obligatoria para todos los agentes del Sistema General de Seguridad Social en Salud y las entidades asociadas a la salud. La política debe tener en cuenta, en su formulación y ejecución, los enfoques de Atención Primaria en Salud, Salud Familiar y Comunitaria, Articulación de las Actividades Individuales y Colectivas y, una visión Poblacional y Diferencial y, los componentes relativos a las rutas de atención para la promoción y mantenimiento de la salud por curso de vida, las rutas de atención específicas por grupos de riesgos, el fortalecimiento del prestador primario, la operación en redes integrales de servicios, el desarrollo del talento humano, la articulación de las intervenciones individuales y colectivas, el desarrollo de incentivos en salud, así como la definición de requerimientos de información que permitan el seguimiento y evaluación de la misma. 
El Ministerio de Salud y Protección Social adopta la Política de Atención Integral de Salud, denominada PAIS, conforme a los marcos estratégico y operacional expresados en el Modelo Integral de Atención en Salud -MIAS-, a través de la cual busca generar un cambio en las prioridades del Estado como regulador, con base en la subordinación de los intereses y prioridades de los agentes del sistema a los objetivos de la regulación, cuyo centro es el ciudadano, dirigidos a la generación de mejores condiciones de salud para la población, con base en la intervención sobre los integrantes responsables de la promoción, prevención, diagnóstico, tratamiento, rehabilitación, paliación de la enfermedad y muerte digna y, la interacción coordinada con las entidades territoriales, las administradoras de planes de beneficios, las prestadoras de servicios de salud y los demás entes que, desde diferentes sectores, inciden, condicionan o influyen en el estado de salud de las personas (Ministerio de Salud y Protección Social, 2016c).

La mencionada política tiene expresión concreta en el Modelo Integral de Atención en Salud, del cual forman parte de diez componentes, cuyos contenidos se expresan así:

$>$ La caracterización de la población queda bajo la responsabilidad de cada integrante del Sistema General de Seguridad Social en Salud y de aquellas instituciones que tienen intervenciones relacionadas con el estado de salud, quienes deberán organizar a las poblaciones según el curso de su vida y los grupos de riesgos, con el objeto de garantizar una planeación de servicios de salud coherente con las necesidades y las metas del Plan Nacional de Salud Pública 2012-2021.

$>$ Las Rutas Integrales de Atención en Salud -RIAS- definen las condiciones de intervención, individuales o colectivas, para la prevención, diagnóstico, tratamiento, rehabilitación y paliación de la enfermedad, a cargo de los diferentes 
agentes del sistema, con base en las condiciones de los grupos poblaciones y su ubicación geográfica, teniendo en cuenta la promoción y protección de la salud, los grupos de riesgo y los eventos específicos de atención.

La implementación de la Gestión Integral del Riego en Salud -GIRS- comprende la coordinación, monitoreo y ajuste de acciones planificadas, cuyo objeto es prevenir eventos de interés en salud pública, controlar riesgos de salud individual, familiar y comunitario y, evitar enfermedades, traumatismos y discapacidades generadas por las enfermedades.

La delimitación territorial de los ámbitos de acción, los cuales se caracterizan en urbanos, alta ruralidad y dispersos, con el objeto de garantizar la prestación de los servicios teniendo en cuenta las condiciones geográficas y poblacionales.

$>$ La Red Integral de Prestadores de Servicios conformada por el conjunto de instituciones prestadoras, independientemente de su naturaleza, en un ámbito territorial específico que contiene componentes primario y complementario, que posee los suficientes recursos humanos, técnicos, financieros y físicos para garantizar la disponibilidad, aceptabilidad, accesibilidad y calidad en la prestación de los servicios.

$>$ El Rol del Asegurador entendido como el responsable de fortalecer la gestión del riesgo financiero, la capacidad técnica para la gestión del riesgo en salud y la interacción con los demás integrantes del Sistema en la planeación, ejecución y seguimiento de los planes territoriales de salud, la gestión del riesgo en salud y el fortalecimiento de la capacidad de gestión de la información requerida por los distintos agentes del sistema. 
El Esquema de Incentivos dirigido a orientar, articular y alinear a los aseguradores, prestadores y proveedores de insumos a los objetivos y resultados esperados en el ámbito del derecho y acceso a los servicios de salud.

El Sistema de Información que permite digitar, procesar, sistematizar y generar datos para todos los agentes del sistema, con el fin de proveer la información necesaria para el cumplimiento de las obligaciones de cada instancia y ser fuente de verificación del cumplimiento del derecho a los servicios de salud.

El fortalecimiento del Talento Humano en Salud a través de la formación, la armonización con el cuidado integral y la provisión de servicios para las personas, el fortalecimiento de la instancias responsable de la planeación y gestión territorial en salud y, el mejoramiento de las condiciones laborales.

$>$ El fortalecimiento de la investigación, innovación y apropiación del conocimiento con base en lo que la disposición legal denomina retos: rectoría del sistema, sostenibilidad financiera, gestión eficiente de talento humano, fortalecimiento de los sistemas de información, mecanismos de transferencia del conocimiento en políticas públicas, acceso, utilización y garantía de calidad y, consolidación de la capacidad de investigación en salud pública.

La norma incorpora, en la implementación y consolidación del Modelo Integral de Atención en Salud, criterios de gobernabilidad entre los que resalta la teoría de la gobernanza, la gradualidad y progresividad en la implementación y, mecanismos de retroalimentación y planes de mejora.

\subsection{Esfuerzos en la caracterización y búsqueda de alternativas de mejoramiento.}

El libro titulado 'Estudio sobre la geografía sanitaria de Colombia' (Páez S., Jaramillo Q., \& Franco R., 2013) intenta atender las observaciones de la Corte Constitucional sobre los deberes del Estado Colombiano, en relación con la garantía del 
derecho a la salud, especialmente en lo relativo a dos características esenciales del derecho, comentadas en anteriores apartados: el carácter prestacional $\mathrm{y}$, simultáneamente, progresivo del mismo, del cual se derivan las obligaciones de adoptar medidas económicas, jurídicas y políticas; garantizar contenidos mínimos de prestación que sean base para su crecimiento hasta lograr la cobertura universal y, mantener, al menos, el nivel alcanzado, el cual no es posible afectar en sentido negativo (Corte Constitucional. Sentencia C-463, 2008a)

El Ministerio de Salud y Protección Social considera, en el texto mencionado (Páez S. et al., 2013), que Colombia tiene dos realidades paralelas que afectan las obligaciones señaladas por la Corte Constitucional, ellas son:

En primer lugar, es un país diverso en su geografía, cultura, concentración demográfica, nivel de desarrollo y carga de la enfermedad. Esta heterogeneidad conduce, en un importante número de casos, a que las políticas de salud estén limitadas a zonas de características particulares, sin que se hayan superado discriminaciones sistemáticas contra algunas regiones, particularmente las más pobres, vulnerables y con menor capacidad de respuesta económica e institucional. Esta situación conduce al órgano rector del sector a caracterizar los territorios y sectores sociales, cuyos determinantes sean, por las variables estudiadas, similares $\mathrm{y}$, en consecuencia, a proponer políticas homogéneas hacia regiones calificadas como de acción diferencial.

En segundo lugar, recuerda que el artículo 179 de la ley 100 de 1993 señala las redes hospitalarias como un mecanismo orgánico de la prestación de servicios de salud, las cuales están e intervienen en los diferentes niveles territoriales; por ello, el Ministerio propone, tal vez en congruencia con el principio de disponibilidad, promover y contribuir en la consolidación de Redes de Atención Sanitaria (RAS), para facilitar el acceso rápido y oportuno a la atención. 
Las alternativas de diseño, adopción y operación de Redes de Acción Diferencial y Redes de Atención Sanitaria se inscriben en una programación y gestión regionalizada, cuya obtención, procesamiento y análisis de información suponen arreglos institucionales que incluyen, además de las redes de atención, la respuesta a las condiciones particulares de algunas zonas, las cuales constituyen zonas de atención integral y diferencial (ZAID), con el fin de buscar garantizar una oferta completa de servicios básicos, a partir de las características homogéneas y las condiciones socioculturales, económicas y sanitarias.

\subsubsection{Límites impuestos oficialmente a los determinantes de la Salud.}

El texto del Ministerio de Salud y Protección Social (Páez S. et al., 2013) señala los determinantes de la salud sobre los cuales propondrá los índices que soportan la creación de las Regiones de Acción Diferencial y las Redes de Atención Sanitaria, entre ellos contempla la geografía, las rutas y transporte, la minería, la educación, los grupos étnicos, los servicios públicos, la violencia, las coberturas e indicadores de salud, la oferta de servicios de salud y, la demanda de salud, sin hacer explícitos temas que afectan directamente la salud como el estilo de vida, la alimentación, las condiciones de seguridad y salud en el trabajo, entre otros. Algunos de estos temas son referidos en el texto como posibilidades de influencia sobre la salud, sin darles la relevancia esencial que los mismos tienen en el estado de salud. Por ejemplo el tema de alimentación está mencionado una sola vez y, estilo de vida aparece dos veces en el texto:

Esta enfermedad se encuentra principalmente en la zona andina y con mayor incidencia en la Orinoquía y al sur del país. Rastrear la enfermedad y asociar su presencia con ciertas características relacionadas con la ubicación geográfica es difícil ya que esta responde principalmente a malformaciones genéticas y dependiendo del tipo de diabetes se manifiesta por detonantes externos o por 
causas hereditarias aunque los detonantes externos están asociados principalmente al tipo de alimentación Social (Páez S. et al., 2013, p. 196)

Adicionalmente, pueden existir aspectos del estilo de vida de alguna comunidad en particular que pueden ser nocivos para la salud de sus propios habitantes y condiciones genéticas que permitan que una enfermedad se desarrolle $-\mathrm{o}$ no- en los individuos que la componen. En Australia, por ejemplo, Woods et. al. (2008) encuentran que existen barreras culturales que impiden que las mujeres embarazadas de ciertas etnias dejen de lado la práctica de fumar tabaco -con las consecuencias negativas que trae sobre la gestación de los infantes (Páez S. et al., 2013, p. 75).

La Enfermedad Respiratoria Crónica al igual que la Diabetes Mellitus aparece principalmente en la región Andina y en el Caribe, aunque se presenta en mayor proporción en Vichada y Amazonas. Los factores de riesgo de estas enfermedades son tabaquismo, la inactividad física, el uso nocivo del alcohol y la dieta no saludable7, estos factores de riesgo corresponden a un estilo de vida propio de los centros urbanos, esta enfermedad se presenta en el país en el $1 \%$ de la poblaciónn de los diferentes municipios (Páez S. et al., 2013, p. 200).

La mención de la geografía tiene su énfasis en los efectos sobre las condiciones climáticas y su efecto en el contagio y transmisión de las enfermedades y, a partir de ahí, se derivan las variables de altura, temperatura, humedad y precipitación que aplicadas a las características territoriales permiten, en el estudio, derivar la capacidad predictiva del modelo, determinar la regionalización y esclarecer su importancia frente a la adquisición o desarrollo de patologías, con base en el argumento de que muchas zonas son excelentes reservorios que contribuyen a la diseminación de vectores de enfermedades del país. 
Las rutas y transportes son considerados en términos de distancia entre capitales de departamentos y capitales de municipios y de movilidad de las personas, individualmente consideradas, con el fin de obtener, con base en parámetros técnicos, las distancias mínimas entre dos municipios, una red que permita señalar la distancia más cercana a la capital del departamento, a alguna capital departamental y las ubicaciones de los aeropuertos, en perspectiva de implementar los contenidos mínimos básicos de salud y garantizar su acceso a los mismos. (Páez S. et al., 2013).

El tratamiento que se da a los factores socioeconómicos está centrado en el estudio de la población, con el fin de conocer el acceso a determinadas poblaciones, entre otras razones frente al contagio de enfermedades y su efecto expansivo como riesgo potencial sobre las demás personas; mencionan los indicadores de pobreza, a fin de interrelacionarlos con el acceso a agua potable, vivienda digna, saneamiento básico, entre otros y, finalmente, señalan como variable el entorno de las personas, el cual permite identificar perfiles epidemiológicos, en la perspectiva, reiterada en diversos apartes del documento, de la intensidad de la transmisión de enfermedades y, el acceso a instituciones de salud. "Si bien los factores socioeconómicos podrían no tener efectos directos en la salud de las personas, estos son los principales responsables de las barreras de entrada de las personas y la disponibilidad de servicios" (Páez S. et al., 2013, p. 40).

Los factores socioeconómicos en los que se enfatiza están asociados al acceso a servicios, denominados básicos, entre ellos salud, la educación, servicios públicos y aquellos que reflejan la calidad de vida de las personas (electrodomésticos, tipo de suelo, saneamiento básico, combustible, entre otros). El examen lleva a concluir que las zonas más pobres están ubicadas en los departamentos de la Amazonía, el Caribe, Chocó, Nariño. 
La educación es vista como un factor fundamental de movilidad social y referente esencial en los programas de promoción de la salud y prevención de la enfermedad, entre otras razones por los efectos sobre el mayor ingreso económico y el acceso a mejores conocimientos sobre la salud. Sin embargo, los ejemplos que se dan en relación con la utilización de los mayores niveles educativos se refieren a programas de vacunación y campañas de salud ocupacional, sin que se mencionen elementos estructurales que inciden en la calidad de vida, el estado de salud y el bienestar, en los cuales el conocimiento puede ser un elemento fundamental y multiplicador para el cuidado y protección de la salud humana, así como de los factores que sistemáticamente interactúan (ambiente, cultura, trabajo, recreación, etc.). En consecuencia, la el estudio de la educación, como factor determinante de la salud, termina reducida al estudio de las variables analfabetismo, cobertura de la educación secundaria y número de colegios y, el desarrollo del capital humano.

Los servicios públicos objeto de análisis son los de agua, luz y el alcantarillado, a partir de los cuales se busca relacionar las situaciones de salud con las condiciones de vida en la que se encuentran las poblaciones y, de allí derivar el nivel de desarrollo socioeconómico y su efecto sobre el estado de salud en un municipio.

\subsubsection{Impotencia en un mundo de datos.}

La persona del común que enferma asiste, inconsciente, al frío espectáculo que brindan las diferentes corrientes del pensamiento, en el ámbito de la medicina, en torno a la dolencia que sufre, sus causas, las alternativas de tratamiento, la posibilidad de mejora y, el intrincado mundo de intereses que acompaña a los diferentes agentes del campo de la medicina, entre ellos, el personal médico. Al respecto Montagnier (1995) afirma: 
La División del trabajo es la regla en la investigación médica. Los clínicos se ocupan del cuidado de los enfermos, a los que consideran un poco como su propiedad. Los investigadores, del trabajo de laboratorio... Lo ideal sería ser médico por el día e investigador por la noche, o al revés (p.111)

Los profesionales de la salud sostienen, en mayoría aplastante, independientemente de la corriente a la cual están adscritos, que cualquier enfermedad es curable, sin que puedan evitar el pánico que vive el paciente por su estado salud y la probabilidad de la muerte; acorde con Sontag (2003):

Aunque la mitificación de una enfermedad siempre tiene lugar en un marco de esperanzas renovadas, la enfermedad en sí (ayer la tuberculosis, hoy el cáncer) infunde un terror totalmente pasado de moda. Basta ver una enfermedad cualquiera como un misterio, y temerla intensamente, para que se vuelva moralmente, si no literalmente, contagiosa (p.2).

Con un enfoque similar plantea Roberts (2009):

Los posibles peligros víricos acaparan, no obstante, gran parte de nuestros fondos para la investigación médica. Hoy en día los anuncios de TV enfatizan, todavía con patente horror, que millones de bacterias y virus habitan en nuestra piel -y que debemos destruirlos comprando este o aquel desinfectante... Hoy nuestros hospitales están infectados de bacterias que desarrollaron resistencia a los antibióticos al hacer lo que hacen todas las células de nuestro cuerpo: desarrollar protección contra los peligros tóxicos (p.308).

Y, sin que el personal médico pueda acceder a información clara, específica y oportuna que le permita conocer cuál es el estado del desarrollo de la ciencia médica y sus posibles alternativas de tratamiento, en un ámbito convulsionado por intereses 
financieros que se mueven alrededor del estudio y recetas para superar las dolencias humanas:

Simultáneamente con los cambios en el rol del Estado, los economistas cambiaron el carácter de "bienes meritorios" o "cuasi-públicos" de los servicios de salud y los convirtieron en una mercancía, ¡como los zapatos o las papas! No cabe duda de que debe haber una diferencia entre el acceso económico a las papas y aquel correspondiente a los servicios de salud (Echeverri, 2008, p. 211). Las empresas farmacéuticas merecen capítulo aparte, pero basta con señalar que el propio premio Nobel de Medicina Richard Roberts reconocía que «no les interesa buscar la curación». Ni las empresas de armamento desean acabar con las guerras ni las de medicamentos con la enfermedad. La razón es que nuestro sistema de mercado se fundamenta en crear empresas a las que paga por atender los problemas, de forma tal que éstas serán las primeras interesadas en que no se solucionen definitivamente esos problemas (García \& Serrano, 2009, p. 14).

La mayoría de las personas enfrentan los mitos, ficciones y apologías de la enfermedad cuando padecen una dolencia que pone en riesgo las capacidades de su organismo o una función vital, sin que, en general, sean conscientes de la relación que múltiples factores, internos y externos, tienen sobre su calidad de vida y el estado de su salud. El miedo humano adquiere, en este evento, un estatus supremo que mueve todas las fuerzas de la persona para lograr "milagrosamente" una cura, un volver a su estado “original”, tan caótica conciencia genera esperanzas, deseos e inquebrantable fervor por encontrar la "cura", especialmente en aquellos estados patológicos que, como un ministerio sin solución, abrazan al paciente y, le producen un pánico tan atroz que todo su ser, así como el de las personas de su círculo afectivo, busca liberar inmediata y totalmente a su cuerpo de su calamitosa situación. La historia humana está, de hecho, 
asociada a los rituales como forma de enfrentar y superar múltiples problemas que aquejan a la persona o a la comunidad. Por ejemplo: "Si un miembro de la tribu se ha salido del orden y ha sido víctima de un accidente o enfermedad, necesita un ritual de curación" (Dahlke, 2000, p. 55).

\subsubsection{Desconocimiento de factores asociados a las patologías y a la carga de la}

\section{enfermedad.}

El Ministerio de Salud y Protección Social ha centrado sus políticas y acciones institucionales en la cobertura de la afiliación al Sistema General de Seguridad Social en Salud y, en el acceso a los servicios de salud, con desconocimiento de otros elementos que pueden ser claves en el mejoramiento de la situación de la salud y la disminución de los costos en los que incurre el Sistema General de Seguridad Social en Salud, entre otras razones por la fuerte presión social sobre la demanda de prestaciones médicas, medicamentos y tratamientos especializados, en las cuales la Corte Constitucional juega un papel activo y, los medios de comunicación un fuerte poder mediático que hace invisibles elementos sustanciales que inciden en la calidad de vida, el bienestar y la situación de salud de las personas. El Máximo Tribunal Constitucional afirma:

En cuanto al carácter prestacional del derecho a la seguridad social en salud y al principio de progresividad para hacer plenamente efectivo este derecho, esta Corte quiere aclarar, en primer lugar, un entendimiento erróneo y equivocado respecto de este carácter, ya que el carácter prestacional y progresivo de los derechos sociales, en este caso, del derecho a la salud, en nada afecta la fundamentabilidad del derecho a la salud, ligada como se anotó, a la universalidad del mismo, sino que por el contrario, estos principios tratan de explicitar una máxima según la cual, el Estado tiene la obligación jurídica de implementar todas las medidas legislativas, administrativas, políticas y 
financieras para hacer efectivo en forma material y pronta el derecho a la salud de todos los habitantes del territorio nacional y respecto de la totalidad de los servicios de salud requeridos para garantizar la prevención, promoción, protección y curación de la salud, precisamente por el carácter fundamental de este derecho (Corte Constitucional. Sentencia C-463, 2008a).

La importancia de la diversidad climática y la existencia de múltiples ecosistemas constituyen elementos que inciden sobre la calidad de la salud; sin embargo, es importante señalar que muchos autores han llamado la atención sobre el exagerado énfasis que se da a los microbios y bacterias como fuentes principales de las enfermedades humanas y, simultáneamente, se desconocen otras causas que, por lo menos en pleno Siglo XXI, tienen un efecto significativo en la situación de salud y el bienestar de las personas. Entre los autores de este enfoque se encuentra Shinya (2014), quien afirma:

Se tenía a los microbios, popularmente llamados gérmenes, como responsables de la mayoría de las enfermedades. Matarlos o armar al propio cuerpo con un ejército de anticuerpos para eliminarlos significaría vivir libres de dolencias. También aprendimos a poner fin a enfermedades aterradoras como la malaria y la peste bubónica al exterminar a los insectos y a los gusanos que las propagaban.

El estamento médico estaba ganando la batalla de la vida y la muerte por medio de tácticas científicas de búsqueda y destrucción. Los investigadores buscaban las causas de las enfermedades relacionadas con los microbios y desarrollaban armas para destruirlos. Después los médicos y los trabajadores de la sanidad pública empleaban estas armas para matar a los "gérmenes malos" de sus 
pacientes, lo que permitía que los enfermos se recuperaran y que los sanos se mantuvieran saludables (p.24).

La literatura señala que muchas de las enfermedades con efecto mortal sobre la vida humana tienen origen, o por lo menos un fuerte efecto, en las deficiencias alimentarias:

Los componentes de los alimentos pueden dañarnos o curarnos...

...Para muchos de nosotros, las situaciones estresantes de la vida y las enfermedades crónicas son tan difíciles de manejar, que la recompensa rápida y fácil del alimento es lo primero a lo que recurrimos. Alimento dulce, cremoso, crujiente o graso. Alimento frito, rico e instantáneamente gratificante. Alimento que "deja buen sabor en la boca", como suelen decir los cocineros (Firshein, 2003, p. 28)

El tabaco, el alcohol, las bebidas azucaradas y otros factores asociados al estilo de vida ((Shinya, 2014), al tiempo que muchos de los microbios y bacterias considerados extinguidos han reaparecido con una fuerza inusitada para afectar más gravemente a las personas. Jara (2009), considera:

Dado su enorme número y lo rápido que se reproducen, algunas bacterias y virus pueden sobrevivir a la acción de prácticamente cualquier antibiótico. Los microbios, que de por sí tienen una ligera resistencia a estos "biopreparados", logran superarlos, se multiplican y así transmiten sus genes a otras generaciones. Con el tiempo surgen cepas que son totalmente resistentes (p.68).

Mientras que poca o ninguna atención se pone en otros componentes que influyen en la salud, los cuales son prácticamente descartados por la institucionalidad responsable del derecho fundamental a la salud y, obviamente, son desconocidos para la 
gran masa de personas, quienes, a pesar del derecho de acceso a la información, ni siquiera tienen referentes sobre el particular. Verbigracia:

La física de la resonancia va mucho más allá de las demostraciones en clases. Piensa en los distintos estados de ánimo que puede producir la música con estos diferentes instrumentos. La resonancia musical afecta a nuestras emociones, provocándonos alegría, ansiedad, tranquilidad, asombro, miedo, dicha o tristeza, entre otros (Lewin, 2013, p. 141).

Mientras que frente a la comida, sus sabores, contextura y presentación, creados y manipulados artificialmente, la desinformación es tal que las personas nunca saben qué consumen y ni cuál es su potencial efecto sobre su organismo y, las instituciones, responsables de la salud pública y del estado de salud de las personas, están lejos de concientizar, o desconocen, los efectos, de todos estos factores, sobre el sistema inmunológico y la "aparición" de las enfermedades. Schlosser (2002) presenta un interesante ejemplo sobre los sabores:

Un sabor a fresa artificial típico, como el que se encuentra en el batilo de leche y fresa de Burger King, contiene los siguientes ingredientes: 47 amilacetato, amilbuterato, amilvalerato, anetol, anisilformato, benzilacetato, benzilisobutirato, ácido butírico, cinamil isobutirato, cinamil valerato... ...mantequilla de lirio, alcohol fenetílico, rosa, éter de ron, Y-undecalactona, vainilla y disolvente.

Aunque los sabores surgen casi siempre de una mezcla de numerosas sustancias químicas volátiles distintas, a menudo un solo compuesto proporciona el aroma dominante. Aunque se huela sola, esa sustancia química proporciona la inconfundible sensación del alimento en cuestión (p.177). 
Los investigadores han encontrado una relación directa entre la dieta y la salud especialmente en la aparición de ciertas enfermedades (Gracia Arnaiz, 2009), desde tiempo atrás se ha observado la incidencia del almacenamiento, el transporte, la manipulación y la conservación, además de la adulteración, de los alimentos en las patologías de las personas.

El desarrollo del conocimiento científico sobre la composición de los elementos brinda mayor información sobre los efectos de los nutrientes (macro, vitaminas, polifenoles) en los organismos humanos, son causa de la diversificación de la dieta a la que tienen acceso las poblaciones de las sociedades industrializadas $y$, algunas investigaciones sostienen que en parte son una de las causas del incremento de la esperanza de vida (Gracia Arnaiz, 2009). Sin embargo, la tendencia al incremento de la producción de alimentos, motivada por los desarrollos tecnológicos y, especialmente, el deseo de mayores ganancias de los comercializadores, motiva acciones dirigidas a que las personas consuman más de lo necesario con menor contenido de nutrientes. Ello en razón a:

...la comida procesada se ha convertido en gran medida en un negocio regido por la oferta, el negocio de encontrar maneras ingeniosas de envasar y comercializar la sobreabundancia de mercancías que sale de las granjas y de los molinos húmedos. En la actualidad las grandes ventajas del proceso de alimentos redundan en los propios procesadores. Para ellos la naturaleza es ante todo un problema, no problema, no tanto porque la comida se pueda echar a perder (aunque esa es siempre una preocupación cuando tu mercado es global), sino porque puedan hacerlo sus beneficios...." 
Eso deja dos opciones a compañías... averiguar el modo de conseguir que la gente gaste más dinero por esos tres cuartos de tonelada de comida o convencerlos de que coman más... (Pollan, 2017, pp. 114-115).

Es otra ironía que los alimentos más recomendados (por ejemplo, verduras) para la salud sean los más rechazados por los jóvenes y adolescentes (Gracia Arnaiz, 2009), entre otras razones porque la preparación de los alimentos se ha desplazado, por el ingreso de la mujer al campo laboral, de la familia a los estantes de los supermercados que expenden alimentos procesados y de "fácil consumo", mientras que los individuos hacen poco o nada para prepararse sus comidas y se "deleitan" con las formas y sabores de una comida sin contenido de nutrientes esenciales, pero "Y ¿Qué pasa después? El exceso de biomasa funciona como una aspiradora a la inversa: más tarde o más temprano, los ingeniosos profesionales del mercado descubrirán el modo de inducir al omnívoro humano a consumir esa plétora de calorías baratas” (Pollan, 2017, p. 122), olvidando que "No solo somos lo que comemos, también somos como comemos" (Pollan, 2017, p. 17)

Es bien diciente que sean las empresas privadas las que más información buscan sobre el comportamiento de los niños, entre otras razones para conocer sus gustos e influir y determinar sus necesidades de consumo, sin que las agencias gubernamentales empleen tales estrategias en el conocimiento, cuidado y protección de los menores, quienes se ven bombardeados diariamente con mensajes, en diferentes medios y canales, que condicionan su necesidades, intereses y deseos. Desde este punto de vista:

Los actuales investigadores del mercado no sólo realizan encuestas a los niños en los centros comerciales, sino que también organizan grupos de asesores para niños cuyas edades puede llegar a ser de sólo dos o tres años. Analizan el material gráfico infantil, contratan a niños para que dirijan los grupos de 
asesores, y organizan fiestas en las que luego entrevistan a los niños por la noche. Envian antropólogos culturales a los hogares, las tiendas, los restaurantes de comida rápida y otros lugares en los que a los niños le gusta reunirse, observando callada y furtivamente el comportamiento de sus futuros clientes. Estudian la literatura académica sobre desarrollo infantil, buscando ideas en el trabajo de teóricos como Erik Erikson y Jean Piaget. Estudian las fantasías de los niños más pequeños, y luego aplican sus descubrimientos a los anuncios y a los diseños de los productos (Pollan, 2017, p. 71).

El desconocimiento de información relacionada con investigaciones, alternativas y prácticas de vida saludables afecta a la mayoría de la población y, en algunos casos, a la propia comunidad que labora en los diversos campos de la salud, a tal punto que las personas ignoran:

La composición orgánica de las personas, los efectos del consumo y las necesidades reales de la multivariedad vital del cuerpo humano:

La gente de las diferentes partes del mundo enferma y muere por causas distintas. Las enfermedades infecciosas, como la neumonía, la malaria y el cólera, son responsables de la mayoría de las muertes acaecidas en los países en vías desarrollo.

Sin embargo, en el mundo desarrollado con frecuencia la gente padece un sinfín de dolencias que los epidemiólogos catalogan de enfermedades de la opulencia, como las cardiopatías y la diabetes...

Los científicos han dejado de considerar a toda clase de bacterias, virus y hongos como desagradables invasores con los que lidiamos una batalla campal por el territorio nuestro cuerpo, y han empezado a ver a esos microbios como simbiontes o cohabitantes de nuestro sistema. Teniendo en cuenta que en el 
cuerpo humano hay entre diez y veinte veces tantas bacterias Como células humanas, estamos, en cierto sentido, en minoría dentro de nosotros mismos. Debido a este hecho, muchos profesionales de la medicina están empezando a creer que, para nosotros, es más saludable fomentar su presencia que reprimirla (Stone, 2014, p. 54)

Las consecuencias de la inconciencia sobre las características de los seres vivos y los efectos de los daños humanos sobre el ecosistema y la naturaleza:

Nunca antes el hombre había respirado un aire polucionado con cadmio, plomo y otros contaminantes, ni había debido el agua ni comido alimentos en la misma situación. El cadmio contribuye a la hipertensión y el endurecimiento de las arterias independientemente de la dieta que se siga. Las fibras de asbestos producen cáncer de pulmón; los fuegos de nuestras cocinas de gas polucionan el aire; la luz fluorescente produce depresión de nuestro sistema inmunológico y trastornos de la conducta como la hiperactividad; el agua de beber clarificada con sulfato de aluminio produce envenenamiento por aluminio y éste es un verdadero asesino junto con el mercurio y el plomo; las modernas tuberías de cobre son la causa insospechada de muchos casos de hipertensión; los aditivos de los comestibles pueden producir alergias en nuestros hijos o cáncer (Ams, 1989, p. 22).

Los efectos del estilo de vida en la salud y las consecuencias de los tratamientos sobre el estado de salud:

La causa de casi el $20 \%$ de todos los casos de pérdida de memoria son una amplia variedad de factores ligados al estilo de vida, entre ellos: mala nutrición, consumo de ciertos fármacos, consumo de drogas recreativas, el tabaco, la 
exposición a toxinas medioambientales, consumo excesivo de alcohol y exposición a sustancias alergenas (Khalsa, 2010, p. 108).

La importancia del sistema gastrointestinal en el estado de la salud del cuerpo humano

Durante décadas de práctica clínica, al dar consulta a literalmente cientos de miles de personas como endoscopista gastrointestinal, he aprendido que cuando el sistema gastrointestinal de una persona está limpio, el cuerpo de esa persona es capaz, con cierta facilidad, de combatir enfermedades de cualquier tipo. Por el contrario, cuando el sistema gastrointestinal está sucio, esa persona será propensa a sufrir de algún tipo de enfermedad (Shinya, 2014, p. 18).

Las consecuencias nocivas de algunas comidas sobre los órganos del cuerpo:

Conoce ese sabor muy especial que tiene la comida de los restaurantes chinos?... Es debido al aditivo 621 más conocido glutamato monosódico... Ese potenciador de sabor actúa aumentando la cantidad de saliva producida en la boca y estimulando las papilas gustativas y se fabrica a partir de la remolacha azucarera y el gluten de trigo, aunque se encuentra en estado natural en algunas algas que se crían en el Japón. La verdadera magia del GMS es que puede hacer que un plato de aburrido arroz blanco o una lata de insípida verdura sepan casi como si éstas serán frescas... se comprobó que el GMS podía ocasionar UN SERIO DAÑO IRREVERSIBLE EN EL CEREBRO, de ratones, ratas, pollos, monos y también bebés humanos (Ams, 1989, p. 53).

El ocultamiento del estado real de la salud del cuerpo por el efecto de los medicamentos:

Desgraciadamente, la confusión de Pasteur entre enfermedad y síntomas se ha transmitido a lo largo de generaciones en forma de una ley científica. A la fecha 
de hoy, la medicina convencional opera bajo esta idea falsa, sin tener en cuenta la causa subyacente de los síntomas; y si no tiene en cuenta la causa latente, no podemos ocuparnos de ella. Los síntomas pueden quedar enmascarados por los fármacos, pero eso no los erradicará. Y no trata el deterioro que acompaña al resto del organismo ni, por supuesto, hace nada con respecto a los ácidos subyacentes a todo ello (Young, 2012, p. 55).

Los efectos del modelo alopático sobre la promoción y prevención de la salud, así como sobre el diagnóstico y tratamiento de las patologías que sufre una persona:

El modelo médico occidental tiene un importante defecto: está demasiado fragmentado. Los especialistas suelen adoptar un enfoque demasiado estrecho, tratando por separado los elementos sueltos y aislados de los complejos problemas de salud. La medicina occidental reduce cada enfermedad a una causa concreta y aislada para la cual ha de haber una sola cura "mágica".

Por ejemplo, en la investigación del Alzheimer, hay una fuerte tendencia a buscar una sola causa, como son la toxicidad del aluminio o la predisposición genética. Pero este método reduccionista, si bien es eficaz para un gran número experimentos científicos, pasa por alto una realidad fundamental de la biología: que la mayoría de las enfermedades degenerativas, entre ellas la de Alzheimer, están provocadas por varias causas, y que éstas pueden diferir según las personas (Khalsa, 2010, p. 21).

Las exigentes condiciones de la vida moderna, las condiciones laborales, las tensiones sociales e individuales y el constante afán por superar estados emocionales que constantemente inciden en los procesos inflamatorios de los órganos del cuerpo humano: 
El estrés crónico expulsa la noradrenalina del sistema límbico, que, como recordará, es el sistema que controla las emociones. Debido a esta falta de noradrenalina en el centro emocional del cerebro, el estrés crónico puede provocar depresión biológica, ansiedad y malestar. Si este estrés continuado dura mucho tiempo incluso hasta puede generar bioquímicamente la anhedonia, es decir, la pérdida de la sensación de placer en los actos que normalmente producen (Khalsa, 2010, p. 187).

La importancia de los vitanutrientes en el nivel celular y su influencia significativa en la depuración, renovación, fortalecimiento y estabilidad de los órganos y del cuerpo humano como requisito para la estabilidad y el desarrollo de la vida, así como para el ejercicio de las capacidades humanas en cada una de las actividades cotidianas.

La pérdida de costumbres de saneamiento y depuración del cuerpo, entre otras las asociadas al ayuno, cuyos efectos son beneficiosos para disminuir muchos de los factores inflamatorios del cuerpo y la mejora de la capacidad de respuesta del sistema inmunológico. Irónicamente, los seres humanos asisten a una paradoja: enfermedades y fallecimientos a causa del exceso de alimento, sin que las personas sean conscientes de tal fenómeno o, las autoridades públicas informen masivamente sobre el particular, mientras otros seres humanos padecen y fallecen precisamente por causa contraria: la inanición por falta de alimento:

La "subalimentación" favorece la longevidad porque proporciona numerosas ventajas fisiológicas. Darle menos trabajo (menos estrés) a los órganos de la digestión y asimilación; produce menos radicales libres; eleva los niveles de enzimas antioxidantes hasta en un 400\%; aumenta la potencia inmunitaria hasta 
en un 300\%; bajan los niveles de insulina y colesterol, aumenta la tolerancia a la glucosa y baja la tensión arterial (Khalsa, 2010, p. 148).

Las interacciones individuales y sociales, así como su impacto en las actividades cotidianas, las creencias, la aceptación pasiva de mensajes masivos o de oídas, y el convencimiento ciego sobre las fórmulas que especialistas, así como vendedores de ilusiones, expenden para la solución de todo tipo de dolencias, sin que existan aptitudes y actitudes críticas que contribuyan a ser conscientes de la valía de la salud y la vida:

En este ensayo se resalta el discurso culpabilizante que generaron las estrategias dictadas desde los modelos de promoción de la salud y modificación de estilo de vida. Así mismo, se hace evidente en el ensayo la ausencia de la categoría de cultura dentro las estrategias de la salud pública, lo cual genera contradicciones en dos ámbitos diferentes: por una parte y a nivel global, entre la sociedad que promociona el consumo de productos no saludables (cultura del consumo) y las recomendaciones formuladas desde el campo de la medicina científica (Wiesner Ceballos, 2005, p. 16).

La cultura generalizada y la creencia humana de la salud como un producto que se adquiere en el mercado de bienes y servicios, bien como una consulta, un diagnóstico, un tratamiento, una intervención, una acción especializada, una cápsula milagrosa o una intervención "divina" de algún milagrero, ha puesto el cuidado, protección y bienestar de las personas por fuera del ámbito de su Ser y de sus más inmediatos intereses $\mathrm{y}$, los ha trasladado, en el mejor de los casos, a instituciones, procedimientos, protocolos y personal de la salud $\mathrm{y}$, en otras circunstancias, a predicadores de milagrerías a quienes asigna potestad divinas. 
El personal de la salud, así como la instituciones del Sistema, interactúan con la persona fundamentalmente cuando una patología mella su ser, entre otras razones porque ellos están convencidos que precisamente están para intervenir en los eventos y momentos en los cuales la persona se enferma o enfrenta una situación orgánica que no le permite el ejercicio de sus capacidades, unos y otros se encuentran en la enfermedad, mientras que en el camino de la salud y bienestar son extraños que, irónicamente, andan a la caza de clientes para venderles los oropeles de su particular creación.

La mayoría de personas desconoce su ser de manera integral, así como sus necesidades para la realización plena de sus potencialidades, simplemente dejan su vida y salud, inconsciente o conscientemente, en manos de personas y entidades que, en nombre y por potestad del Estado, están obligadas a atenderlas bajo el amparo de los derechos fundamentales a la vida y a la salud, sin percibir que la atención en manos impropias conduce inevitablemente por el camino de la enfermedad. 


\section{Conclusiones}

La historia reciente de la salud en Colombia tiene una huella signada por la unificación de la institucionalidad, una práctica enfocada en la atención de la enfermedad y, un énfasis en la prestación de servicios, a partir de objetivos estratégicos encaminados a lograr la cobertura universal, mejorar la eficiencia y garantizar la solidaridad.

La política pública de salud, desde los años 90 del Siglo XX, combina varios instrumentos de gestión estatal, entre los que sobresalen la adopción de un modelo de competencia regulada, el fortalecimiento de recursos para el financiamiento de las prestaciones y acciones, la separación de la provisión de servicios de las fuentes de financiamiento, el fortalecimiento legal de los procesos de descentralización en la asignación de recursos y competencias, la creación de mecanismos de participación social y comunitaria y, la transformación de la salud de una prestación de caridad a la de ejercicio de un derecho fundamental autónomo.

De los resultados del presente estudio que sirven como elementos sustanciales para responder la pregunta de investigación, y confirmar o desvirtuar la hipótesis formulada, vale la pena resaltar los siguientes:

\section{Modulación}

La institucionalización de la concertación entre agentes del sistema, las disposiciones que fijan la capacidad de regulación, las herramientas de organización y gestión de los intervinientes, el papel asignado a las entidades estatales prestadoras de servicios de salud, la concentración de las fuentes de financiamiento y, los mecanismos de distribución y asignación de los recursos, permiten señalar que el Sistema General de Seguridad Social en Salud constituye una forma de intervención pública particular, que si bien introduce mecanismos de mercado que inducen la competencia, opera sobre la 
base de establecer la afiliación obligatoria al sistema, de tal manera que el afiliado y sus beneficiarios son concentrados en una Institución, dentro de la cual pueden ejercer el principio de libre escogencia, evitar la selección adversa, fijar el precio que paga (Unidad de Pago por Capitación) el sistema a las entidades promotoras de salud, sin dejar al arbitrio del mercado tal posibilidad, reglar el Plan Obligatorio de Salud que contempla las prestaciones a las que tienen acceso los afiliados y sus beneficiarios, y, adoptar incentivos encaminados a superar las condiciones de ineficiencia en la asignación y utilización de recursos.

El Ministerio de Salud y Protección Social como rector del Sistema no logró una interacción equilibrada, eficiente y equitativa entre todos los agentes, ya que las múltiples disposiciones se traslapan, contradicen y, en algunos casos, crean confusión, mientras que los incentivos no han sido adecuados. Dichos resultados consolidan la percepción de la incapacidad del ente rector respecto del papel modulador a su cargo.

El Ministerio de Salud y Protección Social ha carecido de la capacidad técnica y de las acciones para deslegitimar y obligar a la superación de las barreras de acceso, especialmente en momentos en que los servicios son imprescindibles, lo que contribuyó al incremento de la justiciabilidad del derecho y, demostró la falta de acción directiva y correctiva sobre las entidades responsables de las acciones de promoción de la salud y prevención de las patologías, tales circunstancias reflejan el limitado y deficiente ejercicio de poder modulatorio del órgano rector.

El Sistema General de Seguridad Social en Salud aún no ha superado la organización por grupos sociales, dadas las restricciones objetivas de las poblaciones rurales y alejadas, así como de las poblaciones más pobres, para acceder oportuna y eficientemente a la prestación de servicios, además de las barreras que aún soportan por las deficiencias de gestión atribuible a diferentes agentes del Sistema y, al 
desconocimiento práctico de las diferencias territoriales, lo cual fomentó la inequidad regional.

El ejercicio de la Función Pública frente a la prestación del servicio y la garantía del derecho a la salud muestra deficiencias en la dirección estratégica del Sistema, limitaciones en la gestión, asignación y control de la gestión de los recursos financieros, inflación normativa, fallas en la orientación, seguimiento y control de la actividad privada, disparidades en la aplicación y acatamiento de las reglas de juego por parte de los agentes, descuido en la protección del ejercicio del derecho fundamental, limitada reacción a las decisiones de la justicia y, particularmente, en la ejecución de acciones que contribuyan a corregir las fallas y violaciones que inciden en el cumplimiento de los fines del Estado relacionados con la cobertura, calidad, oportunidad y pertinencia de las acciones de salud y, el cumplimiento de las obligaciones a cargo de todos los agentes.

Una de las mayores limitaciones de las autoridades responsables de la modulación es su incapacidad de reacción, adaptación y aprendizaje de las causas y efectos de la justiciabilidad del derecho a la salud, particularmente la sorpresa constante que constituyó la clara, perceptible y continúa línea jurisprudencial de la Corte Constitucional en torno a la garantía del derecho, al pasar de considerarlo fundamental por conexidad con otros derechos, desde finales del siglo $\mathrm{XX}$, a su declaratoria de fundamental por sí mismo en el año 2008.

La incapacidad de analizar y aprender de la justiciabilidad del derecho para determinar los intereses en juego, las relaciones de los agentes, la probabilidad de asumir decisiones que contribuyeran a resolver los conflictos y, esencialmente, tomar decisiones encaminadas a fortalecer el papel de modulador que articula, orienta y decide la mejor forma de garantizar el derecho y fortalecer la capacidad resolutiva de los agentes responsables de las funciones de financiamiento, articulación y prestación de 
servicios, llevó a concentrar las decisiones en torno a la prestación de los servicios, consolidó la cultura que equipara el derecho de salud con la superación de la enfermedad e incidió sobre los principios de equidad y eficiencia, al movilizar recursos hacia personas a las que les reconocían tratamientos y medicamentos específicos y, reflejó la ineficiencia de las autoridades del Sistema ante su impotencia para movilizar su capacidad de gestión en la solución previa y oportuna de cualquier contradicción, para poner en la cima de la gestión a la Corte Constitucional, quien, en ejercicio de la protección de la garantía del derecho, llegó a dar órdenes administrativas y a asumir el papel de fiscalizador, sin que los organismos de control, ni la misma Corte, solicitarán la indagación de las características, causas y factores de tal situación, así como la determinación de las responsabilidades de los agentes encargados de las diferentes competencias en el Sistema.

La hipertrofia legal causada por la acción institucional y la reiterada solución, basada en la expedición normativa, dada a todo "vacío", limitación o problema relacionado con la organización, dirección, operación y atención de los servicios de salubridad, mutiló en la práctica la aplicación de los principios y los elementos sustanciales que pueden, por ellos mismos, orientar el estudio, análisis y toma de decisiones frente a cada una de las inquietudes y situaciones, inevitables, que planteaban el ejercicio y la atención de las prestaciones asociadas al derecho y a los servicios de salud.

La organización y asignación de funciones en el campo de la supervisión forman parte de las explicaciones sobre las deficiencias y limitaciones del cumplimiento de las responsabilidades a cargo de los agentes del sistema, por cuanto la carencia de un sistema de inspección, vigilancia y control, la dispersión del ejercicio de las mencionadas funciones entre varios entes estatales sin un norte claro y delimitado, la 
proliferación de funciones, en algunos casos duplicadas, entre los agentes estatales rectores del Sistema, las debilidades institucionales de muchas de las entidades territoriales que les impedía asumir técnica y operativamente la inspección, el conflicto de intereses de funcionarios de los distritos y municipios, al ejercer simultáneamente funciones de afiliación, administración de recursos, giros, prestación de servicios y la inspección, vigilancia y control y, la injerencia de estamentos directamente vinculados a la Rama legislativa, revelan las debilidades crecientes de las autoridades responsables de la modulación.

La supervisión del cumplimiento de los estándares de calidad en la prestación de los servicios de salud es otro indicador de las deficiencias del ejercicio de las funciones de inspección, vigilancia y control, motivada por la multiplicidad, diversidad y complejidad de las normas del Sistema General de Seguridad Social en Salud, la baja capacidad técnica, la deficiente capacitación y el desconocimiento de las normas e instrumentos de supervisión, por buena parte de los funcionarios de las entidades territoriales.

\section{Financiamiento}

El aumento de los costos de transacción, motivado por los trámites de facto en cada una de las actividades asociadas a la prestación de servicios, cuyo impacto preferencial se da sobre los recursos del sistema, independientemente de que las prestaciones hayan sido negadas por entidades responsables de los planes de beneficios, cuyos contenidos, para efectos del conflicto, prefirieron ignorarse.

La demora en el flujo de recursos, frecuente y reiterada, incidió y continúa impactando, negativamente, la prestación de los servicios, influyó en la deficiente calidad de la atención y aumentó el riesgo de deterioro, e incluso de liquidación de instituciones prestadoras de servicios, especialmente de las Empresas Sociales del 
Estado, a las cuales el Gobierno les asignó, en no pocas oportunidades, la atención de personas, independientemente de sus capacidades económicas, técnicas y resolutivas.

Estas conductas tienen un impacto negativo mayor en las Empresas Sociales del Estado por las pesadas cargas financieras con las que iniciaron su gestión, resultado de deudas pasadas sin una solución estructural y, las políticas coyunturales que intentaron solventar la crisis en la prestación de los servicios por medio de mecanismos de subsidio a la oferta, lo que obligó a muchos hospitales a prestar atenciones sin que les fueran cancelados los servicios oportunamente, a más de los problemas asociados a gestión, administración de personal y capacidad resolutiva.

La explosión de los cobros por prestaciones que realizaban las Entidades Promotoras de Salud que no estaban contempladas en el Plan Obligatorio de Salud, conocidos como recobros, y que por diversas razones, entre ellas las decisiones de los jueces de tutela, crearon un escenario de gasto de facto, el cual, a pesar de los fallos y de la jurisprudencia, se desatendió y dejó crecer, con la consecuente afectación negativa para el Sistema.

Los niveles de evasión y elusión de aportes al Sistema obraron en detrimento de los recursos del SGSSS, especialmente por el impacto negativo sobre la ampliación de la cobertura y el acceso a los servicios para las personas y poblaciones más pobres.

La carencia de controles y acciones oportunas y contundentes permitió que los recursos de la salud, asignados a las entidades territoriales, fueran capturados por grupos al margen de la ley y políticos, quienes los utilizaron en favor de sus intereses y en la toma, objetiva, de algunas administraciones territoriales.

Las políticas gubernamentales en materia de control de precios y aseguramiento de la disponibilidad de medicamentos han sido contradictorias, han tenido los mayores 
efectos financieros negativos sobre los recursos del Fondo de Solidaridad y Garantía y, obviamente, inciden en la merma de la equidad del sistema.

\section{Articulación}

Las Entidades Promotoras de Salud desconocieron su papel como representantes de los afiliados y beneficiarios al no intervenir, interceder y proponer, a las autoridades del Sistema, las acciones para evitar la vulneración del derecho y, con base en la jurisprudencia, ejecutar acciones inmediatas y oportunas para la autorización de servicios de salud.

Las Entidades Promotoras de Salud ignoraron la actualización de la información de los afiliados y beneficiarios respecto a su situación socio-económica, sus condiciones de salud, tratamientos, medicamentos y demás datos necesarios para caracterizar la situación epidemiológica, los principales riesgos y afectaciones y, las posibles acciones, con el fin de diseñar y adoptar programas específicos destinados a disminuir la carga de la enfermedad y motivar cambios en los hábitos de las personas, en procura de una mejor calidad de vida y un alto estándar de salud.

La carencia de un sistema de información que permitiera obtener datos, cifras e indicadores de calidad, oportunos, pertinentes y que lograran una cobertura sustancial actuaba contra los fines de la supervisión, limitaba el intercambio de información y la caracterización de procesos, procedimientos, áreas y actividades de riesgo frente al cumplimiento de las obligaciones de los distintos agentes del sistema.

La práctica estatal institucional y el comportamiento de los diferentes agentes del sistema consolidaron una visión que reduce la salud, y en consecuencia el principio de solidaridad, a la financiación de acciones sanitarias, especialmente las dirigidas al acceso a los servicios médicos, clínicos y a los procedimientos asociados a los mismos, 
los cuales se centraron, claramente, en la atención de patologías y la superación de las enfermedades.

Las decisiones y acciones del enfoque objetivo, en el que se encuentra el derecho a la salud, se expresan en las prácticas administrativas, económicas, jurisprudenciales, médicas y operativas realizadas durante los cerca de veinticinco años de existencia del Sistema General de Seguridad Social en Salud, las cuales dejan a un lado la evidencia, incluso tantas veces reivindicada por los organismos multilaterales, los gobiernos y la misma jurisprudencia de la Corte Constitucional, en las que se establece que el estado de salud está asociado, además del acceso a la prestación de servicios médicos, odontológicos, clínicos y las concretas intervenciones para la curación de las enfermedades, a los determinantes que impactan el bienestar de la persona, la familia, la comunidad y la sociedad.

La fragmentación del Sistema y la incapacidad de las autoridades responsables de la dirección y control para suprimir los incentivos perversos, evitar la concentración en actividades de alta complejidad y superar la visión fiscalista de los recursos del Sistema, causó descuidos en el análisis de los riesgos de salud y motivó la consolidación de barreras de entrada.

\section{Prestación de servicios}

El deterioro de las redes de servicios que debían organizar y garantizar las Entidades Promotoras de Salud, causado, entre otras razones, por los déficit en los flujos de recursos, las deficiencias administrativas y de gestión de algunas EPS, especialmente aquellas controladas por intereses económicos y políticos al margen de la legalidad, incidió negativamente en la respuesta a las demandas de prestaciones médicoquirurgicas, tratamientos y acceso a medicamentos. 
La fragmentación de la prestación de los servicios basada en los menores costos de la atención originó discontinuidad en los tratamientos, deficiencias en la atención, incremento en los costos a cargo de los pacientes (transporte, alimentación, mayor tiempo del acompañante), mala calidad y, estimuló la percepción negativa en el servicio de salud.

La política pública de salud sobre los medicamentos tuvo en los agentes privados, particularmente en lo referente a patentes, uno de los elementos de mayor incidencia en los costos de adquisición de los farmacéuticos requeridos por los pacientes y, comportó múltiples barreras que incidieron en la disponibilidad y acceso a los mismos.

Los medicamentos jugaron un papel importante en el incremento del gasto del Sistema General de Seguridad Social en Salud y, son, al mismo tiempo, uno de los temas donde más intereses se juegan, a tal punto que las relaciones entre diagnóstico, formulación, entrega y consumo de medicamentos está mediada por diferentes agentes, señales encontradas, amenazas de poderosas empresas de la industria farmacéutica, para quienes lo más importante son sus ventas, y propaganda masiva que intenta demostrar la calidad e importancia de determinado medicamento en la salud de las personas, para que éstas sean las primeras en exigirlos.

La ausencia de verificación y comprobación de la calidad y efectividad de los medicamentos por la baja capacidad científica y técnica de la entidad competente y, la credibilidad en los estudios presentados por compañías farmacéuticas, los cuales muchas veces no cumplen los estándares internacionales.

La incidencia de las empresas farmacéuticas en los funcionarios de salud, especialmente sobre los médicos, es muy alta y no está, necesariamente, ligada a intercambiar conocimientos, explicar y demostrar la efectividad de los medicamentos; 
más bien se trata de conquistar y convencerlos, por diversos mecanismos, para que formulen los productos que ponen las farmacéuticas a disposición en el mercado.

La multiplicidad de intereses adversos y extraños al Sistema General de Seguridad Social en Salud creó una completa parainstitucionalidad, en la que participaron agentes propios y foráneos, con organizaciones, jerarquías, reglas, ritos, roles y parafernalias propias de un Estado Mafioso, el cual ahogó, en muchos sitios y áreas geográficas, la capacidad de las fuerzas vivas de la democracia para hacer efectivo el derecho fundamental a la salud y, lo trastocó y consolidó como una acción deficiente de caridad, a la cual acuden las personas bajo las reglas e imposiciones de personas al margen de la ley.

La literatura señala que muchas de las enfermedades con efecto mortal sobre la vida humana tienen origen, o por lo menos un fuerte efecto, en las deficiencias alimentarias, el tabaco, el alcohol, las bebidas azucaradas y otros factores asociados al estilo de vida.

El desconocimiento de información relacionada con investigaciones, alternativas, experiencias, prácticas y resultados de estilo de vida saludables afecta a la mayoría de las personas y, en algunos casos, a la propia comunidad de servidores de la salud, de allí que las acciones de promoción y prevención estén limitadas a eventos médicos y, en general, se desconozca qué deben hacer las personas en favor de su bienestar y salud.

La persona afiliada o beneficiaria que participa en el Sistema General de Seguridad Social en Salud parece todo menos un agente que defiende y escoge, para sí misma, racionalmente en el mercado de servicios de salud, entre otras razones, porque las responsabilidades que fueron asignadas a las EPS, como instancias claves en la superación de la asimetría de información, compradoras de servicios, en nombre de sus 
afiliados y beneficiarios, gestoras de la promoción y protección de la salud y, acompañantes en la detección y superación de la enfermedad, han sido pobremente cumplidas.

\section{Política pública}

La política pública sentó sus caudales en la configuración de un sistema de carácter universal, solidario y eficiente, a partir del cambio estructural del acceso y prestación de servicios de salud, el fortalecimiento de las entidades territoriales en competencias relacionadas con los servicios de salud (iniciado con la Ley 10 de 1990), la adopción de mecanismos de competencia entre entidades aseguradoras y prestadoras de los servicios, la adopción del principio de libre escogencia del asegurador y el prestador, la paulatina sustitución de los subsidios de oferta a favor de los de demanda, el desarrollo del principio de equidad y, la adopción de mecanismos institucionales de concertación de las decisiones del sistema, a través de la participación en una instancia plural de las entidades estatales, los aseguradores, los prestadores, los representantes de trabajadores y pensionados.

Los objetivos centrales de la política pública, expresados en la Ley 100 de 1993 y sus posteriores reformas, tienen un relativo buen balance, en especial los referidos a la expansión de la protección financiera de las familias, al lograr reducir el gasto de bolsillo en la compra de prestaciones de salud, el cual decrece de la cifra del $43 \%$, existente en 1995, al $14 \%$ en 2014, entre otras razones por el crecimiento del aseguramiento y la prestación de los servicios de salud, sustentadas, independientemente de la autoridad estatal que ordenó las prestaciones, en el incremento del gasto total en salud que pasó del 5,9\% del PIB en 2000 al 6,5\% en 2011.

Las cifras del período 2005 - 2012 muestran que los indicadores sobre la expectativa de vida han crecido y se han reducido los de mortalidad, especialmente la 
neonatal e infantil, ésta última en razón a las caídas del más del 50\% en enfermedades relacionadas con el sistema respiratorio, infecciosas, endocrinas, del sistema nervioso, digestivas y hematológicas y lesiones por causas externas, mientras que el único incremento ocurre por causas atribuibles al cáncer infantil. Es claro el cambio del patrón epidemiológico el cual camina hacia las etiologías complejas, en las cuales los factores ambientales, los estilos de vida $\mathrm{y}$, las variables asociadas al urbanismo cobran importancia significativa.

La política pública de salud, en particular el Sistema General de Seguridad Social fue transitando la senda de una crisis que muchos consideraron inducida, especialmente en el manejo de los recursos dentro de la órbita de las políticas del Ministerio de Hacienda y Crédito Público, particularmente, la inversión de los recursos del Sistema en TES, Bonos y títulos de deuda, en una cifra que se acercaba a los 5,1 billones en el año 2007 y que en el 2009 frisaba la cifra de los 6 billones, la baja ejecución de las subcuentas de Solidaridad y ECAT, aunados al conjunto de limitaciones y deficiencias señaladas, dan origen a una emergencia social que, con base en facultades del Gobierno Nacional, intentó la redefinición de la política pública y, obviamente, del Sistema General de Seguridad Social en Salud, en variados temas, entre ellos los planes de beneficios, la financiación de los servicios, los criterios del gasto social en salud, la estructura institucional, entre otros.

\section{Justiciabilidad}

Las deficiencias de las entidades públicas, responsables de funciones en el Sistema General de Seguridad Social en Salud, fortalecieron y consolidaron el papel protagónico de la Corte Constitucional, el cual llevó a ésta a inmiscuirse, incluso, en 
decisiones de tipo administrativo, al señalar procedimientos y acciones específicas para garantizar prestaciones médicas ${ }^{63}$.

El amparo constitucional siguió un camino clara y específicamente individual, dedicado a la protección del acceso a servicios médicos, hospitalarios, tratamientos y medicamentos, en el cual la Corte Constitucional ordenó, de manera preferencial, la prestación inmediata de los mismos, camino que invariablemente siguieron los demás jueces constitucionales. En consecuencia, el litigio obró como incentivo recurrente, por las falencias de las autoridades rectoras en el diseño, adopción y control sobre la aplicación de las políticas, la actualización de planes de beneficios y la atención efectiva a la que tenían derecho las personas.

Frente a la pregunta formulada en este trabajo: ¿El Sistema General de Seguridad Social en Salud es, tal como fue concebido en la Ley 100 de 1993, el responsable de las afectaciones al ejercicio del derecho a la salud en su doble connotación de derecho y servicio público? Las conclusiones anteriores contribuyen a responder que el modelo adoptado no es la causa de los problemas recurrentes que sufren las personas frente al acceso al servicio público de salud y, aún menos, a la garantía del derecho fundamental; por consiguiente, la hipótesis formulada tiene, bajo los resultados de la presente investigación, una respuesta afirmativa.

Así pues, el estudio realizado permite señalar que existen significativos avances en el cumplimiento de los principios de universalidad y solidaridad y, que el modelo no es el responsable de muchos de los problemas que se presentan en la garantía y materialización efectiva el derecho fundamental a la salud, ya que se constató que es, principalmente, el incumplimiento de las competencias y responsabilidades de los

$63 \mathrm{La}$ intervención de la Corte Constitucional, sus decisiones y órdenes demuestran que el Sistema puede responder a las demandas y necesidades específicas de servicios de salud y garantía del derecho. 
agentes del Sistema, unos en mayor grado, el que ha originado los problemas y las deficiencias existentes.

Las reiteradas controversias frente a los logros, efectos y condiciones del Sistema General de Seguridad Social Social en Salud limitan el estudio, análisis e investigación de las verdaderas necesidades en materia de salud, oscurecen las causas de las enfermedades que enfrentan las personas en Colombia por múltiples factores y circunstancias, motivan cambios permanentes en la organización y las responsabilidades institucionales, especialmente de entidades públicas, sin que existan balances o diagnósticos claros y específicos que demuestren la necesidad de tales variaciones, impiden aclarar las causas de la falta de coordinación, articulación y colaboración entre las entidades estatales para el cumplimiento del derecho fundamental a la salud y la prestación de servicios de óptima calidad, invisibilizan a quienes negocian, comercializan y se lucran con la enfermedad ajena a través de oscuros mecanismos mercantiles, esconden a los verdaderos responsables del deterioro financiero en el Sector Salud y Protección Social, limitan la comprensión sobre el estado de salud y la incidencia clave de los determinantes en el bienestar y desarrollo del Ser Humano, minan la credibilidad de las personas en su propia capacidad para conocerse, protegerse y cuidarse $y$, crean una aureola sacrosanta que encubre las limitaciones y el estado real de la ciencia y la tecnología en el campo de la medicina, así como su efectos sobre la salud.

Las investigaciones sobre los mencionados temas son de importancia crucial en la búsqueda de soluciones efectivas que permitan garantizar el derecho fundamental a la salud y, aunque existen investigadores en las líneas precedentes, se requiere un renovado y fuerte interés, en estas áreas, para encontrar respuestas a las vastas necesidades que periódicamente salen a la luz pública por las inevitables crisis de una 
sociedad a la que le falta seres conscientes de sus propias responsabilidades en el cuidado, protección y preservación de su salud. 


\section{Bibliografía}

Academia Nacional de Medicina. (2016). Academia Nacional de Medicina solicita al MinSalud cambio en los actuales protocolos de aplicación de la vacuna contra el VPH | Centro Democrático. Centro democrático. Recuperado a partir de http://www.centrodemocratico.com/?q=articulo/academia-nacional-de-medicinasolicita-al-minsalud-cambio-en-los-actuales-protocolos-de

Acuerdo sobre los Aspectos de los Derechos de Propiedad Intelectual. (2000). Propiedad intelectual: protección y observancia. Recuperado 30 de abril de 2016, a partir de https://www.wto.org/spanish/thewto_s/whatis_s/tif_s/agrm7_s.htm

Agin, D. (2007). Ciencia basura : ¿cómo nos engañan los políticos y las multinacionales? [Teia, Barcelona: Star.

Ajustes a la arquitectura del sistema general de salud de Colombia: una propuesta. (s. f.). Ajustes a la arquitectura del sistema general de salud de Colombia: una propuesta. Almeida, C. (2002). Reforma de sistemas de servicios de salud y equidad en América Latina y el Caribe: algunas lecciones de los años 80 y 90. Cadernos de Saúde Pública, 18(4), 905-925. https://doi.org/10.1590/S0102-311X2002000400002

Amat, Y. (2004, octubre 3). El ISS sólo sirve para quebrar hospitales. El Tiempo. Recuperado a partir de http://www.eltiempo.com/archivo/documento/MAM-1583195 Ams, M. (1989). Antídotos para la supervivencia : el programa Adams para la prevención del cáncer. Barcelona: Obelisco.

Angell, \& Freire, L. (2006). La verdad acerca de la industria farmacéutica : cómo nos engaña y qué hacer al respecto. Bogotá: Grupo Editorial Norma.

Arias R., J., Paredes C., N., Santos, A. C., \& Duarte R., J. D. (2012). Dos décadas del Sistema de Seguridad Social en Salud: Desarrollo, crisis y soluciones. Bogotá: Asociación Colombiana de Empresas de Medicina Integral. 
Artículo 4 Ley 1751 de 2015. (2015). Diario Oficial 49427 de febrero 16 de 2015.

Recuperado a partir de

http://www.alcaldiabogota.gov.co/sisjur/normas/Norma1.jsp?i=60733

Asamblea General de las Naciones Unidas. (1966). Pacto Internacional de Derechos

Económicos, Sociales y Culturales. Recuperado 2 de febrero de 2016, a partir de http://www.ohchr.org/SP/ProfessionalInterest/Pages/CESCR.aspx

Asamblea General de las Naciones Unidas. (1969a). Convención Internacional sobre la Eliminación de todas las Formas de Discriminación Racial. Recuperado 2 de febrero de 2016, a partir de http://www.ohchr.org/SP/ProfessionalInterest/Pages/CERD.aspx

Asamblea General de las Naciones Unidas. (1969b). Declaración sobre el progreso y el desarrollo en lo social. Recuperado 2 de febrero de 2016, a partir de http://www.ohchr.org/SP/ProfessionalInterest/Pages/ProgressAndDevelopment.aspx Asamblea General de las Naciones Unidas. (1976). Pacto Internacional de Derechos Civiles y Políticos. Recuperado 2 de febrero de 2016, a partir de http://www.ohchr.org/SP/ProfessionalInterest/Pages/CCPR.aspx Asamblea General de las Naciones Unidas. (1993). Declaración sobre la eliminación de la violencia contra la mujer. Recuperado 2 de febrero de 2016, a partir de http://www.ohchr.org/SP/ProfessionalInterest/Pages/ViolenceAgainstWomen.aspx Asamblea Nacional Constituyente 1991. (1991). Informe de la Sesión de la Comisión quinta del día 14 de mayo de 1991. Bogotá: Presidencia Centro de Información y Sistemas para la Preparación de la Asamblea Nacional Constituyente. Recuperado a partir de http://www.banrepcultural.org/asamblea-nacional-constituyente/comisiones/comisionquinta 
Asistentes a la Conferencia sobre biología molecular. Patogenicidad y ecología de plásmidos. (1981). Declaración respecto al mal uso mundial de antibióticos. Biomédica, 1(4), 226228. https://doi.org/10.7705/biomedica.v1i4.1810

Asociación de Afectadas por la Vacuna del Papiloma. (2016). Actualización Vaers. Recuperado 17 de mayo de 2016, a partir de http://asociacion.aavp.es/

Azuero Z., F. (2012). La organización institucional y la regulación en el sistema general de seguridad social en salud en Colombia. En La salud en Colombia: Logros, retos y recomendaciones (pp. 183-208). Bogotá: Universidad de los Andes.

Banco Mundial. (1978). Informe sobre el desarrollo mundial 1978. Washington, D.C.: Banco Mundial.

Banco Mundial. (1981). Informe sobre el desarrollo mundial 1981. Washington, D.C.: Banco Mundial.

Banco Mundial. (1986). Informe sobre el desarrollo mundial 1986. Washington: Banco Mundial.

Banco Mundial. (1993). Informe sobre el desarrollo mundial 1993 : invertir en salud. Washington, D.C.: Banco Mundial.

Banco Mundial. (1997). Informe Sobre el Desarrollo Mundial 1997 El Estado en un Mundo en Transformacion. Washington: Willse.

Banco Mundial. (2000). Informe sobre el desarrollo mundial 2000-2001 : la lucha contra la pobreza. Madrid [etc.]: Mundi-Prensa.

Banco Mundial. (2003). Informe sobre el desarrollo mundial 2003 : transformación de instituciones, crecimiento y calidad de vida. Madrid: Mundiprensa.

Banco Mundial. (2011). Informe sobre el desarrollo mundial 2011 conflicto, seguridad y desarrollo : panorama general. Washington, D.C: Banco Mundial. 
Banco Mundial Washington, D. C. (1986). Informe sobre el desarrollo mundial 1986.

Washington, D. C: Banco Mundial.

Bernal. (2012). La salud en Colombia : logros, retos y recomendaciones. Bogotá: Universidad de los Andes.

Caines, E. (1997). Reformas sanitarias y equidad. [Madrid]: Fundación Argentaria. Cepeda Espinosa. (2007). Teoría constitucional y políticas públicas : bases críticas para una discusión. Bogotá: Universidad Externado de Colombia.

Chin, J. (2000). El Control de las enfermedades transmisibles. Recuperado a partir de http://public.eblib.com/choice/publicfullrecord.aspx?p=282143

Colmenares. (1999). Historia económica de Colombia. Santafé de Bogotá: Tercer Mundo.

Colombia. Departamento Nacional de Planeación. (1980). Plan de integración nacional, 1979-1982. [Bogotá]: Departamento Nacional de Planeación, República de Colombia. Colombia. Departamento Nacional de Planeación. DNP. (1991). La revolución pacífica plan de desarrollo económico y social 1990-1994. Bogotá (Colombia: Departamento Nacional de Planeación.

Comisión Interamericana de Derechos Humanos. (2012). El derecho de acceso a la información pública en las américas : estándares interamericanos y comparación de marcos legales. Washington, D.C.: Organización de los Estados Americanos.

Comisión Nacional de Precios de Medicamentos. (2002a). Circular No 04 de 2002. Comisión Nacional de Precios de Medicamentos. (2002b). Circular No 05 de 2002. Comisión Nacional de Precios de Medicamentos. (2003). Circular No 01 de 2003. Comisión Nacional de Precios de Medicamentos. (2006). Circular No 04 de 2006. Comité de Apoyo Técnico en la Política de Rendición de Cuentas. (2014). Manual de rendición de cuentas. Bogotá: Presidencia de la República; Departamento Administrativo de la Función Pública; Departamento Nacional de Planeación. 
Recuperado a partir de

http://www.anticorrupcion.gov.co/Documents/Publicaciones/ManualRendicionCuentas. pdf

Comité Internacional de la Cruz Roja. (1977). Protocolo II adicional a los Convenios de Ginebra de 1949 relativo a la protección de las víctimas de los conflictos armados sin carácter internacional, 1977 [Text]. Recuperado 2 de febrero de 2017, a partir de https://www.icrc.org/spa/resources/documents/misc/protocolo-ii.htm

Conferencia Internacional sobre Atención Primaria de Salud. (1978). Atención primaria de salud : informe de la Conferencia Internacional sobre Atención Primaria de Salud, Alma-Ata, URSS, 6-12 de septiembre de 1978. Ginebra: Organización Mundial de la Salud.

Consejo de Estado. Sala de lo Contencioso Administrativo. Sección Tercera. (2014, mayo 16). Sentencia AP-250002325000200301252 02). Recuperado a partir de www.aesa.org.co/legislacion/?upf=dl\&id=6751

Contraloría General de la República. (2007). Auditoría Gubernamental con Enfoque Integral modalidad especial por los períodos 2005 y 2006 al FOSYGA. Bogotá: Contraloría General de la República.

Contraloría General de la República. (2015). Informe de resultados Actuación Especial de Fiscalización. Ministerio de Salud y Protección Social Base de Datos Única de Afiliados. Bogotá: Contraloría General de la República. Recuperado a partir de https://www.minsalud.gov.co/sites/rid/Lists/BibliotecaDigital/RIDE/DE/OCI/Informeactuacion-especial-fiscalizacion-bdua-cgr-2015.PDF

Convención Americana sobre Derechos Humanos. (1988). Protocolo adicional a la Convención Americana sobre Derechos Humanos en materia de derechos económicos, 
sociales y culturales «protocolo de San Salvador». Recuperado 1 de febrero de 2016, a partir de http://oas.org/juridico/spanish/Tratados/a-52.html

Convención de los Derechos del Niño. (1959). Declaración de los Derechos del Niño.

Recuperado 2 de febrero de 2016, a partir de http://www.humanium.org/es/declaracionde-los-derechos-del-nino-texto-completo/

Coronell, D. (2015). Ayúdame que yo te ayudaré. Semana.com. Recuperado a partir de http://www.semana.com/opinion/articulo/daniel-coronell-ayudame-que-yo-teayudare/432768-3

Corte Constitucional de Colombia. (1994a). Sentencia C-180 de 1994. Recuperado a partir de http://www.corteconstitucional.gov.co/relatoria/1994/C-180-94.htm

Corte Constitucional de Colombia. (1994b). Sentencia C-497 de 1994. Recuperado a partir de http://www.corteconstitucional.gov.co/relatoria/1994/C-497-94.htm

Corte Constitucional de Colombia. (1996). Sentencia T-281 de 1996. Recuperado a partir de http://www.corteconstitucional.gov.co/relatoria/1996/T-281-96.htm

Corte Constitucional de Colombia. (1997a). Sentencia C-577 de 1997. Recuperado a partir de http://gt.vlex.com/vid/-423795746

Corte Constitucional de Colombia. (1997b). Sentencia SU-480 de 1997. Recuperado a partir de http://www.corteconstitucional.gov.co/relatoria/1997/SU480-97.htm

Corte Constitucional de Colombia. (1998a). Sentencia C-112 de 1998. Recuperado a partir de http://www.corteconstitucional.gov.co/relatoria/2014/c-123-14.htm

Corte Constitucional de Colombia. (1998b). Sentencia C-542 de 1998. Recuperado a partir de http://www.corteconstitucional.gov.co/relatoria/1998/C-542-98.htm

Corte Constitucional de Colombia. (1999). Sentencia SU-819 de 1999. Recuperado a partir de http://www.corteconstitucional.gov.co/relatoria/1999/SU819-99.htm 
Corte Constitucional de Colombia. (2001). Sentencia C-828 de 2001. Recuperado a partir de http://www.corteconstitucional.gov.co/relatoria/2001/C-828-01.htm

Corte Constitucional de Colombia. (2003a). Sentencia C-253 de 2003. Recuperado a partir de http://www.corteconstitucional.gov.co/relatoria/2003/C-1040-03.htm

Corte Constitucional de Colombia. (2003b). Sentencia C-1040 de 2003. Recuperado a partir de http://www.corteconstitucional.gov.co/relatoria/2003/C-1040-03.htm

Corte Constitucional de Colombia. (2003c). Sentencia T-1167 de 2003. Recuperado a partir de http://www.corteconstitucional.gov.co/relatoria/2003/T-1167-03.htm

Corte Constitucional de Colombia. (2005a). Sentencia C-710 de 2005. Recuperado a partir de http://corteconstitucional.gov.co/relatoria/2005/C-710-05.htm

Corte Constitucional de Colombia. (2005b). Sentencia T-128 de 2005. Recuperado a partir de http://www.corteconstitucional.gov.co/relatoria/2005/T-128-05.htm

Corte Constitucional de Colombia. (2005c). Sentencia T-573 de 2005. Recuperado a partir de http://corteconstitucional.gov.co/relatoria/2005/T-573-05.htm

Corte Constitucional de Colombia. (2005d). Sentencia T-1289 de 2005. Recuperado a partir de http://www.corteconstitucional.gov.co/relatoria/2005/T-1289-05.htm

Corte Constitucional de Colombia. (2007). Sentencia T-016 de 2007. Recuperado a partir de http://www.corteconstitucional.gov.co/relatoria/2008/T-760-08.htm

Corte Constitucional de Colombia. (2008a). Sentencia C-463 de 2008. Recuperado a partir de http://www.corteconstitucional.gov.co/RELATORIA/2008/C-463-08.htm

Corte Constitucional de Colombia. (2008b). Sentencia C-751 de 2008. Recuperado a partir de http://corteconstitucional.gov.co/relatoria/2005/C-710-05.htm

Corte Constitucional de Colombia. (2008c). Sentencia T-760 de 2008. Recuperado a partir de http://www.corteconstitucional.gov.co/relatoria/2008/T-760-08.htm 
Corte Constitucional de Colombia. (2008d). Sentencia T-797 de 2008. Recuperado a partir de http://www.corteconstitucional.gov.co/relatoria/2008/T-797-08.htm

Corte Constitucional de Colombia. (2009). Sentencia C-614 de 2009. Recuperado a partir de http://www.corteconstitucional.gov.co/relatoria/2009/c-614-09.htm

Corte Constitucional de Colombia. (2010). Sentencia C-252 de 2010. Recuperado a partir de http://www.corteconstitucional.gov.co/relatoria/2010/c-252-10.htm

Corte Constitucional de Colombia. (2011). Sentencia T-160 de 2011. Recuperado a partir de http://www.corteconstitucional.gov.co/relatoria/2011/T-160-11.htm

Corte Constitucional de Colombia. (2013a). Sentencia C-262 de 2013. Recuperado a partir de http://www.corteconstitucional.gov.co/relatoria/2013/C-262-13.htm

Corte Constitucional de Colombia. (2013b). Sentencia T-073 de 2013. Recuperado a partir de http://www.corteconstitucional.gov.co/RELATORIA/2013/T-073-13.htm

Corte Constitucional de Colombia. (2013c). Sentencia T-745 de 2013. Recuperado a partir de http://www.corteconstitucional.gov.co/RELATORIA/2013/T-745-13.htm

Corte Constitucional de Colombia. (2014a). Sentencia C-123 de 2014. Recuperado a partir de http://www.corteconstitucional.gov.co/relatoria/2014/c-123-14.htm

Corte Constitucional de Colombia. (2014b). Sentencia C-289 de 2014. Recuperado a partir de http://www.corteconstitucional.gov.co/relatoria/2014/C-289-14.htm

Corte Constitucional de Colombia. (2015a). Sentencia C-752 de 2015. Recuperado a partir de http://www.corteconstitucional.gov.co/RELATORIA/2015/C-752-15.htm

Corte Constitucional de Colombia. (2015b). Sentencia T-056 de 2015. Recuperado a partir de http://www.corteconstitucional.gov.co/relatoria/2015/T-056-15.htm

Corte Constitucional de Colombia. (2015c). Sentencia T-121 de 2015. Recuperado a partir de http://www.corteconstitucional.gov.co/RELATORIA/2015/T-121-15.htm

Dahlke, R. (2000). Las Etapas críticas de la vida. Barcelona: Plaza \& Janés. 
DANE. (2013). Proyecciones de población. Recuperado 12 de abril de 2016, a partir de https://www.dane.gov.co/index.php/estadisticas-por-tema/demografia-ypoblacion/proyecciones-de-poblacion

Decreto 205 de 2003. (2003). Diario Oficial 45.086 de febrero 3 de 2003. Recuperado a partir de http://www.alcaldiabogota.gov.co/sisjur/normas/Norma1.jsp?i=16546

Decreto 1416 de 1990. (1990). Diario Oficial No. 39453 de 5 de julio de 1990. Recuperado a partir de http://www.alcaldiabogota.gov.co/sisjur/normas/Norma1.jsp?i=5248

Decreto 1485 de 1994. (1994). Diario Oficial 41.443 del 15 de Julio de 1994. Recuperado a partir de http://www.alcaldiabogota.gov.co/sisjur/normas/Norma1.jsp?i=5248

Decreto 1938 de 1994. (1994). Diario Oficial No. 41478 de 5 de agosto de 1994. Recuperado a partir de http://www.suin-juriscol.gov.co/viewDocument.asp?id=1755013

Decreto 4147 de 2011. (2011). Diario Oficial 48242 del 3 de noviembre de 2011. Recuperado a partir de http://www.alcaldiabogota.gov.co/sisjur/normas/Norma1.jsp?i=44600

Decreto 4975 de 2009. (2009). Diario Oficial 47572 de diciembre 23 de 2009. Recuperado a partir de http://www.alcaldiabogota.gov.co/sisjur/normas/Norma1.jsp?i=38291

Defensoría del Pueblo. (2005). Evaluación de los servicios de salud que brindan las empresas promotoras de salud 2005. Bogotá (Colombia): Defensoría del Pueblo.

Defensoría del Pueblo. (2015). Sigue creciendo el número de tutelas en salud. Recuperado 17 de mayo de 2016, a partir de http://defensoria.gov.co/es/nube/noticias/3414/Siguecreciendo-el-número-de-tutelas-en-salud-Tutelas-salud-Día-Mundial-de-la-saludjusticia-Plan-Obligatorio-de-Salud-Fallos-de-tutela-Derechos-Humanos-EPS.htm Dossey. (1994). La Nueva salud. Barcelona: Kairós. 
Echeverri, O. (2008). Mercantilización de los servicios de salud para el desarrollo: el caso de Colombia. Revista panamericana de salud publica $=$ Pan American journal of public health, 24(3), 210-6.

El Espectador. Redacción Política. (2016, enero 20). ¿Llegó la hora de establecer cárcel por la negación de los servicios de salud?: A propósito del caso de Rubiela Chivará, en el Congreso está en trámite un proyecto de ley para impartir cárcel por el paseo de la muerte. ELESPECTADOR.COM. Bogotá. Recuperado a partir de http://www.elespectador.com/noticias/politica/llego-hora-de-establecer-carcel-negacionde-los-servici-articulo-611674

El Heraldo. (2016). Salud y corrupción. Recuperado a partir de http://www.elheraldo.co/editorial/salud-y-corrupcion-250988

El Tiempo. (2007). Ex director del DAS Jorge Noguera tuvo nexos con paramilitares, que rozaron con pertenencia al grupo. El Tiempo. Recuperado a partir de http://www.eltiempo.com/archivo/documento/CMS-3470919

El Tiempo. (2011). Policía halló nuevas evidencias en caso de corrupción en la salud. El Tiempo. Recuperado a partir de http://www.eltiempo.com/archivo/documento/CMS9254840

El Tiempo. Justicia. (2015). ¿Por qué Santos dijo que los «paras» saquearon la salud? Recuperado 16 de mayo de 2016, a partir de http://www.eltiempo.com/politica/justicia/paramilitares-saquearon-recursos-de-la-salud$/ 16172000$

El Tiempo. Justicia. (2016). Sigue el fraude con plata de la salud de los colombianos más pobres. El Tiempo. Recuperado a partir de http://www.eltiempo.com/politica/justicia/robo-del-dinero-de-la-salud-encolombia/16586574 
El Tiempo. Redacción Salud. (2015, junio 29). El sistema de salud se lo habían robado los paramilitares: Santos. El Tiempo. Recuperado a partir de http://www.eltiempo.com/estilo-de-vida/salud/sistema-de-salud-en-colombia-yparamilitares/16167536

Federación Médica Colombiana. (2012). Carta de la Federación Médica Colombiana a la Sala Especial de Seguimiento de la Sentencia T-760 de 2008.

Fernández, C., \& Perilla S., S. (2014). La controversia alrededor de la vacuna contra el papiloma. El Tiempo. Recuperado a partir de http://www.eltiempo.com/estilo-devida/salud/controversia-por-la-vacuna-contra-el-papiloma-humano-/14462535

Ferrajoli, \& Bobbio, N. (2014). Derecho y razón : teoría del garantismo penal. Madrid: Trotta.

Firshein, R. N. (2003). La revolución de los Farmanutrientes : 20 eficaces nutrientes que le ayudarán a llevar una vida más sana. Madrid: Edaf.

Fresneda Bautista, Ó. (2003). La focalización en el régimen subsidiado de salud: elementos para un balance. Revista de Salud Pública, 5(3), 209-245. https://doi.org/10.1590/S0124-00642003000300001

Fromm. (1962). Marx y su concepto del hombre : Karl Marx: manuscritos económicofilosóficos. México [u.a.]: Fondo de Cultura Económica.

Gañan Echavarría, J. L. (2013). Los muertos de la Ley 100 : prevalencia de la libertad económica sobre el derecho fundamental a la salud : una razón de su ineficacia, caso del Plan Obligatorio de Salud del Régimen Contributivo. Medellín: Universidad de Antioquia, Facultad de Derecho y Ciencias políticas.

Garay, \& Salcedo A., E. (2012). Narcotráfico, corrupción y Estados: cómo las redes ilícitas han reconfigurado las instituciones en Colombia, Guatemala y México. Bogotá; México, D.F.: Debate. 
Garay S., \& Carrasquilla, A. (1987). Dinámica del desajuste y proceso de saneamiento económico en Colombia en la década de los ochenta. Ensayos Sobre Política Económica (Santafé de Bogotá), (11), 5-72.

García, J., \& Serrano, P. (2009). El Rapto de Higea : mecanismos de poder en el terreno de la salud y la enfermedad. Barcelona: Virus editorial.

García V., M., \& Espinosa, J. R. (2014). La eficacia simbólica del derecho : sociología política del campo jurídico en América Latina. Bogotá: Instituto de Estudios Políticos y Relaciones Internacionales, Universidad Nacional de Colombia : Penguin Random House G.

Gaviria, A. (2015). Vacunación contra el VPH: una política pública seria. Recuperado a partir de http://agaviria.blogspot.com.co/2015/08/vacunacion-contra-el-vph-unapolitica.html

Giraldo, R. (2002). Sida y agentes estresantes. Medellín, Colombia: Editorial Universidad de Antioquia.

Gómez Restrepo. (2003). Homicidio y lesiones infligidas intencionalmente por otra persona. Colombia 1973-1996. Revista Colombiana de Psiquiatría, 32(3), 2003.

González S., E. (1997). El laberinto institucional colombiano : 1974 - 1994 ; fundamentos de administración pública. Santafé de Bogotá: Universidad Nacional de Colombia; ESAP, FESCOL.

González S., E. (2010). La política pública de salud y la fallida emergencia social : ¿hay soluciones? Política Colombiana (Bogotá), (04), 103-127.

Gracia Arnaiz, M. (2009). Qué y cuánto comer: tomando medidas frente a las sociedades obesogénicas. Salud colectiva, 5(3), 363-376.

Gubin, A. (2015, junio 26). Vacuna papiloma humano: alertan sobre sus riesgos. Recuperado 16 de mayo de 2016, a partir de http://www.lagranepoca.com/ciencia-y- 
tecnologia/noticias/9387-mas-pruebas-cientificas-alertan-severos-riesgos-de-vacunadel-virus-papiloma-humano.html

Gutiérrez, C., Acosta, O. L., \& Alfonso, E. (2012). Financiación de la Seguridad Social en Salud: Fuentes de recursos y su administración. Problemas y Alternativas. En La salud en Colombia : logros, retos y recomendaciones. Bogotá: Universidad de los Andes.

Hernández Flórez, L. J., Aristizabal D., G., Vacca G., C. P., \& Mora G., T. (2009). La influenza A (H1N1). Bogotá: Universidad Nacional de Colombia.

Hernández, M. (2002). Reforma sanitaria, equidad y derecho a la salud en Colombia. Cadernos de Saúde Pública, 18(4), 991-1001. https://doi.org/10.1590/S0102$311 X 2002000400007$

Herrera S., L. F., \& Díaz, L. M. (2013). Patentes de medicamentos: ¿incentivos a la innovación o límites a la salud humana? un análisis desde la propiedad intelectual y el derecho de la competencia. Revista La Propiedad Inmaterial, O(17), 31-62.

Idrovo, A. J., Eslava, J. C., Ruiz-Rodríguez, M., \& Rodríguez, J. M. (2008). La otra transición epidemiológica: hitos en el desarrollo de la epidemiología de los factores de riesgo en Colombia. Biomédica, 28(4), 480; 480.

James Chin. (2001). El control de las enfermedades transmisibles, 17a. Edición. Recuperado a partir de http://www.myilibrary.com?id=225239

Jara, M. (2009). Traficantes de salud: cómo nos venden medicamentos peligrosos y juegan con la enfermedad. Barcelona: Icaria Ed.

Jhering. (2010). La lucha por el derecho. México: Porrúa.

Khalsa. (2010). Rejuvenece tu cerebro. Barcelona: Urano.

Krmpotic, C. (2008). Cuidados, terapias y creencias en la atención de la salud. Buenos Aires: Espacio Editorial. 
Las2orillas. (2013, diciembre 20). Roy Barreras el premiado del sector salud. Recuperado a partir de https://www.las2orillas.co/roy-barreras-el-unico-senador-etico-del-congresoen-colombia-pedimos-disculpas-al-senador-por-difamarlo/

Lewin. (2013). Por amor a la física : del final del arco iris a la frontera del tiempo : un viaje a través de las maravillas de la física. Barcelona: Debolsillo.

Ley 100 de 1993. (1993). Diario Oficial 41.148 del 23 de Diciembre de 1993. Recuperado a partir de http://www.alcaldiabogota.gov.co/sisjur/normas/Norma1.jsp?i=5248

Ley 790 de 2002. (2002). Diario Oficial No. 45.046 de Diciembre 27 de 2002. Recuperado a partir de http://www.alcaldiabogota.gov.co/sisjur/normas/Norma1.jsp?i=6675

Ley 1122 de 2007. (2007). Diario Oficial No. 46.506 de 9 de enero de 2007. Recuperado a partir de http://www.secretariasenado.gov.co/senado/basedoc/ley_1122_2007.html

Ley 1164 de 2007. (2007). Diario Oficial 46771 de octubre 04 de 2007. Recuperado a partir de http://www.alcaldiabogota.gov.co/sisjur/normas/Norma1.jsp?i=26903

Ley 1438 de 2011: Por medio de la cual se reforma el Sistema General de Seguridad Social en Salud y se dictan otras disposiciones. (2011). Diario Oficial 47957 de Enero 19 de 2011. Recuperado a partir de http://www.alcaldiabogota.gov.co/sisjur/normas/Norma1.jsp?i=41355

Ley 1444 de 2011. (2011). Diario Oficial 48059 de mayo 4 de 2011. Recuperado a partir de http://www.alcaldiabogota.gov.co/sisjur/normas/Norma1.jsp?i=42796

Ley 1562 de 2012. (2012). Diario Oficial 48488 del 11 de julio de 2012. Recuperado a partir de http://www.alcaldiabogota.gov.co/sisjur/normas/Norma1.jsp?i=61933

Ley 1753 de 2015. (2015). Diario Oficial No. 49.538 de 9 de junio de 2015. Recuperado a partir de http://www.alcaldiabogota.gov.co/sisjur/normas/Norma1.jsp?i=61933 
Ley estatutaria 1751 de 2015. (2015). Diario Oficial 49427 de febrero 16 de 2015.

Recuperado a partir de

http://www.alcaldiabogota.gov.co/sisjur/normas/Norma1.jsp?i=60733

Londoño, J. L. (2001). Eras en la protección social Latinoamericana: Seminario «La Teoría del Desarrollo en los albores del siglo XXI» Santiago de Chile, 29 de agosto de 2001. CEPAL. Recuperado a partir de http://www.cepal.org/prensa/noticias/comunicados/6/7616/londono.pdf

Londoño. (1997). Pluralismo estructurado hacia un modelo innovador para la reforma de los sistemas de salud en América Latina. Recuperado a partir de http://hdl.handle.net/10419/87917

Marco político y legal de la promoción de la salud. (2009). Colombia Médica, 31(2), 86-95.

Martínez, F. (2013). La crisis de la seguridad social en salud en Colombia ¿Efectos inesperados del arreglo institucional? Recuperado 13 de abril de 2016, a partir de http://www.fedesalud.org/documentos/EstudiosFD_15_Crisis-seguridad-social-saludColombia.pdf

Medici, A., \& Solari, A. (2002). El sector salud en los proyectos del BID : una evaluación preliminar. Washington, D.C.: Banco Interamericano de Desarrollo, Departamento de Desarrollo Sostenible, División de Desarrollo Social.

Meza, C. A. (2005). Crecimiento económico, empleo formal y acceso al servicio de salud: algunas escenarios de corto y largo plazo de la cobertura en salud para Colombia. Archivos de Economía, (288). Recuperado a partir de https://colaboracion.dnp.gov.co/CDT/Estudios\%20Econmicos/288.pdf Ministerio de la Protección Social. (2004). Proyecto de Evaluación y Reestructuración de los Procesos, Estrategias y Organismos Públicos y Privados encargados de adelantar las 
Funciones de Vigilancia y Control del Sistema de Salud : Informe final. Bogotá:

Ministerio de Salud y Protección Social.

Ministerio de Salud. (1994a). La reforma a la seguridad social en salud: antecedentes y resultados. Bogotá: Ministerio de Salud. Oficina de comunicaciones.

Ministerio de Salud. (1994b). La reforma a la seguridad social en salud : decretos y reglamentos. Bogotá: Ministerio de Salud.

Ministerio de Salud. Programa de Apoyo a la Reforma de Salud. (2001). Informe piloto de quejas o escucha activa al usuario. Bogotá: Ministerio de Salud. Recuperado a partir de https://www.minsalud.gov.co/salud/Documents/INFORME\%20FINAL\%20PILOTO\%2 0QUEJAS.pdf

Ministerio de Salud y Protección Social. (2012). Estudio sobre el modo de gestionar la salud en Colombia. Bogotá: Ministerio de Salud y Protección Social. Recuperado a partir de https://www.minsalud.gov.co/Documentos\%20y\%20Publicaciones/Estudio\%20sobre\% 20el\%20modo\%20de\%20gestionar\%20la\%20salud\%20en\%20Colombia.pdf

Ministerio de Salud y Protección Social. (2013a). Determinantes sociales en el Nuevo Modelo de salud. Recuperado a partir de https://www.youtube.com/watch?v=gP5coUgLZ0M

Ministerio de Salud y Protección Social. (2013b). Plan decenal de salud pública 2012-2021. Bogotá: Ministerio de Salud y Protección Social. Recuperado a partir de https://www.minsalud.gov.co/Documentos\%20y\%20Publicaciones/Plan\%20Decenal\%2 0-\%20Documento\%20en\%20consulta\%20para\%20aprobaci\%C3\%B3n.pdf

Ministerio de Salud y Protección Social. (2014). Análisis de la Situación en Salud Colombia 2014. Bogotá: Ministerio de Salud y Protección Social. Recuperado a partir de http://www.visiondiweb.com/insight/lecturas/Analisis_de_Situacion-Salud_2014.pdf 
Ministerio de Salud y Protección Social. (2015). Informe al Congreso de la República 20142015 : Sector Administrativo de Salud y Protección Social. Bogotá: Ministerio de Salud y Protección Social. Recuperado a partir de https://www.minsalud.gov.co/sites/rid/Lists/BibliotecaDigital/RIDE/DE/PES/informecongreso-2014-2015.pdf

Ministerio de Salud y Protección Social. (2016a). Informe al Congreso de la República 2015-2016 : Sector Administrativo de Salud y Protección Social. Bogotá: Ministerio de Salud y Protección Social. Recuperado a partir de https://www.minsalud.gov.co/sites/rid/Lists/BibliotecaDigital/RIDE/DE/PES/informecongreso2015-2016.pdf

Ministerio de Salud y Protección Social. (2016b). Política de atención integral en salud: un sistema de salud al servicio de la gente. Bogotá: Ministerio de Salud y Protección Social. Recuperado a partir de https://www.minsalud.gov.co/sites/rid/Lists/BibliotecaDigital/RIDE/DE/modelo-pais2016.pdf

Ministerio de Salud y Protección Social. (2016c). Resolución 429 del 17 de febrero de 2016. Ministerio de Salud y Protección Social. Recuperado a partir de https://www.minsalud.gov.co/Normatividad_Nuevo/Resoluci\%C3\%B3n\%200429\%20d e\%202016.pdf

Ministerio de Salud y Protección Social, \& Organización Panamericana de la Salud. (2010). Resúmenes de Política: Intervenciones Poblacionales en Factores de Riesgo de Enfermedades Crónicas. Estilo de vida saludable y enfermedades no transmisibles. Recuperado a partir de https://www.mindbank.info/item/4643

Montagnier, L. (1995). Sobre virus y hombres : la carrera contra el SIDA. Barcelona: Círculo de Lectores. 
Mukherjee, S. (2011). El emperador de todos los males : una biografía del cáncer. Madrid: Taurus.

Nacional sobre Libertad de Expresión y Acceso a la Información - Google Search. (s. f.). Recuperado 7 de abril de 2017, a partir de https://www.google.com.co/search?q=Comisi\%C3\%B3n+Interamericana+de+Derechos +Humanos.+Jurisprudencia+Nacional+sobre+Libertad+de+Expresi\%C3\%B3n+y+Acce so+a+la+Informaci\%C3\%B3n\&oq=Comisi\%C3\%B3n+Interamericana+de+Derechos+ Humanos.+Jurisprudencia+Nacional+sobre+Libertad+de+Expresi\%C3\%B3n+y+Acces $\mathrm{o}+\mathrm{a}+\mathrm{la}+$ Informaci\%C3\%B3n\&aqs=chrome..69i57.1325j0j8\&sourceid=chrome $\& \mathrm{ie}=\mathrm{UT}$ F8\#q=Nacional+sobre+Libertad+de+Expresi\%C3\%B3n+y+Acceso+a+la+Informaci\%C3 $\% \mathrm{~B} 3 \mathrm{n}$

Nardone. (2012). El arte del cambio. Recuperado a partir de http://public.eblib.com/choice/publicfullrecord.aspx?p=4735175

Niño Torres. (2003). Informe sobre el desarrollo mundial 2004 : servicios para los pobres. Madrid; Bogotá, Colombia; CEPAL: Ediciones Mundi-Prensa ;

Nodarse Hernández, R. (2002). Visión actualizada de las infecciones intrahospitalarias. Revista Cubana de Medicina Militar, 31(3), 201-208.

Observatorio del Medicamento en Colombia. (2008). RITUXIMAB el medicamento de mayor valor recobrado al FOSYGA entre 2006 y 2007. Boletín informática y salud. Recuperado a partir de http://www.med-informatica.net/BIS/WebMail_23a29jun08.htm Ocampo, J. A. (1987). Una década de grandes transformaciones económicas, 1986-1995. En Historia económica de Colombia. Bogotà: Siglo XXI. Recuperado a partir de http://www.banrepcultural.org/blaavirtual/economia/histecon/histecon9a.htm 
OEA. Comisión Interamericana de Derechos Humanos. (2009, agosto 1). Declaración Americana de los Derechos y Deberes del Hombre. La IX Conferencia Internacional Americana, [Text]. Recuperado 8 de abril de 2017, a partir de http://www.oas.org/es/cidh/mandato/Basicos/declaracion.asp

Oficina de Prensa del Senador Gustavo Petro. (2010, abril 23). Acabar con la ley 100 para que la salud deje ser una mercancía: Senador Gustavo Petro. Recuperado 5 de abril de 2017, a partir de http://senado.gov.co/legales/item/5043-acabar-con-la-ley-100-paraque-la-salud-deje-ser-una-mercanc\%C3\%83_a-senador-gustavo-petro

Organización de las Naciones Unidas. (1948). La Declaración Universal de Derechos Humanos. Recuperado 10 de abril de 2016, a partir de http://www.un.org/es/universaldeclaration-human-rights/

Organización Mundial de la Salud. (s. f.). Acerca de los sistemas de salud. Recuperado 8 de abril de 2016, a partir de http://www.who.int/healthsystems/about/es/

Organización Mundial de la Salud. Sala de Prensa. (2015). Objetivos de Desarrollo del Milenio (ODM): nota descriptiva. Recuperado 11 de mayo de 2016, a partir de http://www.who.int/mediacentre/factsheets/fs290/es/

Organización Mundial de la Salud. Sala de Prensa. (2016). Resistencia a los antimicrobianos: nota descriptiva. Recuperado 11 de mayo de 2016, a partir de http://www.who.int/mediacentre/factsheets/fs 194/es/

Organización Panamericana de la Salud. (1998). La salud en las Américas. Washington, D.C.: Organización Panamericana de la Salud. Organización Panamericana de la Salud. (2002). Informe Mundial sobre la Violencia y la Salud. Washington: Organizacion Panamericana de la Salud. 
Organización Panamericana de la Salud. (2002). La Organizacion Panamericana de la Salud y el Estado colombiano: cien anos de historia, 1902-2002. Bogotá: OPS (Organizacion Panamericana de la Salud).

Páez S., G., Jaramillo Q., L. F., \& Franco R., C. (2013). Estudio sobre la Geografía Sanitaria de Colombia. Bogotà: Ministerio de Salud y Protección Social. Recuperado a partir de https://www.minsalud.gov.co/Documentos\%20y\%20Publicaciones/Estudio\%20sobre\% 20la\%20geograf\%C3\%ADa\%20sanitaria\%20de\%20Colombia.pdf

Peñaloza Q., E. (2001). Evolución y resultados del Régimen Subsidiado de Salud en Colombia, 1993-2000. Bogotá: CEJA : Cendex : Fundación Corona : Fundación Social : Banco Interamericano de Desarrollo.

Pérez, G. J., \& Silva U., A. (2015). Una mirada a los gastos de bolsillo en salud para Colombia. Documentos de Trabajo sobre Economía Regional, (218). Recuperado a partir de http://www.banrep.gov.co/es/dtser-218

Perlmutter. (2014). Cerebro de pan. Barcelona: Grijalbo.

Perry, G. (1990, agosto 7). Una década gris oscura. El Tiempo. Recuperado a partir de http://www.eltiempo.com/archivo/documento/MAM-69438

Pinzón Camargo, M. A. (2011). Medicamentos y patentes : un conflicto de derechos y una propuesta para su conciliación desde la nueva economía institucional. Bogotá:

Universidad Externado de Colombia.

Pollan. (2017). El dilema del omnívoro : en busca de la comida perfecta. Recuperado a partir de https://www.overdrive.com/search?q=1F9ADC7C-6B2A-410C-B740-

\section{AFCE087249F8}

Procuraduría General de la Nación, Ministerio de Salud y Protección Social, Ministerio de Educación Nacional, \& Departamento Administrativo de la Función Pública. (2016). 
Circular conjunta 100-01-2016. Recuperado a partir de

http://www.funcionpublica.gov.co/documents/418537/616038/Circular+100-01-

2016+Concurso+directores+ESE.pdf/2e17d1b6-4301-4429-8d15-ccfb5cc9a51a

Programa de las Naciones Unidas para el Desarrollo. (1991). Desarrollo humano : informe 1991. Bogotá, Colombia: Tercer Mundo.

Ramírez, L. (1992). Exposición de motivos del Proyecto de Ley "por la cual se crea el Sistema de Ahorro Pensional y se dictan otras disposiciones sobre seguridad social" [Alcaldía Mayor de Bogotá D.C]. Recuperado 4 de febrero de 2016, a partir de http://www.alcaldiabogota.gov.co/sisjur/normas/Norma1.jsp?i=12887\#0

Redacción El Tiempo. (2000). Trabajo coordinado para sacar adelante a la salud. El Tiempo. Recuperado a partir de http://www.eltiempo.com/archivo/documento/MAM-1305661

Redacción Vivir. (2016, mayo 10). Las presiones de EE.UU. para que Colombia no regule el precio del imatinib. El Espectador. Recuperado a partir de http://www.elespectador.com/noticias/salud/presiones-de-eeuu-colombia-no-regule-elprecio-del-imat-articulo-631535

Regush, N. M. (2003). El virus que llevamos dentro : la historia desconocida de un enemigo invisible que acecha a la humanidad. México: Oceano.

Restrepo V., R. (2007). A propósito de la Ley 1122 del 2007 Reforma del Sistema General de Seguridad Social en Salud en Colombia: esperanza, mito y realidad. Revista Facultad Nacional de Salud Pública, 25(1), 90-105.

Restrepo Z., J. H., Atehortua B., S. C., \& Rodriguez Acosta, S. M. (2008). Introducción a la economía de la salud en Colombia. Medellín: Universidad de Antioquia. Centro de Investigaciones y Consultorias. 
Reyes P., A., Duica A., L., \& Pedraza, W. A. (2009). El despojo de tierras por paramilitares en Colombia. Recuperado 16 de mayo de 2016, a partir de http://www.ideaspaz.org/tools/download/52149

Roberts, J. (2009). Fear of the invisible : an investigation of viruses and vaccines, HIV and AIDS. Bristol, UK: Impact Investigative Media Productions.

Rocha, R. (2000). La economía colombiana tras 25 años de narcotráfico. Recuperado a partir de http://books.google.com/books?id=_SyAAAAIAAJ

Rodríguez, C. (2012). La Judicialización de la Salud: síntomas, diagnóstico y prescripciones. En La salud en Colombia : logros, retos y recomendaciones (pp. 5212-544). Bogotá: Universidad de los Andes, Escuela de Gobierno, Ediciones Uniandes,.

Rodríguez, O. (2015). Colombia. La crisis del sistema de salud. Le Monde Diplomatique.

Eidición Colombia. Bogotá. Recuperado a partir de http://www.eldiplo.info/portal/index.php/1851/item/227-colombia-la-crisis-del-sistemade-salud.

Rubio, O., Ojeda, J., \& Montes, E. (2011). Deuda externa, inversión y crecimiento en Colombia, 1970 y 2002. Banco de la República (banco central de Colombia), (272). Recuperado a partir de http://www.banrep.gov.co/es/borrador-272

Saizar, M. M. (2008). Acuerdos, desacuerdos y lejanías en la relación médico - paciente. En Cuidados, terapias y creencias en la atención de la salud. Buenos Aires: Espacio Editorial.

Saltman, R. (1997). Equidad y Justicia Distributiva en la Reforma Europea de la Sanidad. En Reformas sanitarias y equidad. [Madrid]: Fundación Argentaria.

Santamaría, D. H. G., \& Villa, J. A. E. (2004). Saneamiento hídrico en Colombia: Instituciones y situación actual. Ecos de Economía: A Latin American Journal of Applied Economics, 8(18), 73-97. 
Schlosser. (2002). Fast food : el lado oscuro de la comida rápida. Barcelona: Grijalbo Mondadori.

Semana. (2012). Casi 500 investigados por parapolítica en los últimos cinco años. Durante sus cinco años de existencia la Estructura de Apoyo de la Fiscalía creada para investigar los nexos de políticos con las autodefensas ha vinculado a más de 470 funcionarios en procesos de concierto para delinquir. Recuperado a partir de http://www.semana.com/nacion/articulo/casi-500-investigados-parapolitica-ultimoscinco-anos/266865-3

Semana. (2013). La bancada de la salud en el Congreso. Recuperado 16 de mayo de 2016, a partir de http://www.semana.com/nacion/articulo/la-bancada-salud-congreso/345789-3 Semana. (2015). Así cayó la red de militares que estafó al Estado. Semana.com. Recuperado a partir de http://www.semana.com/nacion/articulo/fiscalia-investiga-desfalco-la-saluden-el-ejercito/425144-3

Semana. (2016a). Vacuna contra el VPH, ¿tan buena como la pintan? Recuperado 16 de marzo de 2016, a partir de http://www.semana.com/nacion/articulo/vacuna-contra-vphacademia-nacional-de-medicina-pide-cambiar-protocolo/466302

Semana. (2016b, mayo 15). Colombia, ¿en la lista 'negra' de los medicamentos en el mundo? Semana. Recuperado a partir de http://www.semana.com/nacion/articulo/eeuusector-farmaceutico-solicito-incluir-a-colombia-en-la-lista-negra/469491

Shinya, H. (2014). La enzima prodigiosa 2. Recuperado a partir de https://www.overdrive.com/search?q=F4581721-6C51-4813-B18C-B18B4AC9ADF5 Sontag, S. (2003). La enfermedad y sus metáforas y el sida y sus metáforas. Buenos Aires: Taurus : Pensamiento.

Stone, G. (2014). Los secretos de las personas que nunca enferman : lo que saben, por qué les funciona y cómo te puede funcionar a ti. [Barcelona: RBA revistas. 
Turbay, G. (1996). Gestión Estatal en los Servicios Públicos: Reorganización Institucional y Políticas de Ajuste en el Sector de Agua Potable y Saneamiento Básico, 1985 - 1992. (p. 70). Bogotá: Universidad Nacional de Colombia. Centro de Investigaciones para el Desarrollo - CID. Recuperado a partir de http://www.cid.unal.edu.co/cidactual/index.php?option=com_publicaciones\&op=view\& Itemid $=305 \&$ adressid $=610$

Uprimny, R., \& Durán, J. (2014). Equidad y protección judicial del derecho a la salud en Colombia. Santiago de Chile: Naciones Unidas, CEPAL [u.a.].

Vélez, A. L. (2014). Marco político y legal de la promoción de la salud. Colombia Médica, 31(2). Recuperado a partir de http://hdl.handle.net/10893/6912

Verdad Abierta. (2010). Siete años de prisión para el ex senador Vicente Blel. Recuperado 16 de mayo de 2016, a partir de http://www.verdadabierta.com/la-historia/2162-sieteanos-de-prision-para-el-ex-senador-vicente-blel

Wiesner Ceballos. (2005). Encrucijadas epistémicas de la medicina : el problema del cáncer. Bogotá: Universidad Externado de Colombia.

Young. (2012). La milagrosa dieta del pH : consigue tu equilibrio natural. Barcelona: Ediciones Obelisco. 